UNIVERSIDADE DE SÃO PAULO

INSTITUTO DE ARQUITETURA E URBANISMO - SÃO CARLOS

LETICIA FRANÇA MATTARAIA LONGO

\title{
Projeto para Desmontagem e BIM: ferramentas projetuais para aperfeiçoar a reutilização dos materiais
}





\section{LETICIA FRANÇA MATTARAIA LONGO}

\section{Projeto para Desmontagem e BIM: ferramentas projetuais para aperfeiçoar a reutilização de materiais}

(versão corrigida)

Tese apresentada ao Programa de Pósgraduação em Arquitetura e Urbanismo do Instituto de Arquitetura e Urbanismo de São Carlos, da Universidade de São Paulo, como parte dos requisitos para obtenção do Título de Doutora em Ciências de Arquitetura e Urbanismo.

Área de Concentração: Arquitetura, Urbanismo e Tecnologia.

Orientador: Prof. Assoc. Márcio M. Fabrício Coorientador: Prof. Dr. Ricardo Codinhoto 
AUTORIZO A REPRODUCAO TOTAL OU PARCIAL DESTE TRABALHO,

POR QUALQUER MEIO CONVENCIONAL OU ELETRONICO, PARA FINS DE ESTUDO E PESQUISA, DESDE QUE CITADA A FONTE

Ficha catalográfica elaborada pela Biblioteca do Instituto de Arquitetura e Urbanismo com os dados fornecidos pelo(a) autor(a)

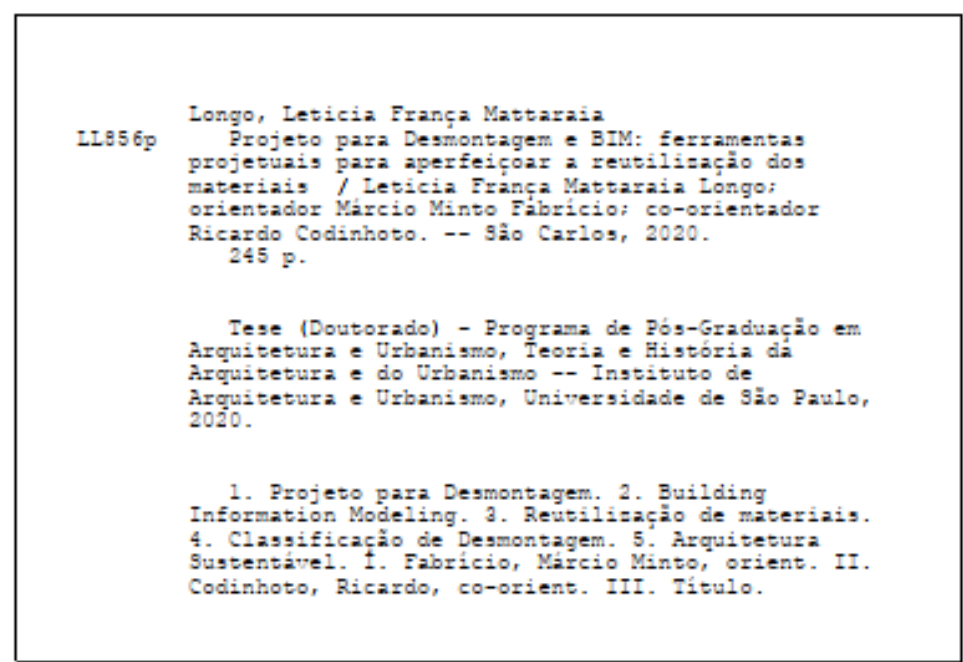

Bibliotecária responsável pela estrutura de catalogação da publicação de acordo com a AACR2: Brianda de Oliveira Ordonho Sígolo - CRB - $8 / 8229$ 


\section{FOLHA DE JULGAMENTO}

\section{Candidato(a): Leticia França Mattaraia Longo}

Titulo da tese: "Projeto para desmontagem e BIM: ferramentas projetuais para aperfeiçoar a reutilização de materiais"

Data da defesa: $15 / 06 / 2020$

Orientador: Prof. Dr. Marcio Minto Fabricio

Comissăo Julgadora:

Resultado:

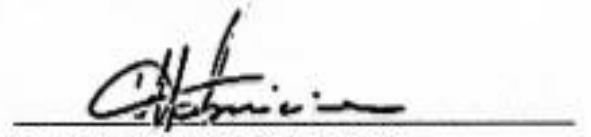

Prof. Dr. Marcio Minto Fabricio

Não votante

(IAU/USP)

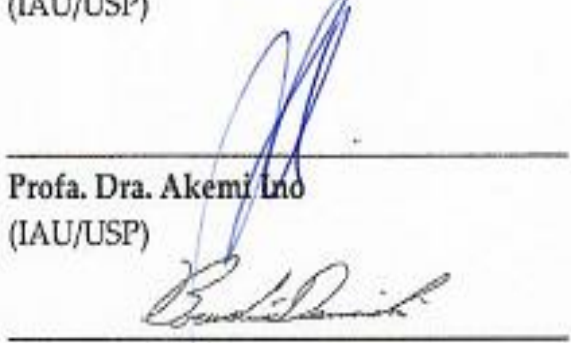

Prof. Dr. Bruno Luís Damineli (IAU/USP)

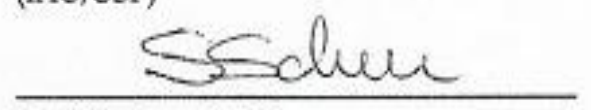

Prof. Dr. Sergio Scheer (UFPR)

Aprovada

Aprovada

Aprovada



Profa. Dra. Cristiane Bueno

Aprovada (UFSCar)

Aprovada

Coordenador e Presidente da Comissão de Pós-Graduação do Programa de PósGraduação em Arquitetura e Urbanismo: Prof. Dr. Tomás Antonio Moreira. 
Dedico este trabalho a todas as pessoas especiais que fizeram parte desta jornada: familiares, colegas, amigos, funcionários e professores. 



\section{AGRADECIMENTO}

Primeiramente, agradeço a Deus, pela minha vida e saúde.

Agradeço a minha família, principalmente aos meus pais, Lincoln e Gislaine Mattaraia, que sempre apoiaram as minhas decisões, e aos meus irmãos, Leandro e Leonardo.

Agradeço ao meu marido, William, pelo apoio e incentivo. À minha filha, Ana Gabriela, que me ensinou tanto em tão pouco tempo e certamente me transformou, inclusive como pesquisadora.

Ao meu orientador, Prof. Dr. Márcio Minto Fabrício, pelo incentivo, motivação e grande contribuição no desenvolvimento do trabalho, ao longo desses anos.

Ao meu coorientador, Prof. Dr. Ricardo Codinhoto, que me recebeu logo no início do doutorado e teve grande contribuição para o resultado desta tese.

Aos colegas do grupo de pesquisa Arquitec, que se tornaram grandes amigos e companheiros ao longo do desenvolvimento deste trabalho, além de contribuírem com informações e incentivos.

Aos meus amigos que me acompanharam neste processo e sempre me incentivaram.

Aos colegas da pós-graduação que contribuíram com ótimas ideias, sugestões e importantes discussões.

Aos professores das disciplinas cursadas, que contribuíram trocando importantes informações e dividiram seu conhecimento.

Aos professores que participaram da minha banca de qualificação, Profa. Dra. Akemi Ino e Prof. Dr. Sérgio Scheer, que fizeram importantes ressalvas sobre o trabalho.

Às pessoas dispostas a darem entrevistas e às empresas que abriram suas portas para enriquecer o trabalho e ampliar a relação entre a academia e o mercado.

Aos professores especialistas que participaram da validação do artefato e contribuíram com o seu conhecimento e tempo, assim incentivando a pesquisa.

Ao Instituto de Arquitetura e Urbanismo da USP de São Carlos, que fornece condições e toda a estrutura para o desenvolvimento das pesquisas.

Finalmente, à CAPES - Coordenação de Aperfeiçoamento de Pessoal de Nível Superior -, que contribuiu com o apoio financeiro, por meio da bolsa do programa Demanda Social. O presente trabalho foi realizado com o apoio da Coordenação de Aperfeiçoamento de Pessoal de Nível Superior - Brasil (CAPES). 

"Tentamos proteger a árvore, esquecidos de que ela é que nos protege." Carlos Drummond de Andrade

"Quando o homem aprender a respeitar até o menor ser da Criação, seja animal ou vegetal, ninguém precisará ensiná-lo a amar seu semelhante." Albert Schweitzer 



\section{RESUMO}

MATTARAIA, L.F. Projeto para Desmontagem e BIM: ferramentas projetuais para aperfeiçoar a reutilização de materiais. Tese (Doutorado) - Programa de Pós-Graduação em Arquitetura e Urbanismo, área de concentração em Arquitetura, Urbanismo e Tecnologia Instituto de Arquitetura e Urbanismo da Universidade de São Paulo. São Carlos, 2019.

O setor da construção civil é um dos grandes consumidores de matérias-primas e gera enorme quantidade de resíduos; é responsável por cerca de $50 \%$ dos materiais extraídos da natureza e pode chegar a $50 \%$ do total dos resíduos. Quando os edifícios chegam ao fim de sua vida útil, porque alguns elementos estão deteriorados ou não atendem mais às necessidades dos usuários, são, na maioria das vezes, demolidos. Isso gera grande poluição e desperdício, pois diversos materiais poderiam ser reutilizados ou reciclados. Considerar a desmontagem do edifício desde o início do desenvolvimento do projeto é fundamental para obter melhores resultados na reutilização ou reciclagem dos materiais, além de reduzir o consumo de matérias-primas para a produção de novos materiais, o que, consequentemente, contribui para o desenvolvimento sustentável do setor. A Modelagem da Informação da Construção envolve diversos softwares e ferramentas que podem auxiliar na desmontagem, tornando-a mais viável, principalmente se for considerada desde o início do projeto. Assim, este trabalho visa a analisar como o processo de Modelagem da Informação da Construção (em inglês, Building Information Modeling - BIM) pode contribuir para o Projeto para Desmontagem (em inglês, Design for Disassembly - DfD). Os encaixes, as conexões e identificação dos materiais utilizados na construção são pontos importantes que devem ser considerados durante o desenvolvimento do projeto, para facilitar a futura desmontagem e reutilização dos materiais no fim da vida útil do edifício ou até mesmo durante sua manutenção. Foi realizada revisão bibliográfica sobre o BIM com o intuito de analisar como suas ferramentas podem contribuir para o Projeto para Desmontagem. Posteriormente, foi verificado como as ferramentas contidas nos softwares podem auxiliar no desenvolvimento do projeto e contribuir com soluções para evitar o desperdício e a poluição causada atualmente pelo setor. Além disso, foram feitas visitas às fábricas e obras, além de entrevistas com profissionais sobre desmontagem das edificações. Por fim, é apresentada uma classificação de desmontagem dos principais materiais utilizados na construção civil, além de três modelos desenvolvidos no Revit com a inserção dos parâmetros de desmontagem. Um plugin contendo um checklist para avaliar a desmontabilidade do edifício também é apresentado como resultado da tese.

Palavras-chave: BIM, DfD, reutilizar, reciclar, Projeto para Desmontagem, arquitetura sustentável 


\section{SUMMARY}

MATTARAIA, L.F. Design for Disassembly and BIM: design tools to improve the reuse of materials. Thesis (PhD) - Program of Postgraduate in Architecture and Urbanism Architecture and Urbanism Institute of São Paulo, São Carlos, 2019.

The construction industry is one of the major consumers of raw materials and generates vast amounts of waste. In addition, it is responsible for about $50 \%$ of the materials extracted from nature and can reach $50 \%$ of the total waste. When buildings come to the end of their useful life because some elements are deteriorated or no longer meets the needs of users, most of the time they are demolished. This creates a lot of pollution and waste, since various materials could be reused or recycled. Considering the disassembly of the building from the beginning of the project's development is fundamental to obtain better results in the reuse or recycling of materials, as well as to reduce the consumption of raw materials for the production of new materials and, consequently, contributes to the sustainable development of the sector. The BIM platform involves several software and tools that can assist with disassembly, making it more feasible, especially if considered from the beginning of the project. Therefore, this paper analyse how the Building Information Modeling (BIM) system can contribute to the Design for Disassembly (DfD). Connections, fittings and identification of the materials used in the construction are important points that must be considered during the development of the design to facilitate the future disassembly and reuse of the materials at the end of the useful life of the building or even during its maintenance. A bibliographic review of BIM was performed to analyse how its tools can contribute to the Design for Disassembly. Subsequently, it was verified how the tools contained in the software can assist in the development of the project and contribute solutions to avoid the waste and pollution currently caused by the sector. In addition, visits were made to factories and constructions site, as well as interviews with professionals about the dismantling of buildings.

Finally, a disassembly classification of the main materials used in civil construction is presented, in addition to three models developed in Revit with the insertion of disassembly parameters. A plugin containing a checklist to assess the building's dismountability is also presented as a result of the thesis.

Keywords: BIM, DfD, reuse, recycle, design for disassembly, sustainable architecture 


\section{SUMÁRIO}



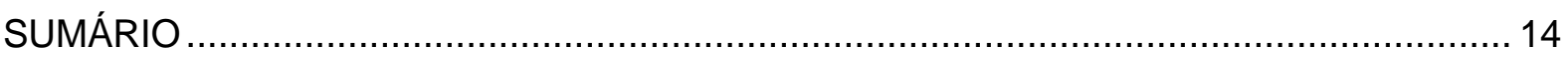

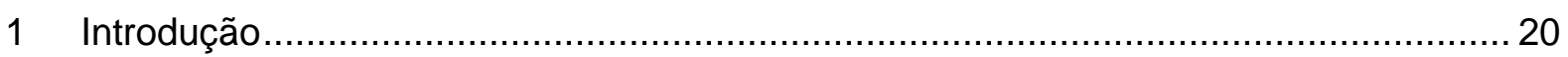

1.1 Resíduos sólidos provenientes das edificações .................................................... 20

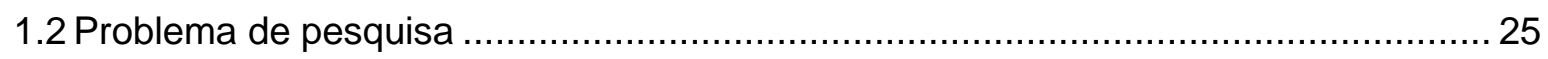

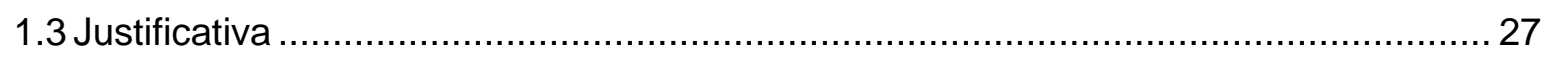

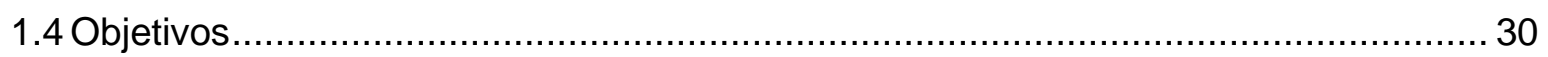

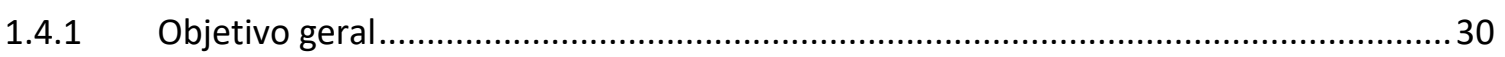

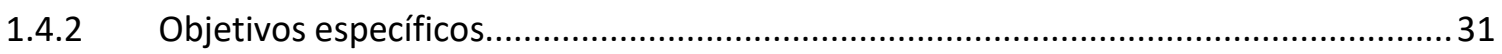

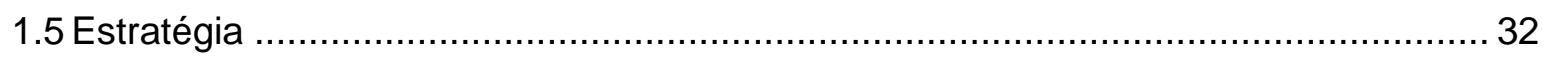

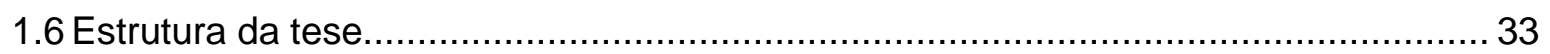

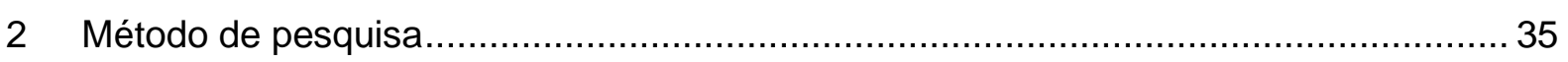



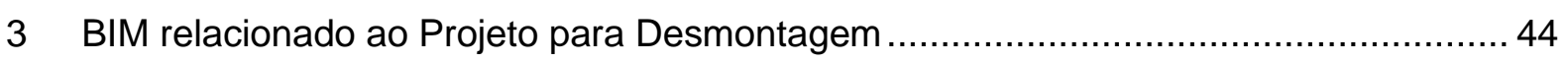

3.1 Projeto para Desmontagem como opção à demolição ........................................... 44

3.2 Utilização do BIM para assistência ao DfD......................................................... 55

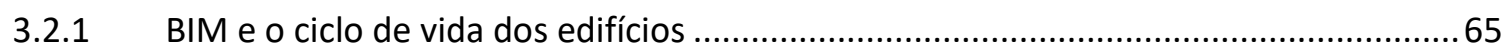

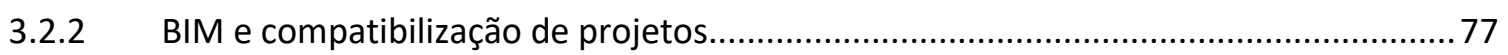

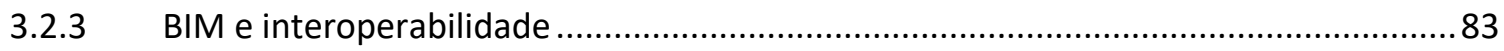



3.2.5 BIM, fabricação, montagem e construtibilidade ………............................................ 90

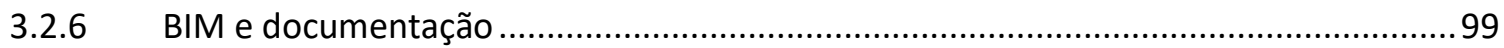





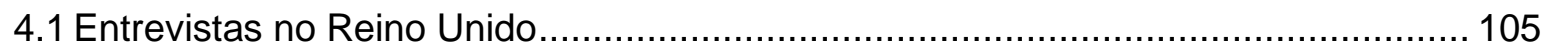

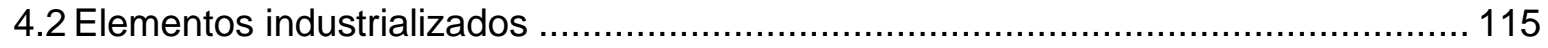

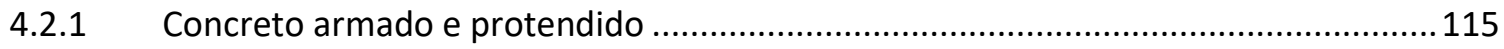

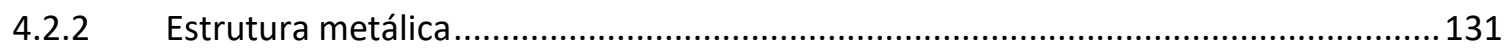



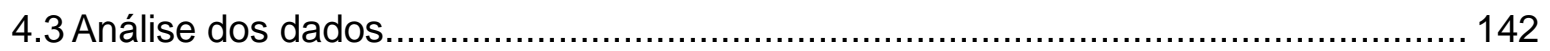

5 BIM e ferramentas projetuais que contribuem para o Projeto para Desmontagem..... 147

5.1 Definição da Classificação de Desmontagem ........................................................ 156

5.2 Parâmetro da Classificação de Desmontagem inserido no modelo.......................... 171

5.3 Projetos com a inserção de parâmetros da Classificação de Desmontagem ............ 179 


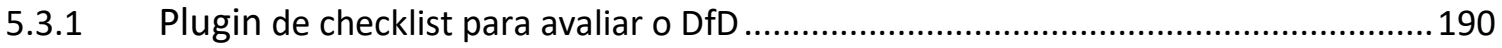

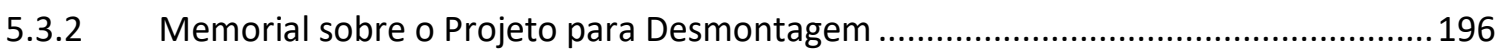

5.4 Avaliações da Classificação de Desmontagem e aplicação em BIM ......................... 201

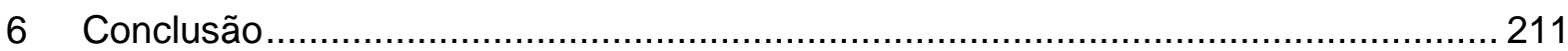

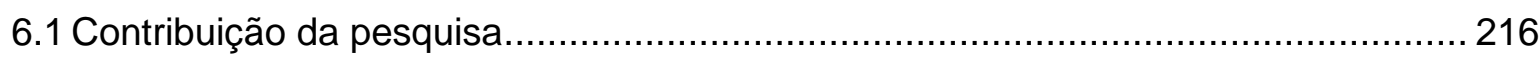

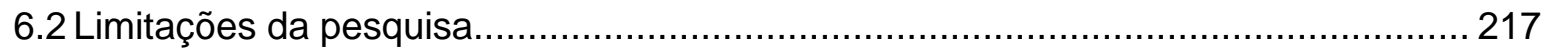

6.3 Recomendações para trabalhos futuros............................................................. 219



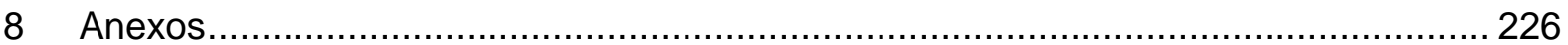

8.1 Questionários para entrevistas com profissionais do Reino Unido ......................... 226

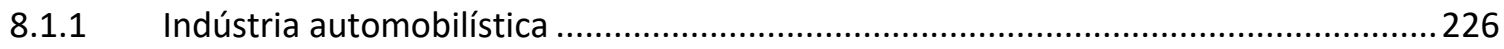

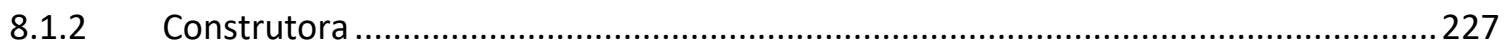

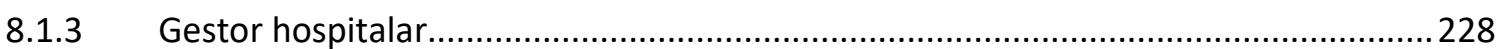

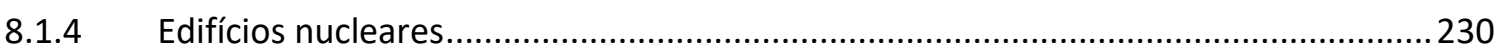



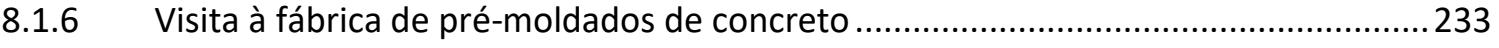

8.2 Questionário sobre a Classificação de Desmontagem ......................................... 237

8.2.1 Respostas do Questionário sobre a Classificação de Desmontagem ...........................246 


\section{Lista de Figuras}

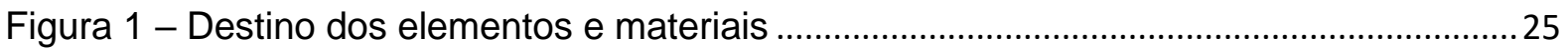

Figura 2 - Fluxograma das principais atividades realizadas ao longo da pesquisa. .............. 41

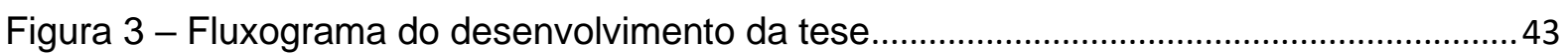

Figura 4 - Influência do DfD no ciclo de vida do edifício ...........................................................54

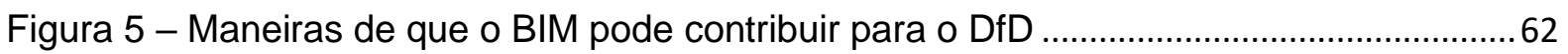

Figura 6 - Ciclo de vida a ser considerado no Projeto para Desmontagem .............................69

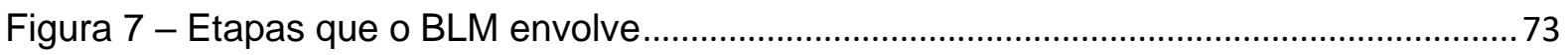

Figura 8 - Critérios e aptidões para a gestão colaborativa e o desenvolvimento de produtos

PLM

Figura 9 - Pilares de concreto pré-moldado sendo colocados na obra ................................119

Figura 10 - Montagem de um galpão em estrutura pré-moldada de concreto protendido ..119

Figura 11 - Detalhes dos encaixes dos painéis de vedação ..................................................120



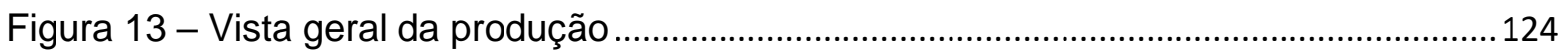

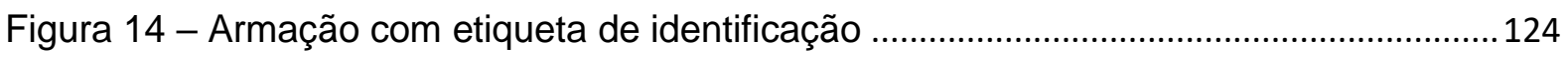

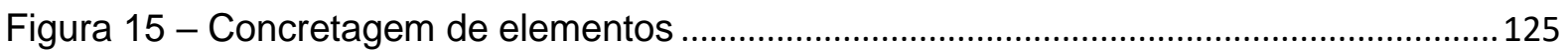

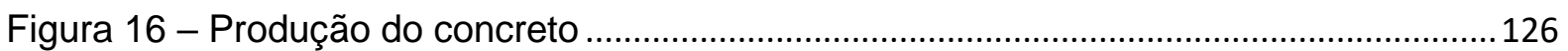

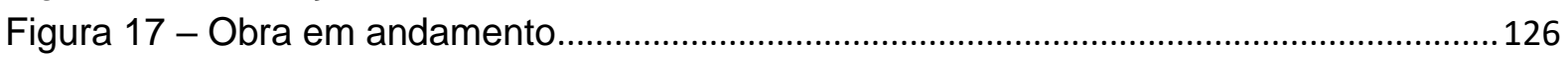

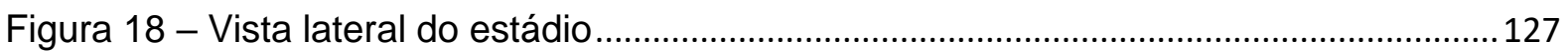

Figura 19 - Detalhe da união entre os elementos de concreto e metálicos .............................127

Figura 20 - Detalhe da união entre os elementos de concreto e metálicos ............................128

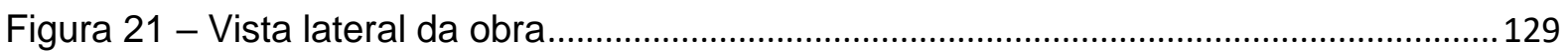

Figura 22 - Detalhe da união entre os elementos de concreto e metálicos............................129

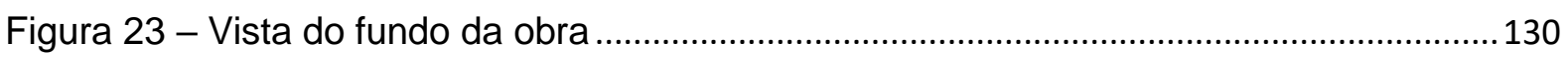



Figura 25 - Detalhe da união entre os elementos de concreto e metálicos.............................131

Figura 26 - Obra de ampliação de um restaurante em estrutura metálica...............................134

Figura 27 - Obra de ampliação de um restaurante em estrutura metálica...............................135

Figura 28 - Obra de ampliação do supermercado. Fachada em estrutura pré-moldada de

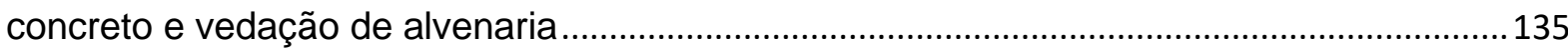

Figuras 29 e 30 - Obra de ampliação do supermercado. Lateral com instalação de estrutura

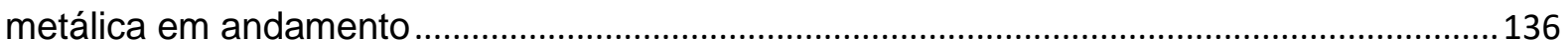

Figuras 31 e 32 - Vista interna da obra com foco nos elementos pré-moldados....................136

Figura 33 - Detalhes dos encaixes dos elementos de concreto e metálicos ..........................136

Figuras 34 e 35 - Detalhes dos encaixes dos elementos de concreto e metálicos ...............137

Figuras 36 e 37 - Resíduos da estrutura metálica .....................................................................137

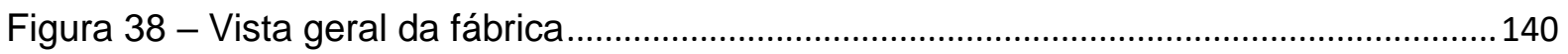

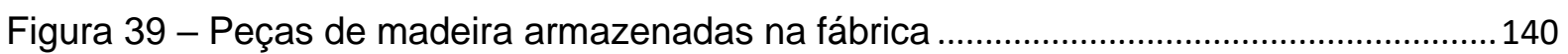

Figura 40 - Esperas para conexões inseridas nos elementos pré-fabricados.........................141

Figura 41 - Detalhe da ligação entre uma peça de madeira e a fundação ..............................141

Figura 42 - Peças a serem inseridas nas peças de madeira ................................................... 142

Figura 43 - Criação de parâmetros para os elementos............................................................149

Figura 44 - Exemplo de linha do tempo desenvolvida a partir do modelo 3D .........................150 
Figura 45 - Modelo em 3D importado do Revit e Figura 46 - Etapas iniciais da construção 151

Figura 47 - Etapas seguintes da construção e Figura 48 - Etapas seguintes da construção 151

Figura 49 - Etapas seguintes da construção e Figura 50 - Etapas seguintes da construção

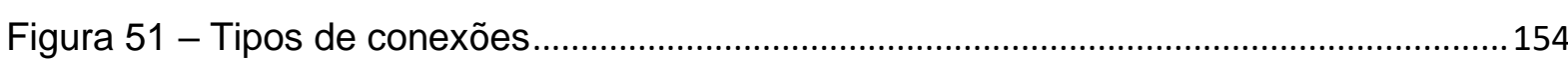



Figura 53 - Possibilidades do BIM em relação ao DfD..........................................................155

Figura 54 - Elementos analisados para a Classificação de Desmontagem do edifício .......164

Figura 55 - Criação de parâmetros do Revit........................................................................171

Figura 56 - Criação de parâmetros do Revit......................................................................172

Figura 57 - Criação de parâmetros do Revit........................................................................173

Figura 58 - Criação da tabela da Classificação de Desmontagem do Revit...........................174

Figura 59 - Tabela sobre a Classificação de Desmontagem ..................................................174

Figura 60 - Tabela da Classificação de Desmontagem multicategoria ...................................174

Figura 61 - Tabela com a Classificação de Desmontagem calculada......................................175

Figura 62 - Classificação de Desmontagem nas propriedades ...............................................176

Figura 63 - Definição da Classificação de Desmontagem aceitável .......................................176

Figura 64 -Tabela com destaque da Classificação de Desmontagem acima do estipulado

Figura 65 - Ferramenta para exportar tabela como relatório em forma de texto ..................177

Figura 66 - Ferramenta para exportar tabela como relatório em forma de texto ...................178

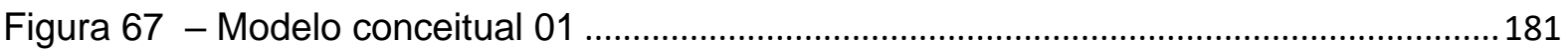

Figura 68 - Tabela de unidades para a Classificação de Desmontagem...............................181

Figura 69 - Tabela com m² para a Classificação de Desmontagem .......................................181

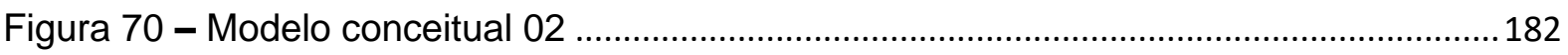

Figura 71 - Tabela de Unidades para a Classificação de Desmontagem ................................182

Figura 72 - Tabela com m² para a Classificação de Desmontagem ........................................182

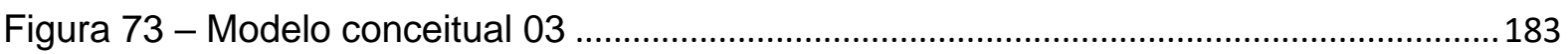

Figura 74 - Tabela de Unidades para a Classificação de Desmontagem ...............................183

Figura 75 - Tabela com m² para a Classificação de Desmontagem .......................................183

Figura 76 - Etapas para verificar a Classificação de Desmontagem (C.D.) ............................ 186

Figura 77 - Etapas para verificar a Classificação de Desmontagem (C.D.) ..........................186

Figura 78 - Processo de Projeto que considera o DfD e a utilização da Classificação de





Figura 80 - Nas páginas add-in foi inserido o plugin para o checklist. ....................................191

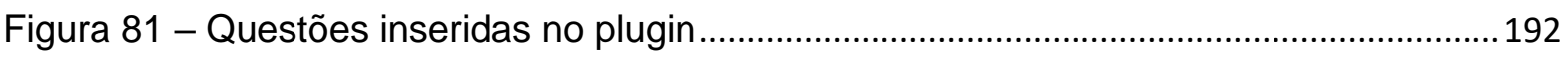

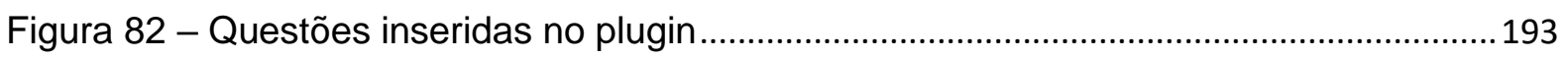

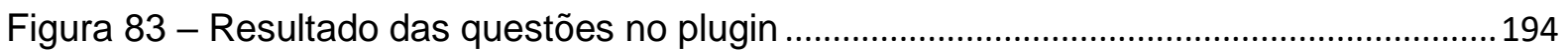

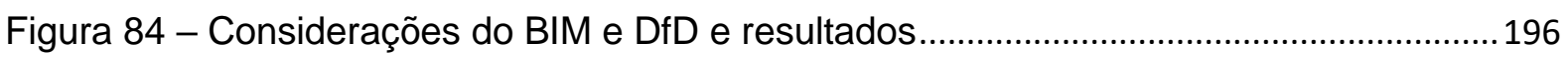

Figura 85 - Novo parâmetro DfD criado no Revit ....................................................................197

Figura 86 - Parâmetro de construção "verde" criado nas propriedades do elemento...........198

Figura 87 - Parâmetro de construção "verde" criado na tabela ................................................ 198 
Figura 88 - Extensões de Arquivos utilizados para o Memorial DfD ........................................200

Figura 89 - Documentos que devem constar no Memorial DfD ...............................................220

\section{Lista de Tabelas}

Tabela 1 - Conceitos que contribuem para o Projeto para Desmontagem de diversos

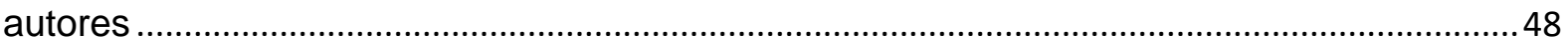

Tabela 2 - Ações BIM para o Projeto para a Montagem em diversos estágios ......................97

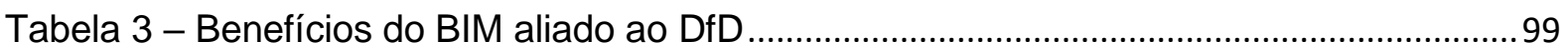

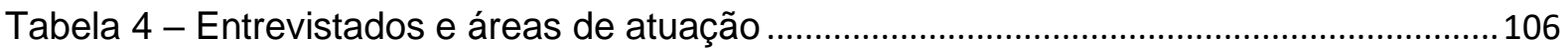





Tabela 7 - Envolvimento dos profissionais e legislação nas etapas do desenvolvimento do

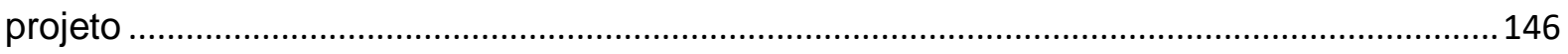

Tabela 8 - Ferramentas presentes nos softwares BIM que auxiliam o DfD ...........................153

Tabela 9 - Tabela de Classificação de Desmontagem............................................................158

Tabela 10 - Tipos de conexões entre os elementos e materiais ................................................166

Tabela 11 - Características dos sistemas estruturais...............................................................167

Tabela 12 - Características das vedações verticais externas ..................................................167

Tabela 13 - Características das vedações verticais internas ..................................................168

Tabela 14 - Respostas dos especialistas em estrutura sobre o questionário de Classificação

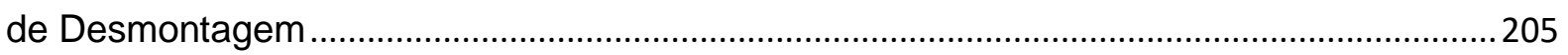

\section{Lista de Gráficos}

Gráfico 1 - Classificação de Desmontagem conforme as camadas do edifício .....................169

Gráfico 2 - Classificação de Desmontagem conforme a estrutura .............................................169

Gráfico 3 - Classificação de Desmontagem conforme o material para vedação vertical

externa do edifício.

Gráfico 4 - Classificação de Desmontagem conforme o material da vedação vertical interna

Gráfico 5 - Classificação de Desmontagem geral dos edifícios 


\section{Lista de Siglas}

AEC - Arquitetura, Engenharia e Construção ou Architecture, Engineering \& Construction

BIM - Building Information Model

BLM - Building Lifecycle Management

C.D. - Classificação de Desmontagem

DfA - Design for Assembly

DfD - Design for Disassembly

DfMA - Design for Manufacturing and Assembly

FM - Facility Management

ICT - Information and Communication Technologies

O\&M - Operation and Maintenance

PLM - Product Lifecycle Management

TI - Tecnologia da Informação

TIC - Tecnologias de Informação e Comunicação 


\section{Introdução}

Projetar considerando a desmontagem da edificação é muito importante para aumentar as possibilidades de reutilização e reciclagem dos materiais. Muitos edifícios são demolidos porque as necessidades mudaram e não se adequam às necessidades atuais; assim, grande parte de seus materiais são considerados entulhos e são despejados em aterros ou até em lugares ilegais. Empresas e clientes buscam produtos que não agravem a poluição do meio ambiente e o mercado está cada vez mais atento a essas questões, pois há pressão da sociedade e legislações que visam a reduzir o alto impacto ambiental causado pelo setor da construção civil.

Considerar o Projeto para Desmontagem pode contribuir para a redução de resíduos gerados do setor, além de contribuir para a diminuição do consumo de matérias-primas. No entanto, para que o processo seja bem-sucedido, é importante conciliar as disciplinas envolvidas, como arquitetura, estrutura, hidráulica, elétrica, entre outras. O BIM pode auxiliar, pois é possível reunir informações no projeto, em um único modelo, e assim contribuir para a futura desmontagem. Devido ao aumento da complexidade dos projetos, suas exigências e a inserção de disciplinas ao longo de seu desenvolvimento, a arquitetura se torna cada vez mais próxima da tecnologia computacional, que pode contribuir para um projeto mais completo.

\subsection{Resíduos sólidos provenientes das edificações}

A questão dos resíduos sólidos e da poluição ambiental tem sido um tema amplamente discutido. O setor da construção é um dos principais responsáveis pela enorme quantidade de lixo acumulado em aterros sanitários, portanto soluções têm sido discutidas para minimizar o problema. A demolição tradicional gera muitos resíduos e desperdícios e diversos materiais que poderiam ser reutilizados são descartados; assim, investimentos são necessários para não se agravar a poluição do meio ambiente; além disso, algumas considerações logo no 
início do desenvolvimento do projeto podem garantir um ciclo de vida mais longo para os materiais.

Segundo Zhong e Wu (2015), considerações importantes sobre sustentabilidade ambiental incluem redução de material, taxa de reciclagem, reciclagem, taxa de resíduos e consumo de água. Cheng e Ma (2013) afirmam que governos e empreiteiros estão à procura de práticas de gestão de resíduos mais eficientes na construção e demolição devido ao crescente interesse na conservação do meio ambiente. Por exemplo, em cidades desenvolvidas, como Hong Kong, está crescendo a quantidade de resíduos depositados em aterros nas últimas duas décadas. Atualmente, é importante buscar ferramentas mais precisas para estimar a quantidade de resíduos de construção, renovação e demolição.

Segundo a ABRELPE (Associação Brasileira de Empresas de Limpeza Pública e Resíduos Especiais), os municípios brasileiros geraram cerca de 78,4 milhões de toneladas de resíduos sólidos urbanos (RSU), sendo 45 milhões de toneladas de resíduos ${ }^{1}$ da construção e demolição (RC.D.), cerca de 57,4\% do total de resíduos, em 2017 (ABRELPE, 2017).

A ABRELPE aborda também o tema da logística reversa e reciclagem, pois, com a vigência da Política Nacional de Resíduos Sólidos (Lei 12.305/2010), algumas medidas estão sendo tomadas para mitigar o impacto ambiental causado pelos resíduos. Por exemplo, a Reciclanip, que é uma entidade que gerencia a logística reversa de pneumáticos inservíveis, impulsionada pela resolução CONAMA N. 416/2009, que estabeleceu a obrigatoriedade de pontos de coletas nos municípios com mais de 100 mil habitantes, coletou e destinou corretamente cerca de 4.2 milhões de toneladas de pneus inservíveis. Outro exemplo são os resíduos recicláveis recuperáveis (plástico, papel/papelão e alumínio): entre 2012 e 2017 foram geradas 43.560 toneladas por dia, no entanto foram recuperadas 13.525 toneladas ao dia (ABRELPE, 2017)

\footnotetext{
${ }^{1}$ São considerados apenas os resíduos lançados ou abandonados em logradouros públicos, assim o número total é maior, pois muitos são despejados em locais irregulares.
} 
Portanto, empresas e governo estão trabalhando juntos para minimizar o impacto ambiental causado pelos resíduos; além disso, 98\% dos brasileiros veem a reciclagem como algo importante para o futuro do país e $94 \%$ concordam que os resíduos devem ser descartados separadamente, porém $75 \%$ das pessoas afirmam que ainda não separam os resíduos domésticos, sendo a principal causa a falta de informações (ABRELPE, 2017).

Estes números demonstram a enorme quantidade de resíduos sólidos gerados e o alto valor financeiro para o despejo, que segue em crescimento a cada ano, portanto é importante buscar alternativas, cada vez mais urgentes, para mitigar a situação atual. Segundo a ABRELPE (2016), a gestão de resíduos se torna cada vez mais essencial em todo o mundo, com o intuito de contribuir para a sustentabilidade ambiental; assim, acordos como o de Paris $^{2}$, além de novas bases para economia, como a Economia Circular e metas que são traçadas, como os Objetivos de Desenvolvimento Sustentável - ODS ${ }^{3}$, visam a contribuir com melhor manejo e resultados.

A questão dos resíduos é uma preocupação global. De acordo com o Departamento do Meio Ambiente do Reino Unido (UK DEPARTMENT FOR ENVIRONMENT FOOD \& RURAL AFFAIRS, 2019), a taxa de recuperação de resíduos não contaminados de construção e demolição no Reino Unido, em 2016, foi em torno de 91\%, pois foram geradas 66.2 milhões de toneladas e recuperadas 60.2 milhões de toneladas. Este índice até ultrapassa a meta da União Europeia para o Reino Unido, que seria de recuperar pelo menos $70 \%$ deste tipo de resíduo até 2020. O Departamento estipula que, no Reino Unido, 61\% dos resíduos são do setor da construção, demolição e escavação; 19\% de outros setores comerciais e industriais, $12 \%$ é lixo doméstico e $8 \%$ são os demais setores (UK DEPARTMENT FOR ENVIRONMENT FOOD \& RURAL AFFAIRS, 2019).

\footnotetext{
2 Firmado em 2015 por 196 países, durante a COP-21, com o intuito de reduzir a emissão de carbono.

${ }^{3}$ Concluídos em 2015 na Cúpula das Nações Unidas para o desenvolvimento sustentável.
} 
A geração de resíduos é um tema recorrente e cidades, em todo o mundo, estão preocupadas com esta questão. De acordo com Cheng e Ma (2013), existem 300 recicladores em Hong Kong para gerenciar a reciclagem, mas o contratante tem que gastar algum tempo para identificar os materiais, quantificar, separar e transportar e isso resulta em desperdício de tempo e dinheiro para os trabalhadores e recicladores durante a demolição e renovação. Normalmente, o contratante estima a quantidade de resíduos com base na experiência, em vez de um cronograma. No entanto, os empreiteiros geralmente não investem muito esforço considerando a reciclagem e a reutilização de resíduos e vão saber o quanto ganham com a retirada de resíduos apenas quando recebem as contas. Reciclagem e uso sustentável dos recursos são progressivamente encorajados na indústria da construção e iniciativas estão sendo criadas na reciclagem de materiais como concreto, madeira e aço. Geralmente o aço, a madeira e o papel são frequentemente reciclados, enquanto o concreto é mais reutilizado; já vidros e plásticos não têm boa taxa de reciclagem e reutilização (CHENG e MA, 2013).

Akbarnezhad, Ong e Chandra (2014) afirmam que a reciclagem é uma das técnicas mais antigas e mais importantes da gestão de resíduos, pois ela economiza matéria-prima e espaço no aterro, no entanto o consumo de energia é necessário para a fabricação de um novo produto e a energia utilizada para o produto original é perdida. Desse modo, ao considerar a reutilização ao invés da reciclagem, é possível alcançar melhores resultados na economia de energia e matérias-primas. O objetivo de desconstruir o edifício é eliminar a demolição como opção no final da vida útil do edifício. Além de favorecer a recuperação de componentes de construção e o desvio de resíduos de aterros, a desconstrução é mais benéfica que a demolição de outras formas (AKINADE et al., 2017).

De acordo com Toth e Szigeti (2016), no início dos anos 1970, a população começou a intensificar a utilização de recursos naturais disponíveis no planeta sem esperar o tempo necessário para o ambiente se recompor, assim o consumo se tornou insustentável. Segundo Fuad-Lucke (2009), no fim da década de 1980 houve uma mudança nos países da Europa Ocidental em direção a um conceito de "consumidor verde". Para Fuad-Lucke (2009), no 
começo dos anos 1990, esta aproximação do projeto do produto adquiriu a descrição do "Projeto para o Meio Ambiente" e ferramentas surgiram para atender a esta necessidade. Uma delas foi o Design for Environment - DfE (do inglês, Projeto para o Meio Ambiente), que foi vista com uma aposta promissora para encorajar as empresas, especialmente pequenas e médias, na Holanda, a melhorar os padrões do meio ambiente e simular o debate entre projetistas. Assim, nas últimas décadas, as questões que envolvem ecologia, produção dos materiais, resíduos e impacto ambiental foram se ampliando; desse modo, novas ferramentas surgiram, com a intenção de suprir a necessidade de conceber projetos que envolvessem estas questões e reduzissem o impacto ambiental.

Na Lei Federal Brasileira n.12.305/10 (PNRS - Política Nacional de Resíduos Sólidos), a reciclagem é uma das ações prioritárias relacionadas à gestão de resíduos, com o intuito de transformar estes insumos ou gerar novos produtos. Além disso, estabelece a logística reversa como responsabilidade compartilhada pelo ciclo de vida dos produtos e resíduos sólidos para o reaproveitamento em outros ciclos produtivos ou destinação adequada (ABRELPE, 2017).

Os materiais e elementos retirados das edificações podem ter quatro destinos diferentes. $\mathrm{O}$ ideal seria reutilizar o material da mesma maneira que foi utilizado inicialmente, assim economizaria recursos naturais e novos materiais. A segunda melhor opção seria adaptar o material, apenas fazer alguns ajustes no tamanho ou conexões para que possa ser reutilizado. A reciclagem seria a terceira opção, pois é necessário passar por uma nova produção, além de consumir energia e matéria-prima, porém menos do que a produção de novos elementos e materiais. A quarta e pior opção é o descarte do material, pois, além de gerar resíduos e desperdício, será necessário o consumo de matérias-primas para a produção de novos materiais. A figura 01 apresenta estas etapas. 




Figura 1 - Destino dos elementos e materiais Fonte: Autora

Para Toth e Szigeti (2016), o desenvolvimento da tecnologia e mecanismos de mercado podem gerar grande progresso, no entanto não se deve negligenciar as consequências deste consumo. Portanto, é importante utilizar isso a favor da população e ter flexibilidade para buscar alternativas. O aumento da população e do consumo está diretamente relacionado ao excesso de utilização de matérias-primas e geração de resíduos, porém é importante não focar apenas no excesso da população, que até está em queda em alguns países, mas sim em como deve ser feito o uso destes materiais, o consumo, o descarte e o tratamento.

\subsection{Problema de pesquisa}

A grande quantidade de resíduos gerada pelo setor da construção civil é um tema amplamente debatido em todo o mundo, portanto é fundamental buscar soluções desde o início dos projetos para mitigar a poluição gerada. A demolição de edificações contribui para o agravamento da situação, assim o Projeto para Desmontagem pode oferecer alternativas para que se torne possível a reutilização dos materiais e, quando aliada a recursos tecnológicos, é possível obter melhores resultados. O BIM ${ }^{4}$ (do inglês Building Information

\footnotetext{
${ }^{4}$ Ao longo do texto será utilizada a sigla em inglês BIM, por ser muito utilizada em textos, artigos e documentos em português.
} 
Modeling, traduzido para o português como Modelagem da Informação da Construção ${ }^{5}$ está sendo muito discutido como forma de melhorar o desenvolvimento do projeto de arquitetura por tornar o processo mais prático, eficiente e reunir informações em um único modelo. Este trabalho busca analisar as ferramentas em diversos softwares que são considerados como parte da plataforma BIM para demonstrar como podem colaborar para o processo de desmontagem e obter melhores resultados.

De acordo com Zhong e Wu (2015), a maneira com que o mundo tem usado recursos naturais globais colocou uma tremenda pressão sobre o meio ambiente, esgotando os recursos naturais, poluindo o meio ambiente, causando aquecimento global, elevando o nível do mar e colocando em risco a biodiversidade.

Normalmente, os projetistas consideram a construção e a manutenção do edifício, mas poucas vezes consideram o final de sua vida útil e soluções que possibilitem avaliar o ciclo de "berço a berço" dos materiais; no entanto, se alguns softwares contribuírem para que as considerações sobre desmontagem sejam inseridas de maneira mais prática e eficiente desde as primeiras decisões de projeto, algumas soluções poderão ser propostas desde o início. Dessa maneira, a pesquisa busca os softwares com a intenção de verificar as ferramentas que podem auxiliar no Projeto para Desmontagem ${ }^{6}$, como simulações, armazenamento de dados, encaixes de elementos e materiais, quantificação, entre outras. Além disso, é importante analisar como estas informações serão conservadas para que seja possível a consulta destes documentos no futuro, pois, atualmente, a questão da interoperabilidade entre softwares e até mesmo entre suas as atualizações é um tema recorrente, por não atender às necessidades de acesso, consulta e modificações dos arquivos.

\footnotetext{
${ }^{5}$ Tradução segundo a norma brasileira ABNT NBR 15965-1:2011.

${ }^{6} \mathrm{Na}$ literatura consultada sobre o tema em que os textos estão em português, os termos utilizados para "Design for Disassembly" são "Projeto para Desmontagem" ou "Projeto para Desconstrução"; neste trabalho, será mais utilizado "Projeto para Desmontagem", para que não se confunda com o movimento Desconstrutivista, que não tem nenhuma relação com esta pesquisa.
} 


\subsection{Justificativa}

A desmontagem das edificações apresenta-se como uma alternativa para a demolição; no entanto, para que seja bem-sucedida e consuma o mínimo de tempo e trabalho possível, é necessário recorrer a alternativas para tornar o processo mais eficiente, como a utilização do BIM, que, quando bem utilizado, pode auxiliar no processo de desmontagem, pois permite que ao longo do desenvolvimento do projeto sejam analisados diversos detalhes, auxiliando na tomada de decisões dos projetistas e armazenando informações importantes sobre os materiais utilizados. Isso contribui de forma significativa para o $\mathrm{DfD}^{7}$, além de permitir que o material seja desmontado mais rápido e tenha maior valor de revenda, pois não será danificado e manterá suas características.

O BIM permite que a construção seja mais rápida, pois facilita a fabricação e montagens de componentes fora do canteiro de trabalho, contribui na automação para adquirir materiais e montagem dos diversos elementos da construção (EASTMAN et al., 2014). O desenvolvimento deste tipo de tecnologia pode contribuir com a construção, montagem de elementos, identificações de materiais, bem como com a desmontagem.

Outro ponto fundamental quando se discute o desmonte dos edifícios são os encaixes e conexões utilizados para unir os diversos materiais e componentes que fazem parte da construção. A maneira com que serão realizados influencia diretamente nos resultados da desmontagem, pois pode tornar o processo complexo e demorado, ou pode torná-lo mais prático. Além disso, muitas vezes pode comprometer o material e torná-lo inutilizável. O BIM também pode contribuir nas escolhas de conexões e encaixes dos diversos componentes da edificação.

\footnotetext{
${ }^{7}$ Será mantida a sigla em inglês para melhor compreensão do texto e por não ser usual utilizar alguma sigla em português que se refira ao Projeto para a Desmontagem.
} 
Para Eastman et al. (2014), é possível analisar cada detalhe dos encaixes estruturais, evitar erros, facilitar a pré-fabricação, montagem da estrutura e encaixes precisos, além de obter peças mais padronizadas. Assim, é possível ter uma construção mais racionalizada, com detalhes construtivos e conexões desenhadas com maior precisão, para facilitar a construção e evitar erros. Além disso, elementos projetados sob encomenda, que demandam um processo sofisticado, envolvendo cuidadosa colaboração entre projetistas, auxiliam na garantia de que os elementos se encaixem corretamente sem interferir em outros sistemas (EASTMAN et al., 2014).

Os projetistas estão reconhecendo os benefícios da utilização desta tecnologia. Para Dossick e Neff (2010), o BIM torna explícita a alta dependência de integração entre o sistema estrutural, o layout e os sistemas mecânicos, elétricos, hidráulicos. Para os autores, a geometria tridimensional do BIM, em teoria, permite que os participantes do projeto se comuniquem mais facilmente sobre as questões espaciais e logísticas, bem como melhora o acesso à informação sobre as especificações e necessidades de material e de desempenho. Quando as equipes trabalham integradas, é possível conseguir bons resultados, como obter melhor estimativa de custos, reduzir o ciclo de detalhamento do projeto e produção, eliminar grande parte dos erros de coordenação de projeto, reduzir custos de engenharia e detalhamento, utilizar dados para uso de tecnologias de fabricação automatizada, além de obter melhores resultados na pré-montagem e pré-fabricação (EASTMAN et al., 2014).

Algumas características do setor da construção civil dificultam a utilização e integração dos modelos de informação, como: a fragmentação do setor, utilização de produtos únicos, apego aos métodos tradicionais, variedade de produtos e detalhes e o crescimento de exigência do setor (ANDRADE; RUSCHEL, 2009). Assim, o BIM pode contribuir para a interação entre as informações contidas no projeto e inseridas pelos diversos profissionais envolvidos.

Portanto, é importante que as equipes envolvidas no projeto tenham consciência da importância do trabalho em grupo e da contribuição de cada equipe. Construir modelos de 
informação pode oferecer desafios tecnológicos enfrentados pela indústria da construção civil e um bom design organizacional do BIM pode resultar em dinâmicas de grupo positivas para a resolução conjunta de problemas (DOSSIC; NEFF, 2010).

Segundo Eastman et al. (2014), a previsão é que, nos próximos anos, as ferramentas BIM básicas devam ser ampliadas consideravelmente, contribuindo, assim, para a pré-fabricação, flexibilidade e variação dos métodos construtivos, tipologias, redução de erros de projetos, documentos, desperdícios e maior produtividade. Segundo os autores, nos Estados Unidos, em 2007, 74\% dos escritórios de arquitetura já estavam utilizando o 3D e ferramentas BIM, no entanto apenas 34\% aplicavam-nos como modelagem inteligente.

Dossick e Neff (2010) observaram que os projetistas hidráulicos e elétricos trabalham separadamente dos arquitetos e engenheiros. Contudo, para que sejam possíveis melhores resultados, é importante que trabalhem mutuamente, e o BIM oferece ferramentas que facilitam isso; assim, é possível identificar os pontos de divergência do projeto e resolvê-los de maneira mais prática e eficiente. Em um módulo de instalação simples, no teto ou corredor, detalhes como componentes de climatização, tubulação, aspersão, elétricos e sistemas de comunicação podem ser reunidos, mas coordenar a integração entre eles só é possível devido à confiabilidade das informações obtidas por meio do BIM (EASTMAN et al., 2014).

Para Dossick e Neff (2010), o BIM incentiva um processo de construção colaborativa virtual antes da construção física e impulsiona os participantes do projeto a trabalhar de forma colaborativa em três dimensões. Segundo os autores, bons líderes podem inspirar os participantes a expandir seu foco além do caráter individual em direção aos objetivos comuns do projeto.

A remanufatura contribui para a economia circular e seu resultado é proveniente das decisões tomadas em todas as atividades que a envolvem. Dadas as fortes correlações entre as decisões tomadas em diferentes atividades, é necessária uma maneira de integrar e gerenciar 
essas decisões, sendo isso uma grande lacuna de pesquisa (SITCHARANGSIE; IJOMAH; WONG, 2019).

Encontrar uma sequência de desmontagem ideal para recuperar componentes de um edifício é complexo e difícil devido a múltiplos fatores, tais como: restrições físicas, ambientais e econômicas, um elevado número de caminhos de desmontagem possíveis até mesmo para montagens simples e vários métodos de recuperação (SANCHEZ; HAAS, 2018). Porém, com as informações reunidas em um memorial, é possível avaliar a melhor opção de desmontagem.

Outro desafio é a classificação dos resíduos provenientes da demolição ou desconstrução. Para Kunieda, Codinhoto e Emmitt (2019) "a ciência sobre a classificação de resíduos ainda é embrionária" (tradução da autora), porém é possível planejar a demolição com base no nível de classificação e reutilização, este processo pode fornecer diretrizes para novas práticas de demolições.

Dessa maneira, o BIM pode se tornar um grande aliado do Projeto para Desmontagem, pois é possível obter melhores resultados na compatibilização dos projetos complementares, tomadas de decisões e armazenagem de informações sobre os materiais e produtos utilizados. No entanto, a implementação do BIM foi ignorada para as atividades de fim de vida (AKINADE et al., 2017). Assim, é necessário desenvolver pesquisas relacionadas ao BIM e o final do ciclo de vida dos edifícios.

\subsection{Objetivos}

\subsubsection{Objetivo geral}

A pesquisa tem como objetivo analisar a Modelagem da Informação da Construção e as maneiras de contribuir para o Projeto para Desmontagem. Verificar como o BIM pode contribuir para melhores resultados para o DfD, com a intenção de tornar mais eficiente a desmontagem do edifício no final da sua vida útil ou durante reformas e manutenções. Assim, 
mais materiais removidos poderão ter mais chances de serem reutilizados ou reciclados, o que, consequentemente, contribuirá para a redução de resíduos e para a economia de matérias-primas na produção de novos materiais.

Portanto, foram analisados conceitos de projetos para montagem e construtibilidade dos edifícios também é necessário, pois isso traz benefícios para a desmontagem e fornece parâmetros sobre os materiais e elementos, além de informações sobre montagem que podem contribuir para a desmontagem.

Para isso, foi desenvolvida uma estrutura de classificação de desmontagem que mede a possibilidade de desmontagem dos materiais e elementos que compõem o edifício. A intenção foi desenvolver uma classificação inicial, que pode ser complementada ou alterada conforme a necessidade, para analisar as possibilidades do software. Cada elemento terá uma avaliação, baseada em suas características. A partir da classificação de cada sistema específico, será possível calcular uma média para todo o edifício, com o intuito de medir, de forma objetiva, o seu grau de desmontabilidade. Posteriormente, com o desenvolvimento deste conceito, é possível estipular um valor mínimo, para que, no futuro, aumentem as reais possibilidades de reutilização ou reciclagem, além de reduzir a geração de resíduos e o consumo de matéria-prima.

Assim, foram desenvolvidos modelos em software BIM para a aplicação da Classificação de Desmontagem em cada elemento que constitui a estrutura de construções pré-moldadas. Foram selecionados três métodos construtivos (elementos pré-fabricados de concreto, metálicos e madeira) para modelagem e inserção dos índices de Classificação.

\subsubsection{Objetivos específicos}

- Relacionar DfD e BIM de modo a contribuir para o planejamento da desmontagem de edificações. 
- Realizar análises sobre a Modelagem de Informações da Construção e ferramentas que contribuam para o DfD, focadas em armazenamento de dados, simulação, criação de parâmetros, interoperabilidade, conexões e modelos 3D.

- Desenvolver uma classificação de desmontagem dos materiais e elementos de edifícios, por meio do BIM, para melhor explorar as possibilidades dos softwares e verificar se os resultados obtidos realmente contribuem para a programação da desmontagem.

- Modelar, em software BIM, três sistemas estruturais compostos por pré-fabricados de concreto, madeira e metálico, para análise comparativa da Classificação de Desmontagem.

- Propor diretrizes para o desenvolvimento de um manual para a desmontagem que contenha informações sobre a classificação de desmontagem, checklist das características dos materiais e sistemas e demais informações fundamentais para a desmontagem.

\subsection{Estratégia}

A proposta de inovação do trabalho é analisar a aplicação do BIM no desenvolvimento de projetos e avaliar maneiras que possam contribuir para o DfD. Ferramentas podem ser utilizadas para armazenar informações essenciais para a futura desmontagem do edifício e criar parâmetros para auxiliar tomadas de decisões na fase projetual. O desenvolvimento de uma classificação de desmontagem que pode ser aplicada em modelos BIM, auxilia na escolha de opções que favorecem a futura desmontagem de materiais e elementos para futura reutilização ou reciclagem.

A utilização do BIM por profissionais da construção civil é ascendente, para aperfeiçoar a compatibilização dos diversos projetos envolvidos e reduzir os erros. Isso também facilita a construção ou montagem dos prédios e, consequentemente, auxilia na desmontagem. Esta tecnologia também pode contribuir para a padronização dos elementos utilizados na edificação e isto é muito importante, pois facilita a construção, manutenção e o desmonte. Quando os elementos são padronizados, as ferramentas utilizadas são as mesmas, assim como o transporte e o armazenamento. Além disso, a desmontagem torna-se mais rápida e 
eficiente, com maior possibilidade de manter os elementos e materiais em bom estado, para futura revenda.

Assim, a proposição de inovação da pesquisa de doutorado é estudar o BIM relacionado a desmontagem dos edifícios, verificar como pode contribuir com o reaproveitamento de materiais por meio das ferramentas de armazenamentos de dados, criação de parâmetros, simulações, modelagem 3D e desenvolvimento de um plugin. Dessa forma, será possível propor soluções que contribuam para a desmontagem dos edifícios, permitindo reutilizar ou reciclar os materiais. Além disso, com o desenvolvimento de uma classificação específica de desmontagem, será possível calcular o potencial de desmontabilidade do edifício.

\subsection{Estrutura da tese}

A tese será estruturada em seis capítulos. O primeiro capítulo aborda a introdução do trabalho, uma breve apresentação, o problema e a justificativa da pesquisa, além dos objetivos e estratégias de pesquisa. A introdução apresenta um problema muito recorrente atualmente, que é a questão dos resíduos do setor da construção civil e as possibilidades de reutilização e desmontagem.

O segundo capítulo apresenta o método de pesquisa e seu delineamento, portanto explica como a tese foi desenvolvida para a obtenção dos resultados que são apresentados e o alcance dos objetivos.

O terceiro capítulo apresenta a revisão bibliográfica focada no BIM e sua possível colaboração para o Projeto para Desmontagem. Assim, são apresentados os principais autores relacionados ao BIM e suas possibilidades, abordando os principais temas relacionados à desmontagem, como o ciclo de vida dos edifícios, compatibilização de projetos, projetos 3D, simulações, fabricação e montagem, documentação e análise de softwares. 
No quarto capítulo apresentam-se os estudos exploratórios, em que estão presentes os levantamentos de dados, como entrevistas, visitas às fábricas e obras, além de análise de dados. Este capítulo é composto pelas informações reunidas com as entrevistas, análise de projetos e documentos, visitas às empresas de pré-fabricados e obras.

No quinto capítulo é apresentada a proposta para verificação da desmontabilidade do edifício. Este capítulo mostra como foi desenvolvida a classificação de desmontagem de diversos elementos que compõem um edifício e como pode ser realizado o cálculo para verificar o potencial do edifício em relação à desmontagem. Também são apresentadas as ferramentas presentes no software que podem contribuir para a desmontagem, verificando, assim, como projetar em ambiente BIM pode auxiliar no processo de projeto e desmontagem.

No sexto capítulo são apresentadas as conclusões provenientes de toda a informação reunida, além das limitações da pesquisa e recomendações para trabalhos futuros.

Posteriormente, apresentam-se as referências bibliográficas e, por fim os anexos, como os questionários desenvolvidos para as entrevistas e visitas. 


\section{Método de pesquisa}

O desenvolvimento da pesquisa se iniciou por meio das coletas de dados, principalmente bibliográficos. No primeiro momento foi realizada a revisão bibliográfica, com disciplinas cursadas, sobre o desenvolvimento das cidades e moradia para dar embasamento à necessidade de os projetistas estarem atentos às transformações e terem consciência de que a sociedade e o espaço habitado estão em constante transformação. Outro tema abordado, também em uma das disciplinas cursadas, foi a necessidade da flexibilidade das edificações e interação de diversos profissionais e disciplinas para o desenvolvimento de edifícios, até mesmo o envolvimento de profissionais que não estão diretamente ligados ao setor. Assim, estas questões estão diretamente relacionadas à abordagem da necessidade de considerar o Projeto para Desmontagem, além de aliar disciplinas com eficiência, como melhor pode ser feito utilizando-se a plataforma BIM.

Para Gil (2002), a pesquisa bibliográfica é desenvolvida com base em material já elaborado, constituído principalmente de livros e artigos científicos. O autor confirma a importância desse método afirmando que a principal vantagem da pesquisa bibliográfica reside no fato de permitir ao investigador a cobertura de uma gama de fenômenos muito mais ampla do que aquela que poderia ser pesquisada diretamente por meio de outros métodos.

Posteriormente, ainda com base em revisão bibliográfica, foram analisadas as funcionalidades do BIM e como podem contribuir para o DfD, principalmente nas questões voltadas a encaixes dos diversos componentes do edifício, informações contidas nos materiais, como dados sobre o ciclo de vida e sua composição e simulações. Além disso, outras questões também foram estudadas, como manutenção dos edifícios, retrofit e construtibilidade.

Além da revisão, julgou-se que seria importante realizar algumas entrevistas para analisar algumas posições dos profissionais em relação ao BIM e ao DfD. Assim, foram selecionados 
profissionais de diversas áreas para que pudessem dar opinião e mostrar o ponto de vista em relação aos temas abordados neste trabalho. Estas entrevistas auxiliaram na compreensão de algumas práticas de mercado e na orientação dos temas abordados e são consideradas ponto de partida para iniciar a coleta de dados empíricos.

As entrevistas foram baseadas em questões semiabertas e foram selecionados cinco profissionais de diferentes áreas para responder ao questionário; uma entrevista foi presencial, três foram realizadas por Skype e uma foi por e-mail. A primeira entrevista foi realizada com um profissional da indústria automobilística, pois o conceito DfD é utilizado mais frequentemente neste setor, além de softwares similares aos da plataforma BIM, no entanto voltados para o produto específico.

A segunda entrevista foi feita com o coordenador da equipe de projetos da reforma de um complexo hospitalar, em que algumas partes estão passando por mudanças substanciais, algumas partes foram demolidas e novas áreas estão em construção. Foi muito importante para analisar quais os desafios nas reformas e demolições, além de verificar o uso de software compatível à plataforma BIM no novo projeto e discutir sobre a previsão do ciclo de vida do novo complexo. A terceira entrevista foi realizada com um especialista em projetos de edifícios nucleares e também especialista em BIM. A vida útil de um edifício nuclear é um fator importante a se considerar desde a concepção inicial do projeto, pois requer diversos cuidados específicos, portanto foi interessante verificar suas considerações, além de analisar a importância de softwares adequados à plataforma BIM para obter resultados importantes.

Posteriormente foi realizada uma entrevista com um gerente de resíduos da construção civil, para analisar algumas questões ligadas à geração de resíduos, reciclagem, reutilização, além do controle e despejo de resíduos. A quinta entrevista foi realizada com um arquiteto responsável pela proposta de um projeto de um centro esportivo para a Copa Mundial de Futebol, em 2018, na Rússia, em que uma parte deveria ser desmontada após o evento. O arquiteto também trabalhou em outros complexos esportivos, o que foi importante para 
absorver informações sobre o processo de projeto focado no DfD e BIM. Os resultados e mais detalhes sobre as entrevistas são apresentados no capítulo 4.

Além das entrevistas, ao longo desta pesquisa, foram realizados estudos exploratórios em empresas de pré-moldado de concreto, estrutura metálica e de madeira. Foram realizadas visitas às empresas, entrevistas com diversos profissionais envolvidos no processo e visitas às obras. A intenção foi estudar os métodos construtivos, analisar o desenvolvimento do projeto e a montagem dos edifícios e, assim, averiguar as possibilidades de desmontagem dos sistemas com o menor índice de danos para que se torne viável a reutilização dos materiais.

Após a reunião dos dados e análises, com as informações obtidas, realizou-se o processo de desenvolvimento da Classificação de Desmontagem e dos modelos que possam ser usados para facilitar o processo de projeto considerando a fase do desmonte. A intenção é reunir dados dos projetos, que serão preenchidos pelo projetista, que podem ser obtidos pelo fabricante e gerar um relatório com as informações essenciais para a futura desmontagem e manutenção do edifício. Posteriormente o modelo pode ser comparado às desmontagens estudadas e o projetista irá analisar como pode contribuir para o processo.

O método de pesquisa Design Science (do inglês, Ciência do Projeto) se enquadra nos objetivos propostos na pesquisa. Segundo Lacerda et al. (2013), a importância do conhecimento produzido e a relação teoria-prática exigem novo foco de pesquisa direcionado ao projeto de artefatos que sustente soluções mais aprimoradas aos problemas abordados. Assim, para Lacerda et al. (2013), “a Design Science seria responsável por conceber e validar sistemas que ainda não existem, seja criando, recombinando, alterando produtos/processos/softwares/métodos para melhorar as situações existentes".

Os artefatos são os resultados desta metodologia de pesquisa e podem ser subclassificados como constructos, modelos, métodos e instanciações (LACERDA et al., 2013). O desenvolvimento de um método é o que mais se adequa a esta pesquisa, pois, segundo 
March e Smith (1995), o método é constituído por etapas utilizadas para realizar uma tarefa, um conjunto de constructos que representa um modelo para a resolução de um problema. Segundo Winter (2008), os métodos descrevem processos que conduzem a soluções para resolver problemas.

Lacerda et al. (2013) afirmam que a metodologia não deve ser um ato burocrático para a pesquisa, e sim corresponder ao problema de pesquisa, ser avaliada pela comunidade científica e evidenciar processo que complementa os resultados. Portanto, não deve ser vista como dificultadora, mas como um procedimento necessário para garantir o rigor no andamento do trabalho, a imparcialidade e a confiabilidade dos resultados.

Além disso, para Lacerda et al. (2013), os estudos de caso podem complementar a Design Science Research para atender a objetivos específicos, portanto é comum encontrar pesquisas que combinam métodos. Quando o estudo é previsto ou se propõe a desenvolver tecnologias (artefatos), é útil para compreender os artefatos existentes e o funcionamento em um determinado contexto.

Para desenvolver uma pesquisa Design Science, o trabalho não deve ser apenas relevante, mas também rigoroso. A pesquisa tem como objetivo criar soluções para classes específicas de problemas relevantes, utilizando uma rigorosa construção de avaliação do processo (WINTER, 2008).

Segundo Dresch, Lacerda e Antunes Jr (2015) as etapas do Design Science Research consistem em identificação do problema, concientização, revisão sistemática da literatura, identificação de artefatos e classes de problemas, proposição de artefatos para identificação para resolver o problema específico. Posteriomente é realizado o projeto, desenvolvimento e avaliação do artefato, seguido da explicação sobre aprendizagem e conclusões. Por fim, a generalização para classe de problemas, através do artefato e comunicação dos resultados. 
Assim este trabalho apresenta revisão bibliografica sobre BIM e DfD, identifica a lacuna de conhecimento sobre considerações de desmontagem na concepção de projeto em ambiente BIM. Portanto foi desenvolvido a estrutura para classifcação de desemontagem, como artefato, para avaliar e criar parametos de desemontagem e projetos BIM. O resultado é apresentado nesta tese.

Portanto, será possível obter informações sobre como o BIM é utilizado na prática, como pode contribuir com o DfD e, consequentemente, obter melhores resultados no desmonte do edifício para que seus materiais possam ser reutilizados e reciclados. Ao longo do processo, serão exploradas maneiras com que essas ferramentas podem contribuir com o Projeto para Desmontagem.

\subsection{Delineamento da pesquisa}

A pesquisa está dividida em quatro etapas. Inicialmente foi realizada revisão bibliográfica relacionada aos dois temas mais amplamente abordados, que são BIM e DfD. Posteriormente, outros temas que estão relacionados a estes dois temas principais das pesquisas foram analisados, como os softwares BIM, modelagem de edifícios, simulação de montagem e desmontagem e sistemas de checagem de informações contidas no projeto. Outros temas também foram estudados, como arquitetura sustentável, arquitetura e meio ambiente, reutilização e reciclagem de resíduos, desenvolvimentos das cidades e das habitações, no entanto não tanto aprofundados, pois são importantes para o desenvolvimento do trabalho, para demonstrar a necessidade de discutir os temas. Assim, estes foram os temas mais pesquisados, que ajudam a compor a tese e reunir importantes informações para o desenvolvimento de um modelo para auxiliar na desmontagem. Além disso, algumas entrevistas foram realizadas com profissionais de diversos setores para iniciar a pesquisa empírica.

A segunda etapa consiste no doutorado sanduíche realizado na Universidade de Bath, Reino Unido. Nesta etapa foi realizada ampla revisão bibliográfica, apresentada ao longo da tese e 
principalmente no capítulo 3. Os temas abordados foram DfD, BIM, construtibilidade, reutilização e reciclagem de resíduos, além de reunião de dados locais com a intenção de comparar como estes temas estão sendo abordados em comparação com o Brasil. Além disso, foram realizadas entrevistas com profissionais para discutir melhor os temas abordados na revisão bibliográfica (descritas com maiores detalhes no capítulo 4).

Na terceira etapa, são analisados os estudos exploratórios, apresentados no capítulo 4, com a intenção de verificar o processo de projeto e sistema estrutural com potencial para se adequar a desmontagem programada e reutilização de partes do edifício. Assim, estes estudos de caso fornecem diretrizes para o desenvolvimento de uma proposta para facilitar a desmontagem. 


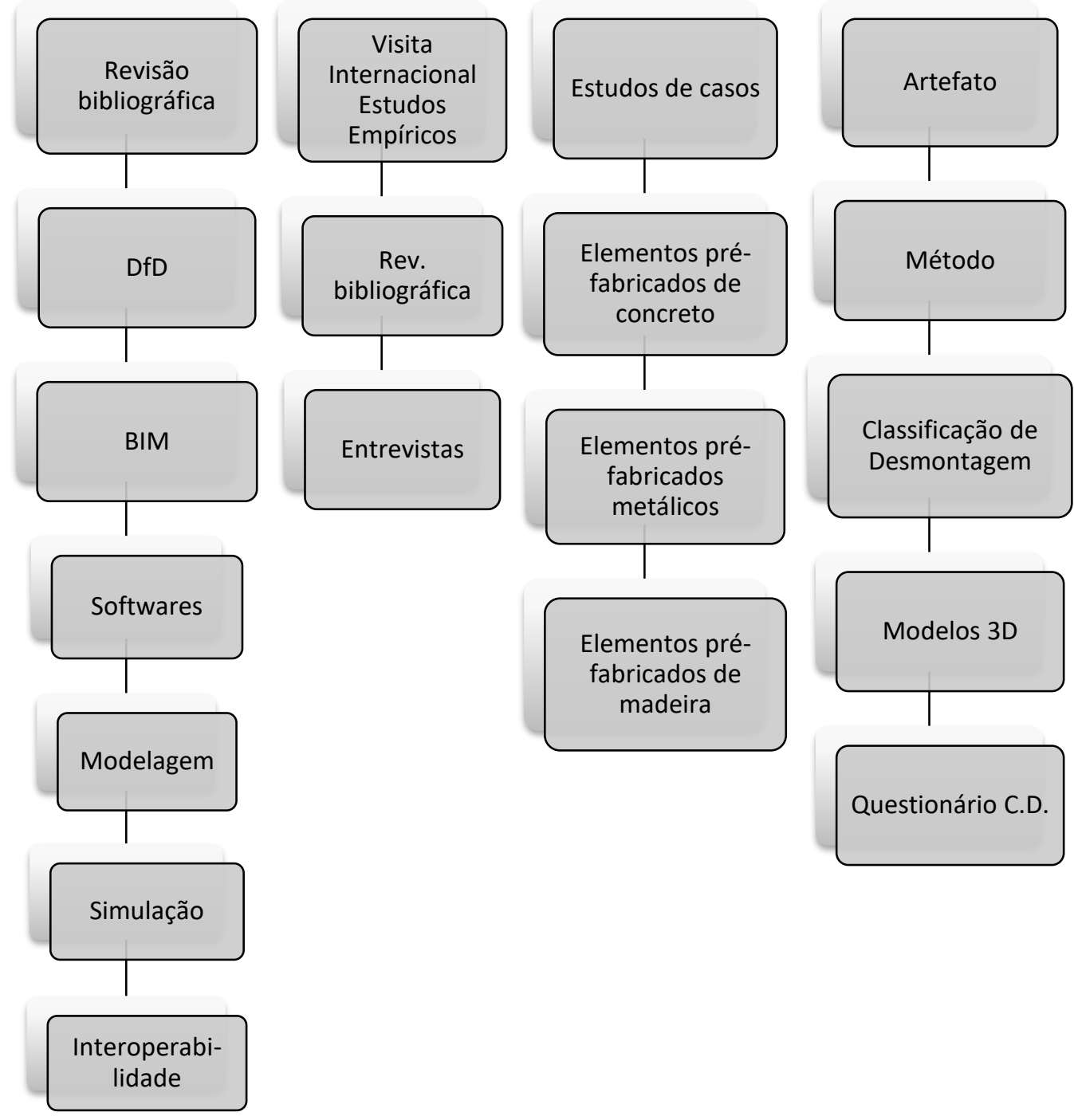

Figura 2 - Fluxograma das principais atividades realizadas ao longo da pesquisa. Fonte: Autora

A quarta etapa consiste no desenvolvimento do artefato. Para isso, foi realizada a análise de diferentes softwares, apresentada no capítulo 5, para verificar suas ferramentas e como podem contribuir para o processo de desmontagem, com decisões tomadas desde a concepção do edifício. Os softwares analisados foram como Revit, Dynamo, Tekla, Archicad e Naviswork. Esta análise foi realizada por meio de pesquisa das ferramentas dos softwares visando maneiras de colaborar com o DfD. 
Além disso, com base nas informações obtidas, foi desenvolvida uma proposta para contribuir para a desmontagem do edifício, assim possibilitando uma análise precisa visando à reutilização ou reciclagem dos materiais e componentes. A intenção foi desenvolver uma estrutura de classificação de desmontagem, baseada nas características dos materiais e elementos, para poder explorar melhor as ferramentas BIM. Foram desenvolvidos modelos 3D em software BIM para análise das ferramentas e para verificar como seria utilizada a classificação de desmontagem.

Posteriormente foi desenvolvido um questionário em relação à Classificação de Desmontagem e sua aplicação em modelos desenvolvidos no software Revit; os resultados estão no final do capítulo 5. Este questionário foi enviado por e-mail para professores da Engenharia Civil especialistas em sistemas estruturais, com a intenção de avaliarem a Classificação e sua aplicação em um software utilizados para projetos desenvolvidos em BIM. Assim, foi possível obter sugestões e questionamentos de especialistas em relação aos sistemas estruturais selecionados para compor a tabela.

Desta maneira, foi possível reunir as informações necessárias para o desenvolvimento deste trabalho, por meio de revisão bibliográfica, entrevistas, estudos de casos, análise de softwares BIM e análise mais aprofundada de um software específico (Revit). Assim, desenvolveram-se os modelos e parâmetros para serem inseridos no projeto, com o propósito de contribuir para a futura desmontagem de elementos e materiais que compõem um edifício.

Por fim, no capítulo 6 são apresentadas as conclusões, limitações da pesquisa e recomendações de trabalhos futuros. 


\section{FLUXOGRAMA DO DESENVOLVIMENTO DA TESE}

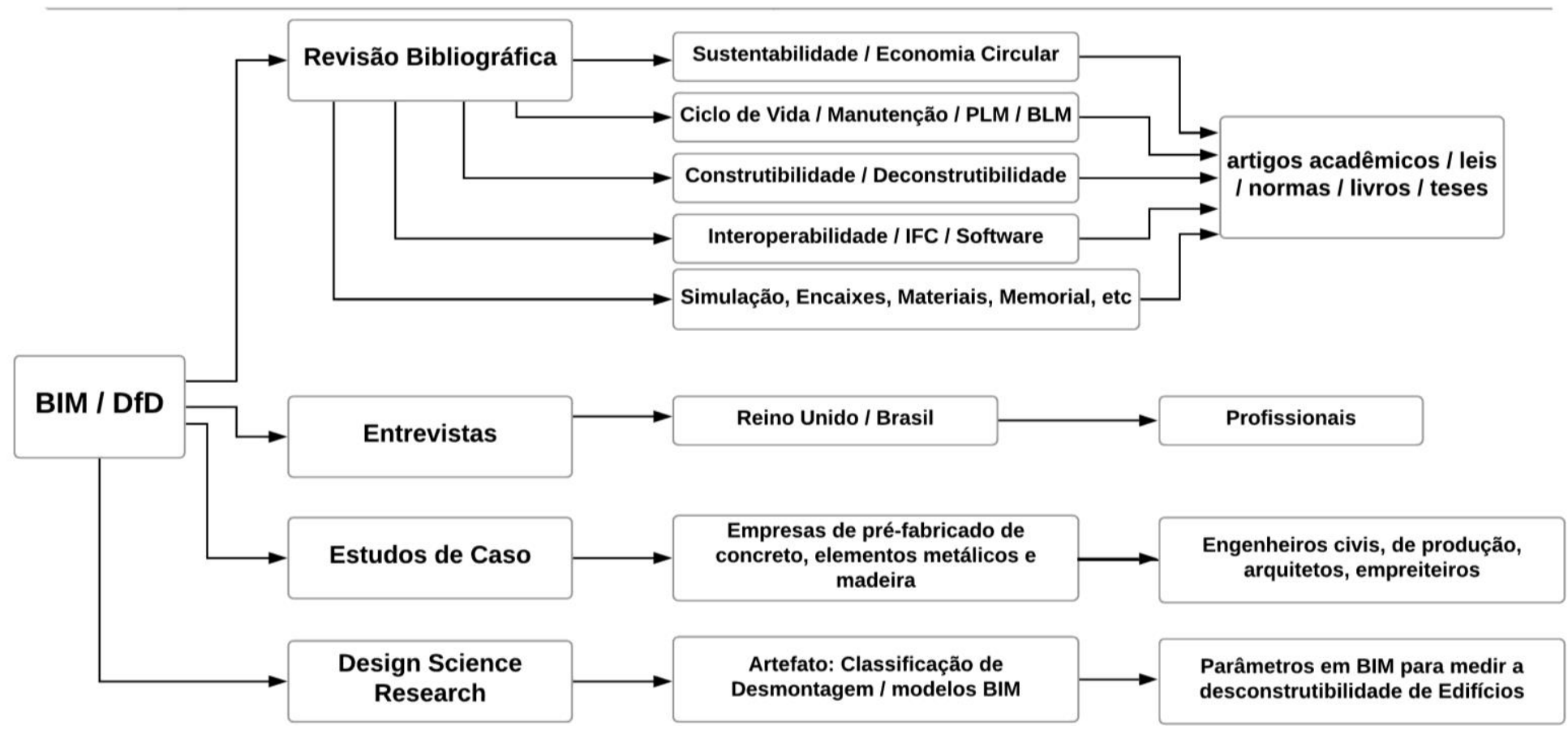

Figura 3 - Fluxograma do desenvolvimento da tese Fonte: Autora

A figura 3 apresenta o fluxograma do desenvolvimento da tese e as etapas percorridas. Assim, com estas informações reunidas e a proposta desenvolvida, é possível analisar decisões tomadas ainda em fase de projeto que possam colaborar para o processo de desmontagem. 


\section{BIM relacionado ao Projeto para Desmontagem}

A Modelagem da Informação da Construção pode garantir melhores resultados na desmontagem das edificações, devido as possibilidades para melhor armazenamento de informações em um único modelo, geração de documentos, possibilidades de simulações e visualização dos elementos em três dimensões, o que contribuem com melhores resultados na conservação dos materiais e futura reutilização ou reciclagem.

\subsection{Projeto para Desmontagem como opção à demolição}

Projeto para Desmontagem (do inglês Design for Disassembly - DfD) é um conceito que que visa a contribuir com a remoção dos materiais e elementos do edifício com o objetivo de ampliar as possibilidades de reuso, oferecendo uma alternativa à demolição. Considerações e decisões durante a fase de projeto podem contribuir significativamente com a desconstrução, facilitando a retirada das partes do edifício sem danos; além disso, pode torná-lo mais rápido e econômico. A desmontagem pode ser facilitada através das conexões entre os materiais e elementos, escolha de materiais resistentes, elementos pré-fabricados e considerações em relação ao ciclo de vida de cada material. Além disso, após a construção, é importante fornecer documentos as built com as informações atualizadas sobre o ciclo de vida, manutenção, além das ligações dos materiais e elementos.

Este tema foi amplamente abordado pela autora na dissertação de mestrado apresentar-se-á de forma mais resumida nesta tese, porém com revisão bibliográfica atualizada, pois esta pesquisa pode ser considerada uma extensão do assunto e aprofundamento para buscar melhores soluções para o Projeto para Desmontagem, além de

\footnotetext{
${ }^{8}$ MATTARAIA, L. Arquitetura e Sustentabilidade: Considerações sobre o Desmonte das Edificações. Dissertação de Mestrado, São Carlos, 2013.
} 
abordar a tecnologia da modelagem da informação como aliada ao processo de desmontagem.

Para Manzini e Vezzoli (2008), DfD significa facilitar a desmontagem desde a concepção do produto, por tornar mais ágil e econômica a separação de componentes e materiais. Romeiro Filho (2010) define o DfD como um método sistemático para separar peças e componentes de um produto, além de ser uma estratégia para o desenvolvimento de produtos em que a reciclagem se torne economicamente justificada.

Guy e Rocha (2005) afirmam que o DfD é um conceito explorado em diversas indústrias com a intenção de reutilizar, reciclar ou remanufatura os materiais. Segundo Go et al. (2011), considerar a desmontagem é importante para recuperar os materiais. Na indústria automobilística, por exemplo, isto contribui para reuso e remanufatura de maneira mais sustentável. Para Santini et al. (2010), o DfD torna mais veloz a desmontagem por considerar as conexões e estruturas dos veículos.

Devido à crescente preocupação com o meio ambiente, a sustentabilidade tornou-se um requisito, e não apenas uma característica desejável para produtos e serviços. Os métodos de projetos sustentáveis tornaram-se uma parte importante do processo de design na maioria das indústrias, incluindo construção. Exemplos de projetos sustentáveis são: projeto para montagem, gerenciamento da cadeia de fornecimento, avaliação de ciclo de vida (LCA), projeto para desmontagem, projeto para remanufatura, planejamento da sequência de desmontagem e reutilização adaptativa (SANCHEZ; HAAS, 2018).

Portanto, o DfD também contribui significativamente para o aumento do ciclo de vida dos materiais. De acordo com Manzini e Vezzoli (2008), o conceito contribui para a ampliação do ciclo de vida do produto e de seus materiais, além de prevenir que se tornem tóxicos e danosos. Segundo Klohn e Ferreira (2009), o DfD contribui para a diminuição dos danos ambientais por facilitar a manutenção, reutilização e reparação; além disso, faz com que os 
materiais tenham mais chances de serem reutilizados sem passar por processamentos e reciclagem e evita que apenas sejam descartados na natureza.

Para Romeiro Filho (2010), quando o DfD é considerado ao longo do projeto, os encaixes são facilitados, assim o produto pode ser desmontado com menos força e através de mecanismos mais simples. Também é importante deixar claros os pontos de identificação e desmontagem, além de considerar uma estrutura simples e não utilizar materiais tóxicos.

Segundo Guy e Rocha (2005), o Projeto para Desmontagem ou Desconstrução, voltado para edifícios, deve considerar os materiais e seu ciclo de vida desde o projeto inicial, para que atinja as metas econômicas e ambientais. O setor da construção civil é diferente dos demais ramos industriais e, devido à grande rotatividade de mão de obra, a produção é feita em locais diferentes, há grande variedade de tipologia e envolvimento de subempreiteiras (BARKOKÉBAS JÚNIOR et al., 2008). Dessa maneira, é importante documentar todas as alterações realizadas no processo da construção.

De acordo com Eckelman et al. (2018) o DfD é uma abordagem de projeto que permite a reutilização de componentes de construção duráveis, incluindo materiais estruturais, em vários projetos de construção. No DfD, materiais recuperados de edifícios antigos são reaproveitados diretamente em novos projetos, eliminando, assim, os custos de descarte de resíduos, fabricação de novos materiais e o processamento associado à reciclagem. A reciclagem de materiais de construção também tem perdas ambientais, pois os materiais devem ser coletados, separados, transportados, limpos/pré-processados e depois remanufaturados. Em muitos casos, os materiais de construção são reduzidos em produtos de menor valor, como concreto triturado e usado como material de base da estrada (ECKELMAN et al., 2018).

Akinade et al. (2016) afirmam que a desconstrução traz diversos benefícios, como economia de energia, redução da emissão de carbono, diminuição do custo e da poluição, além de contribuir para a sustentabilidade ambiental. Além disso, a desconstrução ou demolição 
seletiva de um edifício apresenta vantagens como facilitar a reutilização e a reciclagem de materiais, inovação tecnológica, além de contribuir para a sustentabilidade e o mercado de materiais reutilizados, pois valoriza materiais classificados como resíduos sem valor e depositados em aterros (COUTO; COUTO; TEIXEIRA, 2006).

De acordo com Klohn e Ferreira (2009), o projetista, ao desenvolver o projeto, pode considerar a sua vida útil, todo o seu ciclo, além dos custos e questões ecológicas. Crowther (2005) aponta três pontos centrais na aplicação do DfD: projetar de maneira sustentável, considerar as camadas do edifício e a hierarquia entre os materiais e componentes. Assim, o Projeto para a Desmontagem pode reduzir significativamente a grande quantidade de resíduos gerada pelo setor, que consiste em grande parte de desperdício em todo o mundo (GUY; ROCHA, 2005).

Romeiro Filho (2010) reforça que o DfD apresenta vantagens, como manusear as peças com mais facilidade, redução do trabalho na recuperação de materiais, diminuição de variáveis do produto, além de tornar a desmontagem mais simples e rápida.

A tabela 1 apresenta questões que são abordadas ao longo do desenvolvimento do DfD para tornar o processo mais eficiente. 
(Continua)

\begin{tabular}{|c|c|}
\hline $\begin{array}{c}\text { Orientações para o Projeto para } \\
\text { Desmontagem }\end{array}$ & Autores \\
\hline Projetar de maneira sustentável. & Crowther (2005) \\
\hline $\begin{array}{l}\text { Considerar as diferentes camadas do } \\
\text { edifício. }\end{array}$ & $\begin{array}{l}\text { Crowther (2005); Heriqson, Rocha e } \\
\text { Sattler (2008); Guy e Shell (2002); } \\
\text { Webster e Costello (2005); Morgan e } \\
\text { Stevenson (2005); Akinade et al. (2015) }\end{array}$ \\
\hline $\begin{array}{l}\text { Considerar a hierarquia de diferentes } \\
\text { tipos de materiais e componentes. }\end{array}$ & Crowther (2005) \\
\hline $\begin{array}{l}\text { Entender que o edifício é uma } \\
\text { composição de componentes e materiais. }\end{array}$ & $\begin{array}{l}\text { Heriqson, Rocha e Sattler (2008); } \\
\text { Crowther (2005) }\end{array}$ \\
\hline $\begin{array}{l}\text { Considerar os diferentes ciclos de vida } \\
\text { dos materiais e componentes da } \\
\text { edificação. }\end{array}$ & Crowther (2005); Guy e Shell (2002) \\
\hline $\begin{array}{l}\text { A maneira com que o edifício é } \\
\text { construído influencia na desconstrução. }\end{array}$ & $\begin{array}{l}\text { Heriqson, Rocha e Sattler (2008); Guy e } \\
\text { Shell (2002); Webster e Costello (2005); } \\
\text { Morgan e Stevenson (2005) }\end{array}$ \\
\hline Projetar considerando o desmonte. & $\begin{array}{l}\text { Heriqson, Rocha e Sattler (2008); Guy e } \\
\text { Shell (2002); Webster e Costello (2005); } \\
\text { Morgan e Stevenson (2005) }\end{array}$ \\
\hline Utilizar peças e materiais resistentes. & $\begin{array}{l}\text { Heriqson, Rocha e Sattler (2008); Guy e } \\
\text { Shell (2002); Webster e Costello (2005); } \\
\text { Akinade et al. (2015) }\end{array}$ \\
\hline $\begin{array}{c}\text { Buscar realizar conexões com parafusos } \\
\text { e encaixes. }\end{array}$ & $\begin{array}{l}\text { Heriqson, Rocha e Sattler (2008); } \\
\text { Crowther (1999); Guy e Shell (2002); } \\
\text { Webster e Costello (2005); Morgan e } \\
\text { Stevenson (2005) }\end{array}$ \\
\hline Evitar ligações químicas. & $\begin{array}{l}\text { Heriqson, Rocha e Sattler (2008); } \\
\text { Crowther (1999); Guy e Shell (2002); } \\
\text { Webster e Costello (2005); Morgan e } \\
\text { Stevenson (2005) }\end{array}$ \\
\hline Propor ligações independentes. & Heriqson, Rocha e Sattler (2008) \\
\hline $\begin{array}{l}\text { Utilizar peças de fácil manuseio, } \\
\text { transporte e armazenamento. }\end{array}$ & $\begin{array}{l}\text { Heriqson, Rocha e Sattler (2008); } \\
\text { Crowther (1999); Guy e Shell (2002) }\end{array}$ \\
\hline $\begin{array}{l}\text { Facilitar o acesso em todas as partes da } \\
\text { edificação. }\end{array}$ & $\begin{array}{l}\text { Heriqson, Rocha e Sattler (2008); } \\
\text { Crowther (1999); Guy e Shell (2002); } \\
\text { Morgan eStevenson (2005) }\end{array}$ \\
\hline $\begin{array}{c}\text { Reutilizar materiais nas novas } \\
\text { construções. }\end{array}$ & $\begin{array}{l}\text { Heriqson, Rocha e Sattler (2008); } \\
\text { Webster e Costello (2005) }\end{array}$ \\
\hline Separar estrutura e compartimentos. & $\begin{array}{c}\text { Crowther (1999); Guy e Shell (2002); } \\
\text { Webster e Costello (2005) }\end{array}$ \\
\hline Compatibilizar os sistemas. & Crowther (1999) \\
\hline
\end{tabular}


Tabela 1 - Conceitos que contribuem para o Projeto para Desmontagem de diversos autores

(Continuação)

\section{Orientações para o Projeto para Desmontagem}

Identificação dos materiais e componentes.

Crowther (1999); Guy e Shell (2002);

Webster e Costello (2005); Morgan e Stevenson (2005)

\begin{tabular}{|c|c|}
\hline $\begin{array}{c}\text { Utilizar áreas comuns dos edifícios e } \\
\text { fazer com que o usuário participe do } \\
\text { processo. }\end{array}$ & Crowther (1999) \\
\hline $\begin{array}{l}\text { Permitir que os componentes fossem } \\
\text { desmontados simultaneamente. }\end{array}$ & Crowther (1999) \\
\hline Adotar sistemas abertos. & Yuba (2005); Webster e Costello (2005) \\
\hline $\begin{array}{l}\text { Facilitar a ligação das peças e montagem } \\
\text { dos componentes. }\end{array}$ & $\begin{array}{c}\text { Yuba (2005); Guy, Shell (2002); Webster } \\
\text { e Costello (2005) }\end{array}$ \\
\hline $\begin{array}{c}\text { Utilizar conexões que facilitem a } \\
\text { desmontagem. }\end{array}$ & Akinade et al. (2015) \\
\hline $\begin{array}{c}\text { Utilizar parafusos e conexões que não } \\
\text { danifiquem os elementos. }\end{array}$ & $\begin{array}{l}\text { Heriqson, Rocha, Sattler (2008); Guy e } \\
\text { Shell (2002); Webster e Costello (2005); } \\
\text { Morgan e Stevenson (2005) }\end{array}$ \\
\hline $\begin{array}{l}\text { Utilizar materiais e componentes } \\
\text { resistentes e duráveis. }\end{array}$ & $\begin{array}{c}\text { Heriqson, Rocha, Sattler (2008); Guy e } \\
\text { Shell (2002); Webster e Costello (2005); } \\
\text { Morgan and Stevenson (2005); Akinade } \\
\text { et al. (2015) }\end{array}$ \\
\hline $\begin{array}{l}\text { Não utilizar materiais danosos ao meio } \\
\text { ambiente. }\end{array}$ & $\begin{array}{l}\text { Guy e Shell (2002); Webster e Costello } \\
\text { (2005) }\end{array}$ \\
\hline $\begin{array}{l}\text { Evitar embutir sistemas hidráulicos e } \\
\text { elétricos. }\end{array}$ & $\begin{array}{c}\text { Guy e Shell (2002); Webster e Costello } \\
(2005)\end{array}$ \\
\hline $\begin{array}{c}\text { Concentrar no mesmo local os } \\
\text { subsistemas, como hidráulico e elétrico. }\end{array}$ & Guy e Shell (2002) \\
\hline $\begin{array}{c}\text { Utilizar materiais e componentes que } \\
\text { possam se sustentar independentemente. }\end{array}$ & Guy e Shell (2002) \\
\hline $\begin{array}{l}\text { Utilizar elementos compatíveis à escala } \\
\text { humana. }\end{array}$ & $\begin{array}{l}\text { Guy e Shell (2002); Morgan eStevenson } \\
\text { (2005) }\end{array}$ \\
\hline Utilizar materiais leves e modulares. & $\begin{array}{c}\text { Guy e Shell (2002); Webster e Costello } \\
(2005)\end{array}$ \\
\hline $\begin{array}{l}\text { Utilizar materiais que possam ser } \\
\text { identificados visualmente. }\end{array}$ & Webster e Costello (2005) \\
\hline $\begin{array}{l}\text { Utilizar número limitado de diferentes } \\
\text { componentes. }\end{array}$ & Webster e Costello (2005) \\
\hline $\begin{array}{l}\text { Utilizar materiais que são fáceis de } \\
\text { separar. }\end{array}$ & Webster e Costello (2005) \\
\hline Evitar edificações complexas. & Webster e Costello (2005) \\
\hline
\end{tabular}


Tabela 1 - Conceitos que contribuem para o Projeto para Desmontagem de diversos autores

\begin{tabular}{c|c}
\begin{tabular}{c} 
(Conclusão) \\
\hline $\begin{array}{c}\text { Orientações para o Projeto para } \\
\text { Desmontagem }\end{array}$
\end{tabular} & Autores \\
\hline $\begin{array}{c}\text { Evitar misturar diferentes sistemas } \\
\text { construtivos. }\end{array}$ & Webster e Costello (2005) \\
\hline $\begin{array}{c}\text { Projetar layout simples e regular. } \\
\text { built. }\end{array}$ & Webster e Costello (2005) \\
\hline $\begin{array}{c}\text { Guardar com segurança o projeto as } \\
\text { reutilizadas. }\end{array}$ & Webster e Costello (2005); Morgan e \\
\hline Layout que permson (2005)
\end{tabular}

Fonte: Atualizado e adaptado de Mattaraia (2013)

No entanto, apesar do consenso de que o projeto pode contribuir para a redução de desperdício gerado pelas atividades de construção e demolição, as estratégias de projeto para mitigação real de resíduos ainda não estão claras. Além disso, os papéis decisivos exigidos dos projetistas continuam inadequados (AJAYI et al., 2017).

Além disso, Brewer e Mooney (2008) apontam desafios em aplicar o DfD na construção civil, como a dificuldade de rotulagem de componentes individuais, consultar dados sobre a reciclagem, a utilização de materiais genéricos e compostos, além das diferenças entre o projeto e a execução.

As conexões desmontáveis são importantes para a desmontagem e deveriam ser incentivadas em todos os elementos das edificações, como em sistemas estruturais, 
telhados, fechamentos. Portanto, quando as conexões são consideradas desde o início do projeto, é possível obter melhores resultados. A durabilidade dos elementos também deve ter uma atenção especial, pois pode ter mais valor quando reciclados, como as estruturas em madeira por exemplo (AKINADE et al., 2015).

De acordo com Akbarnezhad, Ong e Chandra (2014), um edifício típico é composto por vários elementos com características diferentes que podem afetar a sua capacidade de reutilização e reciclagem. Portanto, é importante considerar vários aspectos para escolher a estratégia de desconstrução mais sustentável, tais como preços, modalidade de energia de materiais e componentes, distâncias a percorrer, uso de energia e os custos relacionados aos processos de reciclagem, taxa de inflação, custos de concepção de componentes para reutilização, além dos custos de desmontagem e remontagem. Tudo isso envolve uma enorme quantidade de informações que devem ser organizadas e estar disponíveis para análise antes e durante a desconstrução. Para Akinade et al. (2016), os custos do DfD devem ser menores que os de demolição e os de depósito do entulho, para que se justifique o processo, além de se considerarem os benefícios ambientais.

Hoje em dia, a demolição é a prática mais usual quando um edifício atinge o fim da vida, mesmo quando a estrutura e os materiais ainda estão em boas condições, uma vez que, devido à mudança de uso, das necessidades e por não estarem preparados para mudanças, são simplesmente demolidos. No entanto, Akbarnezhad, Ong e Chandra (2014) afirmam que, nas últimas décadas, a consciência entre os proprietários, engenheiros e empreiteiros sobre a importância de se considerar a sustentabilidade na indústria da construção e os benefícios econômicos acessíveis por meio da desconstrução aumentou expressivamente. Como consequência, mais esforços e investimentos são foco em uma desconstrução mais elaborada, considerando a reutilização e a reciclagem, ao invés da demolição tradicional e a disposição em aterros. Por um lado, são necessários mais envolvimento e dedicação dos agentes envolvidos, mas, por outro lado, isso contribuirá para a manutenção do edifício, 
retrofit e construtibilidade. Além disso, haverá muitos ganhos ambientais por meio de economias de espaços em aterro e preservando as matérias-primas.

Segundo Akinade et al. (2016), arquitetos e engenheiros devem ser educados sobre DfD para planejar a desconstrutibilidade do edifício, documentar as informações necessárias, utilizar BIM, além de outras ferramentas, para que os materiais possam ser desmontados com segurança e manuseados corretamente. Algumas ferramentas conceituais estão sendo desenvolvidas para contribuir para o processo de desconstrução mais bem-sucedida. $O$ Projeto para Desmontagem é uma delas e está sendo cada vez mais discutido por fornecer orientações para melhorar o processo. De acordo com Akbarnezhad, Ong e Chandra (2014), este conceito fornece processos técnicos e de gestão para tornar possível a reutilização de elementos e de materiais de um edifício quando este chega ao fim da vida útil. Além disso, a desmontagem tem vantagens quando comparada à demolição, como preservar a energia incorporada nos componentes de construção e de expandir seu ciclo de vida. Outras vantagens são a redução de custos, das emissões de carbono e do consumo de energia (resultado da demolição), a reciclagem e o transporte para aterro.

No entanto, além de dificuldades técnicas na concepção de componentes para a desmontagem e reutilização, é necessário prever um custo adicional para que os elementos possam ser adequados para desmontagem e remontagem. Por exemplo, um elemento estrutural de concreto armado pode precisar de mais aço para fazer conexões mais resistentes nos processos de montagem e desmontagem para evitar danos; como resultado, este elemento pode elevar os custos iniciais, a energia incorporada e as emissões de carbono relacionadas com a fabricação dos componentes (AKBARNEZHAD; ONG; CHANDRA, 2014).

Além do mais, conceitos DfD também podem auxiliar na melhoria da construtibilidade e manutenção do edifício. Verificar como o edifício é construído, materiais, conexões e as camadas é importante durante todas as fases do ciclo de vida do edifício. Por exemplo, se um elemento é considerado na montagem, durante a construção e também na manutenção, 
consequentemente irá facilitar a desconstrução do edifício. De acordo com Low (2001), construtibilidade é um conceito importante para melhorar os padrões de produtividade e qualidade na indústria, alguns materiais e elementos podem contribuir para isso. Por exemplo, o uso padronizado de colunas, vigas ou paredes de cortina pode diminuir a quantidade de mudanças durante a pré-fabricação. Além disso, facilitaria os sistemas construtivos e os detalhes de instalação. Existe uma relação positiva entre construtibilidade, qualidade de construção e produtividade.

Portanto, há uma grande relação entre a construtibilidade do edifício e as possibilidades de desmontagem. Para Low (2001), a construtibilidade pode ser melhorada através da adoção de princípios 3S: padronização (standardization), simplicidade (simplicity) e elementos integrados individuais (single integrated elements). Este princípio torna a construção mais rápida, reduz o trabalho intenso no local e, além disso, pode melhorar a desconstrução, tornando-a mais prática, rápida e econômica.

A figura 04 apresentam as vantagens ao se considerar o DfD ao longo do desenvolvimento do projeto. O projeto para a desmontagem visa ampliar as possibilidade de remoção de materiais e elementos com qualidade para serem reaproveitados, assim contribui com a reutilização, reciclagem, manutenção, construtibilidade, preservação de recursos naturais e redução de desperdício. 


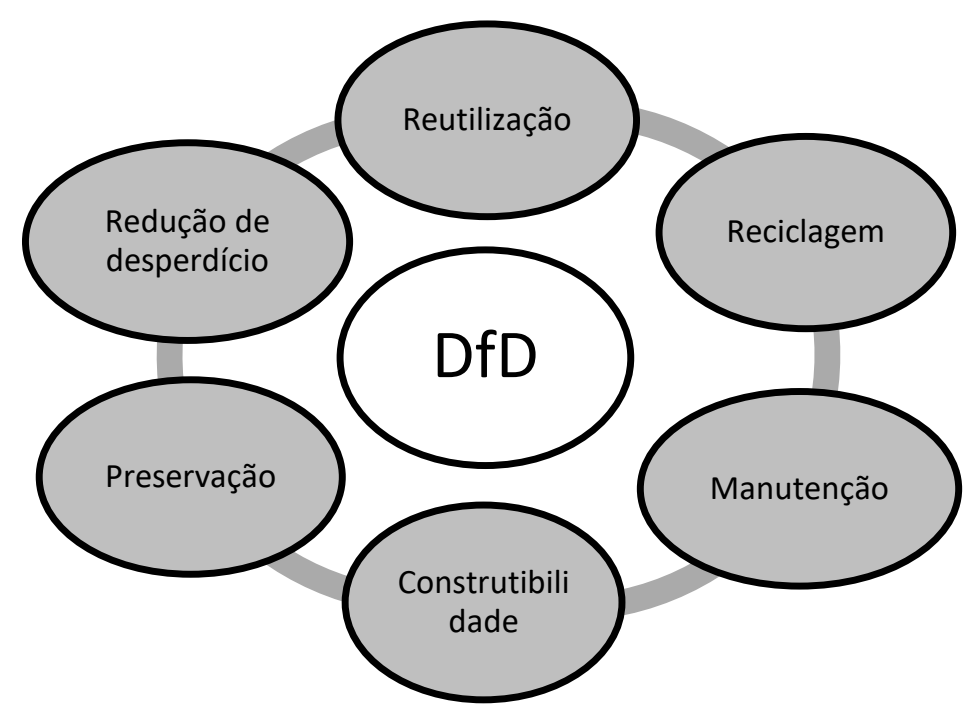

Figura 4 - Influência do DfD no ciclo de vida do edifício Fonte: Autora

Alkass, Jergeas e Tyler (1992) apontam alguns outros conceitos: a concepção e a construção devem estar mais envolvidas e a comunicação ampliada, assim a construtibilidade pode ser melhorada por meio de uma comunicação eficaz entre projetistas e construtores. Além disso, a tecnologia pode contribuir para técnicas de integração e avaliação. Detalhes do projeto para a construção e a compatibilidade com diferentes áreas, como arquitetos e engenheiros, podem desempenhar um papel fundamental.

Portanto, vários conceitos que colaboram para a construtibilidade têm uma contribuição significativa para a manutenção e desmontagem do edifício durante seu ciclo de vida. A tecnologia também melhora o processo durante a fase de desenvolvimento do projeto, pois a concepção está ficando cada vez mais complexa e o caminho para se desenvolver um projeto está mudando por meio de plataformas virtuais que podem contribuir para o desenvolvimento do projeto e reunir inúmeras informações que devem ser armazenadas.

Os processos de tomada de decisão associados à reutilização adaptativa de projetos de construção são diversos e dinâmicos. A complexidade está nos diferentes desafios e oportunidades que devem ser levados em conta simultaneamente, como as implicações técnicas, preocupações econômicas, impactos ambientais envolvidos etc. (SANCHEZ; HAAS, 2018). 
Assim, de acordo com Akbarnezhad, Ong e Chandra (2014), é importante considerar diversos parâmetros do edifício para optar por uma estratégia de desconstrução sustentável, pois envolve custo, consumo de energia e emissão de carbono. Além disso, uma construção é composta de vários componentes com características diferentes que afetam a capacidade de reutilização e reciclagem. Para planejar a desconstrução, é necessário ter acesso às informações sobre o material que deve ser armazenado e ter acesso fácil no futuro. Por exemplo, a tecnologia BIM (do inglês Building Information Modeling) facilita o armazenamento e a reunião de dados, se comparada a técnicas de documentação tradicionais em que seriam necessários mais detalhamentos e instruções e que deveriam ser armazenados por um período substancial.

\subsection{Utilização do BIM para assistência ao DfD}

Cada vez mais o BIM é um tema que vem sendo abordado em pesquisas e artigos devido à capacidade de interação entre vários projetos e profissionais, reunião de informações, possibilidades de simulações, visualização do objeto e praticidade. Neste trabalho, este tema é abordado por poder contribuir com o DfD, pois há funcionalidades, como a identificação dos materiais, o detalhamento de encaixes e a relação entre vários componentes do edifício, podendo ser mais bem analisadas quando o BIM é utilizado. Por meio dele é possível criar um modelo tridimensional e virtual do que está sendo projetado, com informações relevantes para a construção (EASTMAN et al., 2014). As informações contidas no modelo auxiliam na construção, manutenção e até mesmo na futura desmontagem do edifício. Para Eastman et al. (2014), "a Modelagem da Informação da Construção (BIM - Building Information Modeling) pode ser considerada uma transição significativa na prática de projeto". Segundo os mesmos autores, "BIM não é uma coisa ou um tipo de software, mas uma atividade humana que envolve amplas mudanças de processos na indústria da construção".

Além disso, as informações contidas também auxiliam nas tomadas de decisões e resultam em melhores resultados na vida útil do edifício. Diversos dados podem ser inseridos, como análise do ciclo de vida dos materiais e componentes, valores, quantidade de emissão de 
CO2 na produção dos materiais, entre outros. Os projetos ficaram mais complexos, portanto tendem a aparecer mais falhas; assim, para manter um ritmo avançado de mudança e inovação, é imprescindível buscar novas formas de criar modelos do projeto final (LAWSON, 2011).

Segundo Campestrini et al. (2015), as tecnologias da informação no setor da construção civil nacional apresentam a Modelagem da Informação da Construção como resultado de pesquisas realizadas a partir da década de 1970, com o objetivo de melhorar as informações disponíveis e tomadas de decisões devido às novas exigências do mercado, como segurança, certificações ambientais, sustentabilidade, entre outras.

BIM está se tornando o núcleo do gerenciamento de informações na indústria de Arquitetura, Engenharia e Construção, bem como em operação e manutenção e gerenciamento de instalações (HOSSAIN; YEOH, 2018).

De acordo com Eastman et al. (2014) o BIM é uma importante ferramenta que pode contribuir muito para o desenvolvimento da indústria AEC (arquitetura, engenharia e construção), pois auxilia o processo de projeto e construção mais integrada, o que resulta em uma construção de melhor qualidade, com custos e prazos de execução reduzidos. Campestrini et al. (2015) afirmam que, com o avanço da tecnologia, softwares e computadores, é fundamental que os profissionais envolvidos no projeto se mantenham atualizados, pois isso traz vantagens competitivas e requer mudanças e flexibilidade na forma de agir e pensar. Portanto, "o BIM surge como ferramenta para analisar e facilitar o acesso a essas inovações" (CAMPESTRINI et al., 2015).

Segundo Hilgenberg et al. (2012), o BIM é uma potencial ferramenta para resolução de entraves da indústria $\mathrm{AEC}$, como gerenciamento, troca e armazenamento de informações, portanto a tecnologia pode auxiliar no processo, por meio de um modelo colaborativo entre os profissionais em diferentes fases do empreendimento, durante a concepção do projeto, planejamento, orçamento e construção. Para Hilgenberg et al. (2012), “o BIM (Building 
Information Modeling) é um conceito que dispõe de ferramentas tecnológicas para organização e gerenciamento da informação, utilizado durante todo o ciclo de vida de uma edificação: projeto, construção e demolição".

"BIM não é apenas um software. BIM é um processo e software" (HARDIN, 2009, tradução nossa ${ }^{9}$ ). Para Hardin (2009), as tecnologias que envolvem o BIM continuam a crescer e a se desenvolver, sendo cada vez mais evidente que a "velha maneira de fazer as coisas" é limitada. Além disso, os profissionais estão percebendo o BIM como uma ferramenta que pode coordenar e gerenciar melhor a informação de construção e também melhorar o processo de concepção e construção. Profissionais veem a necessidade de ter uma única fonte de informação que pode ser compartilhada, adicionada, alterada e compartilhada com a equipe de projeto.

De acordo com Cheng e Ma (2013, tradução nossa $\left.{ }^{10}\right)$ : "Building Information Modeling (BIM) representa o processo de desenvolvimento e utilização de um modelo gerado por computador para simular o planejamento, projeto, construção e operações de uma das instalações do edifício."

Para Penttila, Rajala e Freese (2007, tradução nossa ${ }^{11}$ ):

"O conceito de modelagem da informação de construção BIM é um quadro proposto de integração para todos os projetos e informações de projeto de construção em forma digital"; além disso, "o conceito Bim cobrirá várias informações sobre o edifício, seu projeto e processo de construção, além das fases de utilização e manutenção durante todo o ciclo de vida do edifício".

A norma britânica PAS 1192-2 (2013, tradução nossa $\left.{ }^{12}\right)$ define BIM como:

"Processo de projeto, construção ou operação de um edifício ou recurso de infraestrutura usando informações orientadas de um objeto eletrônico", além disso," o

\footnotetext{
9 "BIM is not just software. BIM is a process and software."

10 "Building information modeling (BIM) represents the process of development and use of a computer generated model to simulate the planning, design, construction and operation of a building facility."

11 "The concept of building information modeling BIM is a proposed integrative framework for all design and construction project information in digital form" and "BIM-concept will cover several information concerning the building, its design and construction process and also de use and maintenance phases through the whole life-cycle of the building".

12 "Process of designing, constructing or operating a building or infrastructure asset using electronic object oriented information" and "the process of BIM generates information models and their associated information that are used throughout the lifecycle of building/infrastructure facilities or assets".
} 
processo de BIM gera modelos de informação que, associadas, são usadas ao longo do ciclo de vida da construção, instalação e infraestrutura".

De acordo com o PAS 1192-2 (2013), o governo britânico publicou a Estratégia de Construção para reduzir os custos dos ativos do setor público em $20 \%$ até 2016 . Isso define uma série de objetivos estratégicos; um deles é atingir o nível de maturidade 2 do BIM em todos os edifícios públicos e privados, infraestruturas, remodelações e novos projetos de construção. Segundo o PAS 1192-2 (2013), para se atingir a maturidade de modelagem da Informação Nível 2, são necessários:

- soluções de softwares em combinação com muitas capacidades interoperáveis variáveis;

- projeto de manufatura e construção;

- produção baseada em diversas disciplinas e software de análises,

- arquivos colaborativos e gerenciamento de bibliotecas.

Embora o documento PAS 1192-2 (2013) considere o ciclo de vida do edifício desde a concepção até a manutenção, não há muita discussão sobre as informações necessárias que - BIM deve proporcionar para o fim da vida útil. A aplicação do BIM tem áreas de complexidade envolvendo pessoas, processos e tecnologia, no entanto há benefícios durante todo o ciclo de vida do projeto, criando integração e colaboração. Além disso, o BIM tem sido progressivamente implementado na indústria $A E C$ durante a última década, assim modelos de informação digital estarão disponíveis para a maioria dos edifícios no futuro, devido ao crescente uso (CHENG; MA, 2013).

No entanto, de acordo com Campestrini et al. (2015), alguns profissionais brasileiros pensam em BIM apenas como um software, utilizando-o como ferramenta no processo de projeto tradicional (anteprojeto, projeto básico e executivo), porém, se for entendido como uma mudança de processo que envolve cultura, hábito e pessoas, traz mais vantagens, por exemplo, quando se extraem valores relacionados a soluções de projeto inseridas no modelo. Para Campestrini et al. (2015), com o BIM é possível desenvolver projetos mais colaborativos, que tendem a acabar com os processos em que cada profissional entrega sua solução com 
base apenas no plano de necessidades, pois até mesmo as necessidades podem ser definidas de forma conjunta. Além disso, o modelo não seria apenas uma "central de dados", mas, sim, interativo, que pode se "auto-ajustar" conforme as informações inseridas.

Segundo Akinade et al. (2015), uma abordagem de Projeto Integrado, ou, em inglês, Integrated Project Delivery (IPD), promove a comunicação entre participantes, além de contribuir para o acesso à informação sobre o projeto, a construção, as operações e o fim da vida útil dos edifícios. O BIM oferece ferramentas que permitem que estas abordagens sejam mais bem-sucedidas; além disso, o BIM também tem a capacidade de simular custos, consumo de energia, entre outros desempenhos.

De acordo com Eastman et al. (2014), o desenvolvimento de projetos que são baseados nas informações que constam no papel pode apresentar erros e omissões, por ser um processo fragmentado, podendo, assim, resultar em atrasos, gastos financeiros, atritos e até mesmo litígios judiciais entre diversos participantes do empreendimento. Para estes autores, a comunicação baseada em papel, durante o desenvolvimento de projeto, gera diversos problemas como o tempo para gerar informações sobre estimativas de custos, uso de energia, detalhes estruturais, entre outros, pois estas considerações geralmente são feitas no final do processo, tornando-se muito difícil fazer alterações significativas. Portanto, é importante buscar alternativas para tornar o processo de desenvolvimento do projeto mais ágil e eficiente.

De acordo Hilgenberg et al. (2012), programas BIM são responsáveis pela transição entre softwares geométricos como CAD para modelos 3D parametrizados, pois contribuem para a relação do objeto construído com as especificações técnicas, a análise de compatibilidade, estimativa de custo, o cálculo de áreas, portanto não são apenas desenhos desconectados compostos por linhas. Além disso, os programas BIM geram automaticamente cortes, elevações, tabelas, e não apenas linhas, e apresentam um modelo 3D, facilitando, desse 
modo, a compatibilização com projetos hidráulicos, estruturais e elétricos, além de evitar retrabalho e melhorar a qualidade da informação (HILGENBERG et al., 2012).

Com o desenvolvimento 3D e a reunião de diversos dados, o projeto fica mais completo e é possível obter melhores resultados nas construções dos edifícios. Além disso, é mais fácil integrar os diversos projetos e identificar pontos divergentes que precisam ser solucionados. O modelo virtual auxilia no desenvolvimento do projeto, pois torna mais claros os pontos de divergência, sendo possível, também, reunir informações em um mesmo modelo, auxiliando, assim, na obtenção de soluções e na eficiência do projeto.

No entanto, o modelo pode ultrapassar o 3D, podendo ser 4D, 5D até nD. Segundo Debacher (2009), o Projeto Tetradimensional (4D) refere-se a uma atitude do projetista, usando seu talento e conhecimento de acordo com uma perspectiva de ciclo de vida. Isso deve ser considerado desde os primeiros estágios da concepção, pois o tempo não está apenas relacionado com o desgaste, mas também com as mudanças e evoluções que irão afetá-lo.

Desde a concepção do projeto é importante considerar todas as fases do edifício, desde a extração das matérias-primas, passando pela construção e utilização, até o fim de sua vida útil, para que seja evitado o descarte e os materiais possam ser reutilizados ou reciclados. Além disso, é importante buscar maneiras para que as informações contidas no projeto não sejam perdidas ao longo dos anos de vida útil do projeto.

O BIM reúne softwares e ferramentas que podem colaborar para a programação da desmontagem sem acrescentar muito esforço extra aos projetistas. Na maioria das vezes, não é possível reunir as informações dos materiais de construção e suas conexões, mas o BIM pode facilitar o processo, reunindo informações sobre os materiais, elementos e construtibilidade. Além disso, pode contribuir para o projeto sustentável, facilitando a simulação e organizando informações sobre todos os elementos do edifício. BIM, arquitetura sustentável e design eficiente podem se unir para encontrar maneiras para equipar as gerações futuras a construir com mais informações e obter melhores resultados relacionados 
com a sustentabilidade (HARDIN, 2009). De acordo com Volk, Stengel e Schultmann (2014), o aumento de solicitações de sustentabilidade, digitalização e automação, o crescimento de informações de edifícios existentes e tecnologias emergentes, como computação em nuvem, motivarão e estenderão a implementação do BIM também em edifícios existentes.

Uma pesquisa da NBS (National Building Specification), realizada no Reino Unido entre dezembro de 2018 e março de 2019, com 988 profissionais do setor da construção, verificou que quase todos os entrevistados sabem sobre o BIM: apenas $2 \%$ disseram que não sabiam e menos de $1 \%$ não tinha certeza. Dos $98 \%$ que estavam cientes, pouco menos de três quartos $(73 \%)$ disseram que sua organização havia adotado o BIM para projetos com os quais estiveram envolvidos, sendo que as maiores barreiras para a não utilização do BIM são: não ser uma demanda do cliente (65\%), falta de experiência (63\%) e falta de treinamento (59\%) (NATIONAL BUILDING SPECIFICATION, 2019). Portanto, é possível verificar que, apesar das vantagens apresentadas pelo BIM, ainda há espaço para crescimento de seus usuários.

Para Cheng e Ma (2013), o BIM permite reunir informações multidisciplinares e tem sido progressivamente utilizado na indústria de arquitetura, engenharia e construção. O processo de Modelagem de Informações da Construção pode ser utilizado para melhorar a estimativa de resíduos porque os métodos atuais levam muito tempo e esforço, assim não motivam os contratantes. Além disso, o BIM é utilizado para aplicações especializadas, como detalhamento de aço, estimativa de custos, análise de energia, relacionadas ao desenvolvimento do projeto. No entanto, não há muita aplicação relacionada ao estado de demolição.

Volk, Stengel e Schultmann (2014) afirmam que o BIM pode ser usado para integrar dados sobre consumo de energia, águas residuais ou custos de manutenção em sua classificação ou considerações sobre reciclabilidade e fim de vida no nível de componente. Estas adaptações ajudariam a reduzir os danos ambientais de uma estrutura construída e a verificar e monitorizar os valores de consumo e a emissão de estruturas certificadas. 
A figura 05 apresenta com o BIM contribui com o DfD e consequentemente aprimora a reutilização de materiais. Softwares, como o Revit, armazenam grande quantidade de informações sobre os materiais, detalhes sobre as conexões, modelos em três dimensões e até é possível simular a desmontagem, além de prever situações mais favoráveis para possibilitar a reutilização.

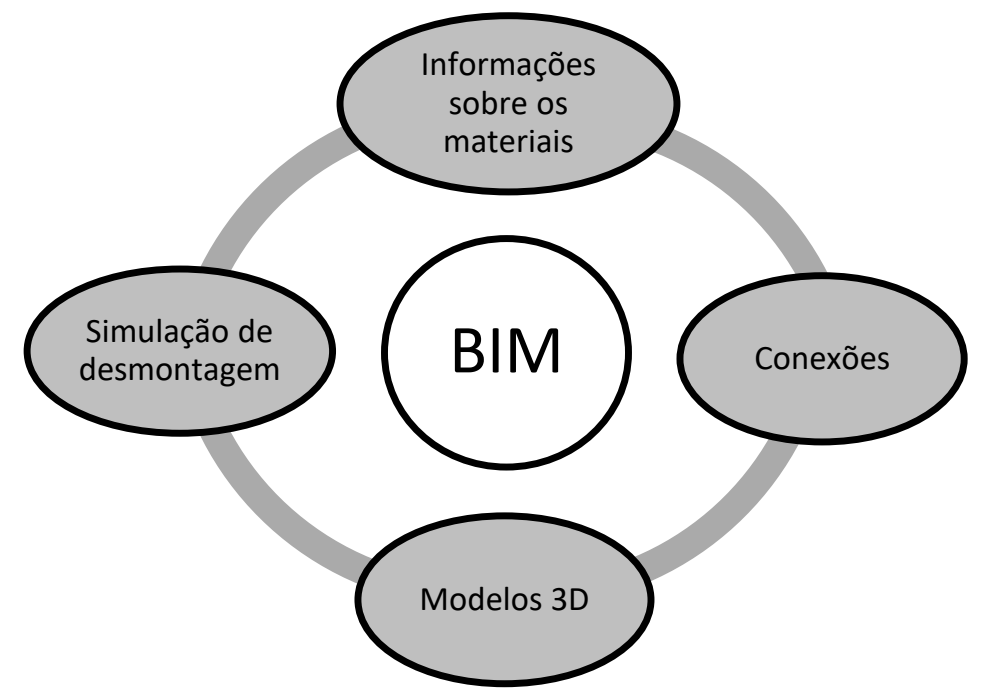

Figura 5 - Maneiras de que o BIM pode contribuir para o DfD Fonte: Autora

De acordo com Akinade et al. (2017), o BIM pode contribuir para a desconstrução das seguintes maneiras:

- melhor colaboração entre as partes interessadas: o BIM pode desempenhar um papel importante para garantir que todos as partes interessadas participem ativamente da desconstrução e das decisões relacionadas à desmontagem, desde o planejamento, construção até todo o ciclo de vida;

- visualização do processo de desconstrução: sugere visualização do processo de desconstrução por meio do BIM para otimizar o processo de desconstrução, a fim de comparar e minimizar o impacto no final de vida. Além disso, ao utilizar este recurso, ajudará a preparar adequadamente a desconstrução. Isso ajudará a desenvolver o planejamento apropriado, por meio de relatórios de auditoria, e estabelecer estratégias considerando o local, o transporte e a gestão de resíduos;

- quantificação de materiais recuperáveis: a informação é preservada dentro de um modelo global para melhorar a tomada de decisões durante a construção, a 
manutenção de edifícios e no fim de vida dos edifícios. Consequentemente, informações sobre os materiais poderiam ser adicionadas ao longo de todo o ciclo de vida. Isso irá capacitar o BIM para ser empregado na identificação de tipos de materiais recuperáveis e na quantidade ao longo de toda a vida dos edifícios. Portanto, além da visualização do processo de desconstrução, uma característica fundamental que o BIM apresenta, com base nas ferramentas DfD, é ter a capacidade de prever a quantidade de materiais recuperáveis e não recuperáveis. Esta característica permitirá prever as características e quantidades de materiais reutilizáveis, aqueles que podem ser reciclados e aqueles que devem ser descartados. Alcançar isso permitirá a previsão de evidências empíricas em apoio ao DfD;

- desenvolvimento do plano de desconstrução: não existe nenhuma ferramenta com a capacidade de gerar projeto para desconstrução por meio de modelos. Os participantes da pesquisa afirmaram que os recursos BIM que permitem a geração de documentos e projetos (como plantas, seções, cronogramas etc.) a partir do modelo dos edifícios poderiam evoluir para o desenvolvimento do plano de desconstrução. Assim, melhoraria a coordenação do projeto, gestão do tempo, documentação e atividades relacionadas ao DfD;

- análise de desempenho e simulação de fim de vida alternativa: o uso do BIM para a análise e a simulação do processo de desconstrução ajudará a justificar os benefícios ambientais e econômicos de desconstrução. O BIM pode ser usado para simular o desempenho custo-benefício da desconstrução para decidir sobre o design apropriado e opções de fim de vida;

- otimização do gerenciamento do ciclo de vida do edifício: uma vez que os resíduos são gerados em todas as etapas do trabalho do projeto, a adoção do BIM para o gerenciamento de resíduos permitirá a efetiva captura de dados relacionados com resíduos do projeto para o final da vida útil dos edifícios,

- interoperabilidade com o software BIM: o uso do padrão IFC melhorou a troca de modelos entre softwares BIM para análises de projeto, assim as futuras ferramentas DfD devem investir no IFC para a troca de modelos com software BIM. O IFC permite a extensão de suas tags para capturar vários parâmetros para elementos do edifício. Apesar desta oportunidade, o IFC não foi equipado com o mecanismo adequado para simplificar a análise de resíduos e o processo de desconstrução. Essa lacuna solicita uma análise mais aprofundada sobre como o IFC poderia ser estendido para suporte à troca de dados entre as ferramentas DfD e o software BIM. Assim, a necessidade de troca de informações do DfD precisa ser identificada e capturada nos Modelos BIM e IFC. 
Além disso, o BIM pode contribuir para a fase de manutenção e modernização. Penttila, Rajala e Freese (2007) afirmam que o BIM pode ser aplicado não só no processo de projeto e construção, mas também ajuda a manter o edifício, organizando as informações e fazendo um inventário de construção, levantamento de dados e medição. Ainda são necessárias mais pesquisas sobre o BIM e sobre a manutenção do edifício, pois aquele não foi testado em projetos de renovação, portanto o BIM não deve ser utilizado apenas para a fase de projeto e construção, mas também durante a fase de manutenção e durante todo o ciclo de vida do edifício.

Volk, Stengel e Schultmann (2014) revisaram mais de 180 publicações recentes sobre BIM e os resultados mostram a escassa utilização dele em edifícios existentes, devido a desafios de alto esforço de modelagem, conversão para capturar informações de construção e enviar para um software BIM. Enquanto o BIM está sendo utilizado para o novo edifício, a maioria dos edifícios existentes não é mantida, remodelada ou desconstruída da mesma maneira. No entanto, documentação deficiente e necessidade de superar as incertezas das condições de construção são motivação para buscar a opção de beneficiar a gestão eficiente.

De acordo com Volk, Stengel e Schultmann (2014), há um número crescente de interfaces de manutenção e funcionalidades relacionadas ao BIM nos edifícios recém-construídos, porém as abordagens para as funcionalidades de desconstrução continuam pouco utilizadas e não consideram todos os aspectos relacionados.

Segundo Akinade et al. (2017), é evidente que, apesar dos benefícios decorrentes do uso do BIM, seu uso no final da vida é frequentemente negligenciado, porém dar mais atenção ao fim da vida de edifícios é importante, porque as atividades de demolição representam mais de $50 \%$ da produção total de resíduos da indústria e da construção. Isso mostra que uma abordagem mais sustentável seria a prevenção de demolição através de DfD. Embora os arquitetos e engenheiros de projeto estejam conscientes do DfD, as ferramentas existentes não podem suportá-las efetivamente (AKINADE et al., 2017). 


\subsubsection{BIM e o ciclo de vida dos edifícios}

Primeiramente, é necessário mudar o conceito de que é suficiente considerar que o edifício resista pelo maior tempo possível, mas também é importante considerar todo o seu ciclo de vida até o final, porém grande parte dos profissionais não considera o fim da vida útil do edifício durante a fase de projeto. Para Hardin (2009, tradução nossa $\left.{ }^{13}\right)$ :

De modo geral, edifícios não são destinados a durar para sempre. Infelizmente, os edifícios muitas vezes sobrevivem à sua tecnologia até o ponto em que os sistemas e estruturas estão desatualizados, o material é ultrapassado (amianto, por exemplo) e o ambiente em torno da estrutura muda de densidade, uso ou propósito.

Portanto, é importante levar em consideração todo o ciclo de construção para que os materiais que estiverem em bom estado possam ter mais chances de serem reutilizados ou reciclados. De acordo com Hardin (2009), as construções verdes têm que considerar o ciclo de vida do edifício e têm uma vida útil limitada. Vários materiais da estrutura poderiam ser reutilizados com um investimento mínimo de tempo e recursos naturais, assim não seriam apenas materiais de aterro, como muitos os considerariam.

Na literatura, porém, poucos artigos abrangem o tema BIM e o fim da vida do edifício, sendo uma lacuna que precisa ser preenchida. Para Volk, Stengel e Schultmann (2014), o planejamento de demolição e desconstrução no contexto BIM é uma nova área de pesquisa e as publicações sobre o BIM têm aumentado significativamente, mas a maioria das publicações são sobre gerenciamento de dados, documentação, controle e acompanhamento ou medição de progresso. Para Hardin (2009), a indústria procurará opções para "fechar o ciclo" e, por isso, é importante incentivar os fabricantes a fornecer mais informações e ferramentas para acessá-lo. De acordo com AKANBI et al. (2019), ainda não é comum que o

\footnotetext{
13 “Generally speaking, buildings aren't meant to last forever. Unfortunately, buildings often outlive their technology to the point where the systems that exit in a structure are outdated, material research is completed (asbestos, for example), and the environment around a structure changes in density, use, or purpose."
} 
BIM seja utilizado no final do ciclo de vida do edifício, mesmo que haja exigências globais de que os edifícios devem reduzir o impacto ambiental ao longo de toda a sua vida útil.

O BIM foi bem adotado no projeto e construção, porém também pode ser benéfico nas fases de O\&M (do inglês, operation and maintenance) e FM (do inglês, facility management - FM) por vários meios, tais como melhor gerenciamento de instalações, uso eficiente de energia, tomada de decisão econômica de retrofit, análise de ciclo de vida para melhor gerenciamento de instalações e reparos seguros, uso de energia, além da demolição organizada. No entanto, o benefício do BIM ainda não foi explorado nestas áreas. Em parte, isso ocorre porque a maioria dos edifícios existentes não possui um BIM e a criação de um BIM para o edifício existente é um desafio (HOSSAIN; YEOH, 2018).

Araújo et al. (2017) constataram, por meio de uma revisão sistemática da literatura, que os processos que buscam melhorar as ferramentas ACV por meio do BIM são voltados para pesquisadores e consultores, assim não são frequentes em escritórios de engenharia e arquitetura. Além disso, são poucos os casos na literatura que abordam metodologias de forma prática, integrando ACV e BIM.

Ainda há questões pouco pesquisadas, como operação, manutenção e gestão de instalações com BIM, as lacunas que englobam a construção de BIM as built, gerenciamento de espaço e ativos, gerenciamento de manutenção (preventivo, preditivo e corretivo), manifestações patológicas, controle de sistemas e monitoramento, modernização e gestão de demolição (VIEIRA; CALMON; CAVALCANTE, 2017).

De acordo com Zhong e Wu (2015), alcançar a sustentabilidade econômica, a sustentabilidade ambiental e o desempenho de construtibilidade têm sido um desafio que a indústria da construção civil precisa abordar. Seguindo o conceito de ciclo de vida, esta questão deve ser incorporada nas fases iniciais do projeto, quando os processos de tomada de decisão para a seleção de materiais estruturais são feitos. Entender o desempenho de edifícios com estrutura de concreto armado e de estruturas de aço em diversos indicadores 
de sustentabilidade econômica, sustentabilidade ambiental e construtibilidade é, portanto, necessário para que o setor de construção evolua rumo a uma indústria sustentável (ZHONG; WU, 2015).

Ao planejar a desconstrução desde a fase de projeto, os resíduos gerados pela indústria seriam substancialmente reduzidos. O planejamento cuidadoso dos prédios para apoiar a desconstrução no final de seu ciclo de vida reduziria os resíduos gerados pela indústria (AJAYI et al., 2017).

De acordo com Zhong e Wu (2015), o fim da vida dos edifícios não é muito considerado por dois motivos: o fim dos custos de vida dos projetos atuais não foi pago pelos clientes atuais e os futuros clientes que comprariam esses projetos para redesenvolvimento precisariam pagar os custos de fim de vida. Além disso, devido à longa vida útil dos edifícios, pode ser difícil prever os custos de fim de vida.

Outros desafios estão na área de análise de ciclo de vida e energia, térmica e acústica, já que análises dedicadas à realidade brasileira, especialmente aquelas que englobam emissões de carbono e índices de energia incorporados nas fases de pré e pós-construção, a verificação de índices de materiais recicláveis, o desenvolvimento de novos materiais, estratégias sustentáveis, certificações ambientais e gerenciamento da geração de resíduos ainda precisam ser explorados (VIEIRA; CALMON; CAVALCANTE, 2017). Para Araújo et al. (2017), a união entre a tecnologia BIM e integração de ferramentas de Ciclo de Vida (ACV) pode promover impactos ambientais positivos, além de métodos mais eficientes e possíveis de serem utilizados por projetista.

Para Campestrini et al. (2015), o BIM pode ser utilizado em todas as fases das edificações, desde o início do projeto, durante a obra e sua utilização, até a demolição. De acordo com Penttila, Rajala e Freese (2007), o projeto de renovação do edifício deve ser considerado nas fases iniciais do desenvolvimento do projeto e deve ser gasto mais tempo e dinheiro para garantir melhores resultados no futuro. Inventários baseados em modelos são trabalhosos 
porque, geralmente, os princípios de modelagem têm que ser criados em primeiro lugar e não há um inventário ou orientação disponível para a renovação ainda. Cada projeto de renovação é único, por isso é mais difícil criar métodos do que o novo projeto de construção. A motivação para a renovação baseada em modelos digitais é muito importante, mas, às vezes, o proprietário não está interessado em todo o ciclo de vida do processo que envolve a concepção, construção e manutenção.

Para Akbarnezhad, Ong e Chandra (2014), uma análise do ciclo de vida, em relação aos custos e à energia consumida, também é necessária para avaliar uma estratégia de reciclagem. Por exemplo, para reciclar o concreto, é necessário triturar e transportar para o centro de reciclagem, o que consome energia e emissões de carbono, portanto o ideal é considerar a reutilização de materiais após o ciclo de vida útil do edifício durante o projeto, caso contrário, o desmantelamento e a reutilização podem ser mais caros do que usar novos materiais.

Além disso, para Penttila, Rajala e Freese (2007), o BIM é importante para o projeto e para a fabricação, porque a intenção não é gerir apenas o produto, mas também o processo de construção, materiais, tempo e dinheiro. Portanto, se o BIM é considerado desde os primeiros estágios de projeto e inclui informações sobre os materiais e construtibilidade, é possível obter melhores resultados durante a manutenção, o retrofit e a desmontagem. Para o edifício existente também é importante organizar o projeto as built e atualizar dados fundamentais sobre o edifício.

A figura 06 apresenta o ciclo de vida do edifício que deve ser considerado ao longo do desenvolvimento do projeto. O projeto deve considerar a extração de matérias primas, processamento, construção, utilização e descarte. Porém, quando se considera o descarte é importante rever as possibilidades de reciclagem e reutilização para estender o ciclo de vida dos elementos e materiais que compõe o edifício. 


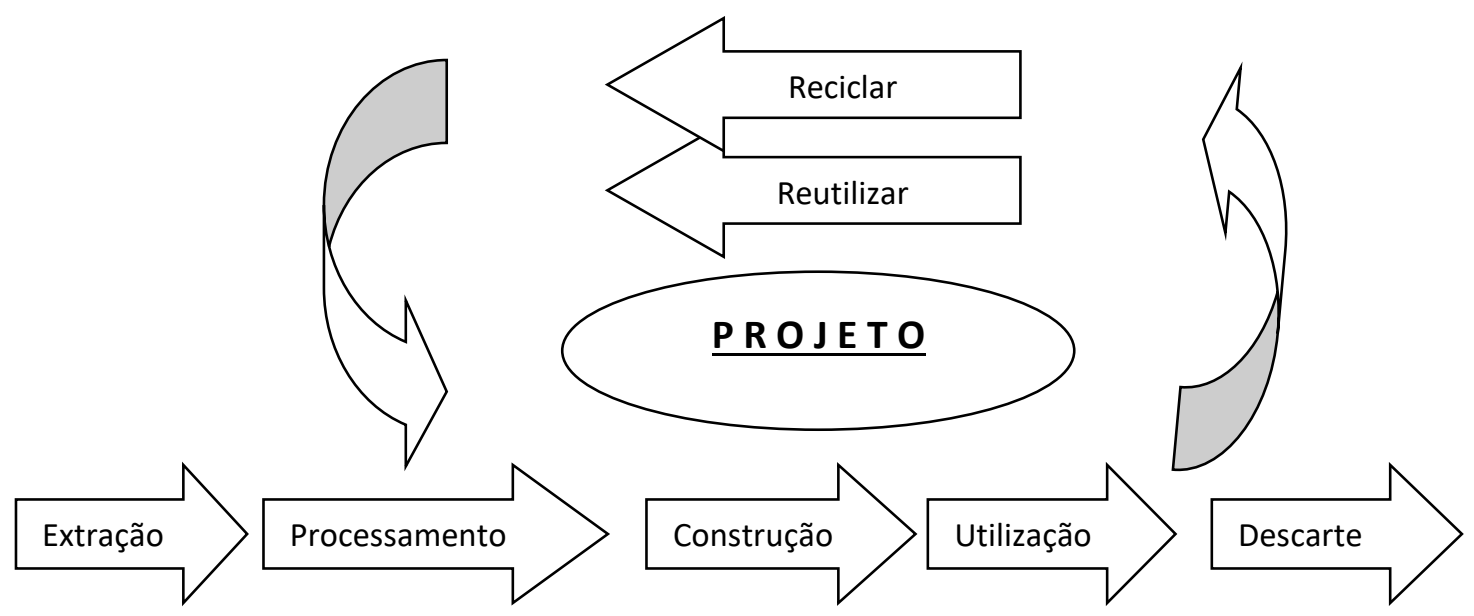

Figura 6 - Ciclo de vida a ser considerado no Projeto para Desmontagem Fonte: Autora

Geldermans (2016) discute a questão dos Edifícios Circulares, com base no conceito de Economia Circular e do Berço ao Berço, que implica mudanças radicais para o setor de construção. Do Berço ao Berço apresenta a ideia de edifícios como bancos de materiais, alterando radicalmente a forma como os fluxos de materiais precisam ser gerenciados. $\mathrm{A}$ noção de bancos de materiais (armazenamento temporário de materiais que compõem as montagens de construção) fornece um novo ponto de vista sobre o valor dos materiais e produtos de construção e como manter e restaurar isso. Os princípios básicos são diretos: alta qualidade, uso do material puro e programar a reutilização de materiais antecipada (GELDERMANS, 2016).

Diversos métodos para otimizar os resultados de remanufatura foram desenvolvidos para tomar decisões, como identificar as melhores opções no final do ciclo de vida, decidir o nível de desmontagem mais adequado, aplicar técnicas de limpeza adequadas e considerar a uniformidade do produto em diferentes famílias de produtos. Uma decisão tomada em uma atividade de remanufatura afetará grandemente as decisões nas atividades subsequentes, que afetarão os resultados da remanufatura, ou seja, a produtividade, a eficácia do desempenho econômico e a proporção dos elementos que podem ser recuperados (SITCHARANGSIE; IJOMAH; WONG, 2019). 
A importância da remanufatura tem aumentado desde que as regulamentações mais rígidas sobre a proteção do meio ambiente foram aplicadas. A remanufatura é considerada o principal meio de manter o valor de produtos e componentes. No entanto, é mais complexa do que a fabricação tradicional, devido às incertezas associadas à qualidade, às quantidades e ao tempo de retorno dos produtos e componentes usados (SITCHARANGSIE; IJOMAH; WONG, 2019).

Dessa maneira, o Building Information Modeling (BIM) pode desempenhar um papel significativo para operação e manutenção (do inglês, operation and maintenance - O\&M) e gestão de instalações de edifícios (do inglês, facility management - FM) por meio do uso de ferramentas de Tecnologias de Informação e Comunicação (TIC). No entanto, a maioria dos edifícios existentes não possui BIM. A pesquisa sobre criação de BIM para edifícios existentes tem recebido crescente atenção nos últimos anos. É evidente, na literatura atual, que a geração de BIM para a construção existente é complexa, tediosa, demorada e dispendiosa (HOSSAIN; YEOH, 2018).

\subsubsection{Integração entre BIM e PLM/BLM}

De acordo com Ustinovičius et al. (2015), com o grande avanço das tecnologias da informação surge a necessidade de desenvolver e implementar um sistema unificado de modelagem de informações de edifícios digitais. O rápido desenvolvimento da tecnologia de projeto no campo da arquitetura, engenharia e construção leva à adaptação contínua do aparelho conceitual para Modelagem de Informações da Construção (ou Building Information Model - BIM). Assim, o processo BIM surge como uma ferramenta que combina uma série de etapas sequenciais relacionadas ao investimento, tais como requisitos de projeto, construção, otimização de operações e demolições e preparações.

Segundo Ustinovičius et al. (2015), diversos países europeus buscam ampliar a utilização do BIM; por exemplo, o governo dinamarquês tem patrocinado um projeto de "Construção Digital" desde 2003, enquanto a Finlândia, a Grã-Bretanha, os Países Baixos, alguns outros 
membros da União Europeia, os EUA e a Austrália estão desenvolvendo iniciativas nacionais para implementar a modelização digital na construção há mais de 10 anos.

Para Campestrini et al. (2015), o modelo 3D contém as informações espaciais (vigas, paredes, pilares, portas etc.), além de especificações de materiais, acabamentos, revestimentos etc. O modelo 4D contém informações sobre prazo, como cronograma da obra e ritmo de produção. $\mathrm{O}$ modelo $5 \mathrm{D}$ envolve os custos da obra. $\mathrm{O}$ modelo considerado $6 \mathrm{D}$ reúne informações sobre o uso da edificação, como custos de operação e manutenção (CAMPESTRINI et al., 2015).

Ustinovičius et al. (2015) classificam os modelos de informação, além do 3D, da seguinte maneira:

- 4D - modelo de construção virtual com informações sobre a construção, a capacidade de controle do progresso do trabalho e a visualização de um edifício;

- 5D - permite uma estimativa precisa dos custos;

- 6D - introdução do princípio do desenvolvimento sustentável no processo de investimento, como a avalição da utilização de energia solar.

- 7D - baseia-se no conceito de Gestão de Instalações e abrange todo o seu ciclo de vida desde o conceito até a demolição. Assim, a integração de diversos projetos permite analisar problemas e acontecimento que estavam além do escopo do processo de projeto do edifício.

O protótipo 6D BIM contém a geometria tridimensional, bem como as propriedades físicas por componente de construção do modelo (3D). Além disso, o protótipo 6D BIM contém informações referentes às fases de construção e cronograma de trabalho (4D), bem como a estimativa de custos e orçamento (5D). Por fim, o protótipo 6D BIM também contém as informações referentes às fases de ACV (6D). Com o desenvolvimento de um protótipo 6D BIM preciso, é possível ter acesso aos dados necessários para os propósitos de um projeto sustentável com uma interface gráfica organizada (SANCHEZ; HAAS, 2018).

Dessa maneira, é oportuno observar a quantidade de informações que o projeto pode reunir, visto que, quando estas informações são inseridas em um só modelo e compartilhadas com 
diversos profissionais em um mesmo modelo, é possível obter melhores resultados. Além disso, é fundamental desenvolver a metodologia do Gerenciamento do Ciclo de Vida do Edifício (BLM, do inglês - Building Lifecycle Management), pois esta será a base das cidades e edifícios inteligentes, em que todos os processos (construção, infraestrutura, engenharia, logística, serviços de engenharia etc.) se baseiam nos modelos de informação desenvolvidos, de maneira a serem facilmente modelados, otimizados, gerenciados e arquivados (USTINOVIčlUS et al., 2015). As etapas que envolvem o BLM estão apresentadas na figura 07.

O BLM está ligado ao PLM (do inglês, Product Lifecycle Management), que, em português, pode ser traduzido como Gerenciamento do Ciclo de vida do Produto. O PLM serve como base para a definição, fabricação e o gerenciamento de serviços colaborativos em muitas indústrias. Sua função é capturar e fornecer acesso a informações sobre produtos e processos, além de preservar a integridade das informações ao longo do ciclo de vida dos produtos (ARAM; EASTMAN, 2013). Assim, o BIM pode se beneficiar ao se adaptar seletivamente à funcionalidade dos sistemas PLM, conforme apresenta a figura 08. 


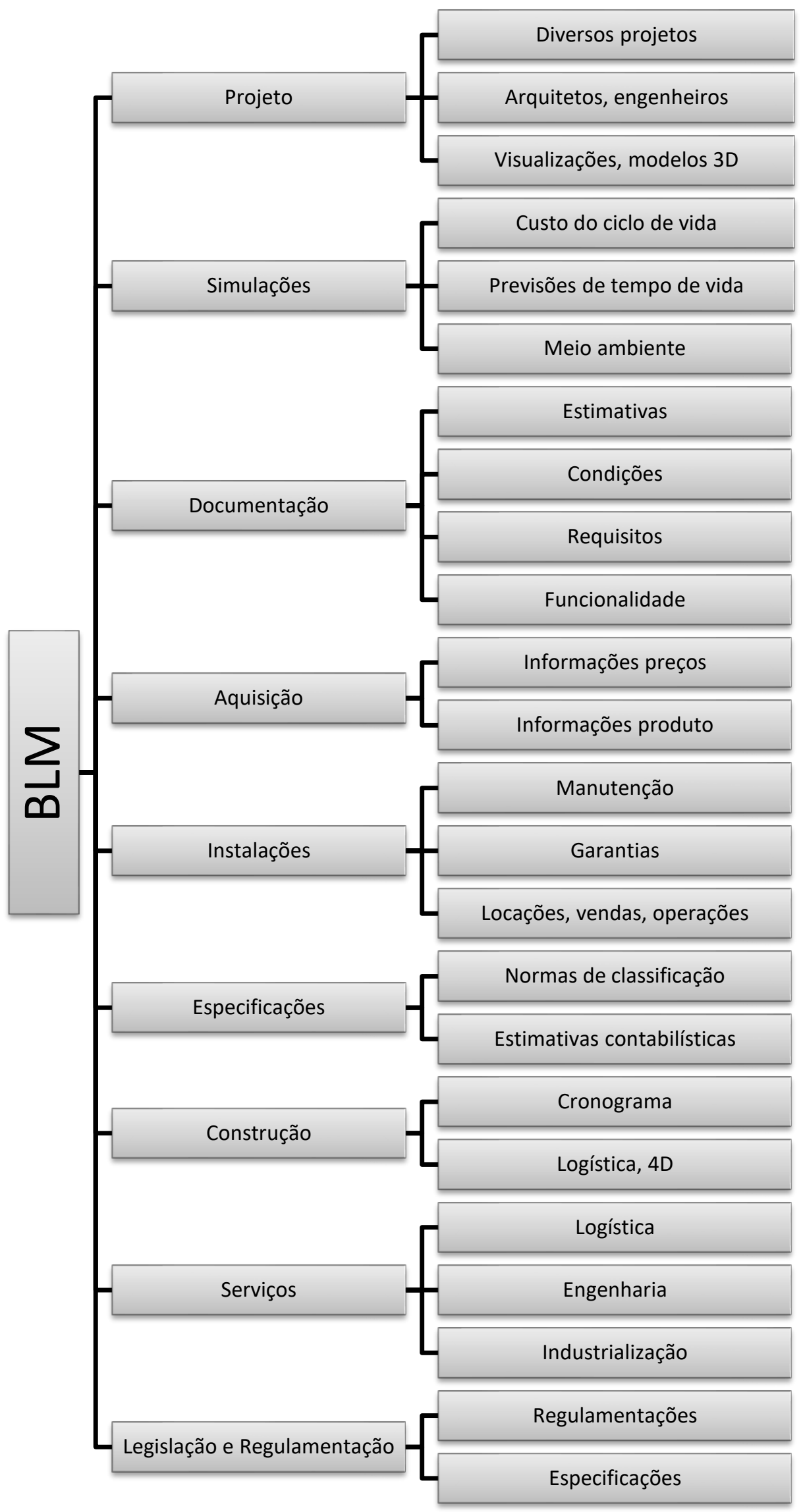

Figura 7 - Etapas que o BLM envolve

Fonte: adaptado de Ustinovičius et al. (2015) 


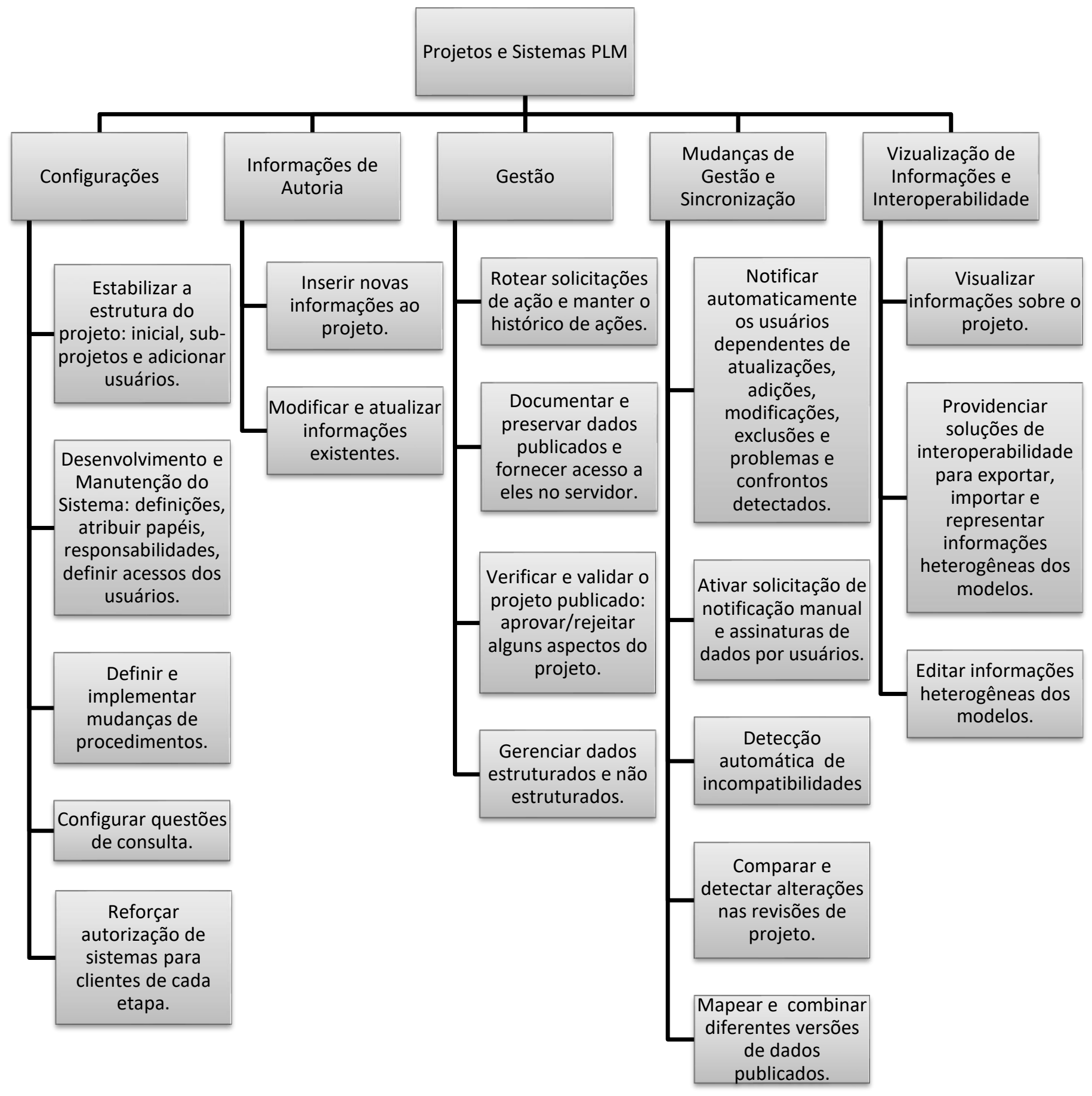

Figura 8 - Critérios e aptidões para a gestão colaborativa e o desenvolvimento de produtos PLM

Fonte: adaptado de Aram e Eastman (2013) 
No entanto, Aram e Eastman (2013) apontam algumas diferenças importantes entre as indústrias que utilizam o PLM e as características da indústria da Arquitetura, Engenharia e Construção (AEC) e, assim, exigem adaptações e modificações. A primeira diferença apontada pelos autores é em relação à indústria $\mathrm{AEC}$, que é composta, principalmente, por pequenas e médias empresas, com características e exigências diferentes das grandes; assim, pode ser onerosa a implementação de soluções de PLM. A segunda é a grande variedade de projetos e métodos de entrega que requerem abordagens que exigem soluções rápidas e funcionais. Algumas pré-configurações podem ser um bom começo, quando disponíveis em PLM na "nuvem", por reduzirem o custo e o conhecimento de TI (Tecnologia da Informação) necessário para o mercado de pequenas e médias empresas, mas não são suficientes.

Dessa maneira, o projeto deve considerar as diferentes etapas que envolvem o edifício. Desde o início do projeto é importante considerar todo o ciclo até o final de seu uso, para que se adeque, da melhor maneira possível, às novas tecnologias, necessidades e transformações. Portanto, ao se continuar a considerar o edifício apenas como algo rígido que deve durar o maior tempo possível, as chances de reciclagem e reutilização dos materiais serão menores e necessitarão de maiores investimentos.

Além disso, a reutilização de componentes de construção permite fechar o ciclo do material, reduzindo, assim, o consumo de recursos e a geração de resíduos. O ciclo fechado dos materiais elimina o padrão linear, que caracteriza o modelo de economia circular, que é mais sustentável (AKINADE et al., 2017).

Os impactos ambientais dos edifícios DfD são favoráveis aos edifícios tradicionais e a fase de produção é o maior contribuinte para os impactos do ciclo de vida completo. Se três reutilizações ocorrerem, os impactos ambientais serão reduzidos em um valor médio de 60 a $70 \%$, dependendo da categoria de impacto e da configuração do edifício. No entanto, as decisões tomadas sobre a desmontagem são fundamentais, pois a durabilidade e a 
adaptabilidade dos componentes do DfD serão decisivas em sua sustentabilidade (ECKELMAN et al., 2018).

Estratégias de economia circular incentivam ações concretas para prolongar a vida útil do produto, mas é importante ter acesso aos componentes para facilitar o reparo e a reutilização. O tempo de desmontagem também deve ser considerado, pois reduz o custo e aumenta a viabilidade econômica da extensão da vida útil do produto e, portanto, aumentará a viabilidade de uma economia circular nas regiões industrializadas. Além disso, a desmontagem tem o potencial de aumentar significativamente o rendimento da reciclagem. Por esta razão, a Comissão Europeia e vários selos ecológicos consideraram incluir os conceitos do Projeto para Desmontagem na legislação ou outros instrumentos ambientais. No entanto, até o momento, não há um método padronizado para avaliar a facilidade de desmontagem de maneira inequívoca, com um bom equilíbrio entre os esforços necessários para aplicar o método e a precisão do tempo de desmontagem determinado (VANEGAS et al., 2018).

Adaptar os edifícios ao reuso pode ser uma alternativa interessante para novas construções em termos de sustentabilidade e economia circular, pois a obtenção de benefícios adquiridos com reutilização adaptativa depende, em parte, do planejamento eficiente da desmontagem de edifícios (SANCHEZ; HAAS, 2018).

De acordo com Kunieda, Codinhoto e Emmitt (2019) reunir informações sobre resíduos de demolição para possível reciclagem em novos projetos de construção melhora o fluxo de material e contribui com a economia circular.

Segundo Geldermans (2016), materiais e produtos precisam preencher critérios para facilitar a circularidade. Podemos distinguir propriedades intrínsecas e propriedades relacionais. Em relação às propriedades intrínsecas, um material ou produto deve ser:

1. de alta qualidade (desempenho funcional);

2. de origem sustentável, capaz de ser reutilizado (após cada novo uso),

3. não tóxico (apenas são utilizados materiais saudáveis). 
Para Geldermans (2016), além de suas qualidades intrínsecas, um material ou produto deve se relacionar com o projeto e uso de edifícios. Essas propriedades relacionais dizem respeito à antecipação de cenários de usuários futuros desconhecidos. Tecnicamente, isso pode ser definido por:

a. dimensões (tendo em conta as capacidades dinâmicas de demanda);

b. conexões (secas e lógicas),

c. tempo de desempenho (definindo a vida útil).

A implementação bem-sucedida, no entanto, depende muito de fatores contextuais, compreendendo mudanças críticas e regulamentos de cadeia de valor. É, portanto, necessária uma grande inovação em diversas frentes, e os desafios nos domínios culturais, jurídicos e financeiros parecem mais profundos do que nos aspectos técnicos (GELDERMANS, 2016).

Portanto, é possível observar que os conceitos de economia circular estão de acordo com o DfD. Facilitar e sustentar os processos circulares requerem a adesão a múltiplos critérios e a participação de múltiplas partes interessadas. Atualmente, faltam ferramentas apropriadas para o controle de qualidade, mesmo que um software como o BIM mostre potencial. Por meio de uma abordagem gradual, as implicações para o processo de design no nível de construção e no nível de material/produto são ilustradas.

\subsubsection{BIM e compatibilização de projetos}

Um dos grandes desafios no desenvolvimento do projeto é a compatibilização dos projetos de diversos profissionais envolvidos no processo. Muitas vezes não é possível desenvolver projetos de forma linear, como, por exemplo, primeiramente desenvolver o projeto de arquitetura, depois de engenharia e assim por diante. O mais comum é desenvolver projetos simultâneos e fazer as compatibilizações e alterações necessárias. Para que a desmontagem seja bem-sucedida, é importante reunir as informações compatibilizadas. 
De acordo com Succar (2009), o desenvolvimento do projeto em BIM envolve diferentes campos de atividades como: política, processos e tecnologia. Segundo o autor, o campo da política envolve entidades reguladoras, instituições educacionais, companhias de seguro, bombeiros, centros de pesquisas e legislações. Enquanto o campo do Processo envolve os proprietários, gerentes de projetos, arquitetos, engenheiros, empreiteiros, fornecedores, fabricantes, gerentes de instalações, agrimensores. O campo da tecnologia está relacionado aos desenvolvedores e revendedores de software, companhias de hardware, provedores de rede. Isso demonstra a grande quantidade de informações e a complexidade que pode existir no desenvolvimento de projetos utilizando esta tecnologia, além da importância de as equipes envolvidas trabalharem juntas.

Segundo Brígitte e Ruschel (2016), soluções e formas computacionais adequadas à integração das análises de desempenho, durante o início do processo de projeto, auxiliam na obtenção de melhor desempenho do edifício; além disso, a preocupação com o desempenho das edificações tem ganhado destaque e impulsionado transformações significativas.

Mikaldo Jr. (2006) afirma que a necessidade da realização da compatibilização de projetos tem como maior motivo a separação da atividade de projeto e de execução de obra, questão que já decorre de longa data. Fatores mais recentes levantados pelo autor são os crescentes usos de novas tecnologias, especialização de cada tipo de projeto e equipes de projeto formadas por profissionais de diferentes localidades.

A coordenação BIM é um processo no qual os diferentes modelos específicos de disciplina são integrados e problemas espaciais e conflitos entre sistemas são identificados. Em projetos de madeira, problemas significativos de coordenação podem resultar nas interfaces entre sistemas, em particular entre sistemas MEP, paredes e pisos. Essas interfaces e conexões entre componentes devem ser identificadas e remediadas antes da fabricação e construção (STAUB-FRENCH et al., 2018). 
De acordo com Brígitte e Ruschel (2016), desde a década de 1970, há estudos de instrumentos de avaliação com o intuito de auxiliar os projetistas a tomarem decisões; no entanto, ainda é complicado reunir uma real análise no processo de projeto por haver dificuldade de utilização e até por alguns softwares ainda serem desconhecidos pelos profissionais. Segundo Brígitte e Ruschel (2016), desde a década de 1980 a TI contribui para o setor da construção, por meio do computer aided drawing (desenho auxiliado por computador), pois permite maior rapidez e eficiência nos desenhos. Posteriormente foram adicionando-se informações não gráficas por meio do CAD 4D, como custos e materiais, até evoluir e chegar ao nD.

Softwares para identificar erros de compatibilidade normalmente são usados durante o processo de coordenação para identificar conflitos físicos entre sistemas prediais em 3D. 0 objetivo da detecção de interferências é eliminar os principais conflitos do sistema antes da instalação. A coordenação baseada no BIM, através do modelo, possibilita inúmeros benefícios, como a capacidade de resolver conflitos espaciais desde o início e a redução ou eliminação de conflitos de campo, o que impacta diretamente na produtividade e reduz os custos de construção e cronograma (STAUB-FRENCH et al., 2018).

De acordo com Campestrini et al. (2015), com o BIM é possível que uma equipe colaborativa utilize o mesmo modelo computacional, possibilitando, assim, propor inúmeras soluções para as necessidades do empreendimento, mas manter apenas as melhores opções, enquanto, no $C A D$, tende-se a fazer as discussões verbalmente e decide-se por uma única solução, que é documentada na fase em que o projeto foi discutido e fazendo apenas a compatibilização daquela decisão tomada.

Para Santos e Ferreira (2008) a compatibilização interfere na qualidade final do projeto e da obra, portanto é assunto de interesse e relevância, pois contribui com a redução de retrabalhos, desperdício de materiais, tempo de execução dos projetos e obras, custos na 
produção. Além disso, o uso de tecnologias como modelos tridimensionais auxiliam no processo.

Outra eficiência do uso do BIM é superar as deficiências enumeradas por Santos e Ferreira (2008): a ambiguidade (a mesma representação pode ser interpretada de diversas maneiras), o simbolismo (um objeto não é retratado como existe na realidade, mas substituído por um símbolo), a omissão (certas informações são omitidas para deixar o desenho mais limpo ou porque se considera que podem ser presumidas), a simplificação (semelhante ao simbolismo, mas quando existe a intenção de preservar características, no desenho, de semelhança com o objeto real, porém com menor quantidade de detalhes) e a fragmentação (para que se possa compreender um projeto, é necessário comparar desenhos encontrados separadamente, como plantas e seções). Este processo apresenta vantagens na compatibilização de projetos. Para Leite et al. (2011), o processo de compatibilização automática realizada por BIM pode revelar diversos pontos críticos que sugerem alterações, no entanto é importante avaliar se estas identificações estão corretas.

Outra vantagem é o grau de detalhamento que se pode obter, sem que seja necessário redesenhar detalhes do projeto. Segundo Leite et al. (2011), é possível obter vários detalhes por meio do modelo que foi desenvolvido sem precisar de esforços adicionais e isso pode gerar detalhes mais precisos, que auxiliam em decisões ao longo do projeto e da construção, o que gera grande economia de tempo e esforço. Dossick et al. (2010) observaram que os projetistas hidráulicos e elétricos trabalham separadamente dos arquitetos e engenheiros. No entanto, para que sejam possíveis melhores resultados, é importante que trabalhem mutuamente, sendo que o BIM oferece ferramentas que facilitam isso. Assim, é possível identificar os pontos de divergência do projeto e resolvê-los de maneira mais prática e eficiente. Por exemplo, em um módulo de instalação simples, no teto ou corredor, detalhes como componentes de climatização, tubulação, aspersão, elétricos e sistemas de comunicação podem ser reunidos, mas coordenar a integração entre eles só é possível devido à confiabilidade das informações obtidas por meio do BIM (EASTMAN et al., 2014). 
Leite et al. (2011) analisam a questão de detecção de possíveis pontos críticos na compatibilização e coordenação de projetos de mecânica, elétrica e hidráulica, com recursos do BIM, e notam que problemas de coordenação podem ser identificados, porém é necessário analisar o que realmente está sendo apresentado. Esta tecnologia pode auxiliar e tornar a compatibilização mais eficiente, no entanto é importante que os engenheiros e arquitetos verifiquem e analisem os resultados obtidos. Leite et al. (2011) afirmam que ainda há grande oportunidade de melhorar as ferramentas do BIM para obter melhor integração de projetos. Assim, os softwares capazes de desenvolver projetos por meio do BIM realmente contribuem para a compatibilização dos projetos de diversas disciplinas, mas não substituem o conhecimento técnico dos arquitetos e engenheiros.

Brígitte e Ruschel (2016) afirmam que a tecnologia da informação se apresenta como uma ferramenta para atender às novas exigências que impulsionam os profissionais a buscar soluções integradas para atingir metas de desempenho, que necessitam de soluções interdisciplinares em um ambiente colaborativo, além de testar propostas e validar soluções. O processo de projeto do edifício é complexo por envolver diversas fases e diversos especialistas (arquitetos, engenheiros, construtores etc.), portanto gestão e coordenação são necessárias para assegurar um bom resultado, e a TI (tecnologia da informação) auxilia no processo por permitir maior armazenamento de informações, além de mais detalhadas e complexas, com o acesso mais rápido (BRÍGITTE; RUSCHEL, 2016).

Staub-French et al. (2018) abordam os fluxos de trabalho do BIM em projetos de construção de madeira em larga escala e identificam as trocas de informações típicas entre diferentes organizações nos diferentes estágios de desenvolvimento. Os fluxos variam de acordo com o método específico usado e se o fabricante e o instalador estão envolvidos desde o início. A sequência típica de processos para implementação do BIM e os fluxos de trabalho foram divididos em seis estágios seguintes do projeto (STAUB-FRENCH et al., 2018):
1. Conceito do Projeto
2. Desenvolvimento de Projeto 


\section{Documentação de Construção}
4. Detalhamento
5. Fabricação
6. Montagem

Existem diferentes disciplinas que podem estar envolvidas em um projeto de pré-fabricados. A diversidade de organizações envolvidas depende fortemente das circunstâncias do projeto e da complexidade do contexto do projeto, ou seja, o tipo de entrega do projeto, as condições contratuais, o nível de pré-fabricação e a complexidade dos componentes modulares. Além disso, diferentes estágios do projeto contêm colaborações simultâneas entre diferentes disciplinas, como organizações separadas e independentes. Assim, as disciplinas típicas envolvidas em um projeto de madeira pré-fabricada em larga escala, além do proprietário, podem ser categorizadas da seguinte maneira (STAUB-FRENCH et al., 2018):
1. Arquiteto
2. Consultor estrutural
3. Consultor do MEP
4. Gerente de construção
5. Fabricante de madeira (detalhamento e fabricação)
6. Instalador de madeira

A análise de um setor industrial pode fornecer diretrizes para os outros setores. Segundo Hilgenberg et al. (2012), o modelo colaborativo, que envolve diversos profissionais nas diversas fases do empreendimento, traz benefícios desde a concepção do projeto, ao longo do planejamento e orçamento, até a construção. Além disso, aumenta a produtividade, a integração entre os projetos e o compartilhamento de informações.

Dessa maneira, há necessidade de haver arquivos e softwares que sejam compatíveis aos diversos projetos que devem ser reunidos e analisados. O BIM fornece opções para a integração de informações, no entanto, ao longo do projeto, diferentes softwares podem ser utilizados por diversos profissionais, portanto seria importante ter a mesma linguagem e a possibilidade de operar em compatibilidade com os demais. 


\subsubsection{BIM e interoperabilidade}

Na última década, a adoção do BIM cresceu rapidamente, o que resultou em um impacto profundo no projeto, nos fluxos de trabalho de construção e na produtividade dos desenhos, assim houve interesse para melhorar vários aspectos dos softwares que permitem o processo BIM e a interoperabilidade entre eles, para expandir o papel do BIM para todo o ciclo de vida dos projetos. Portanto, a funcionalidade e o valor do BIM estão sendo rapidamente expandidos de um simples modelo de visualização para uma plataforma colaborativa de processos, recursos e tomadas de decisões para servir de apoio ao longo do ciclo de vida do edifício (ARAM; EASTMAN, 2013).

De acordo com Hilgenberg et al. (2012), é importante que os projetistas adotem a mesma linguagem de trabalho, pois o esforço individual não teria resultados satisfatórios por dificultar a comunicação e a limitação entre a migração de informações. Portanto, a maior barreira para a adoção de um novo software seria a incompatibilidade de arquivos com outros programas. De maneira geral, os arquitetos são favoráveis à adoção do BIM e estariam dispostos a utilizar um software que aperfeiçoasse o tempo, facilitasse a compatibilização e possíveis modificações. Portanto, de acordo com Hilgenberg et al. (2012), a interoperabilidade entre os softwares é um obstáculo para a difusão do BIM.

Segundo Campestrini et al. (2015), "o modelo BIM é um modelo computacional desenvolvido em softwares voltados para a construção civil", composto por diversos modelos (arquitetura, estrutura, custos etc.) que estão em uma única plataforma e, assim, torna-se um modelo integrado. No entanto, quando são utilizados diferentes softwares, os modelos precisam de interoperabilidade para que possam ser totalmente integrados. Atualmente, o Industry Foundation Classes (IFC) é uma linguagem de padrão internacional que visa a promover a interoperabilidade entre diferentes softwares. 
Uma pesquisa da NBS (National Building Specification), realizada no Reino Unido entre dezembro de 2018 e março de 2019, com 988 profissionais do setor da construção, verificou que 77\% utilizam IFCs (NATIONAL BUILDING SPECIFICATION, 2019).

A criação do BIM a partir dos dados obtidos requer um alto esforço e profissionais habilidosos para a conversão de dados e modelagem. A utilidade do BIM é ainda mais desafiada por questões de funcionalidade e interoperabilidade, falta de interfaces amigáveis ao usuário e BIM incompleto para ser usado pelos funcionários da O\&M e falta de especialistas em BIM no mercado. Portanto, há um grande potencial e oportunidades de pesquisa na criação de BIM econômico e automático para a construção existente para que se alcance um bom nível de maturidade do BIM entre as partes interessadas de O\&M e FM. Além disso, uma estrutura deve ser desenvolvida para educar o pessoal de O\&M e FM sobre o processo e a tecnologia BIM (HOSSAIN; YEOH, 2018).

A interoperabilidade se baseia na troca de arquivos entre diferentes softwares para atender às necessidades de transferir dados, permitindo que diversos especialistas contribuam com tarefas relacionadas a projeto, produção, operação e construção. No entanto, um dos maiores problemas em relação à interoperabilidade é que os diferentes softwares reconhecem a geometria do modelo, mas não as propriedades dos elementos da construção (VIEIRA; CALMON; CAVALCANTE, 2017).

A Interoperabilidade é uma das maiores barreiras para o desenvolvimento do BIM. O conceito de BIM aberto deve criar as bases para a troca sem falhas de dados de ativos e informações durante todo o seu ciclo de vida, portanto é fundamental o suporte a uma ampla variedade de ferramentas e usos, além de fornecer acesso a dados de ativos (STAUB-FRENCH et al., 2018).

Considerando isso, a buildingSMART, uma organização internacional dedicada ao desenvolvimento de padrões abertos para BIM, desenvolve e mantém os 5 padrões metodológicos básicos para o BIM (STAUB-FRENCH et al., 2018): 
1. o International Frameworks Dictionary (IFD) - as definições comuns de objetos e relações que compõem o ambiente construído por meio do dicionário de dados buildingSMART (bSDD);

2. a Industry Foundation Classes (IFC) - o formato de arquivo por meio do qual esses dados e informações são estruturados e transportados;

3. o Manual de Entrega de Informações (IDM) - o processo pelo qual os dados e as informações são gerados e trocados;

4. The Model View Definition (MVD) - a filtragem de dados para suportar usos específicos desses dados,

5. o formato de colaboração BIM (BCF) - a coordenação da mudança ao longo do ciclo de vida de um projeto.

Segundo Andrade e Ruschel (2009), o uso do IFC é um instrumento que pode contribuir para o aumento da interoperabilidade entre os diferentes softwares. O BIM reúne ferramentas que podem contribuir de com a reunião da grande variedade de informações necessárias para o desenvolvimento do projeto e, aliado ao Projeto para Desmontagem, é possível tornar mais eficiente e prática a desmontagem do edifício, aumentando a possibilidade de reuso ou reciclagem dos materiais. Isso pode ocorrer no fim de vida útil e, até mesmo, ao longo da manutenção do edifício.

No entanto, segundo Brígitte e Ruschel (2016), os especialistas relatam baixa interoperabilidade entre os diferentes softwares, quando se consideram as informações exportadas e importadas, modelagem, análises de desempenho, além da complexidade de algumas ferramentas. De acordo com a pesquisa dos autores, os formatos mais recorrentes são DWG, DXF e 3DS, que estão relacionadas aos softwares AutoCAd e SketchUp.

Atualmente, não existe conformidade de padrões entre os softwares que desenvolvem o BIM (ANDRADE; RUSCHEL, 2009). Assim, é importante pesquisar recursos de interoperabilidade para padronizar as informações contidas no projeto e garantir que futuramente os arquivos possam ser utilizados sem que elas se percam. 
O acesso à informação do edifício, seus componentes e materiais são muito importantes para todas as suas fases desde a construção, passando pela manutenção, retrofit até o fim de vida útil. Muitas informações são perdidas durante as décadas, às vezes não há projeto as built e isso dificulta a remodelação e desmontagem. Além disso, a falta de informação reduz as chances de reutilização ou reciclagem dos materiais, porque, na maioria das vezes, não há especificação de como substituir ou desconstruir os elementos. De acordo com Vieira, Calmon e Cavalcante (2017), a interoperabilidade entre plataformas BIM é pouco discutida e requer estudos sobre troca de dados, planejamento, orçamento, comissionamento, manutenção e operação, além de ferramentas para análise térmica, energética e acústica e ciclo de vida.

Cada software atende a necessidades específicas, no entanto é possível gerar um modelo compatível, porém ainda há perda de informações. Segundo Akcay (2017), embora a IFC não se concentre especificamente nos membros do aço estrutural, ela é capaz de representar informações específicas geométricas, materiais e conexões de forma explícita. Por exemplo, para um feixe T, o IFC é capaz de representar todas as informações associadas a esse feixe usando o ifcBeam.

Muitos arquitetos e engenheiros não têm tempo suficiente para personalizar cada componente do edifício, assim a indústria deve disponibilizar on-line o conteúdo da família BIM, pois seria mais fácil obter as informações sobre os materiais no final da vida de um edifício. O gerente da instalação poderia extrair do formulário BIM todos os dados de cada componente, como a fábrica, a quantidade e o processo de montagem, e, em seguida, fornecer aos empreiteiros de demolição ou desconstrução. Portanto, o empreiteiro poderia tomar uma decisão mais informada e poderia começar a encontrar recursos para esses materiais antes das estruturas que estão sendo desmontadas (HARDIN, 2009).

Há poucas publicações que abordam as áreas de criação e customização de softwares e bibliotecas, demonstrando a necessidade de estudos futuros que abordem a criação de 
aplicativos e plugins, padrões e detalhes, além de bibliotecas parametrizadas para o mercado brasileiro. A modelagem e o dimensionamento de sistemas mecânicos, elétricos e hidráulicos (MEP) e o processo multidisciplinar e colaborativo entre equipes são áreas pouco estudadas no Brasil (VIEIRA; CALMON; CAVALCANTE, 2017).

Hardin (2009) afirma que a interoperabilidade do BIM irá melhorar nos próximos anos; hoje em dia são necessárias muitas peças de softwares e tempo adicional para atualizar as informações, mas, com o avanço da Aliança Internacional para Interoperabilidade, as empresas de softwares estarão interessadas em torná-los mais efetivos. A comunicação e a colaboração entre os profissionais também são importantes, e a discussão sobre BIM tem aumentado significativamente entre arquitetos, engenheiros, empreiteiros, proprietários, gerentes de instalações e demais profissionais envolvidos. Dessa maneira, a integração entre os softwares será cada vez mais cobrada pelos usuários e, assim, tende a ser mais precisa e desenvolvida.

\subsubsection{BIM, 3D e simulação}

De acordo com Brígitte e Ruschel (2016), um modelo tridimensional preciso, construído digitalmente por meio do BIM, com informações paramétricas, permite utilizar ferramentas de simulação de avaliação do desempenho, para entender e analisar o comportamento do edifício desde sua concepção até a demolição. A corrida por certificações e o apelo relacionado à sustentabilidade promovem maior interesse em soluções diferenciadas e inovações, portanto os profissionais se interessam pela ferramenta de simulação (BRÍGITTE; RUSCHEL, 2016).

Segundo Clarke e Hensen (2015), projetar o ambiente construído é uma tarefa complexa devido à presença de domínios técnicos interativos, diversas expectativas de desempenho e incertezas generalizadas; no entanto, a Simulação de Desempenho do Edifício (do inglês, Building Performance Simulation - BPS) fornece um meio para a complexidade, pois permite 
a exploração do impacto de parâmetros de projeto em soluções que favoreçam o desempenho do ciclo de vida.

Segundo Campestrini et al. (2015), com a evolução dos softwares e modelos virtuais, é possível substituir os modelos físicos para realizar simulações, por exemplo: simular uma barragem e o impacto na geração de energia. Portanto, os modelos computacionais, chamados de Modelo Integrado ou Modelo BIM, são desenvolvidos para realizar simulações, cálculos, complementações. Assim, estes são a chave para o sucesso do BIM por serem base de dados para a modelagem da informação e serem utilizados em projetos colaborativos para tomadas de decisões e criação de soluções (CAMPESTRINI et al., 2015).

Algumas questões com potencial que devem ser estudas são: a utilização do modelo 3D no planejamento, construção e obra; redução da improvisação, desperdício e retrabalho; controle de qualidade no processo de construção, além do fluxo de trabalho (VIEIRA; CALMON; CAVALCANTE, 2017).

Esta abordagem pode ser utilizada para garantir níveis de conforto, qualidade do ar interior, eficiência energética, reduzir o impacto ambiental, atender às legislações, formular planos de ação. Esta funcionalidade permite uma melhor abordagem do projeto e planejamento porque respeita interações espaciais e temporais, integra domínios de desempenho, trabalho cooperativo e relaciona o desempenho dos impactos ambientais ao longo do ciclo de vida. Além disso, permite uma evolução gradual do problema apresentado, com opções de desempenho e orientações que podem ser tomadas ao longo do projeto. Ademais, a BPS pode ser utilizada como um teste virtual para avaliar materiais, componentes e sistemas que apresentem vantagem competitiva, melhor desempenho e custo (CLARKE; HENSEN, 2015).

A construtibilidade é aprimorada pelo desenvolvimento de sequências de construção virtual, também conhecidas como simulações 4D, em que o reforço estrutural temporal dos elementos pode ser avaliado. O BIM permite que as equipes de projeto estudem sequências 
de construção, o que pode levar a uma resolução antecipada de problemas e permitir que as equipes de projeto encontrem soluções ideais (STAUB-FRENCH et al., 2018).

Quando o modelo 3D está ligado ao tempo (o cronograma de construção), o resultado é um modelo 4D que pode ser simulado para visualizar o processo de construção. Isso permite que a equipe do projeto visualize claramente o estado esperado do projeto em diferentes estágios e prazos (STAUB-FRENCH et al., 2018).

Para Kunieda, Codinhoto e Emmitt (2019) modelos computacionais 4D (3D+tempo) podem auxiliar na reutilização de materiais provenientes de demolições, tornando a demolição mais eficaz e eficiente, além de reduzir a necessidade de tratamentos de resíduos.

De acordo com Kunieda, Codinhoto e Emmitt (2019) através do modelo computacional o usuário pode modificar sequencias de demolição, número e tipos de maquinas a serem aplicadas no projeto, enquanto os dados de geração e classificação de resíduos são descritos em um processo dinâmico em um intervalo de tempo. A visualização do modelo auxilia na escolha de estratégias de recuperação de resíduos e avaliação de riscos no local. Além disso pode contribuir para análise de tempo, eficiência, avalição de risco e tomadas de decisões. Assim a modelagem de demolição pode ajudar os profissionais a direcionar decisões certas e informadas.

BIM não se resume apenas a modelos em três dimensões; no entanto, esta facilidade permite melhor visualização do projeto como um todo, elementos específicos, materiais, compatibilização de projetos. Além disso, é possível simular situações no modelo, como montagem e desmontagem de edificações, selecionar as etapas da construção em ordem cronológica e, assim, programar melhor o cronograma, visualizar encaixes e conexões, diversos tipos de estruturas e até mesmo substituir modelos reais em alguns casos. Dessa maneira, é possível tomar decisões mais precisas, com mais informações disponíveis, e obter melhores resultados, principalmente logo no início do processo de projeto. 


\subsubsection{BIM, fabricação, montagem e construtibilidade}

O processo de montagem do edifício está diretamente ligado ao de desmontagem. Decisões tomadas no desenvolvimento do projeto, como escolha de materiais, encaixes, sistema construtivo, podem contribuir positivamente para a desmontagem. Assim também foi realizada revisão bibliográfica sobre o tema, pois há diretrizes que contribuem para o processo de desmontagem. De acordo com Zhong e Wu (2015), devido à maior conscientização sobre o desenvolvimento sustentável e a capacidade de construção, a indústria da construção está agora enfrentando desafios para reduzir o consumo de energia, as emissões de carbono e outros impactos ambientais negativos, mantendo alta sustentabilidade econômica e desempenho de construtibilidade.

Para Yuan, Sun e Wang (2018), o BIM contribui para o desenvolvimento de projetos paramétricos voltados para o Projeto para Manutenção e Montagem (do inglês, Design for Maintanance and Assembly - DfMA) e afirma que o BIM é mais adequado para edifícios préfabricados. Quando voltado para o DfMA, o projeto paramétrico se torna uma nova filosofia de projeto, pois é a combinação orgânica do design paramétrico DfMA e do BIM. Isso significa que os designers não só levam em consideração os requisitos da fase de projeto, mas também consideram os requisitos da fase de fabricação e montagem, quando eles usam o BIM para projetar um edifício pré-fabricado. Além dos arquitetos, é importante ter projetistas especializados em manufatura e montagem envolvidos no desenvolvimento do projeto, para que o edifício tenha uma boa manufaturabilidade e montabilidade.

As ferramentas BIM para projeto e manufatura oferecem funcionalidade significativa para suportar projetos de fabricação, mas há desafios. Para garantir que os modelos sejam confiáveis e úteis, os engenheiros estruturais devem trabalhar em conjunto com o engenheiro de produção, para garantir que o modelo seja criado com um nível adequado de detalhes e precisão. Caso contrário, pode ser mais eficiente para o fabricante começar do zero, diminuindo, assim, a eficiência da modelagem (STAUB-FRENCH et al., 2018). 
Um elemento-chave do DfMA é seu alinhamento direto com os princípios de design e construção Lean, cujos principais objetivos são a eliminação de desperdícios e a maximização de valor. O DfMA é uma combinação entre o projeto para fabricação e o design para montagem. Isso é implementado por meio de práticas de projetos cujo objetivo é facilitar a fabricação de um produto, sua entrega e sua montagem (STAUB-FRENCH et al., 2018).

BIM e DfMA têm recebido maior atenção na última década, na área acadêmica, em todo o mundo e como objeto de programas governamentais, como em Cingapura e no Reino Unido. A partir dessas iniciativas, lições foram aprendidas e recomendações foram apresentadas, ressaltando os benefícios dessas abordagens. Por exemplo, a Autoridade de Construção Civil (BCA) em Cingapura descobriu que o BIM para DfMA oferece vários benefícios em todo o ciclo de vida de um ativo (STAUB-FRENCH et al., 2018).

Para Staub-French et al. (2018), os benefícios do BIM e do DfMA podem ser resumidos em duas categorias relacionadas:

1. Melhor informação, melhor design, melhor qualidade: o uso de BIM em projetos nos quais os princípios de DfMA são implantados fornece uma infraestrutura robusta para desenvolver melhores informações de projeto. $O$ BIM contribui com preceitos importantes do DfMA em relação ao ciclo de vida. Por exemplo, o uso de BIM permite a visualização e a simulação, o que proporciona uma compreensão das montagens de edifícios e o fornecimento de soluções modeladas viáveis. Ele também suporta um entendimento compartilhado da solução de projeto através do modelo 3D, que pode servir para promover a integração dentro da equipe do projeto. Portanto, o modelo 3D reduz o risco de erro na interpretação humana de desenhos 2D. Combinado com a possibilidade de produzir um modelo de produto altamente coordenado, incluindo suas peças e montagens, em um formato de máquina interpretável que pode ser implantado em um cenário de fábrica impacta diretamente na qualidade do produto final e é mensurável em termos de indicadores como redução de pedidos por informações (RFI - Request for Information) do projeto e alterações no local.

2. Projetos mais rápidos e eficientes: a combinação de princípios BIM e DfMA demonstrou melhorar grandemente a eficiência dos projetos e o desempenho 
dos cronogramas dos projetos. Por exemplo, o uso de BIM durante os estágios de projeto foi mostrado para ajudar a reduzir o tempo de conversão de desenhos arquitetônicos em desenhos de fabricação e melhorar a coordenação entre escritório de projetos e as instalações de fabricação fora do local. O uso de BIM e DfMA também reduz o tempo do desenho de fabricação e a fase de aprovações, bem como reduz significativamente o tempo de verificação das informações de fabricação. Também evita a duplicação de informação que foi grandemente reduzida ou eliminada por meio de implantações estratégicas, como a criação e o uso de bibliotecas de componentes padrão. De fato, o desenvolvimento de bibliotecas de produtos e sua utilização nos modelos no desenvolvimento do projeto poderiam reduzir ou eliminar a necessidade de uma revisão para fins de fabricação e permitir um fluxo contínuo de informações.

De acordo com Lam, Wong e Chan (2006), as equipes de projeto devem assumir a liderança para melhorar a construtibilidade dos edifícios e a capacidade de seus projetos. Os esforços em analisar especificidades do local da obra antes do projeto, integração dos projetos, componentes e sequências de trabalho, bem como em projetar para a padronização, repetição, segurança e facilidade de construção, aumentariam a construtibilidade de qualquer projeto (LAM; WONG; CHAN, 2006).

Certamente, o BIM e o DfMA são complementares. Na indústria aeroespacial automotiva, o 3D auxiliado por computador (CAD), na década de 1980, funcionou como um catalisador para implantar princípios do DfMA. As capacidades de prototipagem virtual apoiadas pelos muitos usos do BIM discutidos anteriormente, como visualização, coordenação e verificação de interferências, facilitam a implantação dos princípios do DfMA na indústria da construção civil. Mais importante ainda, as capacidades paramétricas do BIM e sua abordagem orientada a objetos suportam a integração de "inteligência" diretamente no sistema de produção, incluindo dados específicos para apoiar o processo de fabricação, que pode seguir um ativo em todo o seu ciclo de vida (STAUB-FRENCH et al., 2018). 
Além disso, para Lam, Wong e Chan (2006), os projetistas têm um papel importante a desempenhar para melhorar a capacidade de construção e identificar os problemas comuns no projeto, que, se não forem tratados adequadamente, podem levar a um baixo índice de construtibilidade.

Para Zhong e Wu (2015), existem três princípios-chave de construtibilidade, nos quais os projetos são avaliados, incluindo:

1. Padronização: refere-se a repetição de grades, tamanhos de componentes e detalhes de conexão. Um layout repetido, por exemplo, facilitará a construção mais rápida. Da mesma forma, colunas ou externas. Revestimentos de tamanhos repetidos reduzem as trocas de moldes.

2. Simplicidade: significa sistemas de construção predial e detalhes da instalação descomplicados. Um sistema de lajes planas, por exemplo, facilita a construção, bem como o trabalho de reforço, consideravelmente.

3. Elementos integrados únicos são aqueles que combinam componentes em um único elemento, que pode ser pré-fabricado e instalado no local. Paredes externas de concreto pré-moldado, paredes de cortina ou banheiros préfabricados são bons exemplos desta categoria.

Segundo questionário realizado por Lam, Wong e Chan (2006), os 05 principais atributos de construtibilidade são: compatibilização de projetos, análises do local em que o edifício será construído, considerações sobre fundação e subsolo, atualização de especificações e remoção de ambiguidades e informações desencontradas, garantia de uma sequência segura de tráfego para edifícios altos.

O BIM pode melhorar a construtibilidade ao permitir que os profissionais identifiquem as condições de trabalho. Detalhes são negligenciados durante o projeto e podem ter um impacto significativo na fabricação e instalação. O exercício de construção do projeto virtualmente permite que questões de construtibilidade sejam identificadas rapidamente e resolvidas antes da construção (STAUB-FRENCH et al., 2018). 
Em comparação com o projeto paramétrico tradicional, o projeto paramétrico orientado ao DFMA visa a criar edifícios pré-fabricados com melhor capacidade de fabricação e montagem. Assim, este conceito conta com a equipe de projeto que visa ao DfMA, o processo de criação de componentes pré-fabricados baseado no modelo composto por famílias, na capacidade de programação do BIM e no processo de otimização de informações de construções préfabricadas também voltado ao DfMA, para obter melhores resultados. Assim, estes quatro métodos auxiliares contribuem para o projeto paramétrico orientado ao DfMA e mostram como resolver os problemas de fabricação e montagem de edifícios pré-fabricados com projetos detalhados (Yuan; Sun; Wang, 2018).

O Reino Unido e Cingapura veem o BIM e o DfMA como possíveis soluções para a) melhorar o desempenho e a produtividade da sua indústria AECO e b) aumentar o potencial de exportação e competitividade no mercado global. Ambos tomaram as medidas necessárias para promover e facilitar o uso generalizado de BIM e DfMA nas suas respectivas indústrias AECO, nomeadamente desenvolvendo políticas e diretrizes (STAUB-FRENCH et al., 2018).

No caso da produção de elementos de madeira em larga escala, por exemplo, o BIM pode potencialmente suportar todos os aspectos dos projetos, incluindo a fabricação offsite, em que os modelos de nível de fabricação podem ser aproveitados para detalhar todos os elementos de madeira e automatizar a geração de códigos. Além disso, ao empregar o BIM em um projeto de madeira em larga escala, o alto nível de precisão que pode ser obtido durante a instalação da estrutura leva a um cenário em que as condições as built podem se aproximar do modelo de informações produzido durante o estágio de projeto. Isso elimina uma barreira que impede a indústria de explorar níveis mais altos de fabricação externa, o que poderia permitir que diferentes subcontratados alcancem níveis mais altos de eficiência e menores custos. Finalmente, o BIM permite que os profissionais simulem sequências de instalação e construção e diferentes métodos de construção. Isso permite que as equipes de projeto otimizem o processo de construção, reduzindo o número necessário de trabalhadores 
no local, melhorando a segurança e garantindo ainda mais economia de tempo (STAUBFRENCH et al., 2018).

Se considerações adequadas forem feitas durante o estágio de projeto referente ao potencial de construtibilidade, isso ajudará a economizar esforços desnecessários ao longo de todo o processo de desenvolvimento e haverá aumento de eficiência. Portanto, para contribuir com a construtibilidade, é necessário reunir os dados sobre o terreno e o solo, coordenar os documentos e projetos, considerar a sequência do trabalho, além de projetar para padronização, repetição, segurança e facilidade de construção (LAM; WONG; CHAN, 2006).

O BIM também pode ajudar o instalador e o fabricante a coordenar a entrega dos elementos estruturais (STAUB-FRENCH et al., 2018). Para Lam, Wong e Chan (2006), a construtibilidade, quando considerada ao longo do desenvolvimento do projeto de um edifício, facilita o uso eficiente dos recursos de construção e aumenta a facilidade e a segurança da construção no local, enquanto os requisitos do cliente são atendidos.

O BIM, juntamente com o DfMA, cria a situação ideal, em que a equipe é organizada desde o início para desenvolver e otimizar o BIM para o ciclo de vida do projeto. É fundamental que o projeto seja organizado com o engajamento antecipado das principais partes interessadas do projeto e que todos sejam incentivados a trabalhar juntos (STAUB-FRENCH et al., 2018).

O uso do BIM ao longo do cronograma do projeto deve ser determinado desde o início e o planejamento da execução do BIM deve articular claramente as funções e responsabilidades, o nível de desenvolvimento do modelo e o cronograma para entregas BIM. Para maximizar a fabricação digital, todos os sistemas relevantes devem ser modelados com precisão para que todas as conexões e penetrações sejam claramente identificadas. Os fluxos de trabalho BIM entre os diferentes participantes do projeto e as trocas de informações específicas devem ser mapeados (STAUB-FRENCH et al., 2018). 
De acordo com Staub-French et al. (2018), o BIM auxilia o DfMA (Design for Manufaturing and Assembly) em diversos estágios, conforme apresentado na tabela 2. Diversos princípios do DfMA também contribuem para o DfD, assim estas ações são apresentadas, pois ilustram claramente a contribuição de se projetar em ambiente BIM. Como o DfD deve ser considerado desde o conceito inicial do projeto, estas ações também contribuem para a desmontabilidade do edifício. 
Tabela 2 - Ações BIM para o Projeto para a Montagem em diversos estágios

(Continua)

\begin{tabular}{|c|c|}
\hline ESTÁGIOS & AÇÕES BIM \\
\hline Estágio 01 - Esboço do Projeto & $\begin{array}{l}\text { - Construir estudos de massa com base em } \\
\text { restrições locais, legislações e requisitos do } \\
\text { cliente. } \\
\text { - Inserir princípios do DfMA. } \\
\text { - Desenvolver estratégias de } \\
\text { implementação de DfMA e BIM e incorporar } \\
\text { o projeto ao Plano de Execução BIM. }\end{array}$ \\
\hline $\begin{array}{l}\text { Estágio } 02 \text { - Desenvolvimento do Conceito } \\
\text { do Projeto }\end{array}$ & $\begin{array}{l}\text { - Desenvolver objetos paramétricos para } \\
\text { espaços com grids e layouts modulares. } \\
\text { - Utilizar objetos espaciais para gerar } \\
\text { opções e encontrar o que melhor atende ao } \\
\text { partido do projeto. } \\
\text { - Gerar dados a partir de objetos espaciais } \\
\text { que atendam aos requisitos funcionais, } \\
\text { ambientais e de acabamento. } \\
\text { - Usar modelos para mostrar o conceito } \\
\text { para feedback e aprovação de partes } \\
\text { interessadas. }\end{array}$ \\
\hline Estágio 03 - Projeto Executivo Detalhado & $\begin{array}{l}\text { - Adicionar mais detalhes a objetos } \\
\text { espaciais - geometria e dados em modelos } \\
\text { 3D detalhados. } \\
\text { - Utilizar ferramentas de análise objetiva e } \\
\text { relatórios para demonstrar que objetivos } \\
\text { breves são alcançados. } \\
\text { - Validar soluções de DfMA por meio de } \\
\text { contratação antecipada e envolvimento dos } \\
\text { fornecedores. } \\
\text { - Gerar modelos detalhados de peças e do } \\
\text { produto inteiro, para diferentes disciplinas } \\
\text { para coordenação precoce. }\end{array}$ \\
\hline Estágio 04 - Pré-Construção & $\begin{array}{l}\text { - Refinar modelos para incorporar insumos } \\
\text { da cadeia de suprimentos da DfMA. } \\
\text { - Desenvolver cronograma e } \\
\text { sequenciamento do programa geral de } \\
\text { construção. } \\
\text { - Desenvolver sequências de fabricação e } \\
\text { instalação, declarações de métodos, plano } \\
\text { de gerenciamento de recursos etc. } \\
\text { - Gerar protótipos digitais para verificar a } \\
\text { estratégia de construções. }\end{array}$ \\
\hline
\end{tabular}


Tabela 2 - Ações BIM para o Projeto para Montagem em diversos estágios

(Conclusão)

\begin{tabular}{l|l}
\hline \multicolumn{1}{c|}{ Estágios } & \multicolumn{1}{c}{ Ações BIM } \\
\hline Estágio 05 - Construção & $\begin{array}{l}\text { - Gerar desenhos de oficina para fabricação } \\
\text { de modelos/fabricação integrada com } \\
\text { modelos. } \\
- \text { Rastrear atividades de construção e } \\
\text { programa planejado com base em recursos } \\
\text { e sequências de montagem planejadas. } \\
\text { - Verificar a instalação no local e atualizar } \\
\text { os modelos de acordo. }\end{array}$ \\
\hline Estágio 06 - Pós-Obra & $\begin{array}{l}\text { - Assegure-se de que os modelos as-built } \\
\text { estejam atualizados para a entrega. } \\
- \text { Integrar modelos construídos com o } \\
\text { sistema FM. }\end{array}$ \\
\hline
\end{tabular}

Fonte: Adaptado do BCA (2016)

A tabela 3 apresenta os benefícios do BIM aliado ao DfD, demonstrando como o avanço desta tecnologia e ferramentas podem auxiliar o processo de desmonte e garantir melhores resultados em relação ao reaproveitamento dos materiais quando o edifício precisa ser desativado. 
Tabela 3 - Benefícios do BIM aliado ao DfD

\begin{tabular}{|c|c|}
\hline Benefício do BIM aliado ao DfD & Descrição \\
\hline Redução dos custos & $\begin{array}{l}\text { Utilizar BIM de maneira eficiente no projeto } \\
\text { e manufatura ajuda a reduzir custos na } \\
\text { desmontagem. }\end{array}$ \\
\hline Redução do Cronograma & $\begin{array}{l}\text { Permite acesso rápido às informações e } \\
\text { aos desenhos do material ou camada a ser } \\
\text { desmontada. }\end{array}$ \\
\hline Aumento da Segurança & $\begin{array}{l}\text { Com mais informações dos produtos, a } \\
\text { desmontagem pode ser mais bem } \\
\text { programada e evitar acidentes. }\end{array}$ \\
\hline Redução de Desperdício & $\begin{array}{l}\text { Com a desmontagem programada, é } \\
\text { possível prever a melhor maneira de } \\
\text { desmontar e até mesmo considerar o reuso } \\
\text { do material. }\end{array}$ \\
\hline Redução de Trabalho & $\begin{array}{l}\text { Racionalizar o processo de desmontagem } \\
\text { torna o trabalho mais eficiente. }\end{array}$ \\
\hline Aumento da Produtividade & $\begin{array}{l}\text { Programar a desmontagem faz possível } \\
\text { avaliar tudo o que realmente poderá ser } \\
\text { reaproveitado. }\end{array}$ \\
\hline $\begin{array}{l}\text { Maior aproveitamento dos recursos } \\
\text { naturais }\end{array}$ & $\begin{array}{l}\text { Com o reuso e reciclagem, os materiais } \\
\text { têm aumento significativo nos seus ciclos } \\
\text { de vida, assim economizam-se recursos } \\
\text { naturais, reduzem-se desperdício e } \\
\text { geração de resíduos. }\end{array}$ \\
\hline Maior qualidade & $\begin{array}{l}\text { Com a desmontagem racionalizada, os } \\
\text { produtos são desmontados com melhor } \\
\text { qualidade para reuso. }\end{array}$ \\
\hline Facilitar reuso e construção. & $\begin{array}{l}\text { Os princípios do DfD, aliados com } \\
\text { ferramentas BIM, contribuem para a } \\
\text { construção, desmontagem, reutilização e } \\
\text { reciclagem. }\end{array}$ \\
\hline
\end{tabular}

Fonte: Autora (adaptado de BCA, 2016)

Portanto, como foi verificado na revisão bibliográfica, o DfMA possui características similares e complementares ao DfD, assim o BIM também contribui para a racionalização da desmontagem.

\subsubsection{BIM e documentação}

Para Hardin (2009), a documentação para a desmontagem é muito importante e será usada para quantificar e obter informações sobre os materiais, como linhas elétricas e mudanças de canalização. A documentação também deve identificar materiais perigosos, tanques, caixas 
de gordura ou quaisquer outras questões que precisem ser analisadas com um cuidado especial. Especialmente se a demolição visa a atingir algum padrão de construção verde, é ainda mais importante ter os dados mais precisos na mão, assim eles saberão quais materiais podem ser recuperados, reciclados ou descartados.

Quando os construtores utilizam o BIM, é possível visualizar, de maneira mais clara, o trabalho e as condições de trabalho a serem realizadas, assim resultando em licitações mais competitivas. Além disso, o BIM também pode ajudar a facilitar as aprovações e os procedimentos regulatórios, cronogramas, estimativas de gastos, pois permite melhor visualização, com mais clareza das soluções propostas (STAUB-FRENCH et al., 2018).

Atualmente, as informações sobre os componentes estruturais de aço são, geralmente, trocadas em documentos em papel, como uma folha de corte anexada a um componente durante a fabricação ou uma fatura de entrega durante o transporte ou na fase de montagem. Essa prática não é eficiente, pois esses documentos podem se perder enquanto os componentes estão sendo transferidos de um local para outro. Não é fácil acessar e trocar informações em uma abordagem baseada em papel. Consequentemente, é difícil ver em que fase da cadeia de suprimentos esses itens de informação são gerados e em quais fases (e em quais tarefas específicas) esses itens de informação são usados e modificados, conforme os componentes se movem na cadeia de suprimentos. As modificações feitas nos componentes durante as fases anteriores não são registradas ou são armazenadas em documentos, o que também torna difícil localizar e acessar as informações nas fases seguintes. Assim, tecnologias de identificação de localização têm sido usadas para fornecer informações de componentes de forma eficiente sempre que necessário, e isso pode agilizar o fluxo de informações acessadas e trocadas entre as partes durante o ciclo de vida de um componente (AKCAY; ERGAN; ARDITI, 2017).

Embora a adoção do BIM tenha crescido significativamente dentro do setor de projetos da construção, a documentação em 2D ainda é predominante. Projetos modelados com o BIM, 
no entanto, normalmente geram essa documentação 2D diretamente do modelo depois de ela ter sido coordenada dentro do ambiente BIM. Em alguns casos, os consultores utilizam o BIM para gerar documentos de construção que são submetidos para licitação e os comércios especializados estão usando-o para gerar projetos de instalações. A geração destes desenhos pode ser alcançada por meio de diferentes níveis de automação, permitindo economia de tempo em toda a cadeia de suprimentos (STAUB-FRENCH et al., 2018).

Observa-se que as informações geradas na fase de projeto são frequentemente utilizadas nas fases restantes e devem receber atenção extra, em termos de correção e precisão. Assim, é esperada uma abordagem que agilize o fluxo de informações relacionadas ao projeto em todo o ciclo de vida (AKCAY; ERGAN; ARDITI, 2017).

Para o planejamento sequencial de desmontagem de edifícios, é fundamental agrupar as peças em classes ou módulos de maneira apropriada, de acordo com o julgamento da engenharia. Este julgamento requer compreensão da interação dos diferentes subsistemas embutidos no conjunto, bem como objetivos particulares do projeto de desmontagem, como recuperar um módulo de alto valor em uma peça ou remover um conjunto de peças que estão intertravadas ou fechadas. Por meio desta abordagem, é possível reduzir drasticamente as etapas de desmontagem e o tempo, o que significa uma redução no uso de energia, impactos ambientais e custo de construção. Em outras palavras, o processo se torna mais econômico. (SANCHEZ; HAAS, 2018).

Dessa maneira, quanto mais completo estiver o projeto, com informações atualizadas sobre os materiais e produtos, mais bem-sucedida será a desmontagem. Assim, o BIM colabora para a documentação do projeto, tornando as informações mais acessíveis.

\subsubsection{Análise de softwares BIM}

Softwares BIM foram analisados para verificar as ferramentas que mais podem contribuir para a desmontagem. Os principais softwares analisados foram o Revit, Archicad, Tekla, 
Naviswork e Dynamo. Cada um tem características e funcionalidades diferentes, alguns deles são complementares e, por serem da mesma empresa (Autodesk), oferecem maior possibilidade de serem compatíveis; no entanto, as versões dos softwares também devem ser compatíveis. Os softwares estão evoluindo a cada versão para atender melhor às necessidades do BIM, assim a tendência é que a interoperabilidade se torne mais efetiva, até mesmo entre programas de diferentes empresas, para atender às necessidades dos usuários.

Ao longo das últimas décadas, houve grande evolução de softwares para atender de maneira mais eficiente os profissionais do setor. De acordo com Hilgenberg et al. (2012), os primeiros softwares disponíveis no mercado, Allplan e ArchiCAD, foram lançados no início da década de 1980; posteriormente, na década de 1990, foi lançado o Revit, que foi comprado e difundido pela Autodesk. Além destes, o Bentley também é considerado um software, de acordo com o BIM. Segundo pesquisa realizada por Hilgenberg et al. (2012) com profissionais da $\mathrm{AEC}$ na cidade de Curitiba-PR, em que a maioria das respostas foi de arquitetos, os softwares mais utilizados são o Autocad (89\%), seguido pelo SketchUp (59\%), associados a outro programa. Apenas $49 \%$ tiveram algum contato com o software BIM e apenas $29 \%$ utilizam algum deles, como o Archicad (6\%) e o Revit (18\%).

No entanto, os softwares BIM diferem de programas como AutoCAD por não utilizarem comandos que desenham apenas linhas, mas, sim, elementos. O Revit, por exemplo, possui elementos construtivos, como paredes, janelas e portas, com propriedades fixas e que permitem alterações pelo usuário; além disso, possui ferramentas para o projeto estrutural, elétrico e hidráulico (HILGENBERG et al., 2012).

Há ferramentas de software disponíveis para projetar e analisar estruturas de aço no mercado. Exemplos incluem RAM (sistemas Bentley), Revit Structure (Autodesk), Tekla Structures (Tekla) etc. (STAUB-FRENCH et al., 2018). 
Uma pesquisa da NBS (National Building Specification), realizada no Reino Unido entre dezembro de 2018 e março de 2019, com 988 profissionais do setor da construção, verificou que $70 \%$ utilizam softwares da Autodesk. O segundo mais utilizado é o Graphisoft, com apenas 15\% (NATIONAL BUILDING SPECIFICATION, 2019).

De acordo com Hilgenberg et al. (2012), alguns softwares BIM, como Archicad e Revit, possuem facilidades que auxiliam o profissional da AEC, como: melhor visualização do projeto por meio de modelo 3D, integração entre informações e projetos de diferentes profissionais reunidos em um mesmo modelo digital. Hilgenberg et al. (2012) afirmam que é na fase inicial do projeto que se define o software a ser utilizado, portanto cabe ao arquiteto a iniciativa de optar por um software BIM que atenda às necessidades de se produzirem projetos cada vez mais complexos, detalhados, mais rápidos e com informações mais precisas.

No entanto, as ferramentas de desmontagem não são compatíveis com o BIM, assim como nenhum software BIM oferece funcionalidades DfD. Esta evidência mostra que, apesar do aumento acentuado da implementação do BIM para diversos fins, a implementação do BIM para o final do ciclo de vida dos edifícios não é uma prática comum (AKINADE et al., 2017). Assim, é importante desenvolver ferramentas nos softwares BIM para a implementação do DfD.

Segundo Yuan, Sun e Wang (2018), o Revit, desenvolvido pela Autodesk, envolve o conceito BIM e permite que famílias de elemento pré-fabricados, com conceitos DfMA, sejam inseridas no projeto; além disso, a grande vantagem deste software é que permite a criação de plantas, elevações, cortes, modelos tridimensionais, detalhamento ao longo do desenvolvimento do projeto, portanto é muito adequado ao projeto de edifícios pré-fabricados. Como visto anteriormente, a pré-fabricação é uma das características que contribui também para a desmontagem das edificações. 
Além disso, o Revit também permite que sejam inseridos plugins externos com o objetivo de auxiliar no desenvolvimento de projeto. Por exemplo, é possível criar um plugin para tomada de decisões e análise de resultados devido a escolhas que influenciarão na desmontagem do edifício.

Akanbi et al. (2019) desenvolveram um plugin que auxilia os projetistas na desmontagem. Os recursos de software de modelagem das informações de construção podem ser estendidos para fornecer uma plataforma para avaliar o desempenho de projetos de construção em relação ao princípio da economia circular de manter a energia incorporada de materiais perpetuamente em uma economia. O sistema de análise de desmontagem e desconstrução garante que os edifícios sejam projetados considerando os princípios de desmontagem e desconstrução que asseguram a recuperação eficiente de materiais. A ferramenta de análise de desmontagem e desconstrução também pode servir como uma plataforma de suporte à decisão que o governo e os planejadores podem usar para avaliar o nível de conformidade dos projetos de construção com os requisitos de economia circular e sustentabilidade (AKANBI et al., 2019).

Portanto, o BIM contribui diretamente para o desenvolvimento do projeto que leva em consideração o final da vida útil do edifício, seus elementos e materiais. Entre os softwares BIM voltados para a arquitetura, o Revit apresenta ferramentas que são úteis ao longo do desenvolvimento do projeto. 


\section{Estudos exploratórios}

\subsection{Entrevistas no Reino Unido}

Entrevistas foram realizadas com profissionais de diversas áreas de projeto para analisar como o tema do Projeto para Desmontagem é abordado e como está sendo a implementação e utilização de softwares BIM em diversos setores. Assim, é possível reunir informações de diferentes áreas sobre os temas estudados.

Inicialmente foi realizada uma revisão de literatura sobre BIM, DfD, desperdício de materiais, reutilização de materiais, construtibilidade, manutenção e retrofit na indústria de construção e fabricação. Isso foi fundamental para se ter uma dimensão sobre como esses assuntos estão sendo discutidos. A revisão da literatura não se concentrou apenas no setor da construção, mas também na fabricação, como na indústria automotiva e eletrônica. Diferentes especialidades poderiam fornecer informações importantes sobre o projeto de diferentes perspectivas. O conceito de DfD vem da manufatura, mas pode fornecer importantes perspectivas para a indústria da construção.

Assim, profissionais de diferentes especialidades foram selecionados para serem entrevistados. As perguntas são semiestruturadas e adaptam-se a cada setor específico. A ideia de fazer entrevistas com diferentes áreas de profissionais foi analisar amplamente conceitos que podem ser aplicados na prática. Esta pesquisa fornece informações importantes sobre o que alguns profissionais estão considerando sobre os tópicos em diferentes situações.

Os profissionais são de diferentes especialidades, mas têm algumas questões em comum. Portanto, as entrevistas foram realizadas para verificar a relação entre projeto, desmontagem, reutilização dos materiais, manutenção, ciclo de vida e BIM. De acordo com Lester e Lester Jr. (2015), falar com pessoas que têm experiência no assunto e fazer entrevistas pessoais podem fornecer informações específicas valiosas. 
O primeiro entrevistado foi um astrofísico que trabalha para a área de saúde e atualmente está gerenciando a reforma de um complexo hospitalar (A). A segunda pessoa selecionada é uma gerente de Projetos que trabalha para uma fabricação de automóveis (B). O terceiro trabalha com edifícios nucleares e é especialista em BIM (C). O quarto é um engenheiro civil que trabalha em uma empresa multinacional onde é um especialista em gestão de resíduos (D). O quinto entrevistado é um arquiteto responsável pelo desenvolvimento da proposta de um complexo esportivo para a Copa do Mundo de Futebol, em 2018, na Rússia e tem experiência em outros projetos esportivos (E).

As entrevistas foram feitas no Reino Unido, durante o estágio realizado na Universidade de Bath, ao longo do mestrado. Assim, foi possível obter diferentes pontos de vistas e comparar com a realidade brasileira. A tabela 04 apresenta as áreas de atuação dos entrevistados.

Tabela 4 - Entrevistados e áreas de atuação

\begin{tabular}{|c|c|}
\hline Entrevistados & Áreas de atuação \\
\hline Entrevistado A & Edifícios de saúde \\
\hline Entrevistado B & Fábrica de carros \\
\hline Entrevistado C & Prédios nucleares \\
\hline Entrevistado D & Gestão de resíduos (edificações) \\
\hline Entrevistado E & Edifícios esportivos \\
\hline
\end{tabular}

Fonte: Autora

O entrevistado "A" trabalha para um hospital há 8 anos, tem uma equipe de 15 pessoas e vários funcionários terceirizados envolvidos no projeto, cerca de 60 pessoas. Ele está envolvido na renovação de um complexo de vários edifícios de saúde, localizado na Inglaterra. O edifício mais antigo do complexo tem 188 anos de idade, a reconstrução do hospital levará nove anos para ser concluída e será feita em três etapas, a primeira já iniciada; a segunda começou em 2019 e deve terminar até 2023. Alguns edifícios serão substituídos por duas novas instalações hospitalares e mais de 160.000 pacientes por ano se beneficiarão.

Apenas as placas com homenagens e o interior da capela serão preservados. As pedras e tijolos serão reutilizados para aterrar o terreno, quando for possível, pois, de acordo com o entrevistado, seria ineficiente reutilizar cada tijolo em uma nova alvenaria. A equipe do 
hospital pediu que reutilizassem o máximo possível dos materiais, devido a considerações ambientais, para evitar que o mínimo de materiais fosse para o aterro. A empresa de construção também tinha interesse em reutilizar devido aos seus próprios objetivos. De acordo com o entrevistador "A", a demolição de edifícios deve atender às legislações rigorosas e ter muito cuidado com materiais perigosos, que podem ser nocivos ao meio ambiente.

$\mathrm{Na}$ opinião dele, se for possível obter as informações sobre como o edifício foi construído, aumentam-se as chances de se ter uma desmontagem mais bem-sucedida. Neste caso, não foi possível obter informações atualizadas sobre o projeto dos edifícios, porque foi projetado há muitos anos e houve modificações que não foram documentadas.

A expectativa de vida dos novos edifícios é de, pelo menos, 60 anos, porque é o tempo exigido pelo Reino Unido, mas eles esperam que resista mais do que isso. Os materiais utilizados, como painéis de concreto, devem resistir de 100 a 120 anos, assim a opção foi usar estruturas e painéis pré-fabricados de concreto. A equipe está considerando a manutenção e construtibilidade do edifício, mas não a desmontagem.

Ele concorda que a tecnologia pode mudar e que o edifício deve se adaptar e estar preparado para a manutenção, pois, assim, facilitará o trabalho de adequação no futuro. A equipe de projeto está usando o Revit 2016 e está desenvolvendo o projeto utilizando o BIM na fase 2, visando a atingir o selo verde BREAM.

O entrevistado "B" é gerente de projetos em uma fábrica de carros, começou a trabalhar nessa área há 11 anos e toda a sua carreira é na indústria automotiva. Nesta indústria, algumas partes do carro são montadas na China e alguns elementos no Reino Unido, onde é finalizada toda a montagem do carro.

A montagem do carro é considerada desde o início do projeto; a equipe considera mais a manutenção do que a reutilização e desmontagem, mas a indústria deve atender às políticas 
para a legislação de fim de vida sobre os materiais utilizados nos automóveis. Normalmente, o motor do carro é feito para durar 150.000 milhas, a marca de corrosão é de 10 anos, se o proprietário usar corretamente o produto. Geralmente, a estrutura do corpo do carro é soldada, portanto, no final da vida útil, é esmagada e reciclada. A única parte colada em conjunto são os vidros, mas é uma técnica especial que é possível remover. Os plásticos são parafusados para que fique mais fácil de desmontar. Tudo isso é considerado durante o projeto.

Assim como a indústria da construção, projetar um carro também envolve diferentes equipes de profissionais. Sete a oito diferentes grupos de pessoas estão envolvidos no projeto; se houver uma incompatibilidade, o engenheiro-chefe toma a decisão final. Os automóveis são projetados em 3D, assim ferramentas virtuais são utilizadas para identificar possíveis erros e para facilitar a padronização de elementos. O software CATIA é utilizado há anos e a versão 5 vem sendo utilizada nos últimos 12 anos. Além disso, a equipe simula a montagem e desmontagem do produto com o Robcad.

Todos os materiais utilizados na concepção do produto são identificados na fabricação. Por exemplo, cada plástico usado no carro é marcado, por isso é mais fácil de identificar para reciclar. Também evita-se o uso de materiais perigosos; a maioria deles tem uso autorizado. Para facilitar a desmontagem, evita-se colar elementos, misturar diferentes tipos de plásticos na montagem, misturar aço e alumínio, usar fibra de carbono, porque é muito difícil reciclar. O entrevistado concorda que as leis ambientais estão incentivando as indústrias a apresentarem soluções para o seu produto, para reciclar e minimizar danos ambientais.

O entrevistado "C" é consultor de gestão em uma empresa há 8 anos e tem experiência com a construção nuclear, trabalha com departamentos governamentais, utiliza BIM e Engenharia Digital. Segundo ele, a indústria nuclear é fortemente regulamentada e possui padrões específicos que foram desenvolvidos ao longo de muitos anos. Para a desativação de edifícios deste setor há uma regulamentação rigorosa, além de uma série de condições 
de licença de lugar. Os obstáculos da desativação estão relacionados à falta de informação entre os operadores, os empregadores, as operações, a concepção e a gestão das instalações. Para facilitar o processo é importante estabelecer a correta tecnologia e sistema para montar o plano certo e desenvolver o método correto.

Assim, construir um escopo em um modelo 3D com todas as informações é fundamental. Ele concorda que o BIM poderia contribuir para melhorar o desmonte através do 3D (escopo), 4D (programa), 5D (custo) e 6D (operações e gestão de instalações). Além disso, a estratégia de gestão de dados também pode contribuir.

Segundo o entrevistado, um edifício nuclear pode ser projetado para durar mais de 100 anos, mas tem que definir do "berço" ao "túmulo". Um novo reator pode durar 60 anos com potencial de extensão de vida. No entanto, os materiais que são considerados ativos precisam de eliminação adequada.

O entrevistado "D" é um especialista em gestão de resíduos de edifícios e trabalha para uma empresa multinacional de engenharia em Edimburgo. Ele está nesta empresa, que tem cerca de 40 anos e 1.500 funcionários, há quase 10 anos e trabalha com outros três consultores de resíduos. No entanto, seu trabalho é voltado para resíduos de construção e não tanto com resíduos de demolição.

$\mathrm{Na}$ opinião dele, se as equipes de projeto considerassem a reutilização de resíduos de demolição, isso poderia aumentar as possibilidades de reciclagem. A maior parte dos resíduos no Reino Unido tem reciclagem de baixo nível; isso significa que eles são esmagados e usados para usos de baixo valor. Concreto é um dos favoritos para ser triturado e transformado em novas barras; também a ferragem que vai dentro do concreto pode ser reciclada.

De acordo com o entrevistado, é incomum que os clientes considerem a reutilização ou desmontagem do edifício. Na opinião dele, projetar considerando a desconstrução do edifício 
e como ele pode ser no tempo reutilizado e remodelado pode ajudar a alcançar melhores resultados sobre reciclagem e gestão de resíduos. No entanto, uma demolição de um edifício é esperada em 50 anos, por isso é difícil entender as influências do projeto sobre a demolição futura.

Segundo o entrevistado, é importante considerar o espaço e o tempo. Espaços destinados a resíduos estão se tornando escassos nas cidades e leva muito tempo para a desmontagem e o trabalho intenso; tudo isso precisa ser planejado e considerado. Se há muito tempo disponível, é possível remover o edifício em vários componentes, mas geralmente há muita pressão sobre o tempo da demolição para que se gaste menos dinheiro; assim, é difícil fazer com que as pessoas pensem sobre isso, especialmente em edifícios novos. Se for flexível e adaptável, o seu ciclo pode se estender, porque é possível transformar o edifício e dar a ele um uso diferente, mas o cliente deve solicitar que o edifício seja flexível.

Segundo ele, a Comissão Europeia tem o Pacote de Economia Circular para incentivar as pessoas a pensar sobre consumo, eliminação e reciclagem. Portanto, o produto pode ser redesenhado e retornar para a economia. $\mathrm{Na}$ opinião dele, as leis ambientais incentivam a fazer mudanças que influenciam grandes decisões. Também os selos verdes como LEED e BREAM podem influenciar nas decisões.

Com base na experiência dele, grandes elementos são mais fáceis de serem desmontados (concreto, madeira, tijolos e pedras) e o mais difícil é o que está dentro do edifício, isto é, elementos internos, que representam em torno de $20 \%$ do edifício. Embora isso possa mudar, pois o entrevistado tem visto tecnologias na área de robótica que podem melhorar isso. Modulação e pré-fabricação de elementos podem contribuir para desmontar, por exemplo, os módulos de um banheiro que são anexados em edifícios do hotel e, assim, reduzir o desperdício.

Além disso, o BIM pode contribuir para reunir informações e armazená-las por anos. As informações sobre os elementos e materiais podem ser acessadas no futuro usando o modelo 
BIM. A tecnologia também está ajudando a identificar o material por um chip com os dados sobre ele. Geralmente as informações sobre os edifícios se perdem no tempo, mesmo em um curto período, mas a tecnologia pode ajudar a preservar a informação. A simulação em modelo 3D também pode contribuir para planejar melhor a desmontagem ou a demolição, porém é fundamental manter as informações atualizadas ao longo da vida útil do edifício.

O entrevistado "E" é arquiteto com experiência em complexos esportivos e trabalha em um escritório de arquitetura há dez anos. Para desenvolver este tipo de projeto segue a legislação regular, não havendo legislação específica para desmontagem. Na opinião dele, as conexões são os principais pontos a serem considerados para a desmontagem. O entrevistado afirma que a estrutura é a parte mais difícil a ser desmontada do edifício, pois é composta pelos maiores e mais complexos elementos.

Sobre o projeto que está desenvolvendo - o complexo esportivo -, desde o início foi considerada a desmontagem, principalmente em relação a estrutura, materiais e conexões. Foi requisitado pelo cliente que parte do edifício fosse desmontada. Os elementos a serem desmontados seriam metade dos assentos, parte do ar-condicionado, parte da cobertura, encanamento e ventilação. Se o edifício for construído em camadas, é mais fácil de desmontar e reutilizar. A equipe está analisando um tipo de metal que seja barato e fácil de cortar, ou com utilização de parafusos, para que a estrutura seja desmontada. Uma possibilidade seria utilizar estrutura metálica que também fosse econômica, porém com um bom acabamento. Como o projeto ainda está em fase inicial, o material e os encaixes ainda não estão totalmente definidos.

O entrevistado afirma que o tempo e o custo da desmontagem são questões importantes que devem ser consideradas desde o início do projeto; no entanto, muitas vezes, não é muito detalhada. No projeto que está desenvolvendo está prevista a desmontagem de alguns elementos, porém ainda não há previsão para a futura reutilização, mas há o estudo de algumas possibilidades. Em relação aos demais edifícios, o arquiteto afirma que é possível 
reutilizar e reciclar alguns materiais, mas uma parte vai para aterros. A legislação relacionada à separação de materiais tem influência direta na desmontagem do edifício. Em alguns casos, o cliente pede para considerar a desmontagem, como no projeto de stands e sistemas modulares em residências.

Geralmente a expectativa de vida do edifício a ser considerada é de 60 anos, o que é requerido por lei; no entanto, a desmontagem só é considerada quando é uma exigência do cliente. Também depende da requisição do cliente se o projeto deve atender a algum selo verde. Segundo o entrevistado, em construções de pequeno porte, muitas vezes é difícil separar o material e reutilizá-lo, como o metal que deve ser soldado novamente e é reciclado, em vez de reutilizado.

Ultimamente o escritório está usando BIM em todos os projetos. O entrevistado afirma que auxilia na pré-produção de elementos industrializados e na exibição de modelos eletrônicos. Além disso, acredita que o BIM pode contribuir para a desmontagem por ajudar a visualizar os encaixes e armazenar informações.

A tabela 5 foi desenvolvida para pontuar as questões principais que foram abordadas nas entrevistas. Quando há um "X”, significa que o assunto foi discutido e é considerado no projeto; a ausência do "X" significa que o assunto não é considerado ou não foi discutido na entrevista. 
Tabela 5 - Temas abordados nas entrevistas

\begin{tabular}{|c|c|c|c|c|c|}
\hline \multicolumn{6}{|l|}{ Temas abordados } \\
\hline & Ent. A & Ent. B & Ent. C & Ent. D & Ent. E \\
\hline $\begin{array}{l}\text { Considera } \\
\text { montagem/construtibilidade no } \\
\text { projeto. }\end{array}$ & $X$ & $\mathrm{X}$ & & & $X$ \\
\hline Considera a manutenção no projeto. & $X$ & $X$ & $\mathrm{X}$ & $X$ & $X$ \\
\hline $\begin{array}{l}\text { Considera possibilidades de } \\
\text { desmontagem. }\end{array}$ & & $\mathrm{X}$ & & & $X$ \\
\hline $\begin{array}{l}\text { Considera desmontar para } \\
\text { reutilização. }\end{array}$ & & & & & $X$ \\
\hline Segue a legislação ambiental. & $X$ & $X$ & $X$ & $X$ & $X$ \\
\hline $\begin{array}{l}\text { Considera o tempo de vida útil do } \\
\text { produto. }\end{array}$ & $X$ & $X$ & $X$ & & $X$ \\
\hline $\begin{array}{l}\text { Considera a futura reciclagem de } \\
\text { materiais. }\end{array}$ & & $X$ & & & \\
\hline $\begin{array}{l}\text { Concorda que as leis ambientais } \\
\text { contribuem para encontrar soluções } \\
\text { para a gestão de resíduos. }\end{array}$ & $X$ & $X$ & $X$ & $X$ & $X$ \\
\hline Considera a desmontagem. & & $X$ & $X$ & & $X$ \\
\hline $\begin{array}{l}\text { Utiliza softwares para coletar } \\
\text { informações de projeto. }\end{array}$ & $X$ & $X$ & $X$ & & $X$ \\
\hline Utiliza modelo 3D. & $X$ & $X$ & $X$ & & $X$ \\
\hline $\begin{array}{l}\text { Concorda que o BIM pode contribuir } \\
\text { com reuso e desmontagem. }\end{array}$ & $X$ & $X$ & $\mathrm{X}$ & $X$ & $X$ \\
\hline Busca conquistar um selo verde. & $X$ & & & & \\
\hline $\begin{array}{l}\text { O selo verde pode influenciar } \\
\text { algumas decisões. }\end{array}$ & & & & $X$ & \\
\hline
\end{tabular}

Fonte: Autora

Portanto, com base nas entrevistas realizadas, podem-se verificar pontos importantes abordados em relação a desmontagem ou demolição dos produtos ou edifícios. Nas indústrias, a questão do descarte dos produtos após serem utilizados já é uma realidade, enquanto, na construção civil, ainda não se tem o planejamento correto dos materiais após a vida útil do edifício. Porém a questão dos resíduos sólidos gerados pelo setor da construção civil já é um problema atual, mas com poucas propostas de solução.

Todos os entrevistados afirmaram que a manutenção do produto/edifício é considerada desde a concepção do projeto. No entanto, ainda falta maior discussão sobre o descarte final. Umas das razões citadas seria a falta de interesse dos consumidores, que se preocupam com 
questões ambientais, mas não consideram o descarte. No caso de edificações, seria uma questão a ser encarada em algumas décadas e provavelmente não pelo cliente que contratou o projeto e construiu o edifício. Apenas o entrevistado "E" afirma que houve a preocupação da desmontagem para reutilização do projeto, no entanto uma parte das instalações seria logo desmontada.

Todos os entrevistados afirmaram que conhecem e seguem as normas vigentes, legislações e recomendações ambientais. Isso enfatiza a forte influência dos órgãos públicos e seu papel fundamental na cobrança e fiscalização na fabricação de produtos que atendam aos requisitos ambientais. Apenas um entrevistado afirma que pretende certificar os edifícios com selos verdes e, sendo assim, segue algumas especificações. Portanto, as certificações também influenciam na tomada de decisões ao longo do projeto e podem contribuir para resultados melhores e soluções para preservar o meio ambiente.

Os entrevistados também projetam uma estimativa de vida útil dos produtos, muitas vezes ligada a manutenção e garantias, mas é uma questão muito importante para possibilitar a reutilização dos produtos. O entrevistado "B" afirma que considera a futura reciclagem dos elementos fabricados e evita materiais tóxicos.

Os entrevistados desenvolvem os projetos em softwares, utilizam modelos 3D e consideram que o BIM pode contribuir para a desmontagem do edifício. Todos estão familiarizados com o termo BIM e utilizam softwares com capacidade de modelagem e reunião de informações, que permitem compatibilidade entre projetos em outros softwares.

Dessa maneira, pode-se observar que a questão dos resíduos sólidos é discutida, no entanto faltam definições mais claras e objetivas para realmente ter soluções que contribuam para a redução do desperdício e o consumo de matérias-primas. Assim, o desenvolvimento da tecnologia, aumento da consciência ambiental da população e leis ambientais podem contribuir para melhores resultados. 


\subsection{Elementos industrializados}

Ao longo da pesquisa, julgou-se necessário avaliar sistemas estruturais que consideram a montagem do edifício, desde a concepção do projeto. Considerar a desmontagem ainda não é usual no setor; no entanto, como visto na revisão bibliográfica e reforçado nas entrevistas, alguns pontos considerados na montagem contribuem para a desmontagem.

Assim, foram selecionadas quatro empresas, no estado de São Paulo, para análises de materiais da construção civil com foco na montagem de edifícios. Duas delas são especializadas em elementos de concreto armado e protendido, a outra é especialista em estrutura metálica e a quarta é focada em estruturas de madeira.

A escolha dos materiais e sistemas analisados é importante para verificar pontos da montagem e para o desenvolvimento do modelo apresentado no capítulo 5. Segundo Zhong e Wu (2015), na indústria da construção, dois dos principais materiais de construção, concreto e aço, são considerados materiais com alta energia incorporada. A apropriada seleção destes dois materiais de construção pode ajudar a indústria a minimizar os impactos ambientais. Para Zhong e Wu (2015), a seleção do sistema estrutural afeta significativamente a sustentabilidade econômica, sustentabilidade ambiental e a construtibilidade.

Portanto, foram selecionadas estas empresas para analisar o processo de produção, montagem e características específicas de cada elemento que possa contribuir para a desmontabilidade do edifício.

\subsubsection{Concreto armado e protendido}

Foram realizadas visitas em duas indústrias de elementos pré-fabricados de concreto, onde foram feitas entrevistas com engenheiros civis e de produção, além de visita à linha de produção e a duas obras. O objetivo da visita foi analisar o processo de montagem e verificar 
possíveis características que possam contribuir para a futura desmontagem, além de analisar as contribuições do BIM.

A empresa "A" tem 30 anos de mercado e cerca de 200 funcionários, está localizada em Américo Brasiliense, estado de São Paulo, Brasil. É especializada em elementos de concreto protendido pré-fabricado. Realiza obras comerciais, institucionais e galpões de armazenamento. A escolha do concreto protendido é devido à resistência do material.

A primeira entrevistada foi uma engenheira que trabalha com projeto de ferragem há 6 anos. $\mathrm{Na}$ área de detalhamento de projetos trabalham, no total, 8 pessoas, entre engenheiros e estagiários.

Inicialmente é feita uma reunião com os profissionais do projeto executivo e responsáveis pela montagem sobre a liberação da obra, para analisar questões sobre localização, transporte e montagem. Características como ferramentas utilizadas e encaixes das peças também são consideradas. Por exemplo, evitar fazer soldas na obra, preferir fazer as soldas necessárias na fábrica e realizar apenas os encaixes na obra, para evitar levar a máquina de solda.

Segundo a engenheira civil entrevistada, as ligações apoiadas e parafusadas contribuem para a montagem da estrutura e a possível desmontagem. As peças já têm dimensionamentos pré-estabelecidos, mas é possível fazer peças específicas quando se tem alguma necessidade especial. As dimensões das peças são adequadas ao transporte e armazenamento disponíveis.

Uma das maiores dificuldades é adaptar projetos desenvolvidos para construção in loco ${ }^{14}$ para harmonizar-se a elementos pré-fabricados, o que pode ser um pouco complexo, mas é possível solucionar. O BIM contribui por facilitar a integração de projetos. Na empresa, de

\footnotetext{
14 In loco é uma expressão em latim que significa "no lugar" ou "no próprio local", expressão utilizada na construção civil para designar elementos moldados no local da construção, não provenientes de fábrica.
} 
dois a três profissionais trabalham ao mesmo tempo, no mesmo arquivo, e este mesmo arquivo segue em todas as etapas do desenvolvimento do projeto, orçamento e produção. $\mathrm{O}$ software utilizado é o Revit; em relação ao AutoCad, que era utilizado anteriormente, é possível visualizar com mais facilidade as interferências entre os elementos do projeto. Mesmo quando recebem o projeto em AutoCad dos arquitetos, eles colocam uma "máscara" no Revit para trabalhar. Até a data da entrevista, eles só haviam recebido um projeto em Revit, que foi no mesmo ano da entrevista. A modelagem em 3D é muito utilizada e facilita a produção dos elementos. Também já foi utilizado o 3D do edifício para mostrar para o cliente.

De acordo com a entrevistada, o software funciona muito bem em relação à necessidade das pessoas trabalharem no mesmo arquivo e torna o processo mais eficiente. No entanto, houve algumas dificuldades na transição de softwares.

A questão da desmontagem não é recorrente do processo de projeto, apenas quando há alguma exigência do cliente voltada para a flexibilidade do edifício, quando ele requer possibilidades de ampliação, e, para isso, alguma parte poderá ser desmontada, por exemplo, retirar os painéis de fechamento para fazer uma futura ampliação. Portanto, painéis de fechamento podem ser desmontados e remontados sem nenhum dano.

As normas que utilizam é a NBR 6118, sobre concreto, e NBR 9062, sobre pré-fabricados.

Segundo a entrevistada, os painéis de vedação de concreto são os elementos mais fáceis de serem desmontados, por serem apenas apoiados; também as terças não apresentam dificuldade, por serem apenas parafusadas, enquanto as vigas e os pilares são elementos mais difíceis de serem desmontados, por serem grauteados. No entanto, todos os elementos podem ser reciclados.

As fases de montagem do edifício são: montagem dos pavimentos, concretagem e capeamento das lajes, terças de cobertura e, por fim, o fechamento. No caso de apenas um 
pavimento, como galpões, é necessário parar a obra para concretar. Possivelmente, a desmontagem seria o processo inverso.

A entrevistada afirma que as lajes seriam os elementos mais difíceis de serem reutilizados devido à ligação de concreto entre as placas.

Geralmente as ferramentas utilizadas para a montagem são: guindaste, plataforma e ferramentas manuais, como parafusadeira.

A exigência de selos verdes não é recorrente. A expectativa de vida do edifício é de 50 anos. No entanto, o final do ciclo de vida não é um tema recorrente.

Também foi realizada entrevista com um engenheiro de produção durante a visita à linha de produção. A fábrica produz $70 \mathrm{~m} 3$ de concreto ao dia. A escolha do material é devido à resistência. Segundo ele, o Revit traz benefícios para a produção, pois diminui erros e permite maior integração entre a engenharia civil e a de produção. Alguns clientes pedem certificações ISO e procedência dos materiais para garantir a qualidade do material.

Outra entrevista foi realizada com um engenheiro de produção durante as visitas a um galpão em construção e um edifício comercial de 4 pavimentos. Segundo o entrevistado, os painéis de vedação são fáceis de montar e desmontar, apesar do uso de silicone de alta resistência entre os painéis, e podem ser cortados com a utilização de uma faca específica, por apenas um operário. Já os pilares concretados na fundação são difíceis de ser desmontados. O entrevistado também ressaltou que o concreto protendido oferece grande resistência, principalmente quando comparado à estrutura metálica.

A primeira obra visitada foi uma fábrica de embalagem, que estava sendo construída, composta por um galpão de $1.166 \mathrm{~m}^{2}$ que foi montado em 15 dias. Foram necessários 2 montadores, 2 ajudantes, 1 guindasteiro e 1 encarregado. Posteriormente, foi visitado um edifício comercial de 4 andares, composto por lojas, estoques e salas. Sua estrutura foi montada em 20 dias e seus elementos foram produzidos em, aproximadamente, 20 dias 
também. As figuras 09, 10, 11 e 12 demonstram os elementos pré-fabricados sendo montados.

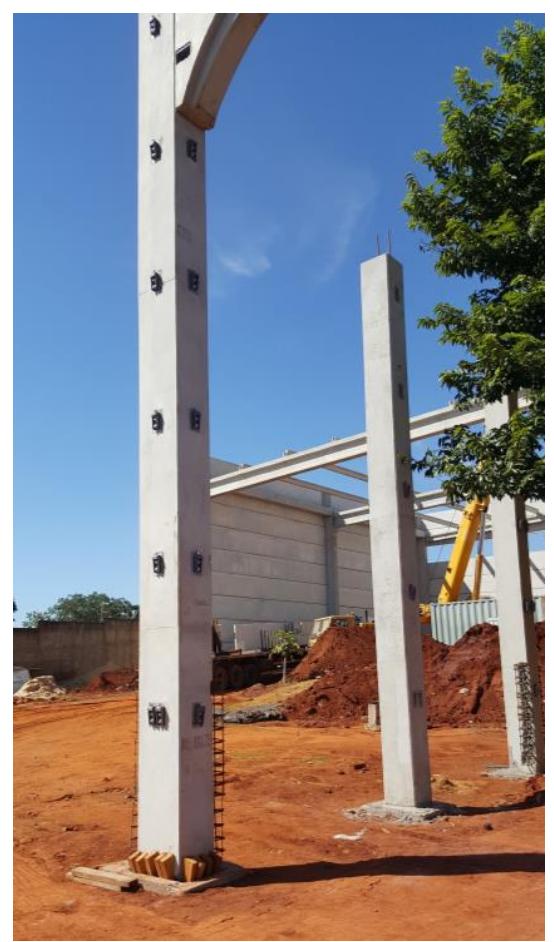

Figura 9 - Pilares de concreto pré-moldado sendo colocados na obra Fonte: Autora

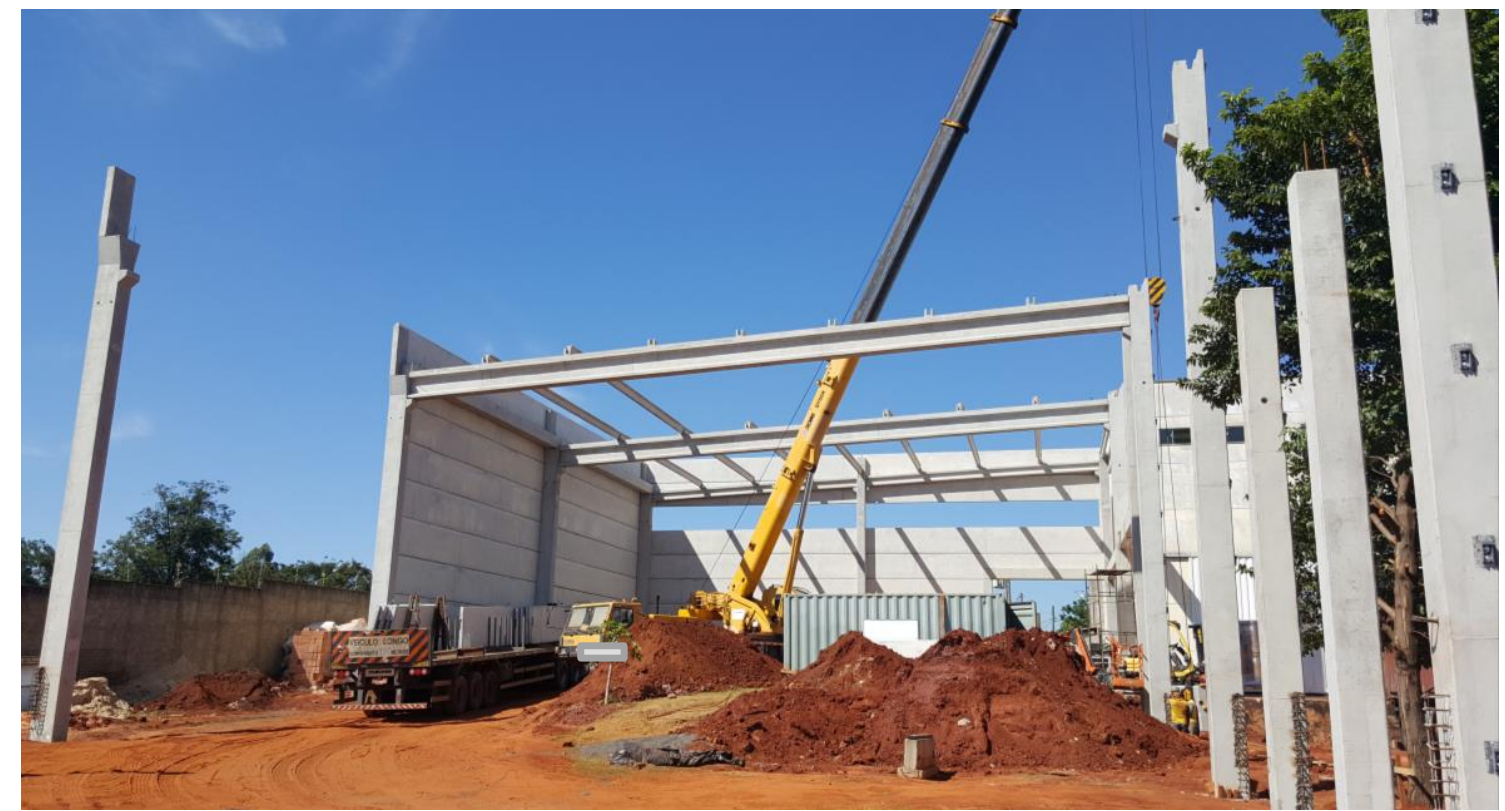

Figura 10 - Montagem de um galpão em estrutura pré-moldada de concreto protendido Fonte: Autora 


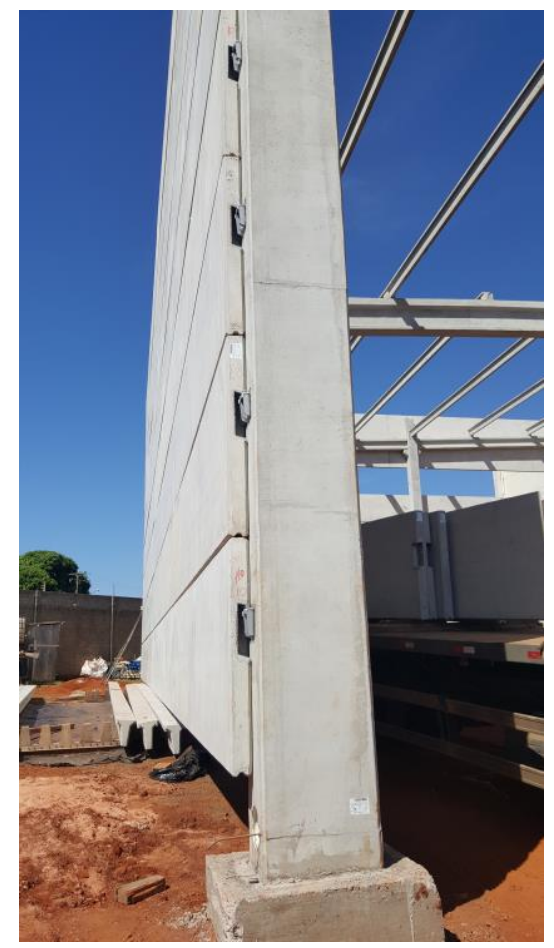

Figura 11 - Detalhes dos encaixes dos painéis de vedação Fonte: Autora

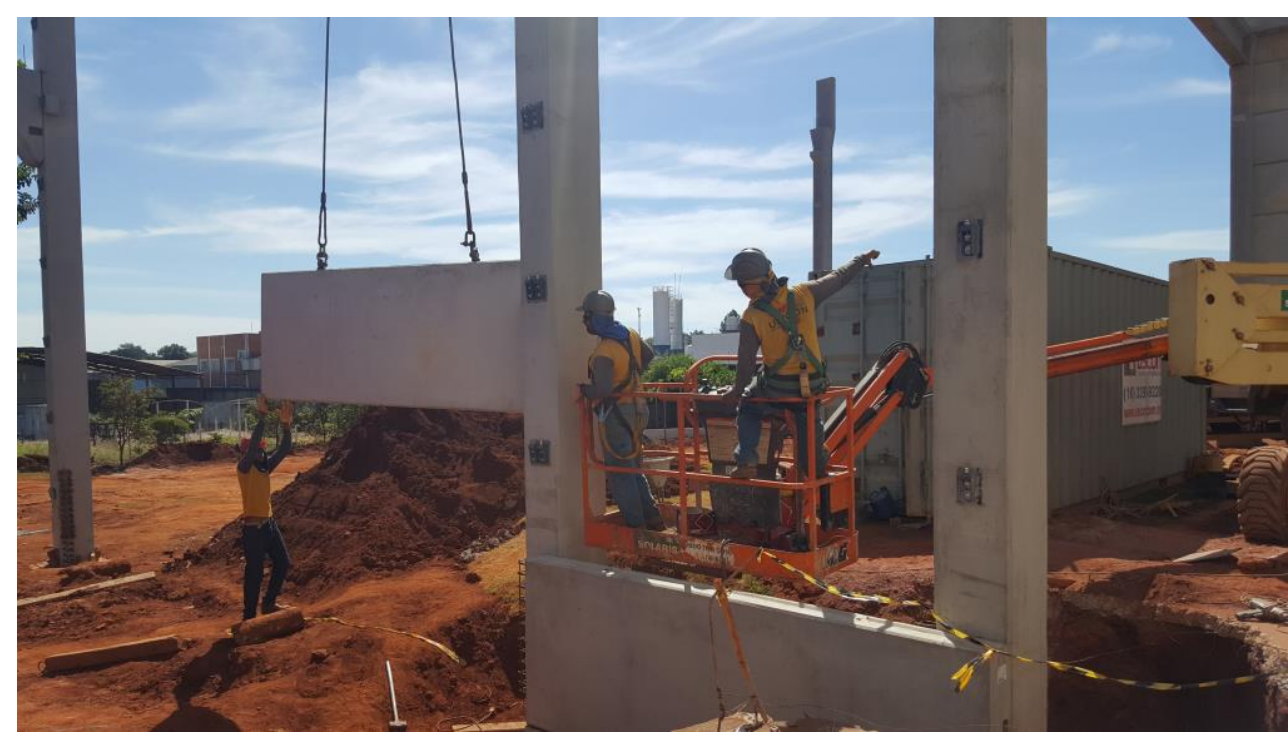

Figura 12 - Funcionários montando os painéis

Fonte: Autora

Outra visita foi realizada na empresa "B", que também forneceu importantes esclarecimentos sobre a construção com este sistema construtivo em relação à montagem e desmontagem dos elementos. A empresa é especializada em elementos pré-fabricados de concreto, que pode ser armado ou protendido. A empresa está no mercado há 27 anos e tem em torno de 70 empregados. Ela está localizada no interior de São Paulo, no município de Brodowski. 
Foram realizadas entrevistas com dois engenheiros civis, que trabalham com os projetos, e um engenheiro mecânico, que supervisiona a produção.

A empresa desenvolve o projeto de cálculo estrutural e montagem da obra e recebe o projeto arquitetônico de terceiros. Além disso, realiza o plano de montagem, pois cada obra tem necessidades específicas, apesar de a maioria dos elementos ser padronizada. Para a montagem dos edifícios, as primeiras questões a serem consideradas são a estrutura, as armaduras, os esforços e as ligações adequadas entre os elementos para reduzir deformações da estrutura. Posteriormente, é considerado o local, as condições de içamento, transporte e montagem. Algumas vezes as peças têm que ser reforçadas para resistir aos esforços do içamento.

Em relação à desmontagem, esta não costuma ser considerada, segundo o entrevistado, pois seria complicado reutilizar as peças em outra obra. Além disso, a maioria dos elementos é concretada ou grauteada para melhor fixação e resistência, mas isso dificulta a desmontagem. A única exceção é o painel de vedação, que é apenas encaixado.

$\mathrm{Na}$ opinião do entrevistado, quando o conceito da desmontagem estiver mais divulgado e cobrado, será possível buscar melhores opções para tornar isso possível. Segundo ele, as estruturas metálicas parafusadas seriam mais viáveis para serem desmontadas e remontadas. As ligações seriam pontos importantes a serem considerados. No caso do prémoldado de concreto, a reciclagem seria uma opção mais viável. No momento, ele considera um grande desafio a desmontagem deste sistema. Para a desmontagem, possivelmente seria feito o inverso da montagem: retirar a cobertura, camadas de vedação e depois a estrutura, no entanto as ligações químicas dificultariam e até inviabilizariam o processo.

A empresa trabalha com elementos pré-fabricados de concreto por ser um material simples, que não precisa de manutenção e tem estética agradável. Ela trabalha com protensão de cordoalha nua, o que permite peças com menores secções, reduzindo, assim, o consumo de material e facilitando o transporte. Isso faz com que estes elementos sejam vantajosos e se 
torne favorável a pré-fabricação. Além disso, o desperdício é muito menor que de uma construção convencional (estrutura de concreto moldada no local), e tem-se maior controle sobre a qualidade dos elementos. Com o desenvolvimento de novas tecnologias, como concretos mais resistentes como o UHPC (Ultra-High Performance Concrete, do inglês, Concreto de Ultra-Alta Performance), é possível ter peças ainda mais leves, portanto mais fáceis de serem montadas e transportadas.

Em relação à expectativa de vida dos elementos, os profissionais seguem a norma específica para pré-fabricados. No entanto, em relação à durabilidade, esta pode chegar a 100 anos, ultrapassando a exigência da norma.

Para desenvolver os projetos, eles utilizam softwares com tecnologia BIM. Atualmente, usam um chamado Allplan, que é voltado para a indústria de pré-fabricados. Porém, recebem projetos de outros softwares, como Autocad, Revit, Archicad, entre outros. Muitas vezes recebem projetos em 2D, que, às vezes, não contêm nem cortes e tampouco estão envolvidos com a tecnologia BIM. Geralmente exportam para o arquivo IFC para poder abrir no Allplan, mas muitas vezes acontecem alguns erros e, então, todos os projetos são refeitos diretamente no Allplan. Na empresa, eles fazem toda a compatibilização, pois a préfabricação não permite modificações na obra, assim tudo deve estar resolvido e compatibilizado antes da produção. Mesmo quando há alguma alteração, eles atualizam todo o projeto.

Há 7 anos começaram a utilizar o Allplan, que, na opinião deles, facilitou o processo, apesar do tempo que levou para a equipe se adequar ao novo software. Além disso, o Allplan facilitou a visualização 3D e o processo de produção. No entanto, ainda há ferramentas no software que podem contribuir para o processo que eles pretendem explorar melhor, como em relação a identificar o que já foi ou não produzido. Eles desenvolveram biblioteca própria.

Em relação aos selos verdes, ainda não houve nenhuma exigência, assim como medidas em relação à desmontagem ou reciclagem dos materiais. 
A fábrica produz de 25 a $30 \mathrm{~m}^{3}$ de concreto por dia. Durante a visita, estavam produzindo os elementos para a ampliação e reforma de um estádio de futebol, em Ribeirão Preto. Segundo o entrevistado responsável pela produção, leva em torno de um a dois meses a realização do projeto e o mesmo tempo de produção. Para a montagem, são necessárias de duas a três semanas, em média, para um projeto desta escala.

A fábrica reutiliza a água da produção e gera poucos resíduos. A empresa cogitou a possibilidade de implementar uma usina de reciclagem, mas a quantidade é pequena e não iria compensar o investimento. Os resíduos produzidos são restos de madeiras, devido às formas para a produção de peças personalizadas, pois as peças-padrões são feitas em formas de ferro.

A empresa trabalha com sistema de etiquetagem dos elementos e atualização do projeto de acordo com as mudanças dos elementos. Isso ajuda na identificação das peças durante a produção, o transporte e a montagem da estrutura. Eles trabalham com vão máximo de 30 $\mathrm{m}$, a viga é transportada inteira, porém requer planejamento do transporte. A empresa começou atendendo principalmente usinas de álcool, mas, na última década, diversificou mais as construções, como obras de supermercado, institucionais, estádio de futebol. Não trabalha com construções residenciais, mas há estudos para viabilizar isso.

As figuras 13,14,15, 16 e 17 demonstram o a linha de produção, a identificação dos elementos, processo de concretagem, produção do concreto e montagem da estrutura. Assim é possível observar como são produzidos os elementos. 




Figura 13 - Vista geral da produção Fonte: Autora



Figura 14 - Armação com etiqueta de identificação

Fonte: Autora 


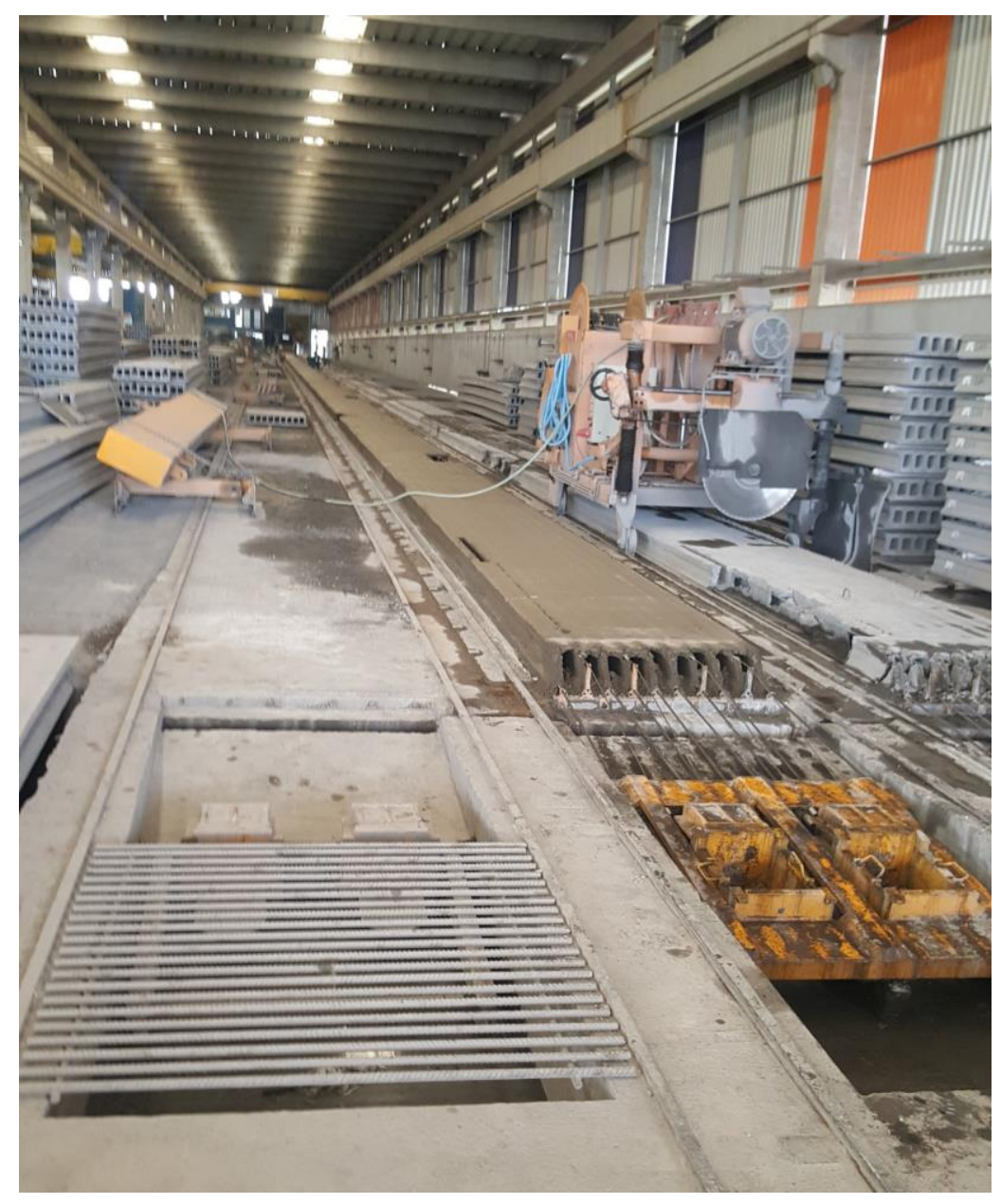

Figura 15 - Concretagem de elementos Fonte: Autora 


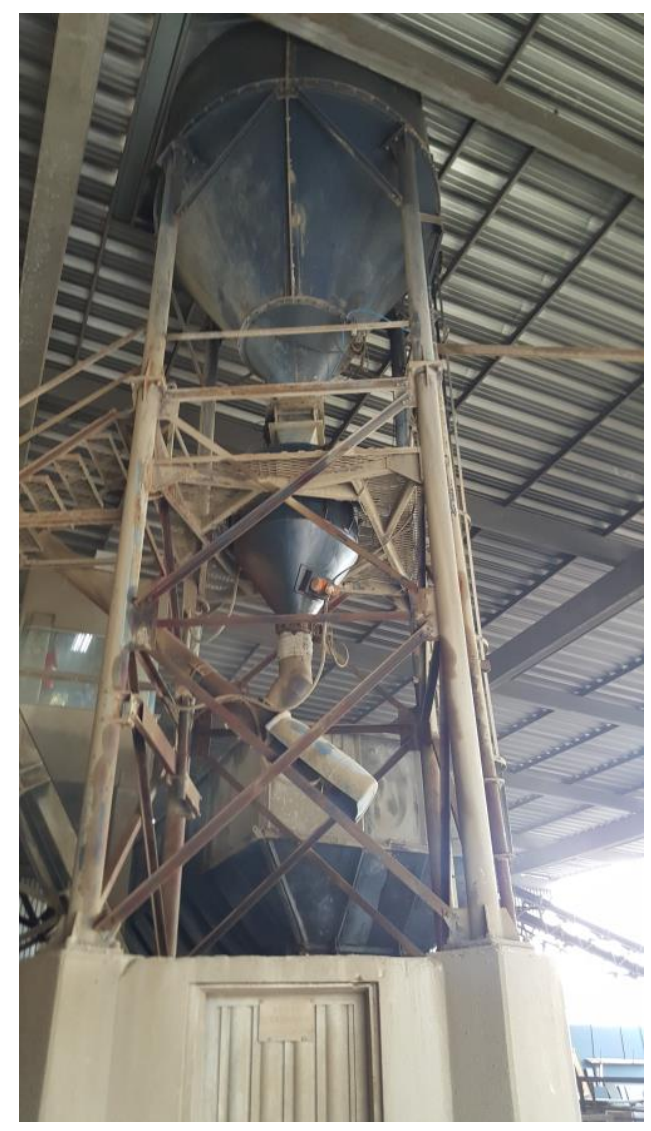

Figura 16 - Produção do concreto Fonte: Autora

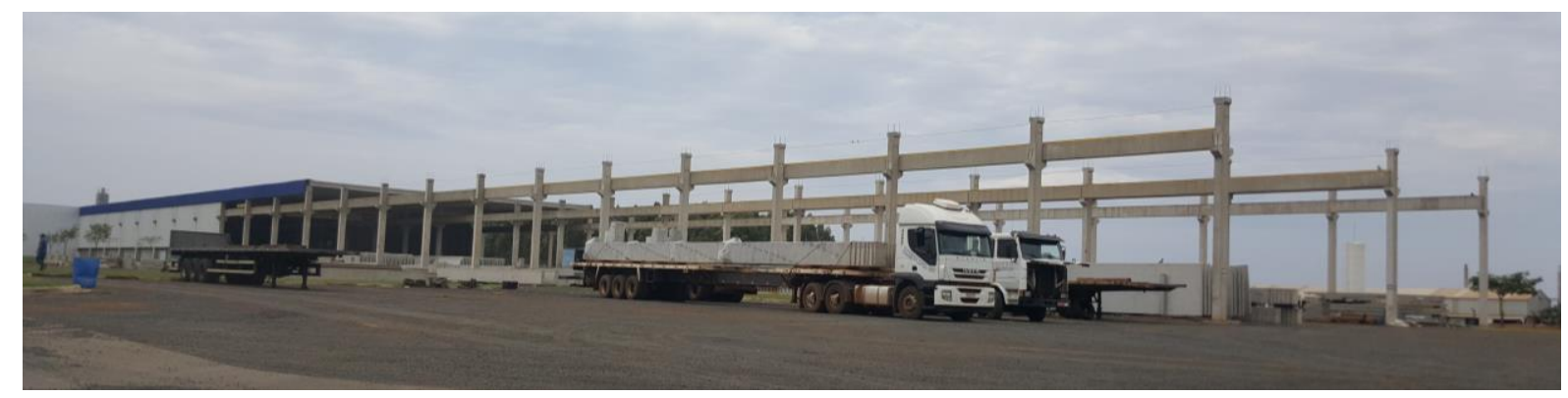

Figura 17 - Obra em andamento Fonte: Autora

\subsubsection{Reforma de estádio de futebol}

Foi realizada uma visita à obra de reforma de um estádio de futebol, localizado em Ribeirão Preto-SP. A estrutura utilizada foi pré-fabricada com concreto e cobertura metálica. Ao longo da visita foi importante observar como foram colocados e encaixados os elementos préfabricados. A obra é predominantemente de elementos estruturais pré-fabricado de concreto, 
com a cobertura metálica. As figuras 18 a 25 apresentam a reforma do estádio e pode verificar como foi feita as ligações entres os elementos.

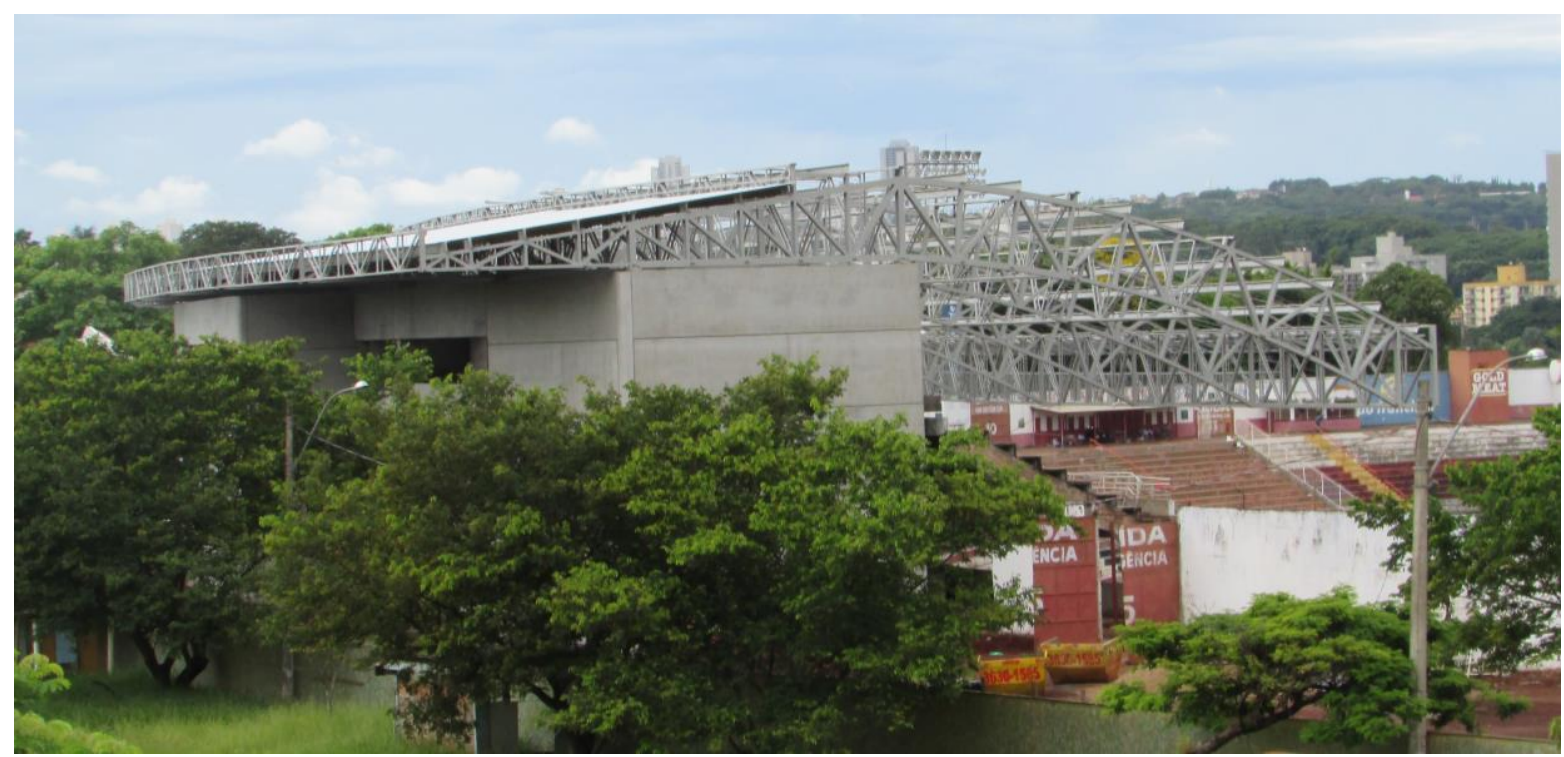

Figura 18 - Vista lateral do estádio Fonte: Autora

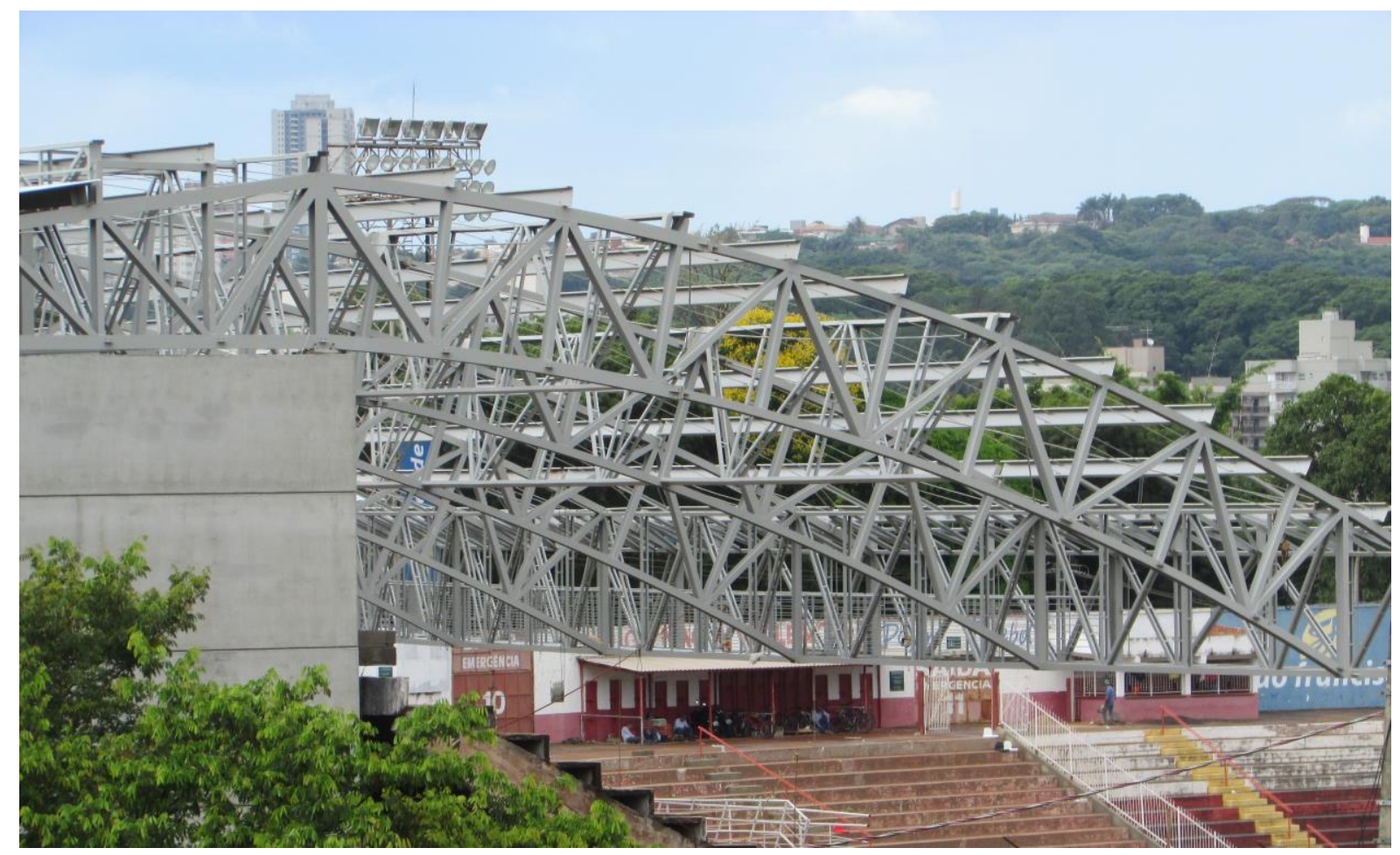

Figura 19 - Detalhe da união entre os elementos de concreto e metálicos Fonte: Autora 


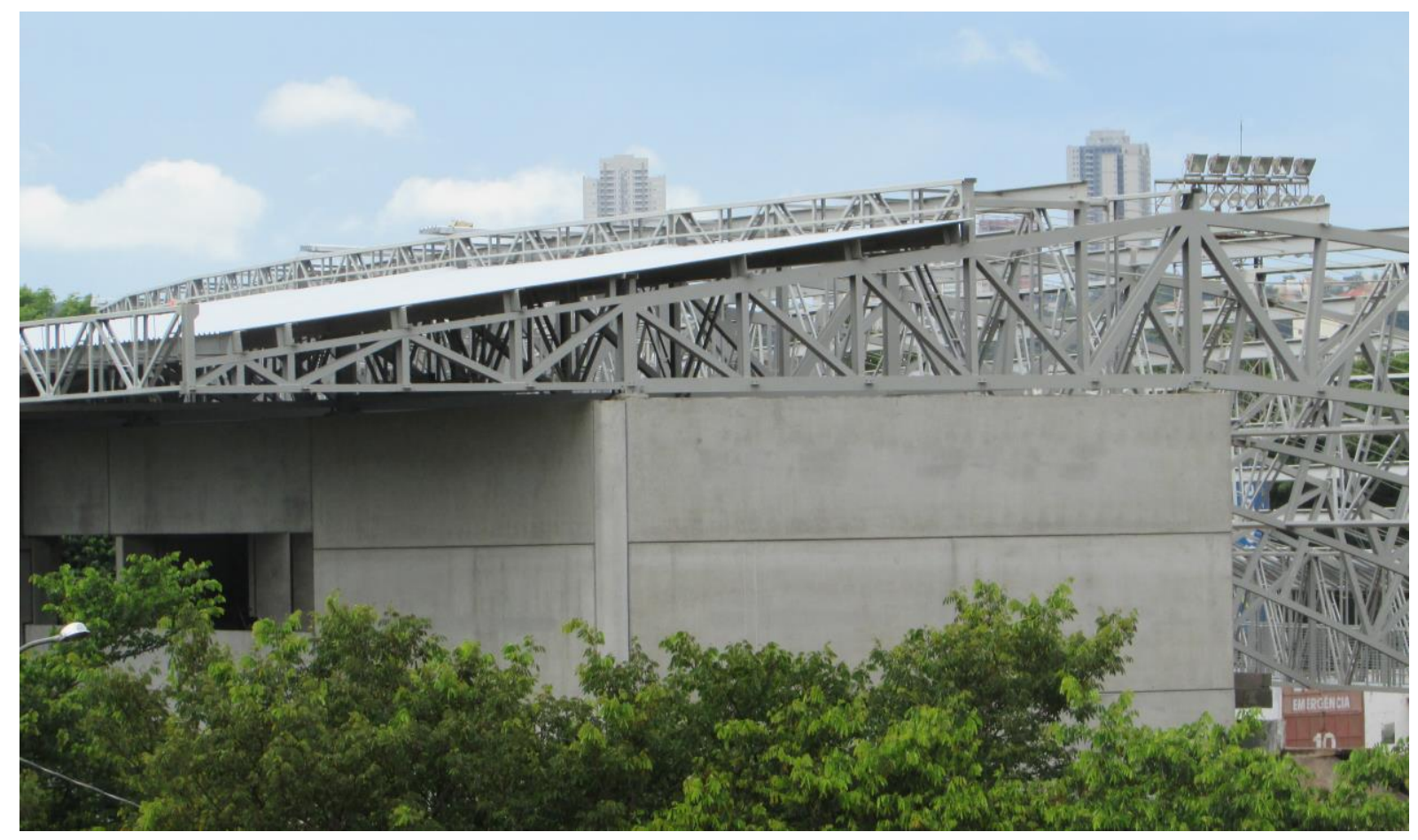

Figura 20 - Detalhe da união entre os elementos de concreto e metálicos Fonte: Autora

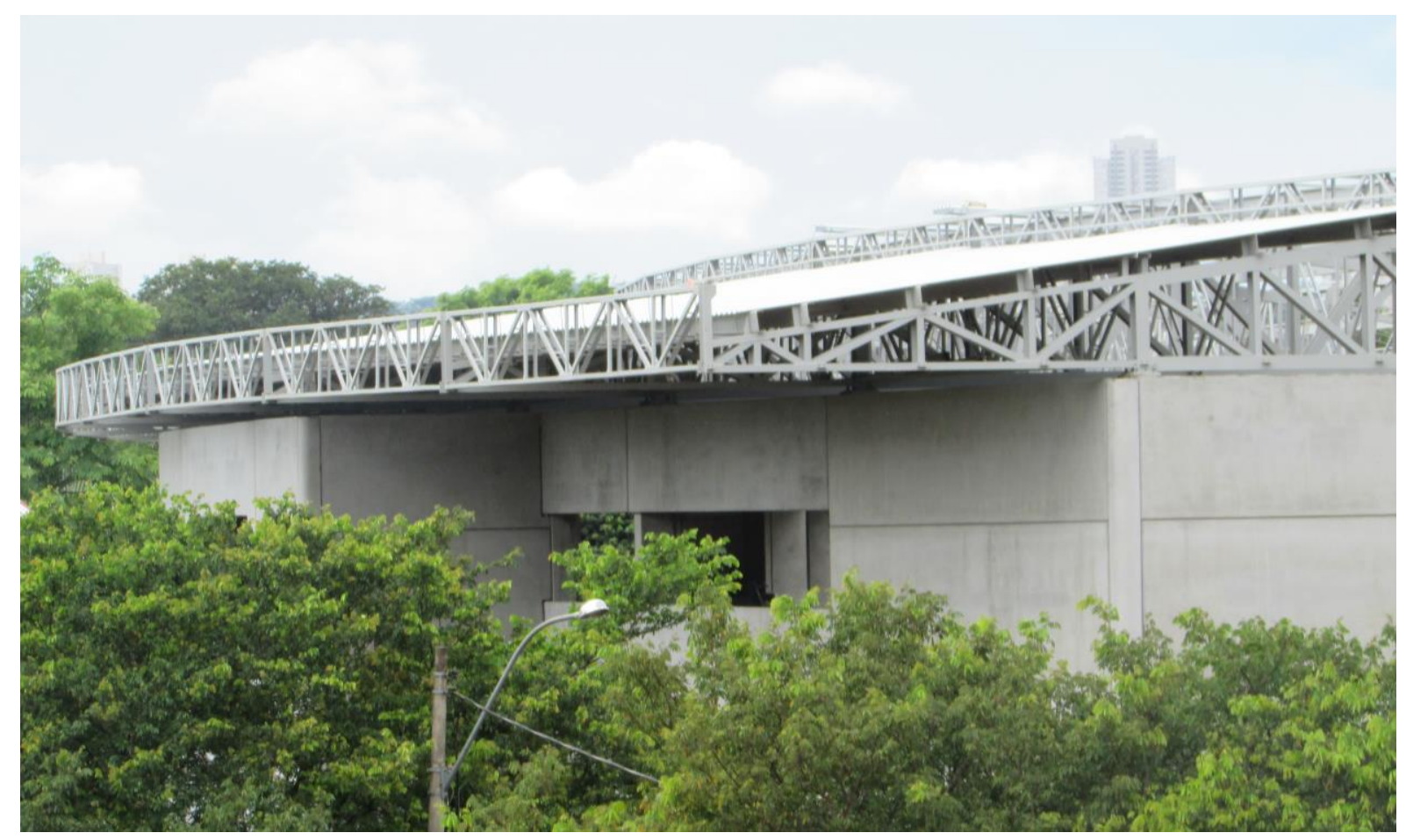


Figura 21 - Vista lateral da obra

Fonte: Autora



Figura 22 - Detalhe da união entre os elementos de concreto e metálicos Fonte: Autora 




Figura 23 - Vista do fundo da obra

Fonte: Autora

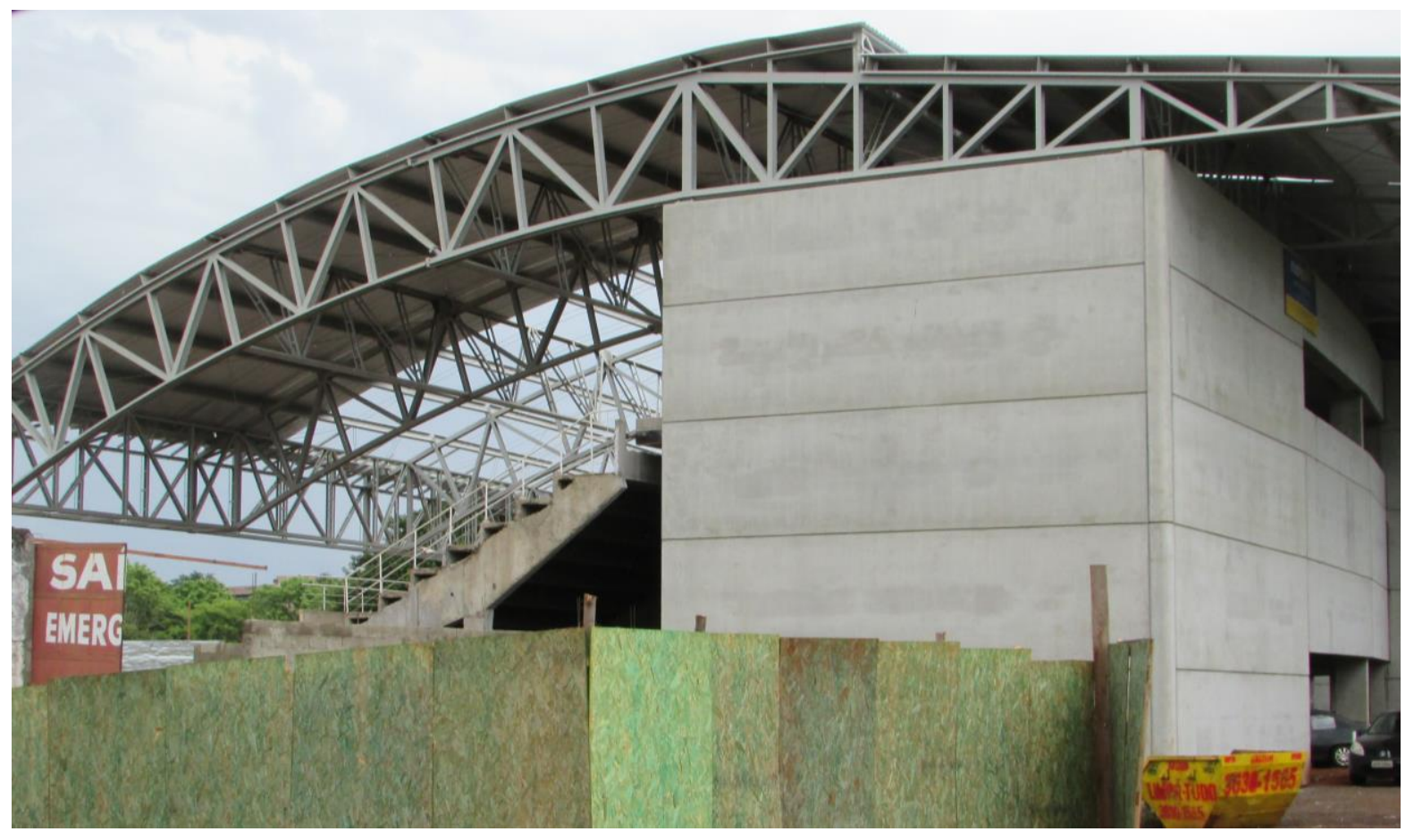

Figura 24 - Vista lateral da obra, onde será a entrada Fonte: Autora 


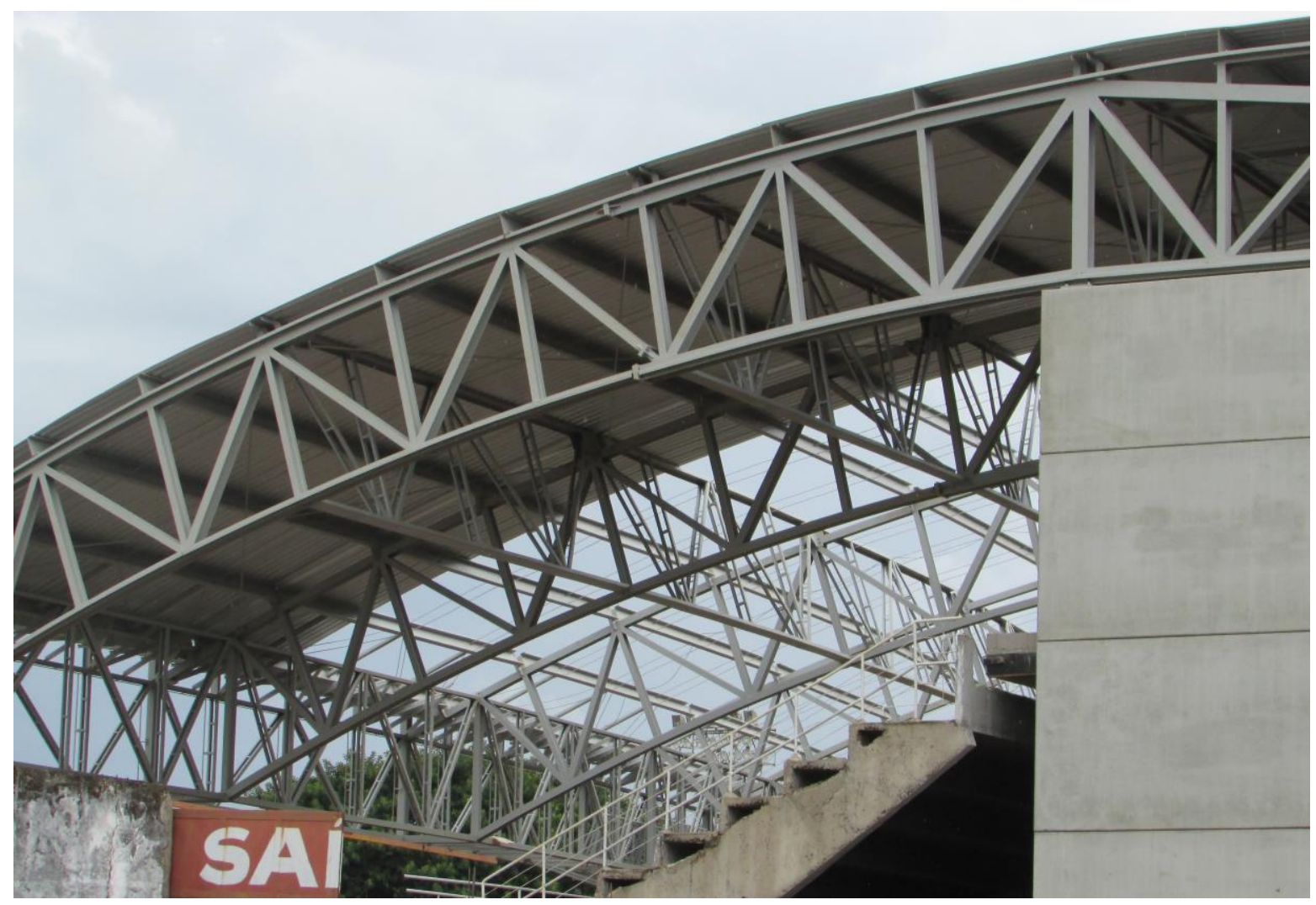

Figura 25 - Detalhe da união entre os elementos de concreto e metálicos Fonte: Autora

Esta obra foi importante para verificar a relação entre os diferentes materiais e suas conexões. Outra obra foi visitada, a de um supermercado em Ribeirão Preto-SP, que será apresentada no próximo item, pois sua cobertura foi feita pela empresa de estrutura metálica apresentada a seguir.

\subsubsection{Estrutura metálica}

Foi realizada uma visita a uma empresa especializada em construção com elementos metálicos. A empresa "C" faz projetos, fabrica os elementos e constrói com peças metálicas. Ela é composta por 3 engenheiros civis, 2 secretárias e tem em torno de 90 funcionários especializados em estruturas metálicas, que fabricam, montam e soldam as estruturas. Localiza-se em Ribeirão Preto, interior de São Paulo. 
A empresa trabalha com diversos tipos de construções, como supermercados, galpões, residências, além de elementos como portões, beirais, marquises, e também trabalha com estrutura mista com concreto.

O engenheiro entrevistado utiliza diversos softwares, principalmente voltados para estrutura metálica. Atualmente, utiliza o software Tecnometal e, em algumas obras, utiliza o Tekla. No entanto, o entrevistado afirma que o software que mais atende suas necessidades é o SDS, o qual utilizava em seu emprego anterior, no entanto o valor da licença é muito maior. $O$ engenheiro tem conhecimento e interesse por BIM, porém conhece pouco o Revit, porque quando o conheceu, há alguns anos, não tinha muitas ferramentas para estrutura metálica.

Sobre as obras, geralmente não são padronizadas, portanto os elementos são feitos sob medida; assim, a grande maioria (em torno de 99\%) das obras é soldada no local. Segundo o entrevistado, as peças parafusadas seriam mais eficientes, tornando a montagem mais rápida e as peças mais bem aproveitadas, além de favorecer a desmontagem. Porém, essas peças não permitem adaptações no local e o projeto deve estar muito bem detalhado e compatibilizado, pois deve ter uma precisão milimétrica. $O$ engenheiro trabalhou em outra empresa maior, em que, na maioria das construções, as peças eram parafusadas e utilizavase o software SDS, assim havia menos erros, mas as peças devem ser mais precisas e o projeto também. Este processo facilita a desmontagem, reutilização e ampliação.

Durante as construções, ele considera que não há muita perda de materiais; o que sobra é levado de volta para a fábrica para reutilizar ou reciclar, assim sobram poucos resíduos.

Atualmente, o entrevistado relatou que os órgãos públicos e os clientes não cobram soluções sobre o final da vida útil, reciclagem e reutilização.

A empresa segue as ISOs e legislações, mas nenhuma norma específica sobre final do ciclo de vida, reutilização e reciclagem. O entrevistado já trabalhou com obras que exigem 
certificação, mas, na empresa atual, não é comum esta exigência pelo cliente ou por órgãos públicos.

Além da visita à empresa, também foram visitadas duas obras. Uma de menor porte, em que estava sendo realizada a ampliação de um edifício para se transformar em um restaurante, e a segunda obra é a ampliação de um supermercado. Na visita à segunda obra, também foi possível entrevistar o arquiteto e o construtor responsável.

Ambas obras se localizam em Ribeirão Preto-SP. Na primeira foi possível observar as vigas, os pilares e a cobertura, que foi toda construída em estrutura metálica. As peças eram soldadas e apenas na fundação foram utilizados parafusos. As peças foram produzidas e montadas em poucas semanas.

Na segunda obra visitada, a ampliação do supermercado, a estrutura é mista de pré-moldado de concreto e estrutura metálica. A estrutura principal, pilares e vigas, são de concreto protendido pré-moldado e o fechamento, a cobertura, o pergolado e outros detalhes são de elementos metálicos. Em algumas áreas, a vedação é de alvenaria de tijolo com furos e argamassa. O fechamento lateral e a cobertura são de telhas metálicas do tipo sanduíche.

Em entrevista realizada com o arquiteto, na obra, ele afirma que o software utilizado para o desenvolvimento do projeto de arquitetura é o Archicad, que ele já utiliza há mais de dez anos. O Arquiteto falou dos benefícios e das facilidades do BIM; no entanto, é necessário mais tempo inicial, mas o cliente não quer esperar.

O engenheiro civil, o construtor e o arquiteto conhecem o BIM e seus benefícios, principalmente em relação ao projeto e à compatibilização, porém afirmam que muitas vezes o cliente não tem conhecimento sobre BIM e seus benefícios, portanto não investe. Além disso, eles afirmam que exige um investimento de tempo inicial para colocar o BIM em prática e grande envolvimento de todos os membros das equipes de projeto, além de uma mudança 
de comportamento, e isso ainda é um obstáculo na prática, assim como foi a transição de desenhos feitos à mão para o AutoCad.

A estrutura metálica é parafusada na estrutura de concreto pré-moldada, mas é soldada uma peça na metálica e entre elas também há solda. Havia 15 funcionários da empresa no local. Nesta obra, a estrutura metálica permite modificações e adaptações, peças podem ser reaproveitadas e há poucos resíduos. A estrutura de concreto não tem tanta flexibilidade. Foi verificado que compatibilização entre projetos e soluções detalhadas são resolvidas parte no projeto, parte na obra.

Enquanto a obra estava em andamento, decidiu-se comprar mais um terreno e fazer a ampliação da obra. Como ainda estava em andamento, não foi necessário fazer grandes modificações. No entanto, no terreno adquirido havia uma residência que foi totalmente demolida. Os entulhos foram retirados rapidamente e houve interesse apenas pela empresa para saber sobre o destino dos entulhos, mas a empresa contratada para retirado do material se responsabilizou e levou todo o entulho.

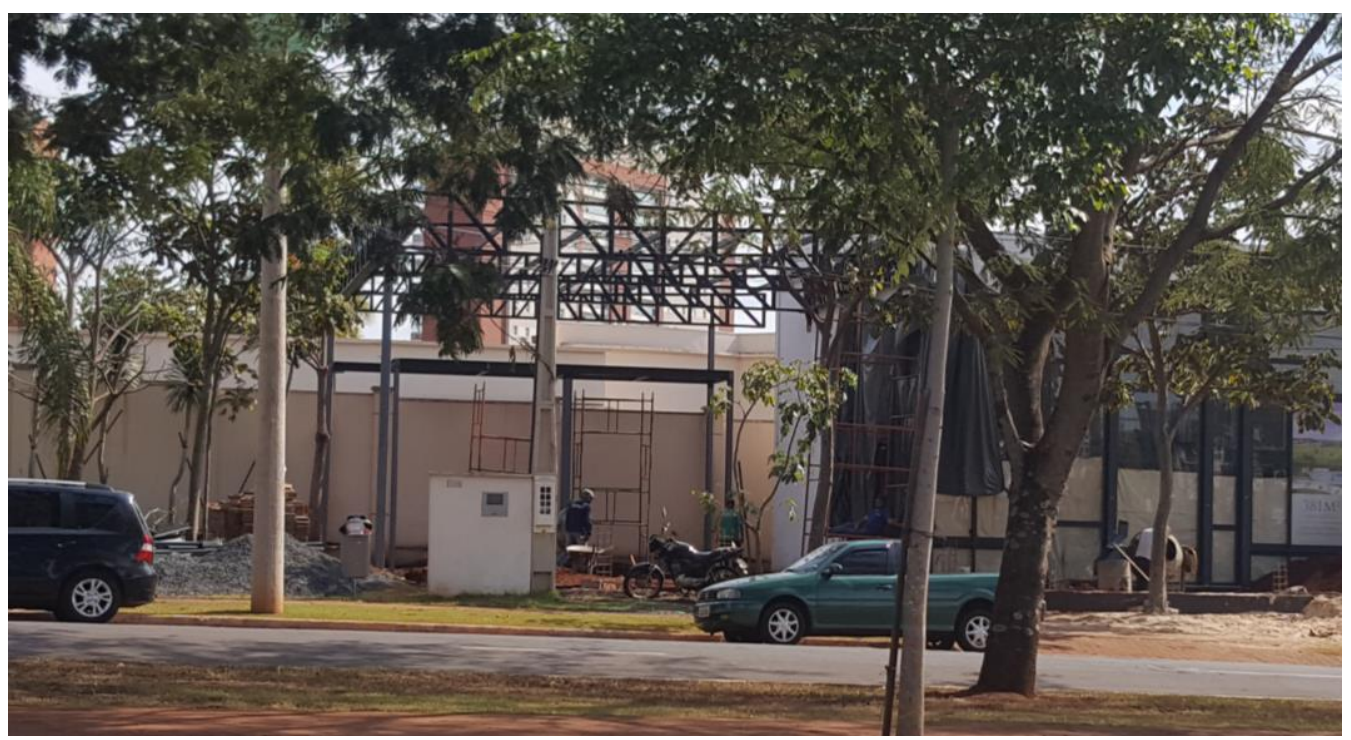

Figura 26 - Obra de ampliação de um restaurante em estrutura metálica Fonte: Autora 




Figura 27 - Obra de ampliação de um restaurante em estrutura metálica Fonte: Autora

As figuras 26 e 27 mostram a montagem da estrutura metálica de ampliação de um restaurante. Nesta obra foram observadas as conexões que são soldadas no local. No caso da ligação com a estrutura existente existem peças específicas para a ligação.

As figuras 28, 29 e 30 são da ampliação do supermecado, nelas é possivel observar a relação entre a estrutura pré-fabricada de concreto e a estrutura metálica.

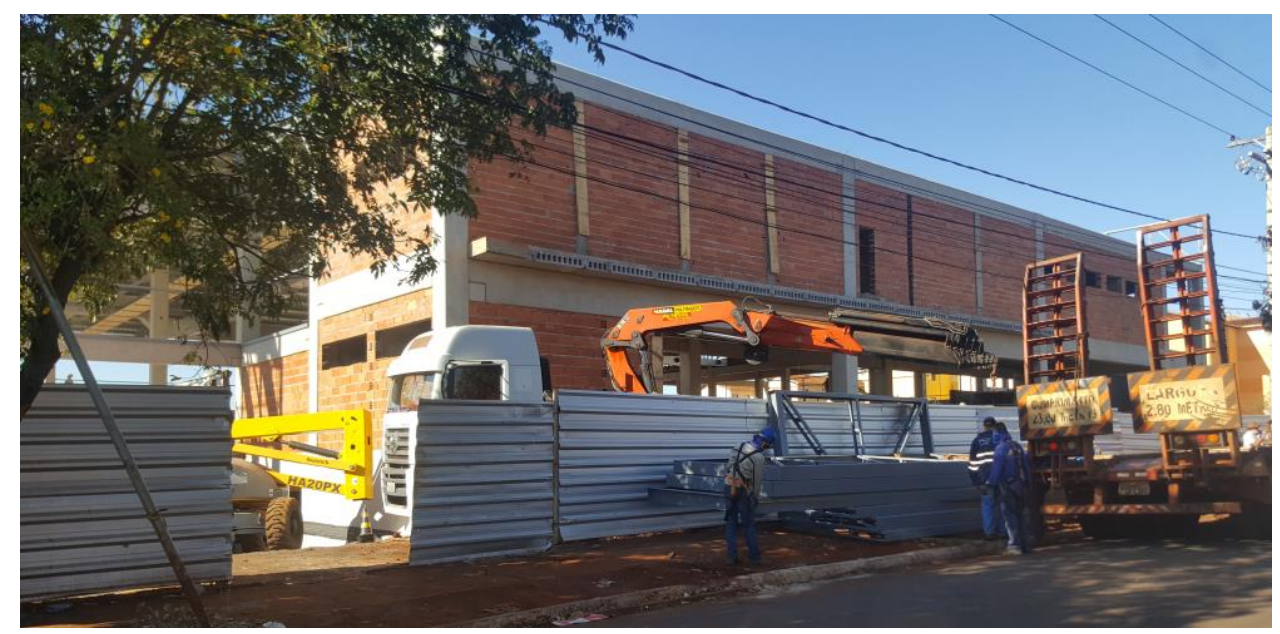

Figura 28 - Obra de ampliação do supermercado. Fachada em estrutura pré-moldada de concreto e vedação de alvenaria

Fonte: Autora 

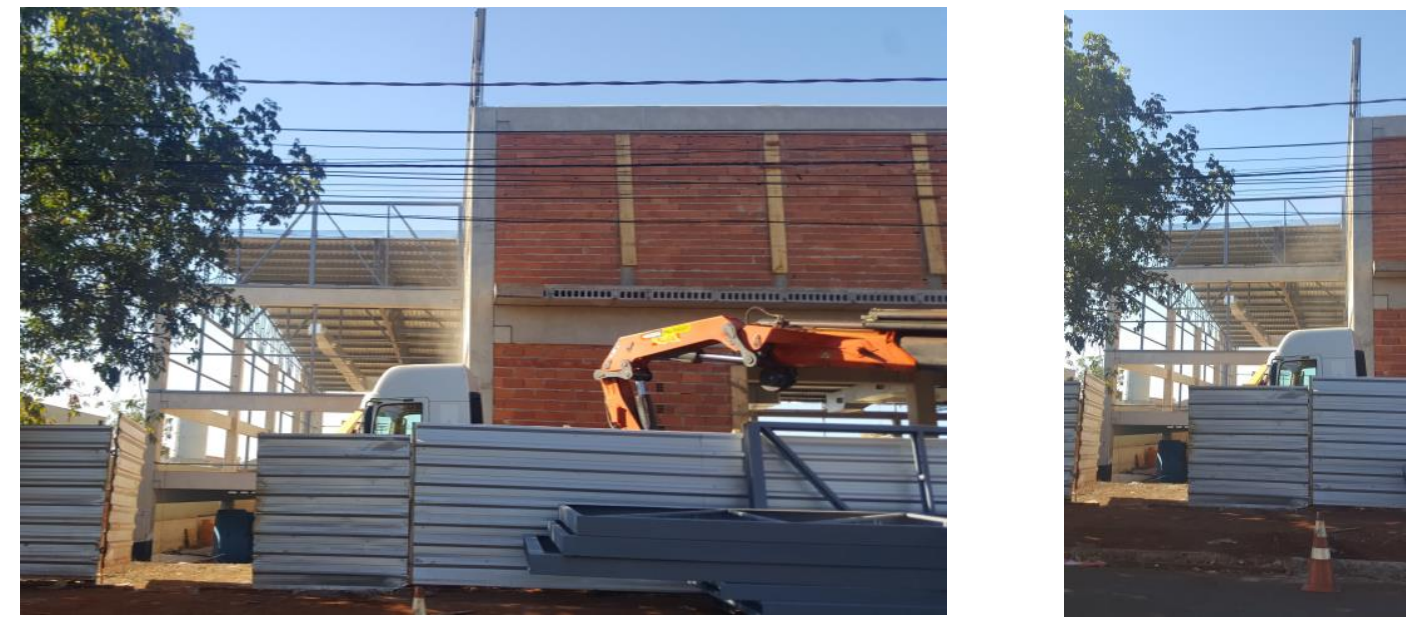

Figuras 29 e 30 - Obra de ampliação do supermercado. Lateral com instalação de estrutura metálica em andamento

Fonte: Autora

As figuras 32, 32 e 33 mostram a cobertura metálica do supermercado e ligações com a estrutura de concreto.
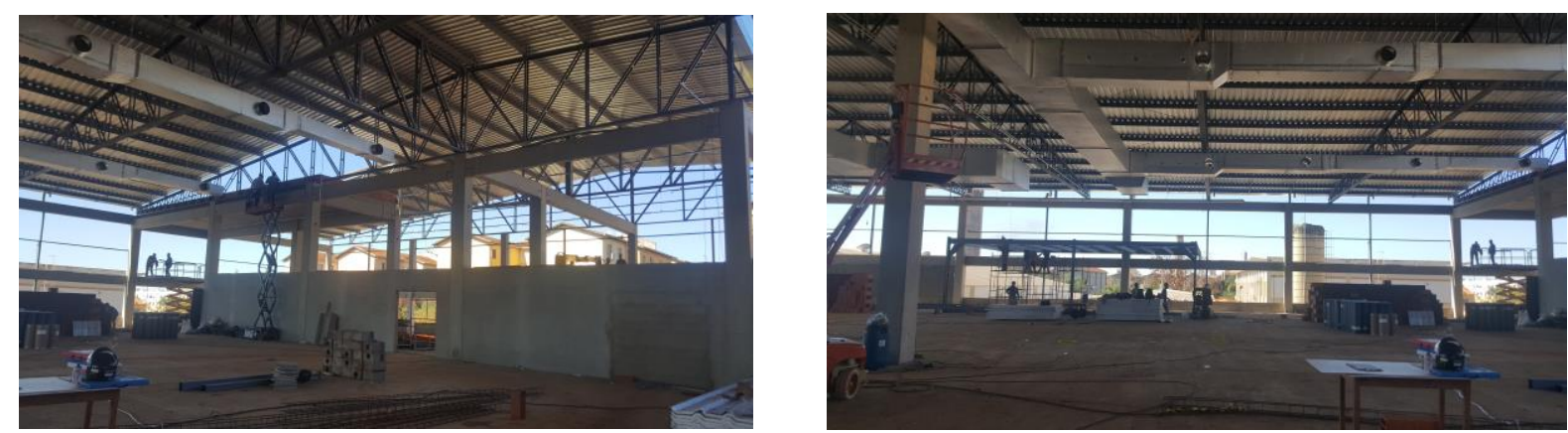

Figuras 31 e 32 - Vista interna da obra com foco nos elementos pré-moldados Fonte: Autora



Figura 33 - Detalhes dos encaixes dos elementos de concreto e metálicos Fonte: Autora 

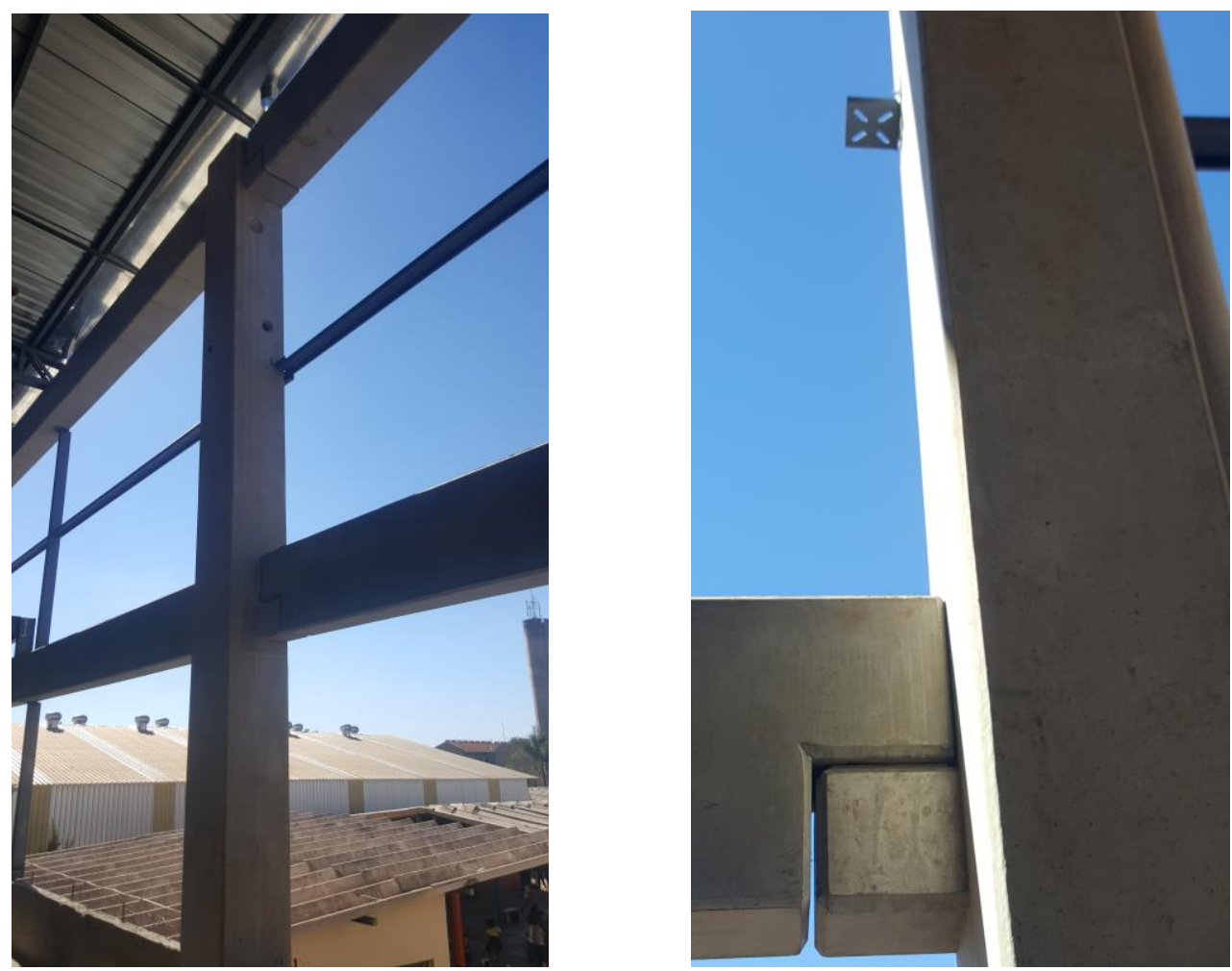

Figuras 34 e 35 - Detalhes dos encaixes dos elementos de concreto e metálicos Fonte: Autora

As figuras 34 e 35 demonstram detalhes construtivos das conexões entre vigas e pilares de concreto. As figuras 36 e 37 são referentes aos resíduos da montagem da estrutura metálica, demonstra que gera pouco resíduo quando compara a uma construção tradicional. Ainda assim é possível aproveitar estas peças em outras obras.
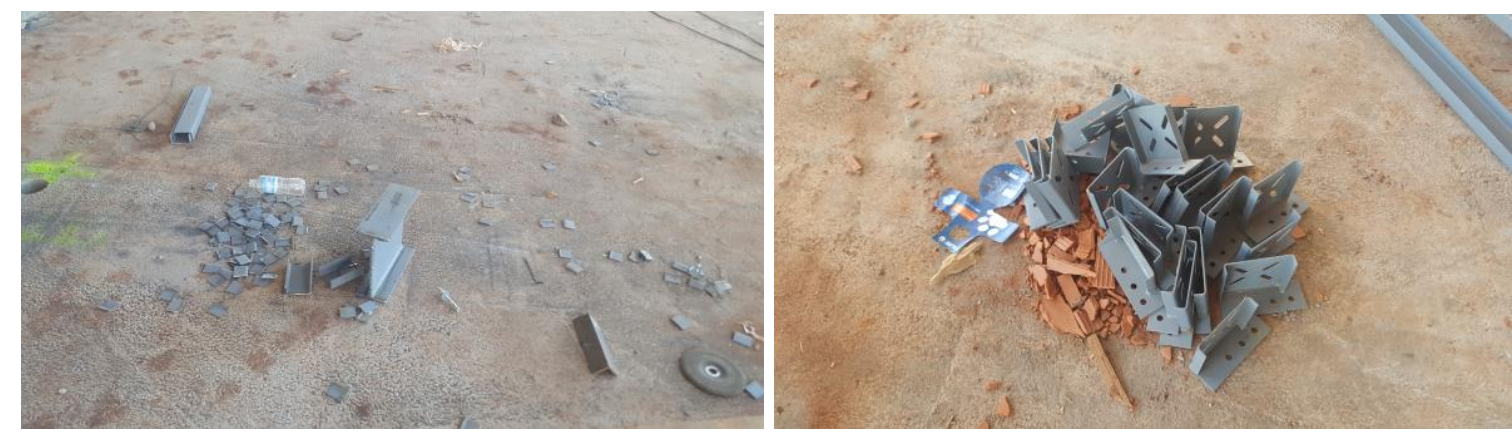

Figuras 36 e 37 - Resíduos da estrutura metálica Fonte: Autora 


\subsubsection{Estrutura em madeira laminada}

A construção com elementos de madeira em larga escala também pode se beneficiar do BIM, de maneira a aumentar a produtividade, reduzir pedidos de alteração e problemas durante a construção, obter maior qualidade e redução de desperdício de materiais. Além disso, o BIM pode ajudar a derrubar as barreiras que impedem que os produtos de madeira em massa sejam implementados na indústria de construção local e permitir que os membros da equipe de projeto explorem completamente as vantagens da construção maciça de madeira. Os resultados deste projeto de pesquisa fornecem uma série de recomendações que devem fornecer à indústria local as informações necessárias para implementar essa tecnologia com sucesso e tomar medidas para uma implementação mais ampla e abrangente do BIM e do DfMA no contexto da construção maciça de madeira (STAUB-FRENCH et al., 2018).

A madeira laminada apresenta grande potencial para a desmontagem; o material certificado é considerado sustentável por ser uma matéria-prima renovável e cumprir as exigências legais. A madeira é um material versátil, que tem grandes possibilidades de reutilização, pois se adapta a novos projetos; além disso, é possível removê-la e reutilizá-la sem muito desperdício (MATTARAIA, 2013).

As vantagens da construção em madeira pré-fabricada incluem uma alta precisão das condições construídas, cronogramas de projetos compactados e uma oportunidade para grandes quantidades de produção externa (STAUB-FRENCH et al., 2018).

Foi selecionada uma empresa especializada em estrutura feita com madeira laminada, por ser referência neste sistema estrutural. A empresa "D" trabalha com Madeira Laminada Colada (MLC), que é fabricada com madeira de eucalipto, proveniente de reflorestamentos e $100 \%$ certificada. Para a colagem é utilizado um adesivo à base de poliuretano. A empresa está há quase quarenta anos no mercado, trabalhando com madeira, e está localizada no interior de São Paulo. 
Em visita à empresa, foi relatado que esta tem a tradição de trabalhar com madeiras nativas; no entanto, nos últimos anos, o foco é o eucalipto, por apresentar alta resistência mecânica, durabilidade e boa ligação química entre as peças laminadas, mas essa ligação não é tóxica. A empresa geralmente trabalha com peças modulares, porém é possível encomendar peças com diferentes formatos e dimensões.

Foi enviado, por e-mail, o questionário para o engenheiro da empresa, o qual foi respondido também por e-mail. Além disso, foi realizada uma visita à fábrica, onde foi apresentado todo o processo da fabricação dos elementos e o material utilizado.

Em resposta ao questionário enviado ao engenheiro da empresa, ele afirma que nunca fizeram uma desmontagem das estruturas em madeira, apesar de a desmontagem ser considerada de forma intuitiva. A empresa trabalha com diversos tipos de ligações e todas são desmontáveis, com níveis variados de dificuldade. O engenheiro acredita ser possível desmontar a estrutura e reaproveitar; o maior desafio se encontraria nas conexões. Além disso, na remontagem, provavelmente seriam utilizados mais parafusos e pinos de maior diâmetro.

No desenvolvimento dos projetos, os profissionais utilizam o sistema CAD/CAM. No entanto, para modelagem e desenhos de produção, eles utilizam o software CARWOR, que é compatível com o BIM.

As figuras $38,39,40,41$ e 42 foram tiradas em visita a fábrica, demonstram detalhes da produção da estrutura de madeira e detalhes de peças utilizadas em encaixes. 


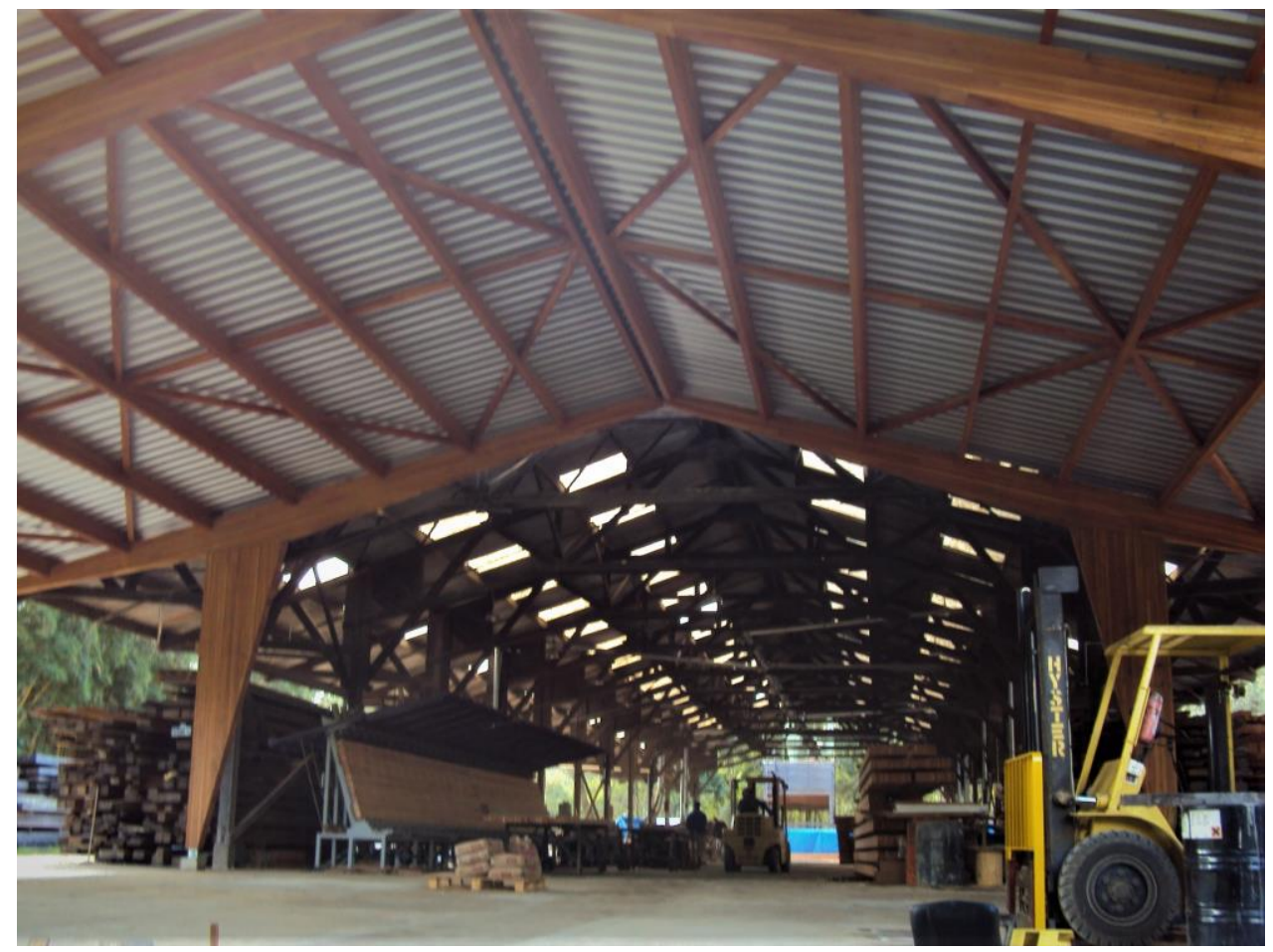

Figura 38 - Vista geral da fábrica

Fonte: Autora

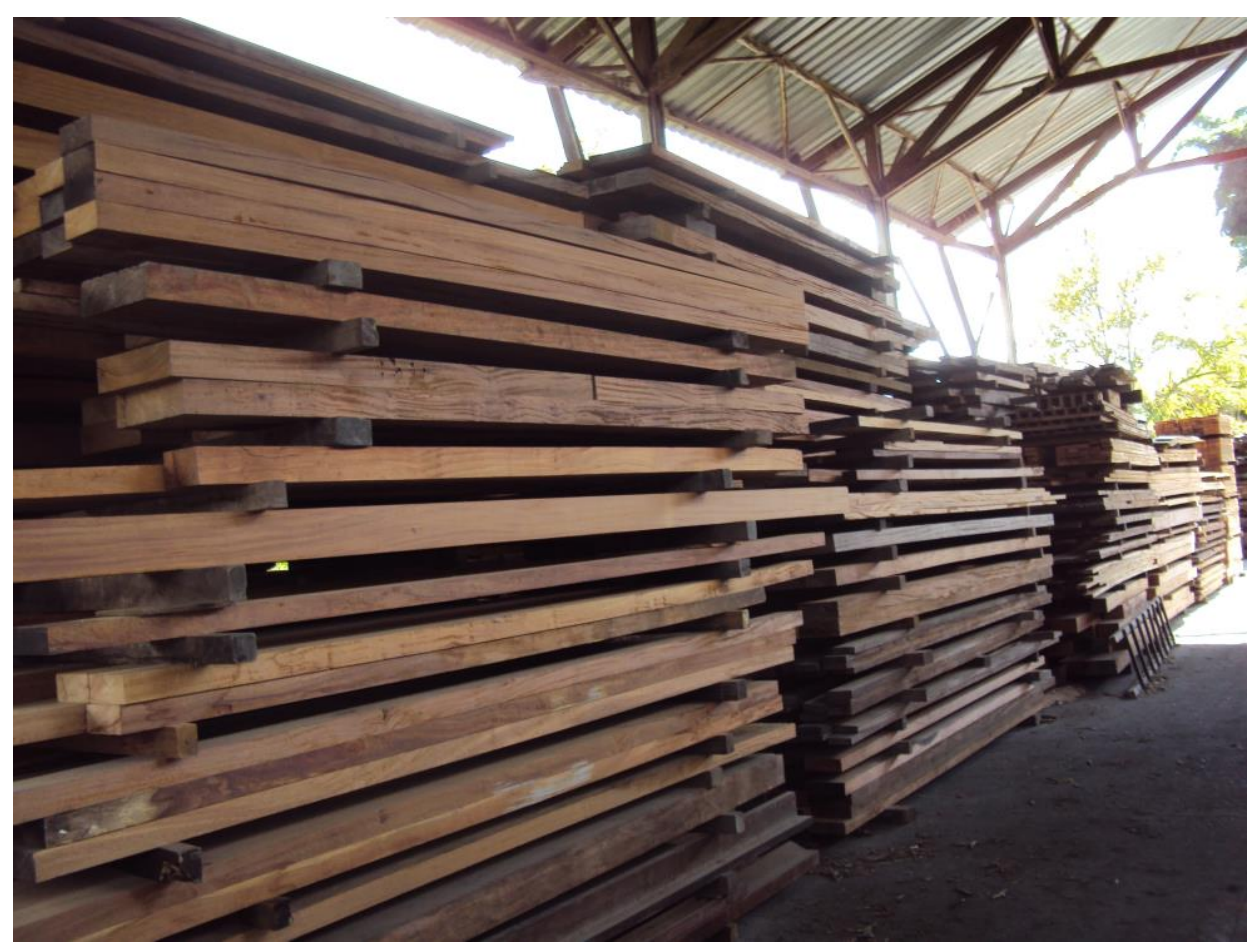

Figura 39 - Peças de madeira armazenadas na fábrica

Fonte: Autora 


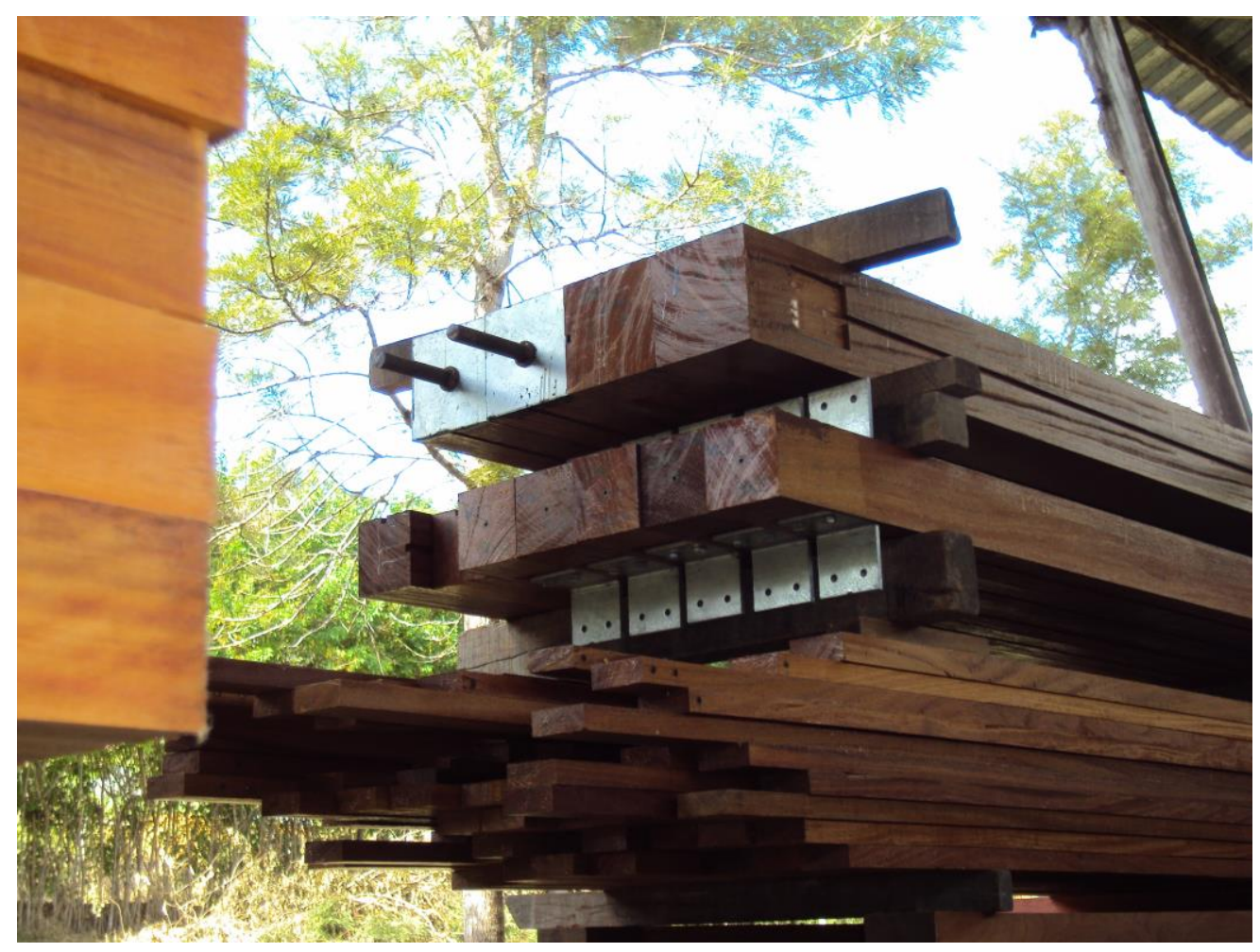

Figura 40 - Esperas para conexões inseridas nos elementos pré-fabricados Fonte: Autora



Figura 41 - Detalhe da ligação entre uma peça de madeira e a fundação Fonte: Autora 


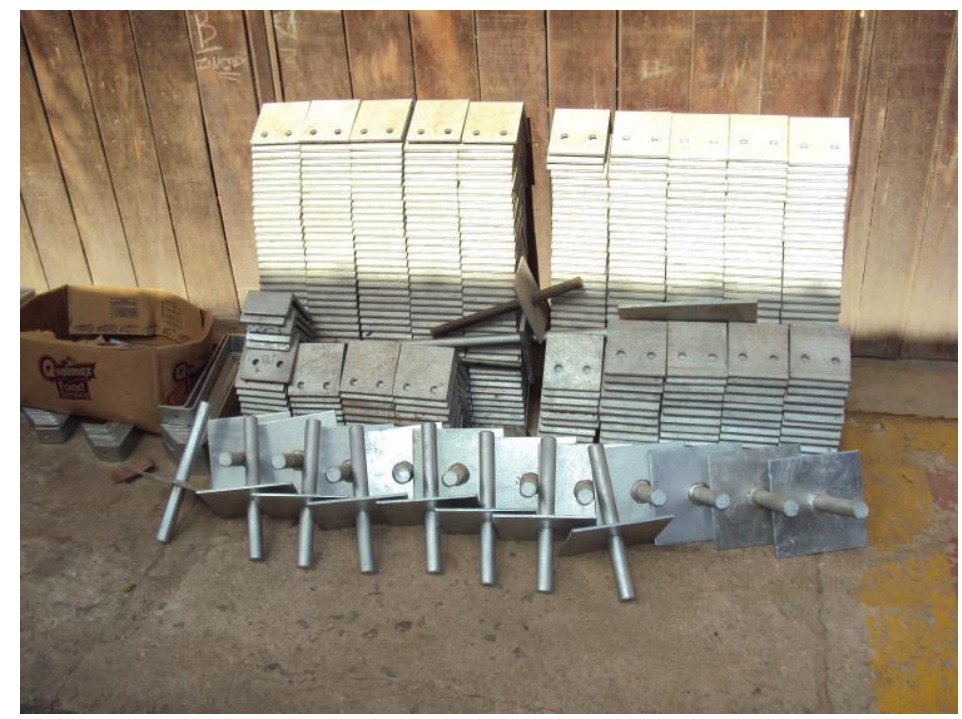

Figura 42 - Peças a serem inseridas nas peças de madeira Fonte: Autora

\subsection{Análise dos dados}

Com base nas empresas e obras visitadas, além das entrevistas realizadas, foi possível reunir informações sobre BIM e DfD importantes para o desenvolvimento desta pesquisa. Em relação ao BIM, todos os entrevistados do setor da construção civil, tanto no Reino Unido quanto no Brasil, estão familiarizados com o termo e utilizam softwares com esta tecnologia. Porém, cada empresa utiliza um software diferente. Os entrevistados afirmam que poderiam explorar mais recursos dos softwares e citam questões sobre adaptação dos projetos desenvolvidos em outros softwares.

Os materiais dos elementos industrializados analisados foram: concreto, madeira e aço. Cada material e cada elemento possuem características específicas que podem facilitar a futura desmontagem do edifício. No entanto, o conceito de desmontagem não é usual, apesar da preocupação com os resíduos gerados, até mesmo ao longo da produção e construção.

De maneira geral, os temas abordados nas entrevistas e visitas realizadas no Brasil são apresentados na tabela 6 . 
Tabela 6 - Temas abordados nas entrevistas e visitas

(Continua)

\begin{tabular}{|c|c|}
\hline Empresas & Temas abordados \\
\hline $\begin{array}{c}\text { A } \\
\text { (pré- } \\
\text { fabricado } \\
\text { de } \\
\text { concreto) }\end{array}$ & $\begin{array}{l}\text { - Dados gerais: } 30 \text { anos de mercado, } 200 \text { funcionários, localizada em } \\
\text { Américo Brasiliense-SP/obras comerciais, institucionais e galpões. } \\
\text { - Reunião para montagem e liberação da obra, transporte e montagem, } \\
\text { - Encaixes das peças: evitam soldas, preferem apoiadas e parafusadas, } \\
\text { - Peças padronizadas, mas permitem personalizar. } \\
\text { - Dimensões das peças de acordo com transporte e armazenamento. } \\
\text { - Dificuldade em adaptar projetos feitos para construção no local sem } \\
\text { considerar a utilização de elementos pré-fabricados. } \\
\text { - Integração do projeto é feita por diversos profissionais, que trabalham, ao } \\
\text { mesmo tempo, no mesmo arquivo (projeto, orçamento e produção). } \\
\text { - Usa o software Revit, pois facilita a visualização de interferências. } \\
\text { - Mesmo quando recebe projetos em outro software, passa para o Revit, } \\
\text { mas nem sempre é compatível. } \\
\text { - A modelagem 3D é muito utilizada, facilita a produção dos elementos e a } \\
\text { apresentação para clientes. } \\
\text { - Houve algumas dificuldades na transição para o software BIM. } \\
\text { - A desmontagem não é considerada. } \\
\text { - A flexibilidade do edifício é considerada apenas quando o cliente exige. } \\
\text { - Segue as normas. } \\
\text { - Alguns elementos seriam mais fáceis de serem desmontados (terças e } \\
\text { painéis de vedação, por serem parafusados ou encaixados), outros mais } \\
\text { difíceis (vigas e pilares, por serem grauteados); as lajes seriam mais difíceis, } \\
\text { por serem concretadas. } \\
\text { - Os elementos podem ser reciclados. } \\
\text { - As ferramentas utilizadas são guindaste, plataformas e ferramentas } \\
\text { manuais, como parafusadeiras. } \\
\text { - A exigência de selos verdes não é recorrente. } \\
\text { - Alguns clientes exigem ISO e verificam a procedência dos materiais. } \\
\text { - A expectativa de vida é de } 50 \text { anos. } \\
\text { - O material é resistente. } \\
\text { - O Revit auxilia na produção e integração entre engenharia e produção. } \\
\text { - Atividades realizadas: entrevista com dois engenheiros civis e dois } \\
\text { engenheiros de produção; visita a uma fábrica e um edifício comercial; visita } \\
\text { à fábrica. }\end{array}$ \\
\hline
\end{tabular}


\begin{tabular}{l} 
Empresas $\quad$ Temas abordados \\
\hline
\end{tabular} Brodowski-SP

- No começo atendia usinas de álcool, mas agora faz supermercados,

edifícios institucionais, até estádios de futebol, mas não fazem residências.

$\begin{array}{ll}\text { fabricado } & \text { é fornecido por terceiros. } \\ \text { - Realiza um Plano de Montagem para atender necessidades específicas. }\end{array}$

- A maioria dos elementos é padronizada.

de - Para a montagem, consideram-se estrutura, armaduras, esforços, ligações, local, condições de içamento e transporte.

concreto) - $\quad$ A desmontagem não é considerada, pois seria complicado reutilizar as peças.

- A maioria dos elementos é concretada ou grauteada; isso torna o edifício mais resistente, mas dificulta a desmontagem.

- Os elementos de vedação são apenas encaixados.

- Se o conceito de desmontagem fosse mais divulgado, seria possível buscar melhores soluções.

- As ligações são pontos importantes na montagem e desmontagem.

- Atualmente a reciclagem seria mais viável.

- O processo de desmontagem seria o inverso da montagem.

- O concreto é um material simples, resistente, bonito, não precisa de manutenção.

- A protensão permite peças menores, reduz o consumo de material e facilita o transporte.

- O pré-fabricado reduz o desperdício e permite maior controle da qualidade.

- Segue as normas para expectativa de vida, no entanto alguns elementos podem chegar a 100 anos.

- Utiliza o software BIM, o Allplan, mas recebe projetos em AutoCad, Revit

- Recebe projetos pouco detalhados e refazem no Allplan.

- Faz a compatibilização para evitar erros na construção.

- A utilização do Allplan melhorou o processo, mas a equipe teve que se adequar.

- Algumas ferramentas do software podem ser mais bem exploradas.

- Desenvolveu a própria biblioteca.

- Não houve exigência de selos verdes, nem cobranças sobre reciclagem e desmontagem.

- Há pouca geração de resíduos.

- Utiliza etiquetagem dos elementos produzidos para identificação.

- Atividades realizadas: visita à obra de um galpão, supermercado e estádio de futebol; entrevista com dois engenheiros civis e um engenheiro de produção; visita à fábrica.

C

- Dados gerais: localizada em Ribeirão Preto-SP, possui 90 funcionários; 0 dono da empresa atua há 27 anos no mercado.

- Trabalha com supermercados, galpões, residências, além de elementos como portões, beirais, marquises.

(estrutura - Faz projetos, fabrica elementos metálicos e os monta.

- Utiliza os softwares Tecnometal e Tekla, já utilizou o SDS, conhece pouco

metálica) o Revit (devido às limitações que tinha em relação à produção de elementos metálicos).

- Os elementos são padronizados, mas aceitam personalização.

- Os elementos são soldados na obra. 
(Conclusão)

\begin{tabular}{c|l}
\hline \multirow{2}{*}{ Empresas } & \multicolumn{1}{|c}{ Temas abordados } \\
\hline \multirow{3}{*}{ C } & $\begin{array}{l}\text { - As peças parafusadas são mais rápidas de serem montadas, porém } \\
\text { precisam ser mais precisas; também são mais viáveis de serem } \\
\text { desmontadas. } \\
\text { - Há pouca geração de resíduos. } \\
\text { metálica) } \\
\text { - Não há requisição de soluções para desmontagem, reutilização e } \\
\text { reciclagem. Algumas peças voltam para a fábrica, se não forem utilizadas, e } \\
\text { podem ser reutilizadas. } \\
\text { - Segue ISOs e legislações. } \\
\text { - Não fez obras certificadas por selos verdes. } \\
\text { - Atividades realizadas: visita à obra de um restaurante e um supermercado; } \\
\text { visita à fábrica; entrevista com um engenheiro civil, um arquiteto e um } \\
\text { empreiteiro. }\end{array}$ \\
\hline \multirow{5}{*}{ (estrutura } & $\begin{array}{l}\text { Gados gerais: há mais de 30 anos no mercado, localizada em Vargem } \\
\text { Ge made Paulista-SP. } \\
\text { - Peças laminadas de madeira duráveis. } \\
\text { - Ligação química na fabricação das peças laminadas, não tóxica. } \\
\text { - Diferentes formatos e dimensões. } \\
\text { - Nunca fez desmontagem. } \\
\text { - As ligações entre as peças são desmontáveis, com diferentes níveis de } \\
\text { dificuldade. } \\
\text { - Seria possível desmontar a estrutura e reaproveitar; o desafio estaria nas } \\
\text { conexões. } \\
\text { - Na remontagem, os parafusos e pinos seriam maiores. } \\
\text { - Utiliza o software CARWOR, sistema CAD/CAM, compatível com o BIM. } \\
\text { - Atividades realizadas: entrevista com um engenheiro civil; visita à fábrica; } \\
\text { visita a um condomínio de casas. }\end{array}$ \\
\hline
\end{tabular}

Fonte: Autora

Assim, é possível observar que diversos pontos em comuns foram comentados ao longo das entrevistas realizadas no Reino Unido e no Brasil. A utilização do BIM no desenvolvimento do projeto é um tema recorrente e todos concordam que traz benefícios. No entanto, diferentes softwares são utilizados; cada área busca o programa que melhor atende às suas necessidades específicas.

Com base na revisão bibliográfica e nos estudos apresentados, foi possível desenvolver a tabela 7, que mostra os principais agentes envolvidos no desenvolvimento do projeto, que considera a desmontagem e as fases envolvidas. 
Tabela 7 - Envolvimento dos profissionais e legislação nas etapas do desenvolvimento do projeto

\begin{tabular}{|c|c|c|c|c|c|c|c|c|c|c|}
\hline & $\begin{array}{l}\frac{0}{0} \\
\frac{0}{0} \\
\frac{0}{0} \\
\frac{d}{0} \\
\frac{0}{0}\end{array}$ & $\frac{\frac{0}{0}}{\frac{0}{0}}$ & 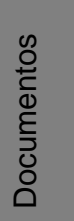 & 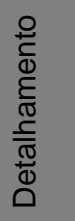 & 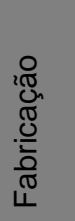 &  & 怘 & 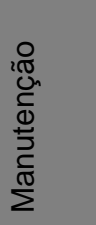 & 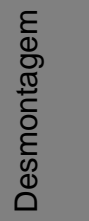 & 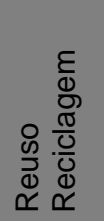 \\
\hline $\begin{array}{l}\text { Cliente } \\
\text { Idealizador }\end{array}$ & $X$ & $X$ & & & & & $X$ & $X$ & & \\
\hline $\begin{array}{l}\text { Legislação } \\
\text { Certificadores }\end{array}$ & $X$ & $X$ & $X$ & & & & & $X$ & $X$ & $X$ \\
\hline Arquiteto & $\mathrm{X}$ & $\bar{X}$ & $X$ & $X$ & & & & $X$ & $X$ & $X$ \\
\hline Engenheiros & $\mathrm{X}$ & $\mathrm{X}$ & $X$ & $\mathrm{X}$ & $\mathrm{X}$ & $X$ & & $\mathrm{X}$ & $\mathrm{X}$ & \\
\hline $\begin{array}{l}\text { Técnicos de } \\
\text { produção }\end{array}$ & $X$ & $X$ & $X$ & $X$ & $X$ & $X$ & $X$ & $X$ & $X$ & $X$ \\
\hline Construtores & & & & & & $X$ & & $X$ & $X$ & $X$ \\
\hline
\end{tabular}

Fonte: Autora

A questão dos resíduos sólidos é discutida; todos seguem as legislações em relação a produtos tóxicos e descarte de materiais, no entanto poucas soluções se apresentam em relação aos materiais provenientes da demolição. Em outros setores, a questão do descarte dos produtos é mais discutida, como verificado na entrevista com o profissional da empresa automobilística; no entanto, ainda faltam ações mais precisas, pois geralmente são voltadas apenas aos produtos tóxicos.

Portanto, a partir da análise das entrevistas realizadas no Reino Unido e no Brasil, foi possível identificar os principais temas abordados, a posição das empresas e entrevistados e pesquisar ferramentas que possam contribuir para a desmontabilidade do edifício e desenvolver propostas para facilitar o processo de projeto, conforme será apresentado no próximo capítulo. 


\section{BIM e ferramentas projetuais que contribuem para 0 Projeto para Desmontagem}

O BIM oferece inúmeras ferramentas projetuais que contribuem para o Projeto para Desmontagem e para medir o seu potencial de desmontabilidade. Softwares inteligentes têm a capacidade de detectar, de maneira automática, características dos materiais, elementos e do edifício como um todo. Além disso, é possível criar parâmetros para identificar os detalhes do projeto referente a desmontagem. Ferramentas como modelagem em 3D, simulação, compatibilidade de projeto, identificação de características específicas, cálculos, entre outras, também ajudam a identificar questões particulares a serem analisadas.

No caso da desmontagem, estas ferramentas auxiliam no desenvolvimento do projeto e na escolha de materiais que têm melhor classificação de desmontagem. Assim, a escolha do Revit para análise da pesquisa se deu por ser um software presente na revisão bibliográfica (como visto no capítulo 3) e por ter potencial para desenvolver as ferramentas para o Projeto para Desmontagem, relacionado ao BIM, o que foi constatado por meio das entrevistas realizadas (apresentadas no capítulo 4).

Além do mais, foram realizadas breves análises em diversos softwares ao longo da pesquisa, como Archicad, Tekla, Dynamo, Naviswork, AutoCad e Revit. A escolha destes softwares se deu devido ao conhecimento prévio da autora em relação à utilização deles, à possibilidade de instalar a versão de estudante e analisar suas ferramentas, possibilidade de participar de cursos e informações suficientes disponíveis nos websites dos fornecedores.

O Archicad, Tekla e AutoCad não foram utilizados nesta pesquisa, pelos seguintes motivos: o Archicad tem funções parecidas com o Revit, no entanto a autora tem maior conhecimento em Revit e trabalha com os softwares da Autodesk, o que facilita a interoperabilidade; em relação ao Tekla, a autora participou de um curso de apresentação do software e suas funcionalidades, no entanto foi muito específico para estrutura e cálculos estruturais, pois ele 
tem ferramentas que podem contribuir para o Projeto para Desmontagem, no entanto outros softwares voltados para arquitetos apresentam mais funções; o AutoCad apresenta algumas funcionalidades que podem contribuir, como modelagem em 3D, por exemplo, mas, quando comparado ao Revit, apresenta menos ferramentas BIM.

Portanto, o Revit apresentou as ferramentas necessárias e compatibilidade com diversos outros softwares, além de que conhecimento prévio da autora em relação ao software pode colaborar para o desenvolvimento deste trabalho. Ele apresenta ferramentas que podem contribuir para a desmontagem, como armazenamento sobre os elementos e produtos utilizados no edifício: modelo, ano, fábrica, tipo de material, informações sobre o ciclo de vida de cada elemento, montagem, entre outras. Também há a possibilidade de criar documentos relacionados às informações dos materiais e elementos utilizados. Além disso, há a opção de inserir as conexões entre as estruturas, assim fica documentado como são feitos os encaixes e demais detalhes construtivos. A visualização do projeto em modelo virtual 3D também pode contribuir para a programação da desmontagem.

Uma das ferramentas que foi explorada ao longo da pesquisa é a possibilidade de criar parâmetros de famílias e elementos do projeto. A figura 43 apresenta um exemplo de criação de parâmetros de um dos elementos utilizados, o que é relevante para a pesquisa, pois é possível criar parâmetros relacionados à desmontagem da estrutura e demais elementos. 


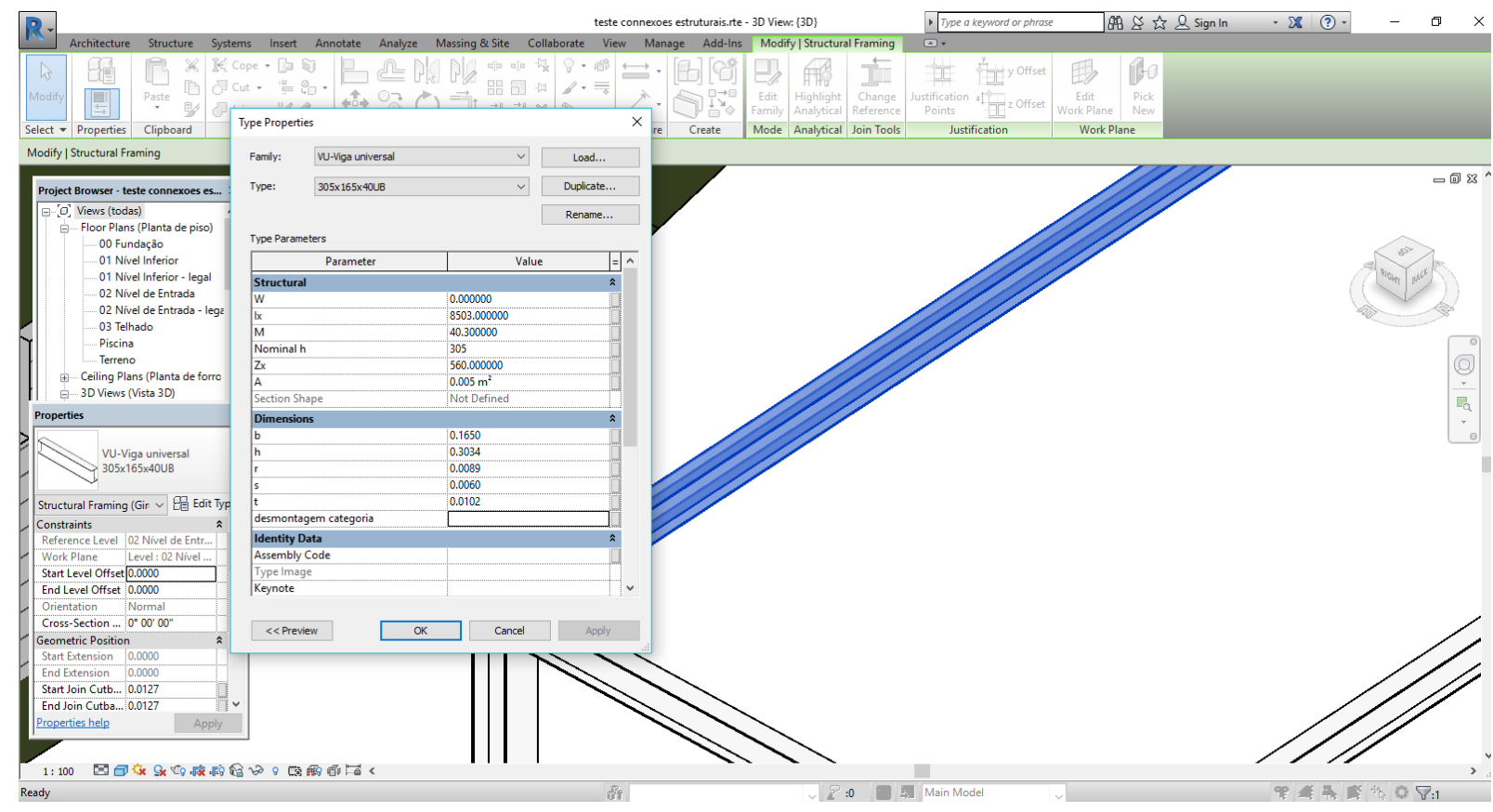

Figura 43 - Criação de parâmetros para os elementos Fonte: https://www.youtube.com/watch?v=gtKZWZpuW3I (acesso outubro/2016)

Outro software analisado é o Naviswork 2016, que permite importar o modelo desenvolvido no Revit; assim, os softwares são compatíveis. Por meio de conhecimentos básicos do software, é possível verificar suas ferramentas. Pode ser utilizado para criar simulações da construção do edifício e para simular a desmontagem. A figura 44 demonstra a simulação, por meio de uma linha do tempo (timeline), da construção de uma residência apresentada no site do programa. 


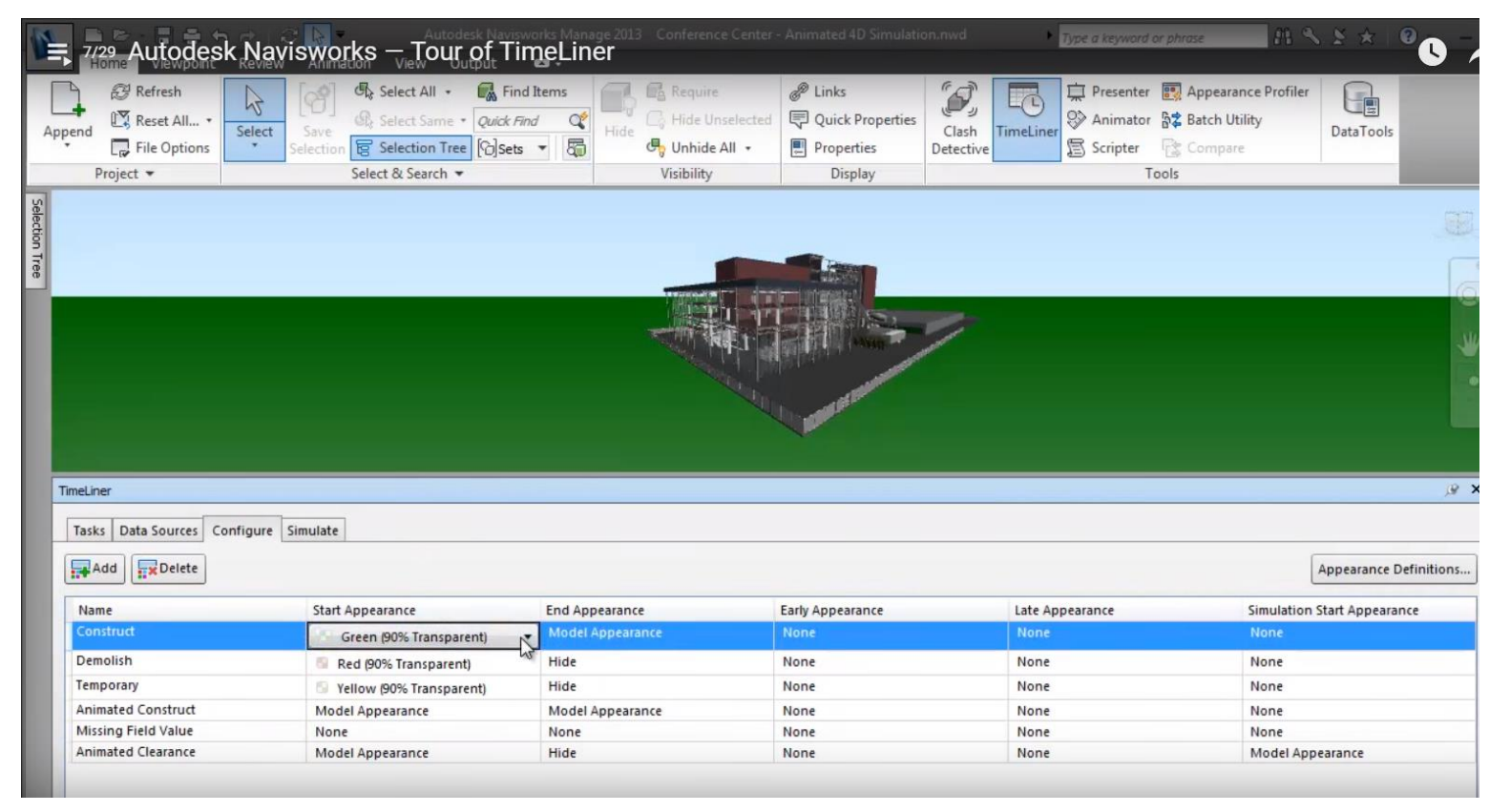

Figura 44 - Exemplo de linha do tempo desenvolvida a partir do modelo 3D Fonte:

https://www.youtube.com/watch?v=DSpflqgq4pE\&index=7\&list=PL87AF6290D6BDFABA (acesso 11/2016)

As figuras de 45 a 50 mostram as etapas da construção de uma residência. O modelo foi desenvolvido pela autora e utilizado para explorar esta ferramenta do software. A visualização das etapas de construção de um edifício auxilia na organização e até mesmo nas tomadas de decisões para agilizar no processo de construção, mas também pode ser utilizada na desmontagem.

Para uma melhor análise do software, um modelo foi importado do Revit para o Naviswork, para criar uma simulação de desmontagem. As figuras 45 a 50 demonstram as diferentes fases das etapas do edifício, mas a intenção, ao longo da pesquisa, é buscar uma maneira de simular as etapas de desmontagem. 

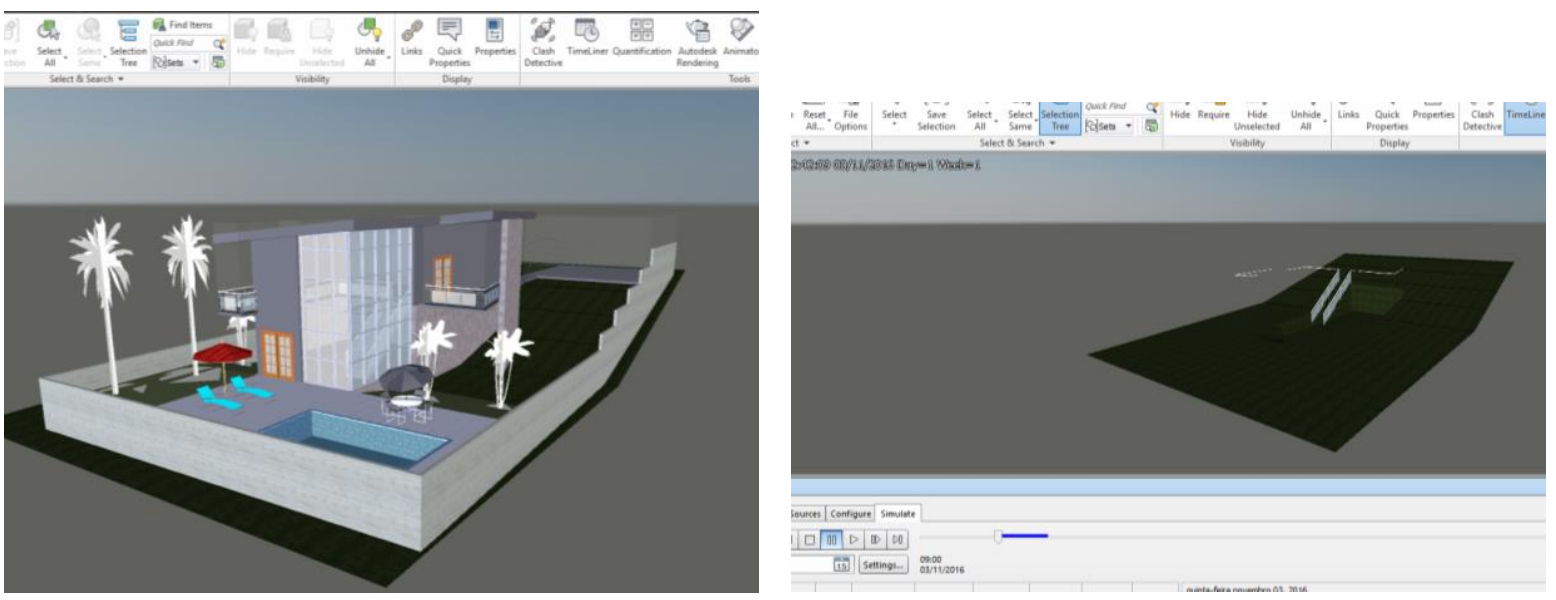

Figura 45 - Modelo em 3D importado do Revit e Figura 46 - Etapas iniciais da construção Fonte: Autora
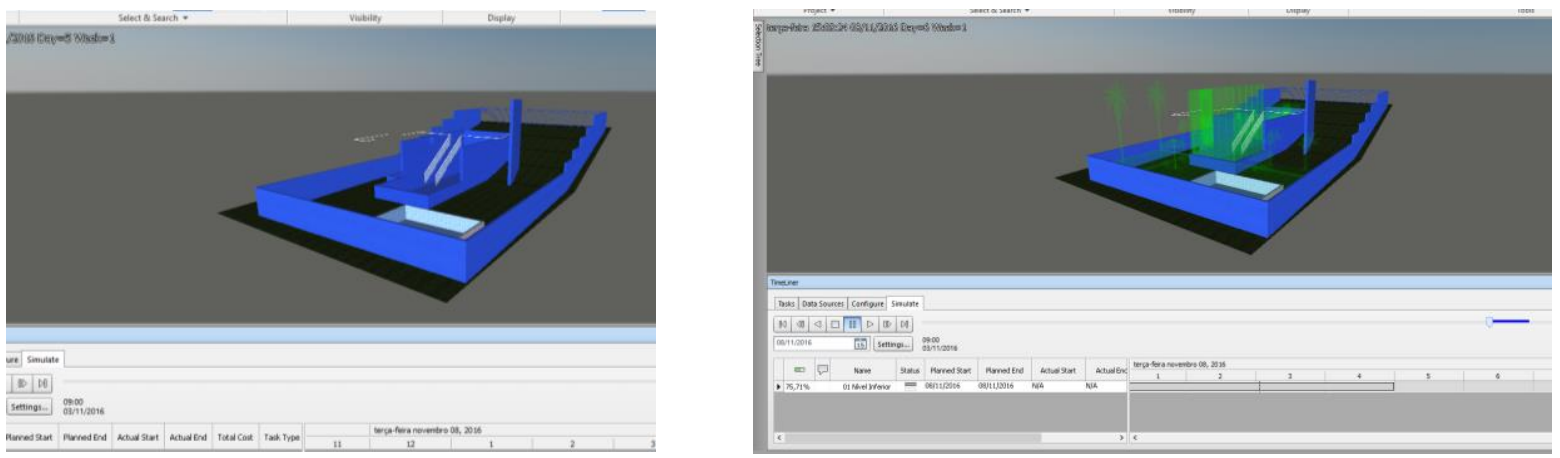

Figura 47 - Etapas seguintes da construção e Figura 48 - Etapas seguintes da construção Fonte: Autora
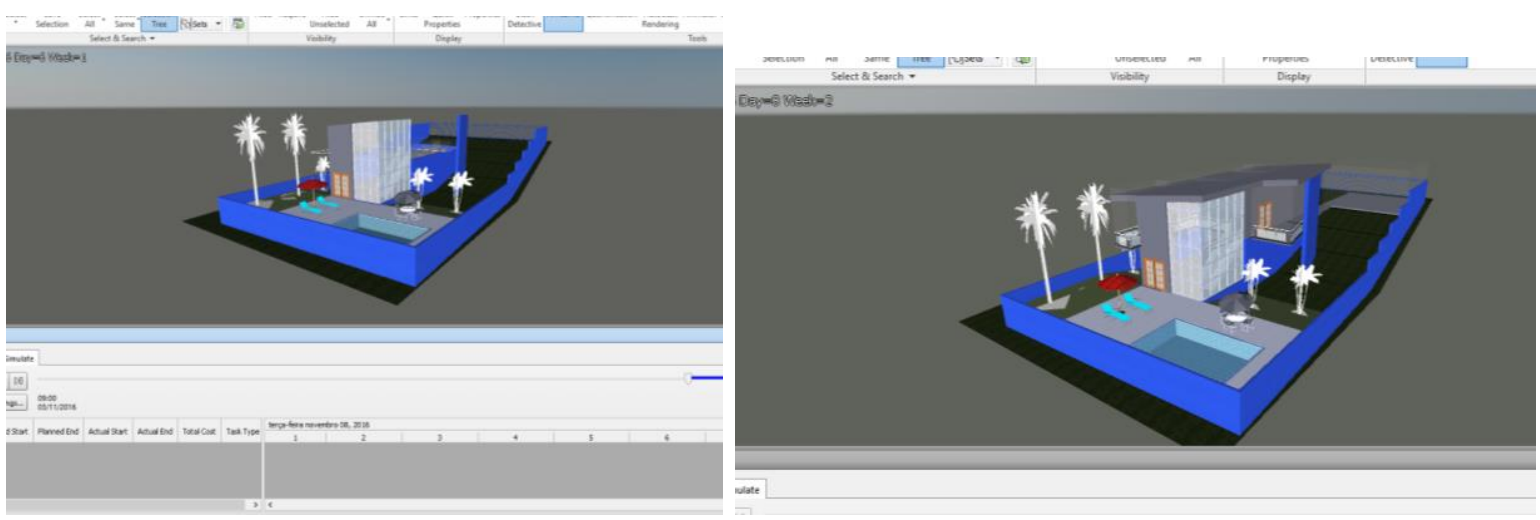

Figura 49 - Etapas seguintes da construção e Figura 50 - Etapas seguintes da construção Fonte: Autora

Outro software analisado é o Dynamo, que está diretamente ligado ao Revit, por ser um plugin que pode ser instalado no software e auxiliar no processo de projeto. Este aplicativo permite criar parâmetros para o projeto, assim facilitando a padronização de elementos. 
Segundo a Autodesk (2016):

O Dynamo fornece um ambiente de programação visual que é acessível para os projetistas, permitindo que você crie visualmente a lógica que define a geometria e o comportamento de elementos e dados do Revit. A interface de programação gráfica do Dynamo para projetos de cálculo está totalmente integrada e é instalada com o Revit, o que torna ainda mais fácil para você tirar vantagem da potência da API do Revit.

O conhecimento em Revit facilita o entendimento do Dynamo, no entanto é um programa complexo e são necessários dedicação e estudo específico para entender seu funcionamento. Em consulta a informações disponibilizadas pela empresa que comercializa o software, em seu site e vídeos foi possível observar que é indicado para o desenvolvimento de desenhos paramétricos, no entanto seriam necessárias outras ferramentas para o desenvolvimento do artefato deste trabalho. Porém, por ser um plugin do Revit, também há a possibilidade de acrescentar informações sobre desmontagem por meio deste programa em um futuro trabalho.

A partir destas análises, foi desenvolvida a tabela 8, que apresenta as ferramentas avaliadas e disponíveis em cada software que contribuem para a análise das possibilidades de desmonte do edifício. Assim, o Naviswork pode ser utilizado para fazer simulação de montagem/construção e desmontagem da obra. O Revit permite desenvolver inventários e memoriais por conter informações específicas de cada elemento utilizado. O Dynamo está relacionado a rotinas e programações específicas. Além disso, estes três programas podem trabalhar de maneira complementar e contribuir para o desenvolvimento do projeto. 
Tabela 8 - Ferramentas presentes nos softwares BIM que auxiliam o DfD

\begin{tabular}{|c|c|c|c|c|c|c|c|}
\hline  & 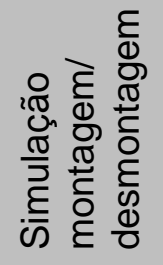 & 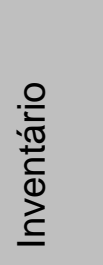 & 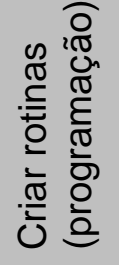 & 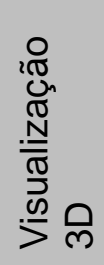 & 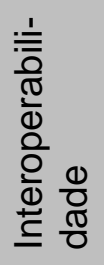 & 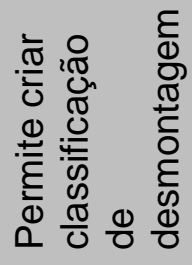 & 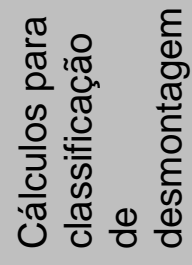 \\
\hline Revit 2016 & & $x$ & & $\mathrm{X}$ & $x$ & $x$ & $x$ \\
\hline $\begin{array}{l}\text { Naviswork } \\
2016\end{array}$ & $x$ & & & $x$ & $x$ & & \\
\hline $\begin{array}{l}\text { Dynamo } \\
1.3 .1\end{array}$ & & & $x$ & $x$ & $x$ & & \\
\hline
\end{tabular}

Fonte: Autora

Os três softwares permitem visualização em 3D e possuem interoperabilidade. No entanto, conforme as análises realizadas pela autora, o Revit apresentou melhores possibilidades para criar a classificação de desmontagem e calculá-la, devido à facilidade de inserir parâmetros, visualização do projeto, reunião de informações e realização de cálculos específicos.

Além das ferramentas, é importante ressaltar as questões específicas dos materiais e os elementos a serem avaliados. Diversos pontos podem ser analisados para classificar a desmontagem (MATTARAIA, 2013), no entanto alguns pontos são essenciais para facilitar o processo e garantir a qualidade dos materiais. No capítulo 3, foram abordadas as questões a serem consideradas para a desmontagem de maneira mais detalhada e neste item são ressaltados alguns dos principais pontos relacionados ao BIM que têm maior impacto no sucesso da desmontagem e, consequentemente, na classificação desenvolvida. Assim, é importante ressaltar os critérios que serão analisados relacionados às ferramentas dos softwares que serão utilizadas.

O primeiro seriam as conexões entre os materiais que podem ser encaixados, conectados por meio de algum elemento físico, ligações químicas ou soldadas. As peças encaixadas são as mais indicadas para facilitar a desmontagem, no entanto exigem bastante cuidado na hora do detalhamento, para que sejam seguras. As peças ligadas por parafusos que podem ser 
retirados com ferramentas manuais também podem facilitar a desmontagem, desde que não danifiquem os materiais na retirada dos conectores. Além dessas, existem as ligações químicas e peças soldadas, que são consideradas as mais difíceis de serem desmontadas, pois normalmente causam danos aos elementos e precisam de máquinas para separá-las, assim não são indicadas para a desmontagem, pois diminuem as chances de reutilização, mas ainda podem ser consideradas para a reciclagem. A figura 51 apresenta os principais tipos de conexões utilizados nas estruturas.



Figura 51 - Tipos de conexões

Fonte: Autora

A segunda questão a ser considerada, para avaliação da classificação de desmontagem, são os materiais que devem ser resistentes para montagem e desmontagem, além de ter dimensões padronizadas, conforme indicado na figura 52. Isso facilita a racionalização do processo, tornando-o mais eficiente, rápido e econômico.

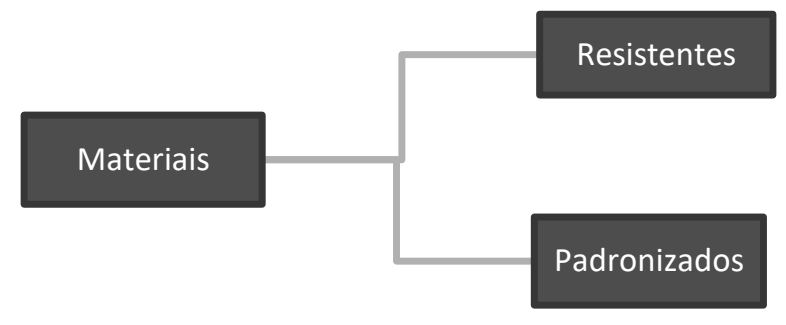

Figura 52 - Tipos de materiais

Fonte: Autora

Para facilitar o processo, é importante analisar qual sistema é mais econômico e rápido para ser desmontado sem danificar os materiais; além disso, quanto antes for considerada esta questão na concepção do projeto, melhores resultados serão obtidos no futuro. Assim, os softwares podem auxiliar no processo, pois podem providenciar informações importantes ao 
longo do desenvolvimento do projeto. Por exemplo, inserir uma viga metálica que já contenha informações sobre seu material, fabricação, seu ciclo de vida, conexões, entre outros, facilita a análise da desmontagem pelos projetistas.

Além disso, a simulação da desmontagem por softwares BIM pode facilitar o processo, mesmo em edifícios que foram construídos sem a utilização do BIM, pois pode facilitar também a manutenção. A figura 53 representa estas duas questões abordadas em relação ao BIM e que contribuem com o DfD.



Figura 53 - Possibilidades do BIM em relação ao DfD Fonte: Autora

Alguns projetistas veem como vantagem utilizar BIM para auxiliar na produção de elementos pré-fabricados (como constatado nas entrevistas apresentadas no capítulo 4). Isso também auxilia na desmontagem, pois as informações necessárias para a fabricação ficam salvas no arquivo do projeto.

Portanto, a escolha do software Revit e as características dos materiais e elementos analisados foram questões relevantes para o desenvolvimento dos parâmetros que podem contribuir para a desmontagem. Estes temas foram estudados em relação às ferramentas que cada software apresenta para colaborar para a análise da desmontagem, visando a obter melhores resultados na desconstrução e até mesmo na manutenção do edifício. Assim, as conexões, durabilidade dos materiais, dimensões, ferramentas utilizadas na montagem e desmontagem, e padronização dos elementos são fundamentais no desenvolvimento da classificação de desmontagem, que será apresentada mais detalhadamente a seguir. 


\subsection{Definição da Classificação de Desmontagem}

Foram selecionados materiais e elementos amplamente utilizados na construção civil com o objetivo de estipular uma classificação de desmontagem para cada elemento. A classificação foi desenvolvida com a intenção de explorar os recursos BIM, as possibilidades do software e testar sua aplicação. Os edifícios possuem grande variedade de elementos, diversos projetos e envolvimento de diversos profissionais; assim, não é o objetivo desta tese ditar a classificação de desmontagem de cada elemento que compõe o edifício e todos os materiais que possam ser utilizados, de maneira definitiva, e sim explorar as possibilidades que possam servir de diretrizes para facilitar as tomadas de decisões ao longo do desenvolvimento do projeto para uma desmontagem mais eficaz e dinâmica.

Os materiais escolhidos para a montagem de uma tabela com a classificação de desmontagem são bastante usuais na construção civil no Brasil, de onde provêm mais referências, mas também em diversos locais do mundo, como Reino Unido, conforme informações da revisão bibliográfica e das entrevistas. Outros materiais podem ser adequados à tabela conforme a necessidade da análise de desmontagem e seguir os parâmetros de desmontagem. A classificação de desmontagem foi desenvolvida com base nas informações reunidas das entrevistas e das visitas a obras e empresas, conforme relatado no capítulo prático, sobre as análises práticas. Além disso, foi realizada a revisão bibliográfica sobre desmontagem, montagem, reutilização e reciclagem, segundo foi apresentado no capítulo 3.

De acordo com Mattaraia, Martins e Fabrício (2016), a escolha do material tem influência direta na desmontagem, pois pode ajudar ou atrapalhar o processo. Os materiais mais utilizados atualmente dificultam a desmontagem, como o concreto armado ou estruturas metálicas, as paredes de alvenaria e fiação elétrica embutida. A madeira, o aço, a alvenaria e o concreto são alguns dos materiais mais encontrados em edifícios na atualidade (MATTARAIA; MARTINS e FABRÍCIO, 2016). 
Dessa maneira, foram analisadas as características dos materiais abaixo para a definição da classificação de desmontagem. No entanto, a tabela permite alterações, como a inclusão de outros materiais e até alteração da classificação de desmontagem, caso o projetista ou algum órgão que pretenda utilizar o processo para avaliação da desmontagem julgue necessário.

A tabela 9 apresenta os materiais abordados nesta tese e sua classificação de desmontagem, além do "peso" para a média ponderada. A tabela é um exemplo, um ponto de partida para classificar os materiais conforme a possibilidade de desmontagem de cada um. A classificação de desmontagem varia entre 0 e 1, sendo que, quanto mais próximo a 1, maior a possibilidade de desmontagem e reuso.

Além disso, foi estipulado um peso entre 1 e 3 para calcular a classificação final do edifício. Normalmente, o edifício é construído em camadas, como estrutura, vedação e divisórias. As divisórias são mais fáceis de serem removidas, pois geralmente não comprometem a alvenaria e vedação, enquanto a retirada da estrutura influencia diretamente nas divisórias e vedações. Além disso, é mais rápido retirar as divisórias, uma vez que são mais leves que a estrutura, e a escala é menor. Portanto, as estruturas têm o peso 01 e as vedações verticais internas peso 03. As vedações verticais externas têm peso intermediário, pois, quando retiradas, podem degradar as divisórias, mas agridem menos as estruturas, assim o peso é 02. Assim a definição dos pesos foi feita de acordo com as camadas e os danos que podem causar nas outras camadas na desmontagem.

A seguir é apresentada a tabela 9 com a Classificação de Desmontagem; logo em seguida, são apresentados os materiais abordados, suas características e justificativa para a classificação e peso, com base no que foi observado nos estudos exploratórios apresentados. Posteriormente, são apresentadas as características que foram consideradas para o desenvolvimento da tabela. 


\begin{tabular}{|c|c|c|c|}
\hline $\begin{array}{l}\text { Materiais e } \\
\text { elementos }\end{array}$ & $\begin{array}{c}\text { Classificação } \\
\left(\begin{array}{l}0 \text { a 1) }\end{array}\right.\end{array}$ & $\begin{array}{l}\text { Peso para } \\
\text { média } \\
\text { ponderada }\end{array}$ & Características \\
\hline \multicolumn{4}{|l|}{$\begin{array}{l}\text { ESTRUTURA } \\
\text { PRINCIPAL }\end{array}$} \\
\hline $\begin{array}{l}\text { Concreto } \\
\text { armado } \\
\text { moldado no } \\
\text { local }\end{array}$ & 0,1 & 1 & $\begin{array}{l}\text { - Ligações químicas } \\
\text { - Necessita de equipamentos pesados. } \\
\text { - Difícil manuseio, transporte e armazenamento } \\
\text { - Alto custo, trabalho e tempo } \\
\text { - Geralmente é demolido. } \\
\text { - Pode ser reciclado, mas para outros usos. } \\
\text { - Não pode ser reutilizado com a função original. }\end{array}$ \\
\hline $\begin{array}{c}\text { Elementos } \\
\text { pré-fabricados } \\
\text { de concreto } \\
\text { protendido }\end{array}$ & 0,3 & 1 & $\begin{array}{l}\text { - Algumas ligações podem ser desfeitas. } \\
\text { - Peças são produzidas considerando transporte e } \\
\text { armazenamento. } \\
\text { - Podem se quebrar na desmontagem. } \\
\text { - Equipamentos utilizados na montagem podem ser } \\
\text { usados na desmontagem. } \\
\text { - A maioria das ligações é química. } \\
\text { - Podem ser reciclados, mas para outros usos. } \\
\text { - Dificilmente são reutilizados. }\end{array}$ \\
\hline $\begin{array}{l}\text { Metálica } \\
\text { soldada }\end{array}$ & 0,6 & 1 & $\begin{array}{l}\text { - Elementos pré-fabricados facilitam o transporte e } \\
\text { armazenamento. } \\
\text { - Equipamentos utilizados na montagem podem ser } \\
\text { usados na desmontagem. } \\
\text { - Resiste à desmontagem. } \\
\text { - Ligacaão por solda dificulta a separação das peças e pode } \\
\text { causar danos. } \\
\text { - Pode ser reciclada. } \\
\text { - Pode ser reutilizada, mas não é usual. }\end{array}$ \\
\hline $\begin{array}{l}\text { Metálica } \\
\text { parafusada }\end{array}$ & 0,8 & 1 & $\begin{array}{l}\text { - Elementos pré-fabricados facilitam } \circ \text { transporte e } \\
\text { armazenamento. } \\
\text { - Equipamentos utilizados na montagem podem ser } \\
\text { usados na desmontagem. } \\
\text { - Resiste à desmontagem. } \\
\text { - Ligação por parafusos facilita a separação das peças e } \\
\text { reduz os danos. } \\
\text { - Pode ser reciclada. } \\
\text { - Pode ser reutilizada. }\end{array}$ \\
\hline Madeira & 1,0 & 1 & $\begin{array}{l}\text { - Elementos pré-fabricados facilitam o transporte e } \\
\text { armazenamento. } \\
\text { - Equipamentos utilizados na montagem podem ser } \\
\text { usados na desmontagem. } \\
\text { - Resiste à desmontagem. } \\
\text { - Ligações mecânicas através de peças ou encaixes } \\
\text { facilita a separação dos elementos reduz os danos } \\
\text { - Pode ser reciclada. } \\
\text { - Pode ser reutilizada. } \\
\text { - É um material sustentável, desde que certificada e sem } \\
\text { aditivos químicos danosos ao meio ambiente. }\end{array}$ \\
\hline
\end{tabular}




\begin{tabular}{|c|c|c|c|}
\hline $\begin{array}{l}\text { Materiais e } \\
\text { elementos }\end{array}$ & $\begin{array}{c}\text { Classificação } \\
\qquad(0 \text { a 1) }\end{array}$ & $\begin{array}{l}\text { Peso para } \\
\text { média } \\
\text { ponderada }\end{array}$ & Características \\
\hline \multicolumn{4}{|l|}{$\begin{array}{l}\text { VEDAÇÃO } \\
\text { VERTICAL } \\
\text { EXTERNA }\end{array}$} \\
\hline Vidro & 0,3 & 2 & $\begin{array}{l}\text { - Requer muito cuidado na desmontagem e se } \\
\text { quebra com facilidade. } \\
\text { - No armazenamento e no transporte também } \\
\text { necessita de cuidados para não quebrar. } \\
\text { - Geralmente é descartado quando há } \\
\text { demolições e reformas. } \\
\text { - Não costuma ser reaproveitado. }\end{array}$ \\
\hline $\begin{array}{l}\text { Alvenaria de } \\
\text { tijolos com } \\
\text { furos }\end{array}$ & 0,4 & 2 & $\begin{array}{l}\text { - Não resiste à desmontagem. } \\
\text { - Geralmente é quebrada, removida e } \\
\text { descartada. } \\
\text { - Pode ser reciclada, mas não reutilizada. }\end{array}$ \\
\hline $\begin{array}{l}\text { Alvenaria de } \\
\text { tijolos maciços }\end{array}$ & 0,8 & 2 & $\begin{array}{l}\text { - Dependendo do modelo e da argamassa que } \\
\text { foram utilizados podem facilitar ou dificultar o } \\
\text { processo. } \\
\text { - É um material pequeno que pode ser removido } \\
\text { com poucas ferramentas e manualmente. } \\
\text { - Fácil de transportar e armazenar. } \\
\text { - Pode ser reutilizada da mesma maneira que o } \\
\text { uso original. }\end{array}$ \\
\hline $\begin{array}{l}\text { Elementos } \\
\text { pré-fabricados } \\
\text { de concreto }\end{array}$ & 0,8 & 2 & $\begin{array}{l}\text { - Elementos resistente e encaixados } \\
\text { - Resistem à desmontagem. } \\
\text { - Podem ser reutilizados da mesma maneira que } \\
\text { originalmente. } \\
\text { - Podem ser reciclados também. }\end{array}$ \\
\hline \multicolumn{4}{|l|}{$\begin{array}{l}\text { VEDAÇÃO } \\
\text { VERTICAL } \\
\text { INTERNA }\end{array}$} \\
\hline Gesso & 0,2 & 3 & $\begin{array}{l}\text { - Ligações químicas } \\
\text { - Não resiste à desmontagem. } \\
\text { - Não é reutilizado nem reciclado. }\end{array}$ \\
\hline Vidro & 0,3 & 3 & $\begin{array}{l}\text { - Requer muito cuidado na desmontagem e se } \\
\text { quebra com facilidade. } \\
\text { - No armazenamento e no transporte também } \\
\text { necessita de cuidados para não quebrar. } \\
\text { - Geralmente é descartado quando há } \\
\text { demolições e reformas. } \\
\text { - Não costuma ser reaproveitado. }\end{array}$ \\
\hline $\begin{array}{l}\text { Alvenaria com } \\
\text { tijolos com } \\
\text { furos }\end{array}$ & 0,4 & 3 & $\begin{array}{l}\text { - Não resiste à desmontagem. } \\
-\quad \text { Geralmente é quebrada, removida e } \\
\text { descartada. } \\
\text { - Pode ser reciclada, mas não reutilizada. }\end{array}$ \\
\hline
\end{tabular}


Tabela 9 - Tabela de Classificação de Desmontagem

(Conclusão)

\begin{tabular}{c|l|l|l}
$\begin{array}{c}\text { Alvenaria com } \\
\text { tijolos maciços }\end{array}$ & 0,8 & 3 & $\begin{array}{l}\text { - Depende do modelo e da argamassa que } \\
\text { foram utilizados, que podem facilitar ou dificultar } \\
\text { o processo. } \\
-E \text { É um material pequeno que pode ser removido } \\
\text { com poucas ferramentas e manualmente. } \\
- \text { Fácil de transportar e armazenar. } \\
- \text { Pode ser reutilizada da mesma maneira que o } \\
\text { uso original. }\end{array}$ \\
\hline
\end{tabular}

Fonte: Autora

Dessa maneira, a tabela 9 está dividida em três partes: estrutura, vedação vertical externa e interna. O edifício foi separado desta maneira seguindo a ABNT NBR 15575:2013 Edificações Habitacionais - Desempenho, que está dividida em sistemas estruturais (NBR 15575-2) e sistemas de vedações verticais internas e externas (ABNT NBR 15575-4), entre outras divisões.

\section{Estrutura}

Em relação à estrutura, foi considerada a estrutura de concreto moldada no local e préfabricada, além da estrutura metálica e de madeira.

A estrutura de concreto moldada no local tem baixo potencial de desmontagem, por possuir ligações químicas e precisar de equipamentos pesados, de difícil manuseio para desmontar, além de ser difícil de transportar quando desmontada. Muitas vezes, a única opção é a demolição, devido a altos custos, quantidade de trabalho e tempo para uma efetiva desmontagem (MATTARAIA, 2013). Assim, sua classificação de desmontagem é 0,1.

A estrutura de concreto pré-fabricada é mais fácil de ser desmontada quando comparada à de concreto moldado no local, por permitir pontos de encaixes e ligações que podem ser desfeitas. Além disso, as peças são produzidas já considerando o transporte e o armazenamento na montagem, o que contribuirá para a desmontagem. No entanto, podem se quebrar na desmontagem e possuem ligações químicas. As lajes de concreto da empresa que foi visitada, por exemplo, são fabricadas e apenas montadas no local, mas depois 
precisam ser grauteadas, impossibilitando, assim, a futura separação e desmontagem sem danos nas peças. No entanto, outros elementos, como terças, podem ser desmontados sem maiores prejuízos. Como estamos analisando a estrutura pré-fabricada de concreto como um todo, neste trabalho, a sua classificação de desmontagem será prejudicada por alguns elementos e beneficiada por outros, portanto será $\mathbf{0 , 3}$.

A estrutura metálica também tem algumas vantagens e desvantagens. As considerações sobre montagem, assim como os elementos pré-fabricados de concreto, também contribuem para a desmontagem. Considerar transporte, armazenamento e equipamentos para montagem traz benefícios para a desmontagem. A possibilidade de reciclagem e a durabilidade do material também são vantagens, no entanto há riscos de corrosão. Além disso, quando os elementos são soldados, tornam-se mais difíceis de serem removidos sem danos, porém, se forem parafusados, permitem maior flexibilidade de desmontagem e remontagem (MATTARAIA, 2013). Assim, neste método construtivo, alguns elementos beneficiam o processo de desmontagem para facilitar uma futura reciclagem e até reutilização. Portanto, sua classificação de desmontagem é $\mathbf{0 , 6}$ para as estruturas soldadas e $\mathbf{0 , 8}$ para as parafusadas.

As estruturas de madeira também são consideradas, por serem muito utilizadas em algumas regiões do Brasil, serem flexíveis, serem um material renovável; portanto, se as madeiras são certificadas, são consideradas sustentáveis. Além disso, são utilizados parafusos ou pequenas peças para ligar os elementos, mas, em alguns casos, as estruturas são apenas encaixadas. Por utilizar peças que também são consideradas na montagem, facilitam o transporte, contribuindo para a desmontagem. A madeira é um material considerado sustentável, com ligações mecânicas ou encaixes, permite reutilização, é muito flexível e também duradouro (MATTARAIA, 2013). Portanto, tem uma alta classificação de desmontagem: $\mathbf{1 , 0}$. 


\section{Vedações verticais externas}

Algumas vedações foram consideradas, como as de vidro, alvenaria e elementos préfabricados de concreto. Geralmente estão relacionadas com a estrutura escolhida, como as alvenarias para estruturas de concreto, os vidros para as estruturas metálicas e elementos de concreto pré-fabricado utilizados com estruturas também pré-fabricadas de concreto. No entanto, também pode haver variações, como alvenaria de tijolos com estrutura metálica, fechamentos de vidro para estruturas de concreto moldadas no local, entre outras.

O vidro é um material frágil, pois requer muito cuidado na desmontagem. Porém, por ser considerada sua montagem, seu armazenamento e transporte, o processo de fabricação do vidro pode contribuir para a desmontagem. No entanto, não foi encontrado nenhum caso de reutilização de vidro sem que estivesse quebrado. Geralmente os vidros são quebrados e descartados e, quando são reutilizados, é para fazer algum detalhe, mas não como foi utilizado originalmente (MATTARAIA, 2013). Portanto, a classificação de reutilização é baixa: 0,3 .

Há as vedações de alvenaria e, neste caso, serão considerados os tijolos maciços de barro, sendo esta uma opção bastante utilizada no Brasil. Esta opção tem variáveis, como o tipo de tijolo utilizado, como foi feita sua ligação, se ficaram aparentes ou foram rebocados, se podem ter sidos envernizados ou pintados. Neste trabalho, iremos considerar tijolos maciços aparentes, ligados por argamassa. Por ser um material resistente e pequeno, permite ser desmontado, armazenado e transportado (MATTARAIA, 2013). No entanto, demanda cuidado e tempo para que seja desmontado corretamente e seja possível reutilizá-lo, sendo que, muitas vezes, o custo do processo não compensa o esforço. Assim, sua classificação é 0,8. No entanto, os tijolos de barro com furos não são tão resistentes e quebram na desmontagem, portanto sua classificação é $\mathbf{0 , 4}$.

As vedações feitas por elementos pré-fabricados de concreto, como visto nas visitas a empresas especializadas neste processo, permitem desmontagem e remontagem. Além 
disso, é possível armazenar e transportar sem maiores danos. Por serem apenas encaixados, facilitam o desencaixe sem danificar as peças. Em alguns casos, utiliza-se um silicone para maior vedação, no entanto é possível removê-lo com apenas algumas horas de trabalho. Assim, este elemento tem a classificação de $\mathbf{0 , 8}$.

\section{Vedação vertical interna}

As paredes que compões as edificações também têm grande importância na classificação de desmontagem da estrutura. Alguns dos materiais mais utilizados são gesso, vidro e plástico, além de alvenaria de tijolos com furos e maciços.

As divisórias de gesso geralmente são demolidas quando se precisa alterar a disposição interna dos ambientes. Não é um material resistente à desmontagem e pode ser tóxico (MATTARAIA, 2013). Assim, sua classificação é $\mathbf{0 , 2}$.

As divisórias de vidro também costumam ser destruídas e não permitem a adaptação a novas medidas. No entanto, o vidro não é um material tóxico, mas requer bastante cuidado no seu manuseio. Portanto, sua classificação é $\mathbf{0 , 3}$.

As paredes de alvenaria de tijolo com furos são muito utilizadas, principalmente em edifícios residenciais de até 02 pavimentos. No entanto, quando passam por reformas, geralmente são demolidas (MATTARAIA, 2013). Assim, sua classificação de desmontagem é $\mathbf{0 , 4}$.

As paredes de alvenaria de tijolos maciços são mais resistentes quando comparadas à opção anterior. No entanto, o responsável pela reforma pode optar por demolir ou remover os tijolos, dependendo da necessidade e disponibilidade. Portanto, sua classificação de desmontagem é $\mathbf{0 , 8}$.

\section{Peso para média ponderada}


Para se obter uma classificação de desmontagem geral do edifício, é possível fazer uma média dos diversos materiais e elementos utilizados. No entanto, algumas partes da edificação são mais viáveis de serem desmontadas que outras, pois o edifício é composto por camadas que normalmente seguem a sequência oposta da montagem ou construção.

Por exemplo, as vedações costumas ser menos complicadas que as estruturas. Assim, tornase necessário fazer uma média ponderada. Neste estudo, as divisórias internas terão peso 03, as vedações peso 02 e as estruturas peso 01.

A figura 54 apresenta os materiais que foram considerados na Classificação de Desmontagem conforme a estrutura, vedação vertical externa e vedação vertical interna.

\begin{tabular}{|llll} 
concreto moldado no \\
local \\
pré-moldado de \\
concreto \\
metálica soldada \\
metálica parafusada \\
madeira
\end{tabular}

Figura 54 - Elementos analisados para a Classificação de Desmontagem do edifício Fonte: Autora

As principais características dos sistemas e materiais utilizados para a classificação de desmontagem dos sistemas construtivos, elementos e materiais são:

1. CONEXÕES: conforme a escolha de ligação entre as peças, o processo de desmontagem pode ser prejudicado. Quando são peças encaixadas, por exemplo, é possível desmontá-las sem danificá-las, enquanto peças com ligações químicas dificilmente podem ser separadas sem danos.

2. RESISTÊNCIA À DESMONTAGEM E REMONTAGEM: é importante que o material resista à desmontagem para que possa ser mais bem aproveitado e ser reutilizado; diversos materiais não resistem e precisam ser reciclados ou descartados.

3. PADRONIZAÇÃO: se os elementos e materiais são padronizados, a desmontagem é mais eficiente, pois são necessárias as mesmas ferramentas, o mesmo número de pessoas, além de ser mais viável projetar a reutilização.

4. ARMAZENAGEM e TRANSPORTE: assim como na montagem, o armazenamento e o transporte são fundamentais para que o material possa ser reaproveitado. Por exemplo, peças muito grandes que dificultam o transporte e o armazenamento dificilmente serão reutilizadas, o que é o objetivo da desmontagem projetada.

5. ESCALA: a escala dos elementos é fundamental para programar sua retirada e reutilização, pois quanto menos ferramentas, pessoas e tempo levar para a desmontagem, mais chances os elementos terão de ser reutilizados. 
6. FABRICAÇÃO: manter as informações sobre a fabricação dos elementos é importante para saber a melhor maneira de proceder com a desmontagem e remontagem; além disso, assim como o BIM contribui para a racionalização da fabricação, também contribui par a desmontagem e remontagem.

7. CAMADAS: o edifício é construído em camadas, como estrutura, vedações, sistemas hidráulicos, elétricos, entre outros. Assim, quanto melhor o acesso a cada um desses elementos, mais chances de serem desmontados sem danificar outros, até mesmo na manutenção do edifício.

8. RECICLAGEM: alguns materiais não são reciclados quando removidos dos edifícios por serem tóxicos, se quebrarem facilmente ou pelo valor e o tempo para desmontar e reciclar não serem suficientemente rentáveis ao mercado, como no caso de vidro e gesso. No entanto, alguns materiais podem ser demolidos, separados e reciclados, como o concreto.

9. REUTILIZAÇÃO: alguns materiais resistem à desmontagem e podem ser reutilizados da mesma maneira, como as estruturas metálicas parafusadas, por exemplo, que podem ser reaproveitadas se precisarem de elementos exatamente com a mesma medida em uma nova obra.

10. ADAPTAÇÃO: poucos materiais resistem à desmontagem e ainda podem ser adaptados a novos usos. Os elementos em madeira, por exemplo, podem ser reutilizados de diferentes maneiras.

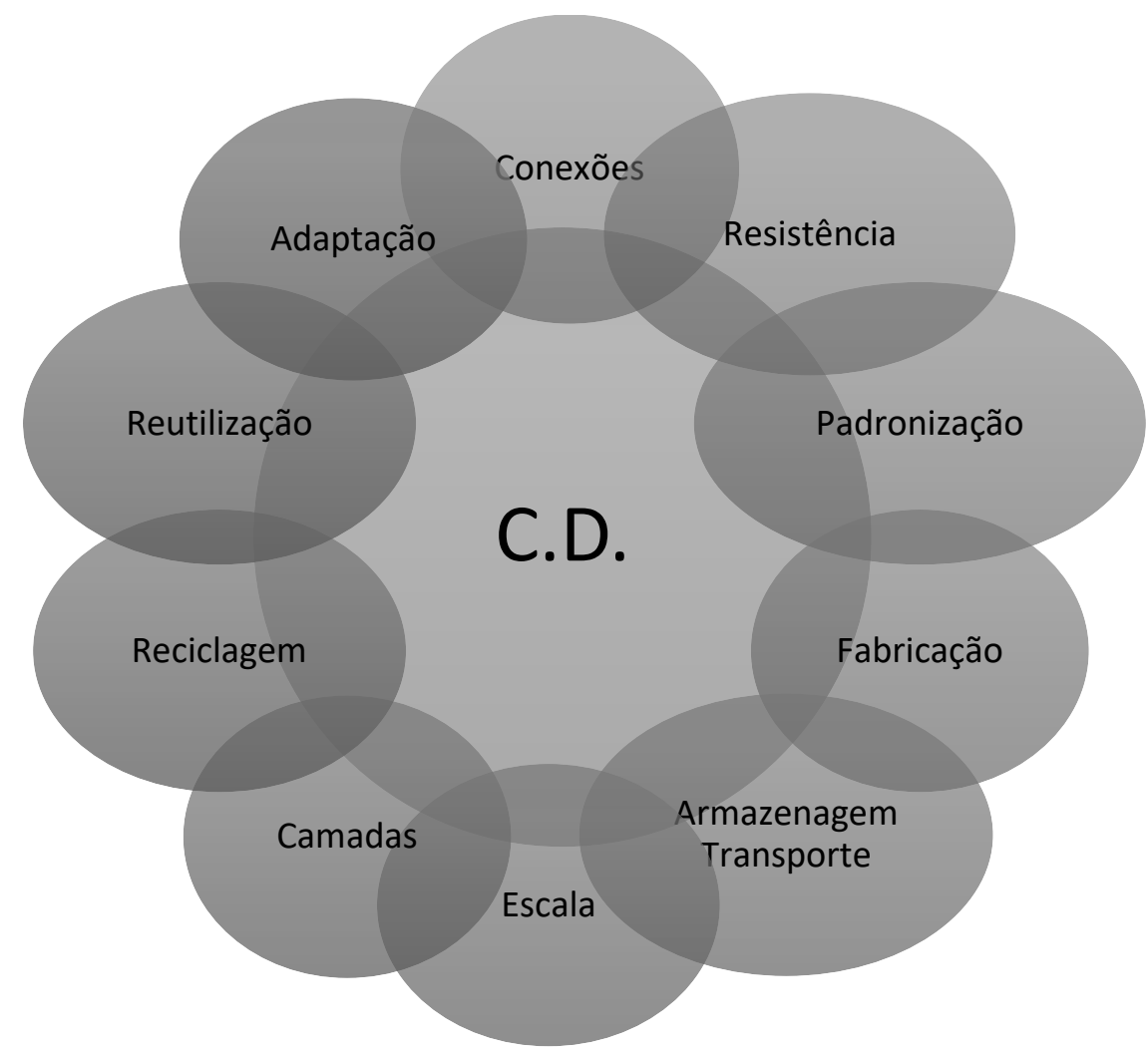

Figura 55 - Características consideradas na Classificação de Desmontagem

Fonte: Autora

A figura 55 apresenta as características que foram consideradas para o desenvolvimento da Classificação de Desmontagem.

Para a análise da Classificação de Desmontagem do edifício em BIM, o foco deste trabalho serão as conexões entre os principais elementos que compõe a estrutura, vedação externa e 
interna. A tabela 10 apresenta os tipos de conexões possíveis nos sistemas estruturais abordados nos modelos que foram desenvolvidos. As ligações apresentadas podem ser lineares ou pontuais. Por exemplo, no caso do encontro de pilares com vigas metálicas, as conexões são pontuais, enquanto o encontro entre pilares com alvenaria é linear, pois a argamassa atinge todo o elemento.

Tabela 10 - Tipos de conexões entre os elementos e materiais

\begin{tabular}{|c|c|c|c|c|}
\hline & Pilar & Viga & $\begin{array}{l}\text { Vedação } \\
\text { vertical externa }\end{array}$ & $\begin{array}{l}\text { Vedação } \\
\text { vertical interna }\end{array}$ \\
\hline Pilar & & & & \\
\hline Viga & & & & \\
\hline $\begin{array}{l}\text { Vedação } \\
\text { vertical externa }\end{array}$ & & & & \\
\hline $\begin{array}{l}\text { Vedação } \\
\text { vertical interna }\end{array}$ & & & & \\
\hline
\end{tabular}

Fonte: Autora

Legenda:

Conexão pontual

— Conexão linear horizontal

I Conexão linear vertical

X Sem conexão

As tabelas 11,12, 13 apresentam as características dos materiais e suas ligações. As tabelas foram desenvolvidas com base nos dados obtidos ao longo das entrevistas, visitas às obras, fábricas, além da revisão bibliográfica, conforme apresentado anteriormente neste capítulo. 
Tabela 11 - Características dos sistemas estruturais

\begin{tabular}{|c|c|c|c|c|c|c|c|c|c|c|c|}
\hline 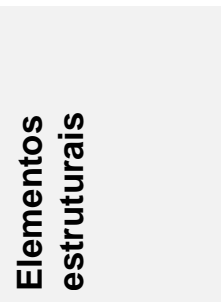 & 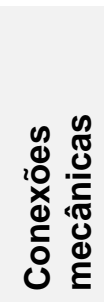 & 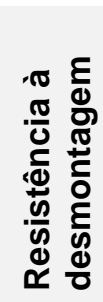 & 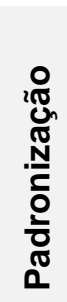 &  & 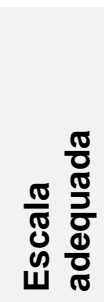 &  & 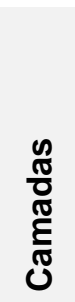 & 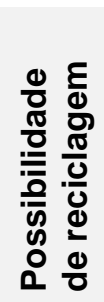 & 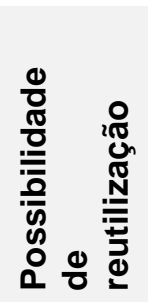 & 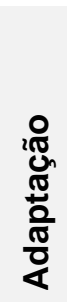 & ن \\
\hline $\begin{array}{l}\text { Concreto } \\
\text { moldado no } \\
\text { Local }\end{array}$ & & & & & & & & $x$ & & & 0,1 \\
\hline $\begin{array}{l}\text { Pré-moldado } \\
\text { de concreto }\end{array}$ & & & $x$ & & & $x$ & & $x$ & & & 0,3 \\
\hline $\begin{array}{l}\text { Metálicos } \\
\text { soldados }\end{array}$ & & $x$ & $x$ & $x$ & & $x$ & $x$ & $x$ & & & 0,6 \\
\hline $\begin{array}{l}\text { Metálicos } \\
\text { parafusados }\end{array}$ & $x$ & $x$ & $x$ & $x$ & & $x$ & $x$ & $x$ & $x$ & & 0,8 \\
\hline Madeira & $x$ & $x$ & $x$ & $x$ & $x$ & $x$ & $x$ & $x$ & $x$ & $x$ & 1,0 \\
\hline
\end{tabular}

Fonte: Autora

Tabela 12 - Características das vedações verticais externas

\begin{tabular}{|c|c|c|c|c|c|c|c|c|c|c|c|}
\hline 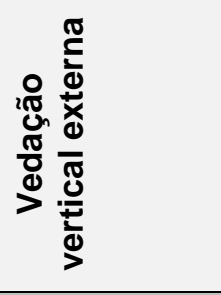 &  & 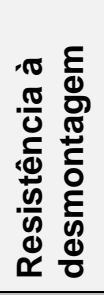 & 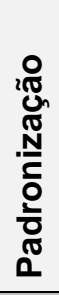 & 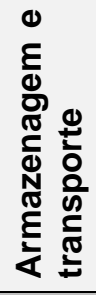 &  & 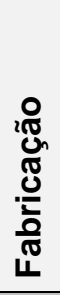 & 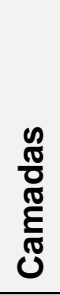 & 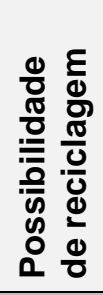 &  & 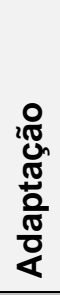 & نُ \\
\hline Vidro & & & & & $X$ & $x$ & & $x$ & & & 0,3 \\
\hline $\begin{array}{l}\text { Alvenaria de } \\
\text { tijolos com } \\
\text { furos }\end{array}$ & & & $x$ & & $X$ & $x$ & & $x$ & & & 0,4 \\
\hline $\begin{array}{l}\text { Alvenaria de } \\
\text { tijolos } \\
\text { maciços }\end{array}$ & & $x$ & $x$ & $X$ & $x$ & $x$ & & $x$ & $x$ & $x$ & 0,8 \\
\hline $\begin{array}{l}\text { Elementos } \\
\text { pré- } \\
\text { fabricados } \\
\text { de concreto }\end{array}$ & $X$ & $X$ & $X$ & $X$ & $X$ & $X$ & $x$ & $X$ & & & 0,8 \\
\hline
\end{tabular}

Fonte: Autora 
Tabela 13 - Características das vedações verticais internas

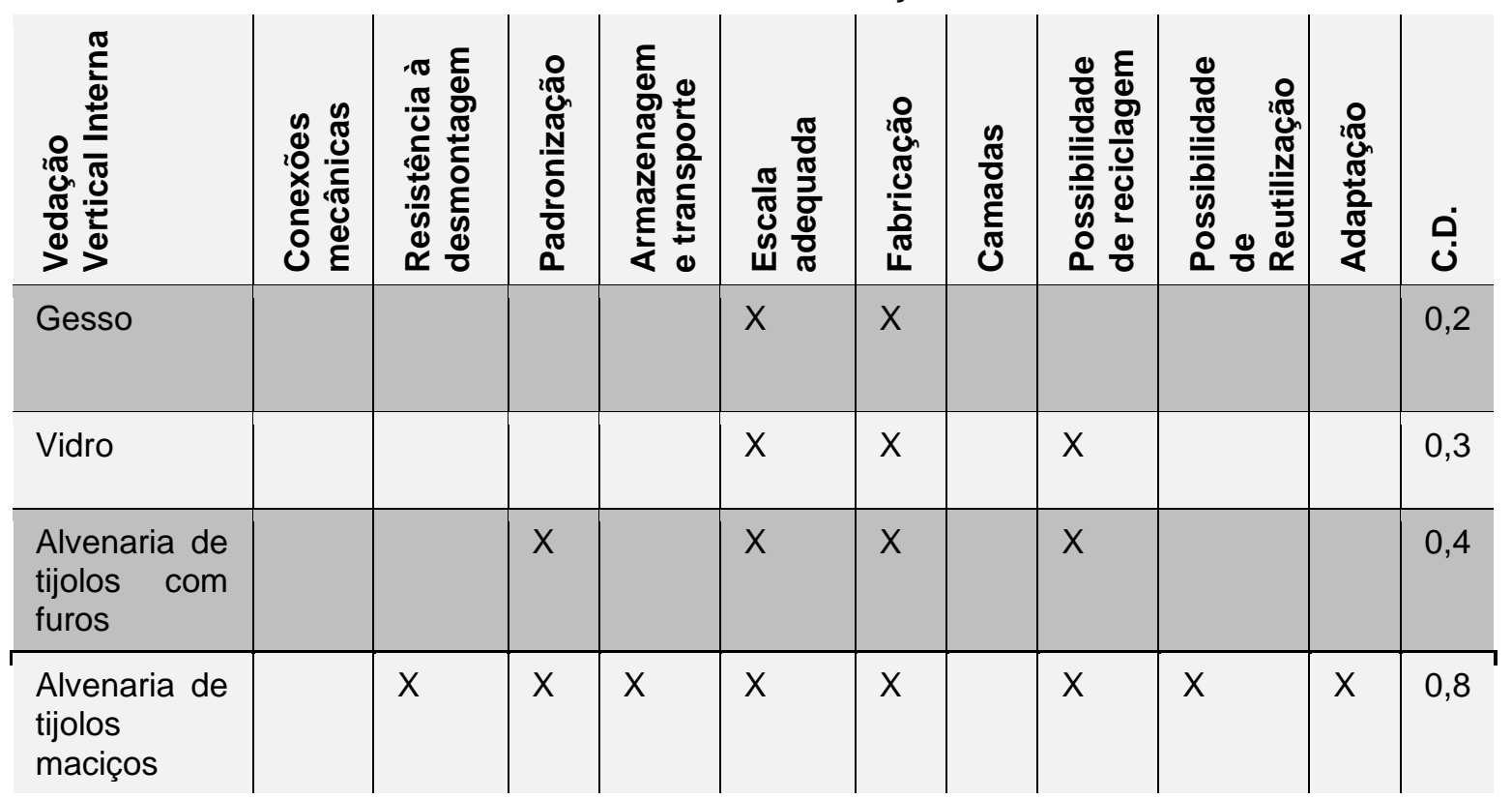

Fonte: Autora

Por fim, o cálculo final é realizado da seguinte maneira: Classificação de Desmontagem vezes o valor para média ponderada e o resultado é dividido pelo número de elementos (ou $\mathrm{m}^{2}$ ). Uma fórmula simples foi desenvolvida para colocar a classificação de desmontagem em prática e analisar as possibilidades do software. No entanto, conforme a tabela se torna mais complexa, a fórmula também pode ser mais específica, desde que siga os mesmos princípios abordados ao longo da tese. Assim, a fórmula é:

\section{$\frac{\text { C.D. } x \text { média ponderada }}{n^{\circ} \text { elementos }\left(\text { ou } \mathrm{m}^{2}\right)}$}

Abaixo os gráficos demonstram a classificação de desmontagem conformes as camadas do edifício e o peso atribuídos a eles. 


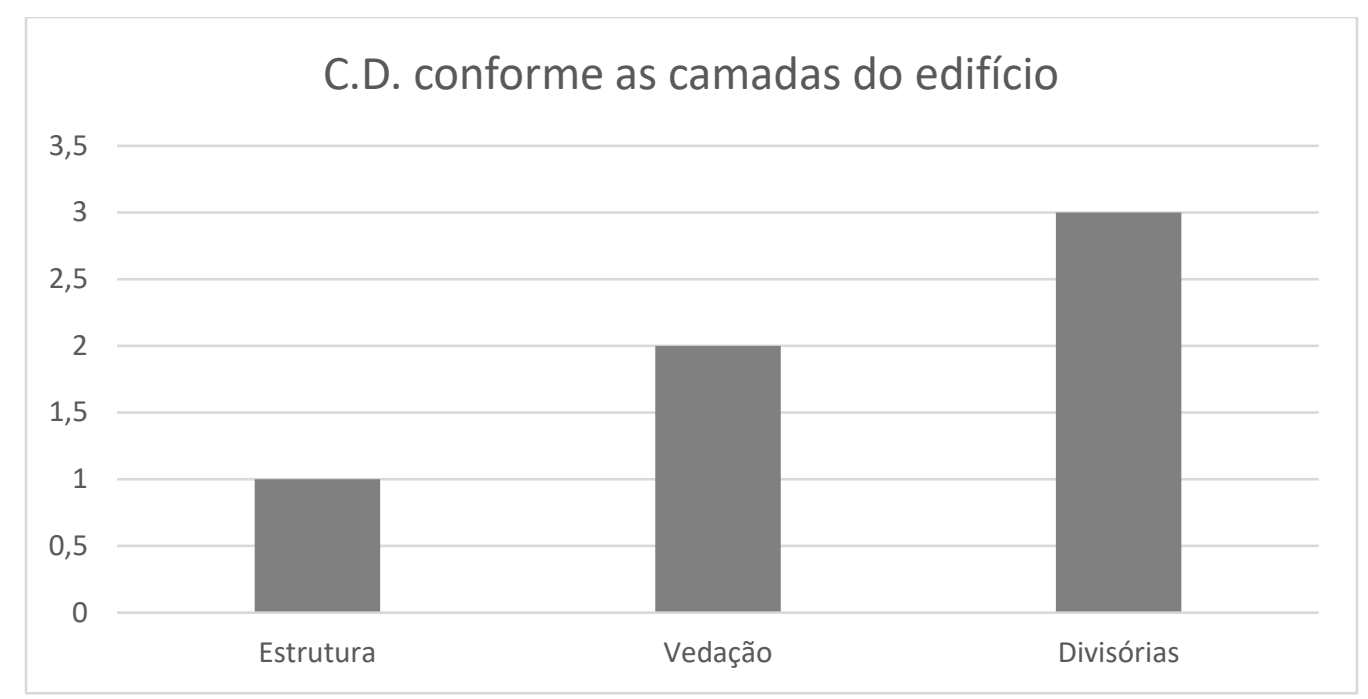

Gráfico 1 - Classificação de Desmontagem conforme as camadas do edifício

Os gráficos 2, 3 e 4 demonstram a classificação de desmontagem conforme o material escolhido para estrutura, vedação e divisórias.



Gráfico 2 - Classificação de Desmontagem conforme a estrutura 




Gráfico 3 - Classificação de Desmontagem conforme o material para vedação vertical externa do edifício



Gráfico 4 - Classificação de Desmontagem conforme o material da vedação vertical interna

Assim, foi desenvolvida a classificação que mede o potencial de desmontagem do edifício, considerando os materiais e elementos utilizados em sua composição. A classificação auxilia o projetista a escolher materiais que estejam de acordo com as necessidades e contribuam 
para a futura desmontagem, para que se possa ter mais sucesso na futura reutilização dos materiais e se reduza o grande desperdício no setor.

\subsection{Parâmetro da Classificação de Desmontagem inserido no modelo}

Para tornar o processo mais dinâmico para os projetistas e demais interessados em analisar as possibilidades de desmontagem do edifício, foram criados parâmetros por meio do software Revit, pois permite inserir novas informações referentes aos projetos. Por exemplo, é possível inserir a Classificação de Desmontagem (C.D.) de cada material e elemento utilizado, conforme as figuras 55, 56 e 57.

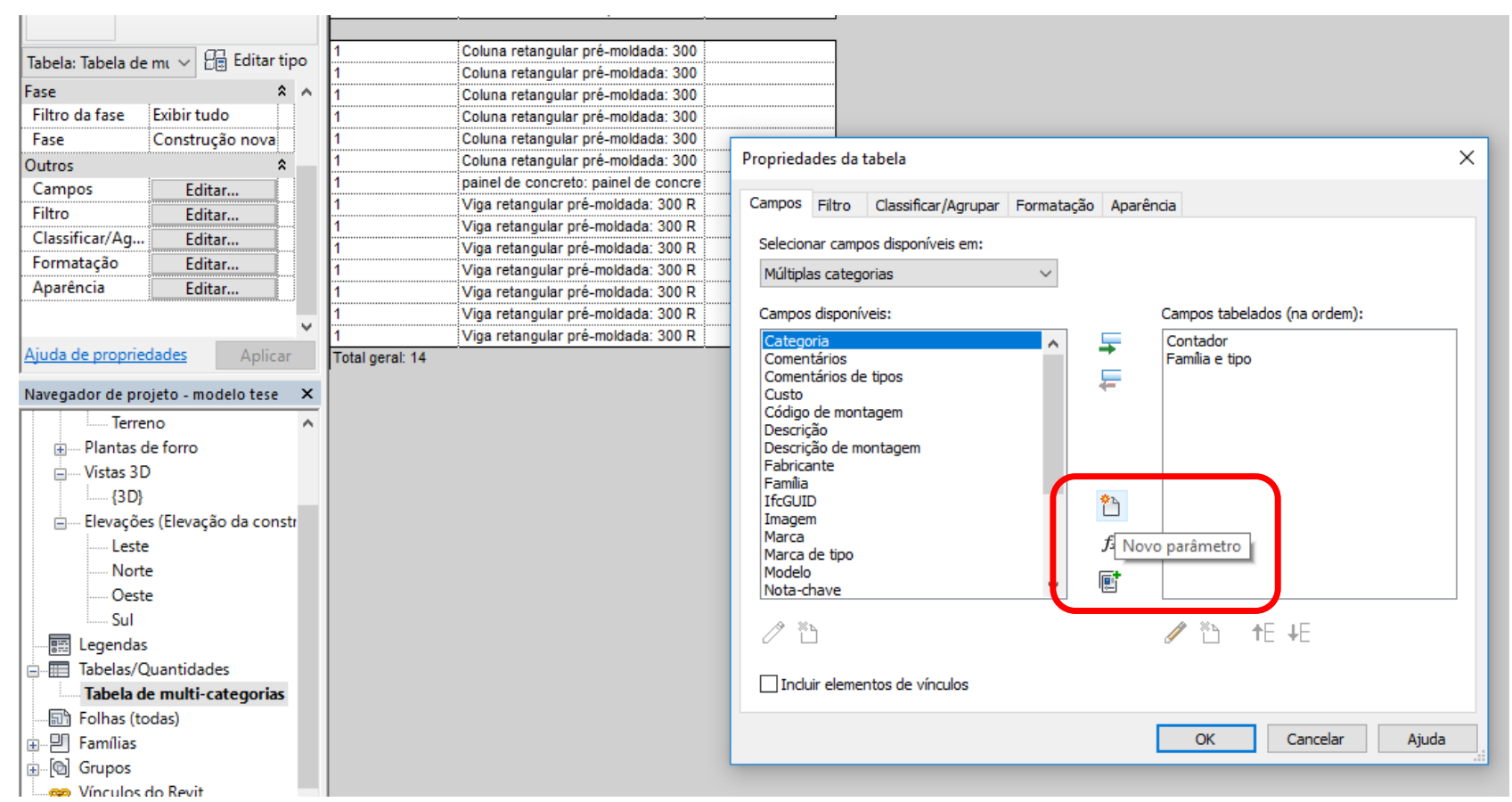

Figura 55 - Criação de parâmetros do Revit Fonte: Autora

Na figura 55, é possível observar como se cria um parâmetro por meio da criação da tabela. A figura 56 apresenta as definições do novo parâmetro, que, neste caso, é a classificação de desmontagem. 


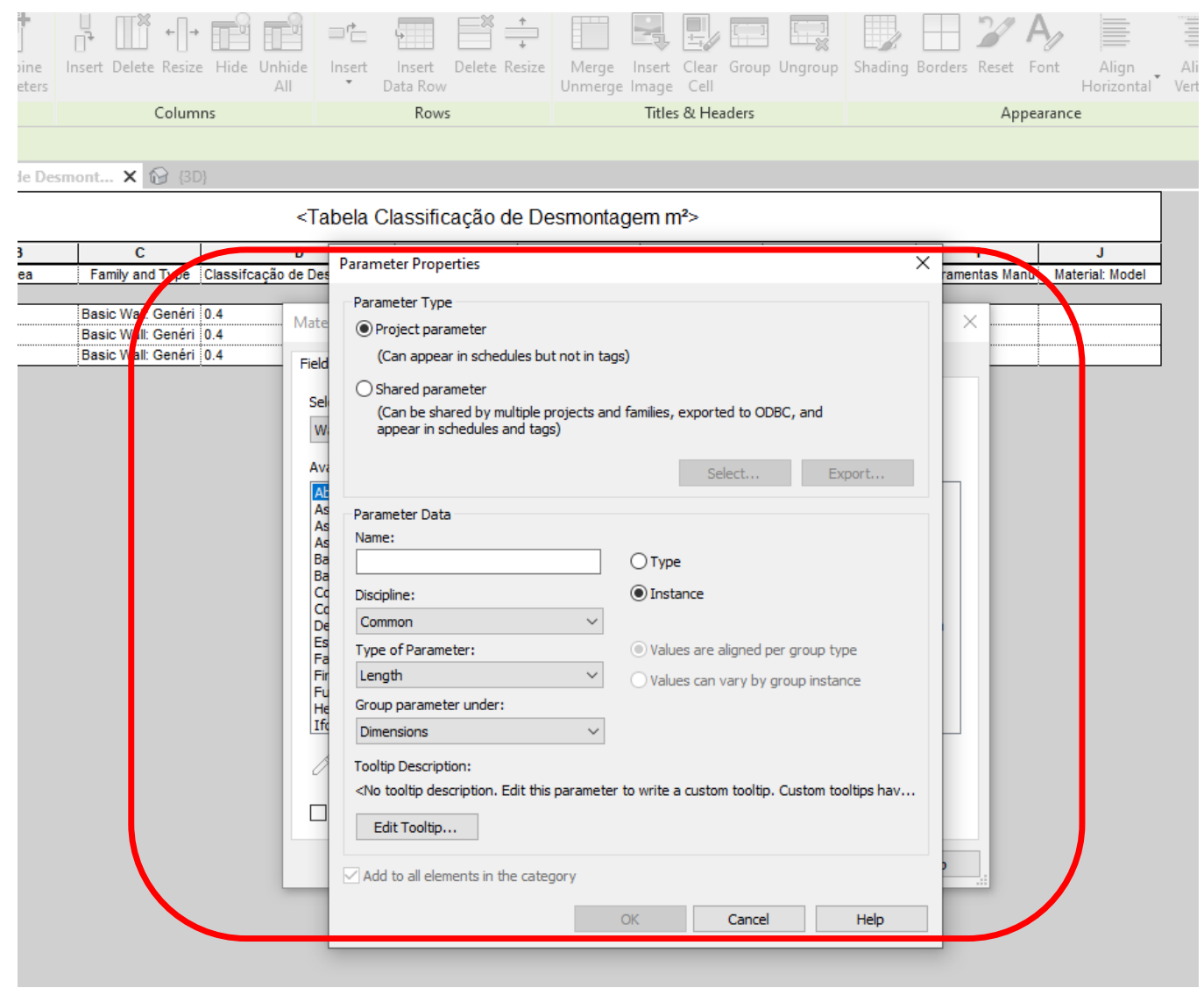

Figura 56 - Criação de parâmetros do Revit Fonte: Autora

A figura 57 apresenta o parâmetro criado na janela de propriedades do elemento. Neste caso, é o painel de concreto pré-moldado utilizado para vedação. Como visto no item anterior, a classificação de desmontagem foi estipulada em 0.4. Assim, a figura apresenta o parâmetro com o número da classificação inserida. 


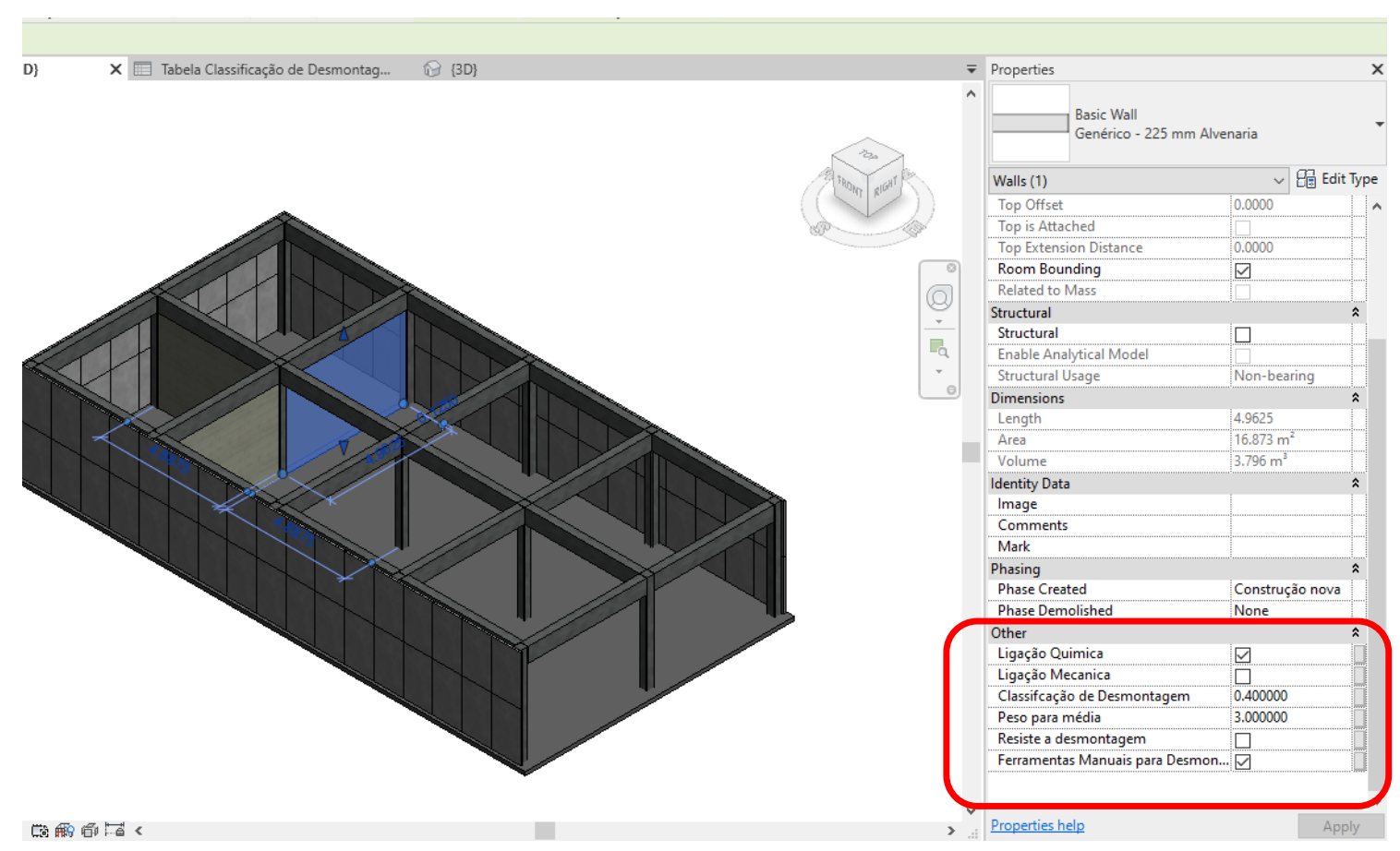

Figura 57 - Criação de parâmetros do Revit Fonte: Autora

Posteriormente, foi criada uma tabela com os parâmetros para fazer o cálculo da média ponderada do edifício e obter o resultado final. A figura 58 mostra a criação da classificação de desmontagem, que foi gerada da seguinte maneira: gerenciar/parâmetros do projeto/adicionar. As figuras 58, 59 e 60 mostram a tabela com a "classificação de desmontagem" separadas por elementos, por exemplo: estrutura, alvenaria, janelas, portas etc. A partir desta tabela é possível fazer o cálculo para obter o resultado final da classificação de desmontagem de todo o projeto. 


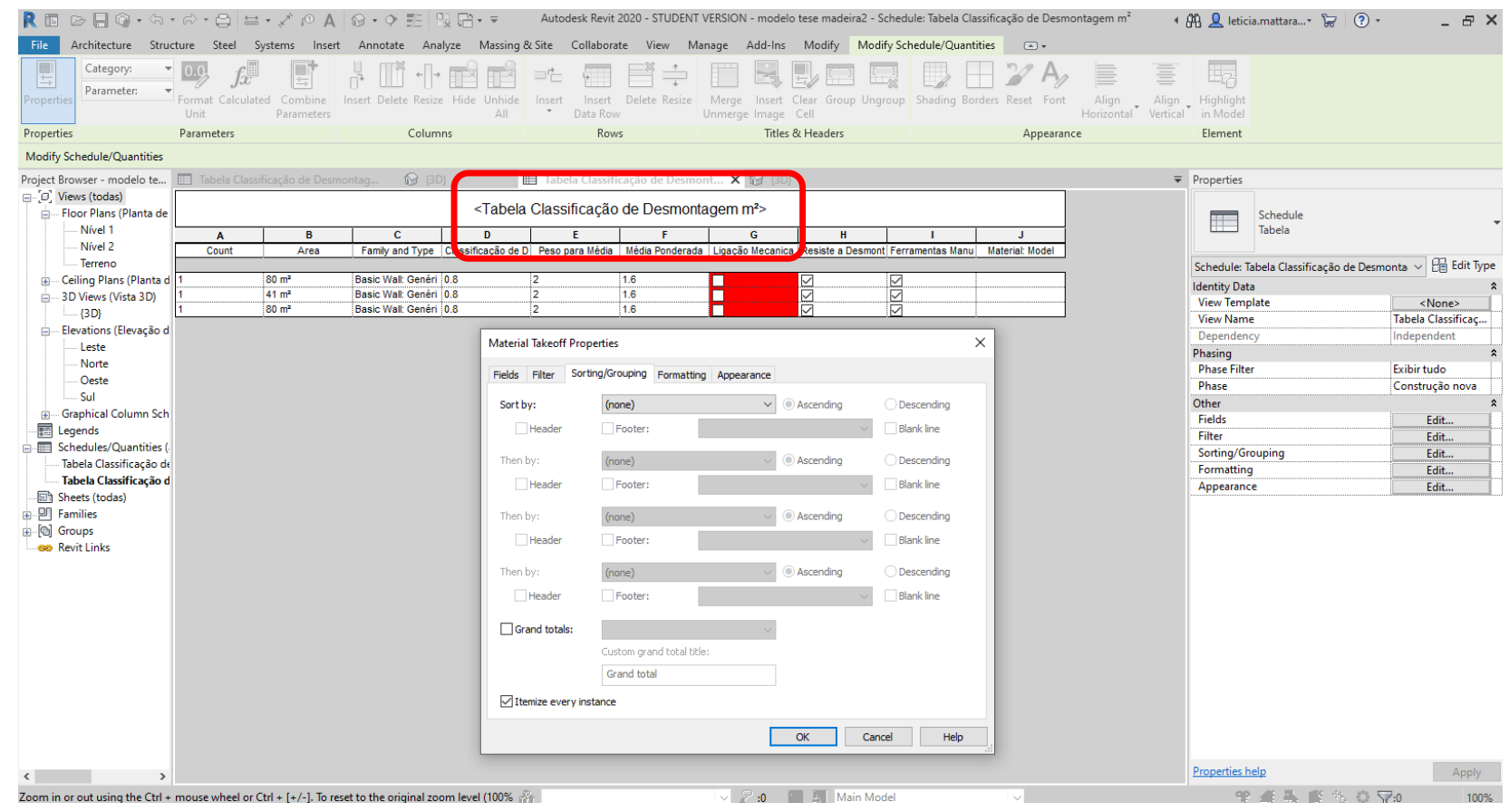

Figura 58 - Criação da tabela da Classificação de Desmontagem do Revit Fonte: Autora

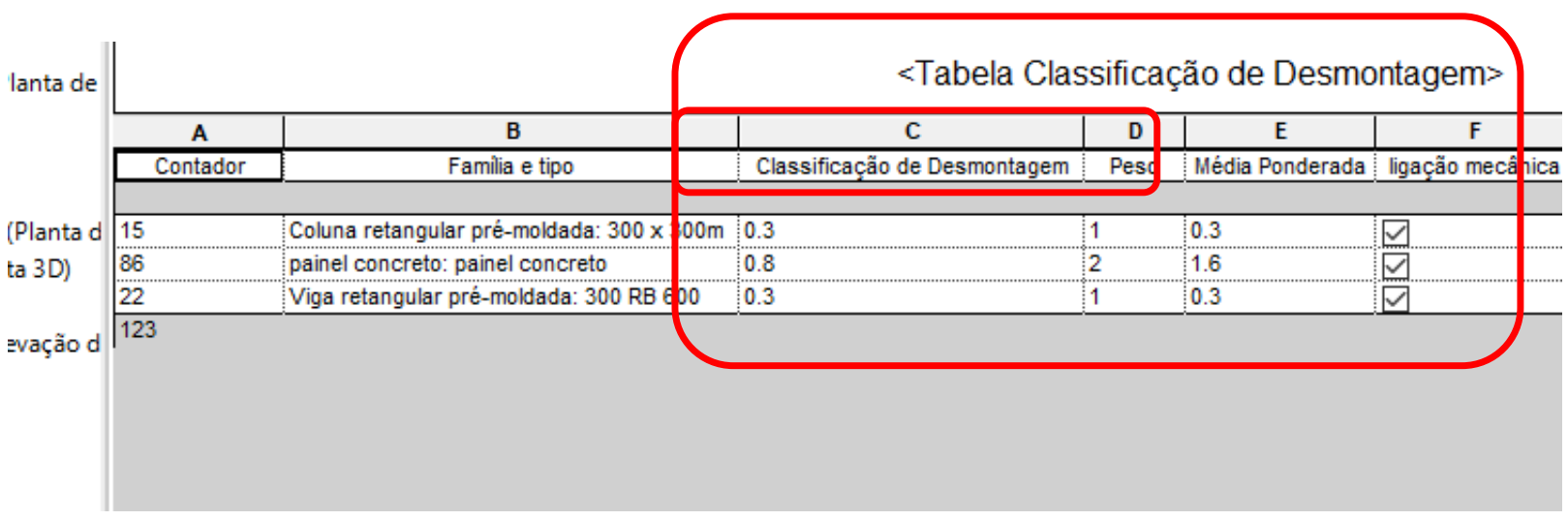

Figura 59 - Tabela sobre a Classificação de Desmontagem Fonte: Autora

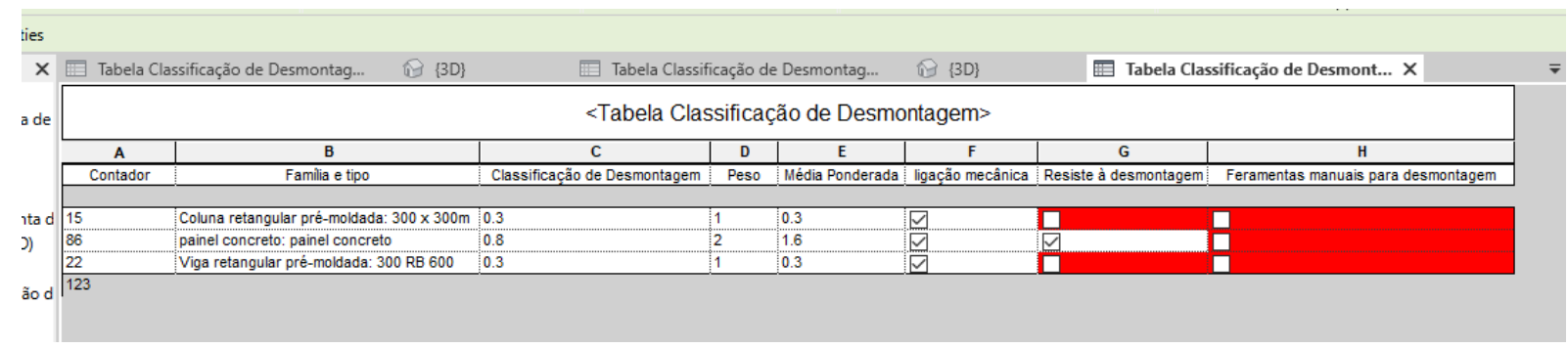

Figura 60 - Tabela da Classificação de Desmontagem multicategoria Fonte: Autora. 
A figura 61 mostra a classificação de desmontagem. Ela apresenta os diversos elementos do projeto, sua classificação de desmontagem, o peso para média ponderada e o resultado da classificação do edifício, que está no valor total que será dividido pelo número de componentes. Neste caso, o valor da classificação de desmontagem é 3.4, que, quando dividido por 14 (número de elementos), terá o resultado de 0.27 , que será a classificação de desmontagem do edifício. Porém, como foi informado anteriormente, tanto a classificação quanto a fórmula e o projeto foram desenvolvidos para explorar as ferramentas do software.



Figura 61 - Tabela com a Classificação de Desmontagem calculada Fonte: Autora

Nas propriedades também aparece, de maneira automática, o peso dado ao elemento para o cálculo da classificação, conforme apresentado na figura 62. 


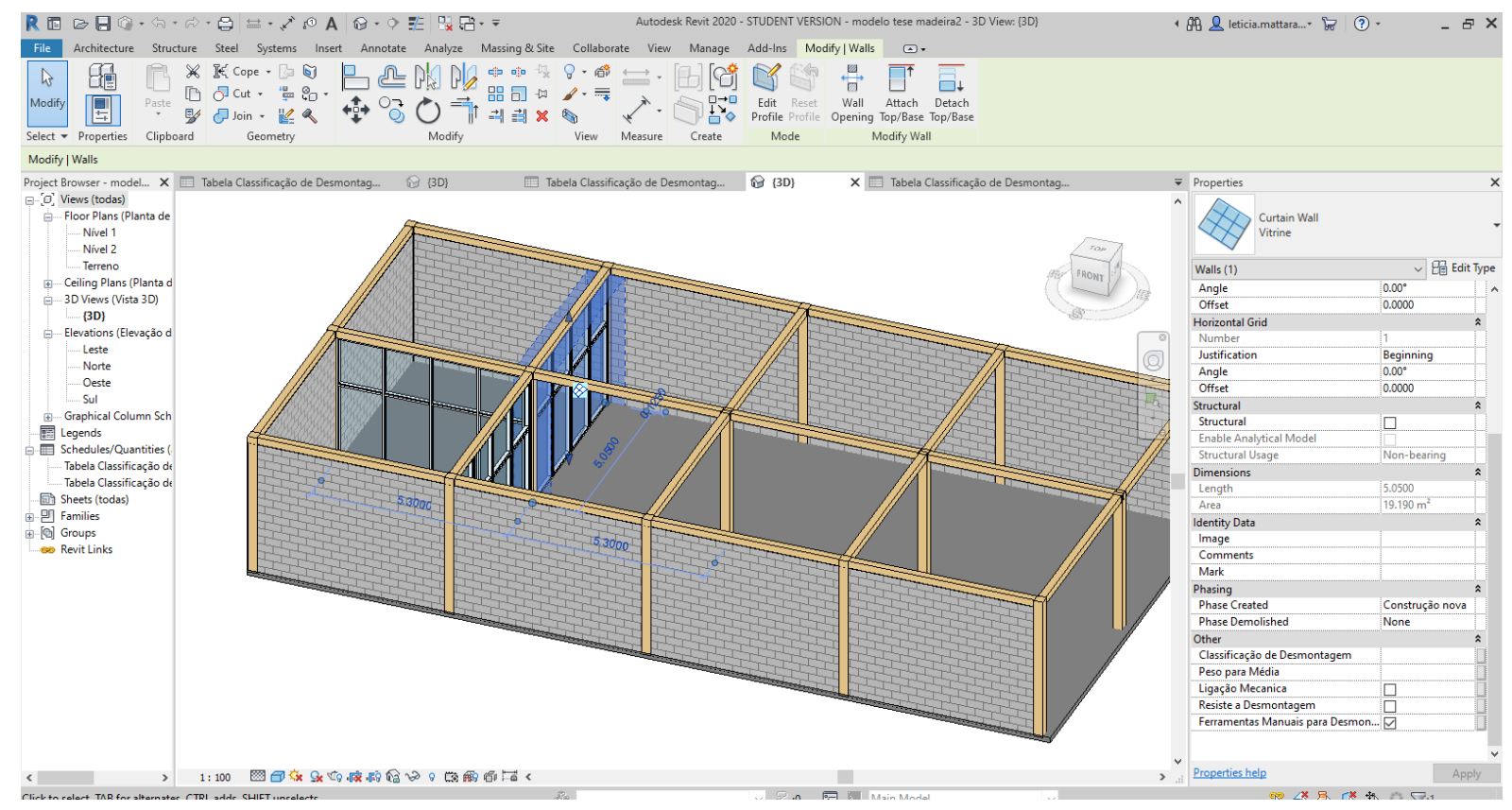

Figura 62 - Classificação de Desmontagem nas propriedades

Fonte: Autora

Na figura 63, é possível observar outra ferramenta que contribui para a melhor visualização das questões de desmontagem. Por exemplo, é possível estipular que a classificação de desmontagem maior que 0.3 é aceitável e menor que isso é preciso fazer uma análise específica. Assim, na tabela, é possível configurar um parâmetro que destaque a classificação abaixo de 0.3 .

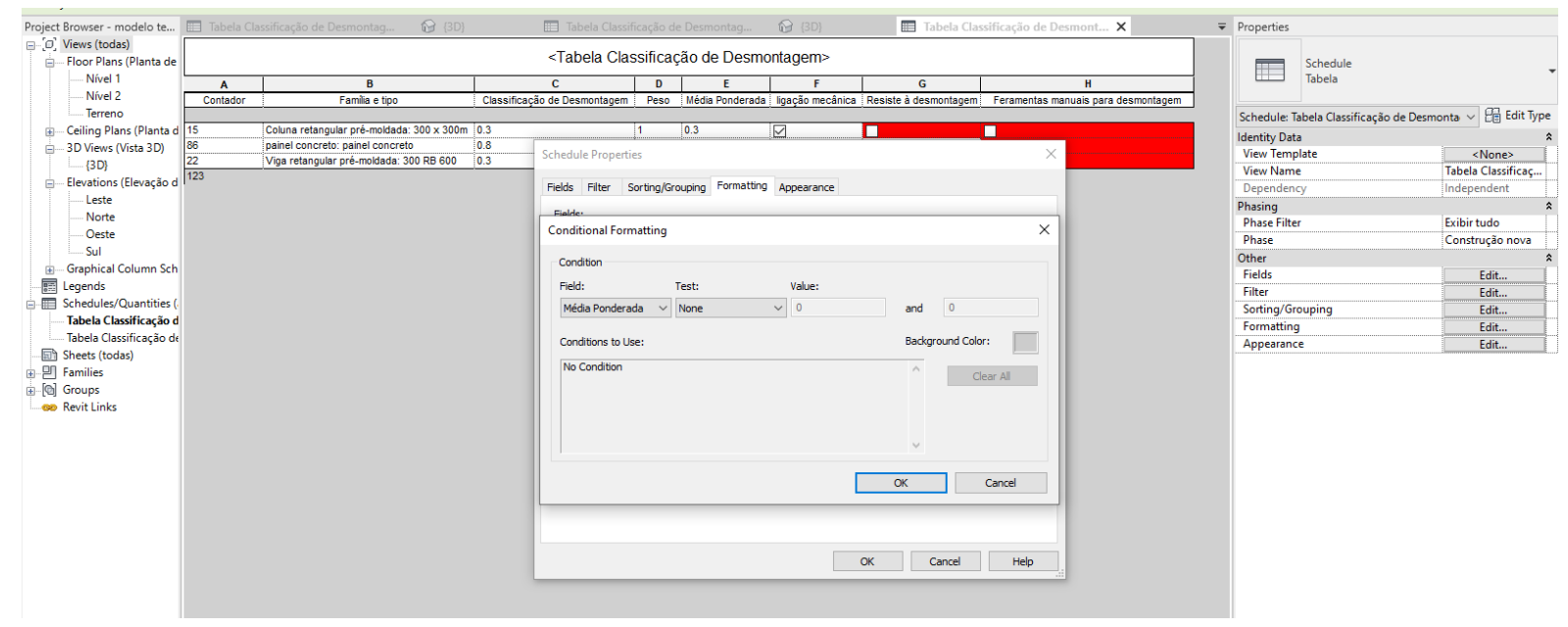

Figura 63 - Definição da Classificação de Desmontagem aceitável Fonte: Autora

A imagem 64 apresenta a tabela já com elementos destacados. Isso facilita a visualização dos parâmetros que precisam passar por análise específica ou não seriam aceitáveis. 


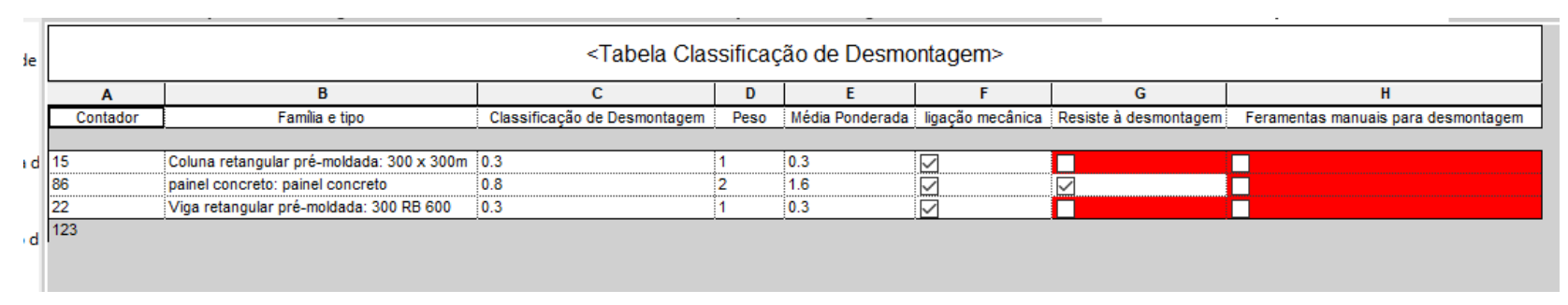

Figura 64 -Tabela com destaque da Classificação de Desmontagem acima do estipulado Fonte: Autora

A documentação e os memoriais também são importantes para o processo de desmontagem e reutilização, conforme visto no item 3.2.6. O Revit tem ferramentas que contribuem para o armazenamento de informações. As tabelas, por exemplo, estão salvas no mesmo arquivo do projeto, apenas em outras janelas. Além disso, para minimizar problemas com incompatibilização de softwares, as informações podem ser exportadas em forma de texto. A figura 65 demonstra o processo no Revit e abaixo segue a informação em texto.



Figura 65 - Ferramenta para exportar tabela como relatório em forma de texto Fonte: Autora

Quando as informações da tabela 65 são exportadas em formato de texto aparecem da seguinte maneira:

"Tabela Classificação de Desmontagem"

"Contador" "Família e tipo" "Classificação de Desmontagem" "Peso" "Média Ponderada" "ligação mecânica" "Resiste à desmontagem" "Ferramentas manuais para desmontagem"

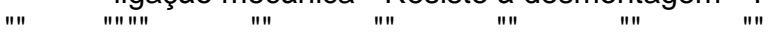

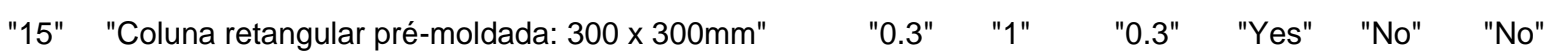

$\begin{array}{llllllll}\text { "86" } & \text { "painel concreto: painel concreto" } & \text { "0.8" } & \text { "2" } & \text { "1.6" } & \text { "Yes" } & \text { "Yes" } & \text { "No" } \\ \text { "22" } & \text { "Viga retangular pré-moldada: } 300 \text { RB 600" } & \text { "0.3" } & \text { "1" } & \text { "0.3" } & \text { "Yes" } & \text { "No" } & \text { "No" }\end{array}$ "123"

A figura 66 apresenta os dados sobre as propriedades dos elementos, como as vigas, que são elementos que fazem parte da família estrutural. As informações específicas constam em suas propriedades. 




Figura 66 - Ferramenta para exportar tabela como relatório em forma de texto Fonte: Autora

Além disso, as informações sobre os produtos e materiais constam nas propriedades dos elementos e podem ser acrescentadas novas informações ao longo do desenvolvimento. Também é possível criar novos campos e parâmetros, como os da classificação de desmontagem, assim estes dados ficam armazenados também no arquivo. Se houver o cuidado em atualizar o projeto conforme foi construído, será ainda melhor para a reutilização dos elementos e materiais.

Portanto, estas foram análises gerais de algumas ferramentas do software Revit que auxiliam na tomada de decisões ao longo do desenvolvimento do projeto, que leva em consideração a desmontagem de parte ou total do edifício, ao longo de sua manutenção e no final de sua vida útil. Porém, para uma análise mais específica, foi desenvolvido um projeto modelado em 3D, com base nas entrevistas e nos estudos de casos apresentados no capítulo 4. 


\subsection{Projetos com a inserção de parâmetros da Classificação de Desmontagem}

Um projeto foi desenvolvido para colocar em prática a classificação de desmontagem e analisar as possibilidades de avaliação da desmontabilidade do edifício. O modelo 3D executado no software Revit 2019 foi criado com o objetivo de explorar diversos recursos BIM e inserir a classificação, como se fosse um protótipo, para verificar como o Projeto para Desmontagem pode ser aprimorado quando aliado ao BIM.

O projeto desenvolvido é um galpão, composto por vigas, pilares e painéis de vedação, de elementos pré-fabricados de concreto armado e protendido. O projeto foi desenvolvido no Revit e foi gerado o modelo 3D. A escolha destes elementos foi feita com base nas análises práticas apresentadas no capítulo 4. Conforme apresentado, foram visitadas duas fábricas de elementos pré-fabricados de concreto e diversas obras (galpões, supermercados, edifício comercial, ampliação de estádio de futebol etc.). Também foram realizadas entrevistas com diversos profissionais envolvidos (projetistas, arquitetos, engenheiros civis e de produção e empreiteiros) e análises de documentos (projetos e memoriais). Portanto, foi decidido desenvolver modelos com base no que foi analisado para melhor explorar as ferramentas e possibilidades de um projeto BIM que teria considerações em relação à desmontagem.

Para a aplicação da classificação ser utilizada de maneira mais prática e objetiva, sem aumentar consideravelmente o tempo do desenvolvimento do projeto e, consequentemente, o custo, utilizar um software BIM como o Revit facilitaria o processo. A partir do mesmo projeto foram desenvolvidos três modelos conceituais para implementar a classificação. São três galpões com a mesma área construída, sendo o primeiro em estrutura pré-fabricada de concreto, vedação vertical externa de painéis de concreto e vedação vertical interna de tijolos com furos (figuras 67, 68 e 69). O segundo galpão é de estrutura metálica, vedação vertical externa de tijolos com furos e interna de gesso (figuras 70, 71 e 72). Por fim, o terceiro é composto por estrutura de madeira, vedação vertical externa de tijolos maciços e interna de vidro (figuras 73, 74 e 75). 
Os modelos foram criados em um template, também desenvolvido pela autora, no Revit, com a intenção de gerar tabelas com informações sobre quantidade de elementos utilizados, materiais, classificação de desmontagem e tags sobre pontos importantes a serem considerados no Projeto para Desmontagem. Outras questões também são fundamentais para a desmontagem, como peso, expectativa de vida, entre outras, no entanto este estudo focou na quantidade dos materiais utilizados e como seriam as conexões entre eles e a possibilidade de desmontagem. As linhas destacadas em vermelho representam que não atendem a alguma exigência específica, como não serem possíveis ligações mecânicas, e serão utilizadas ligações químicas, como argamassa, por exemplo. 


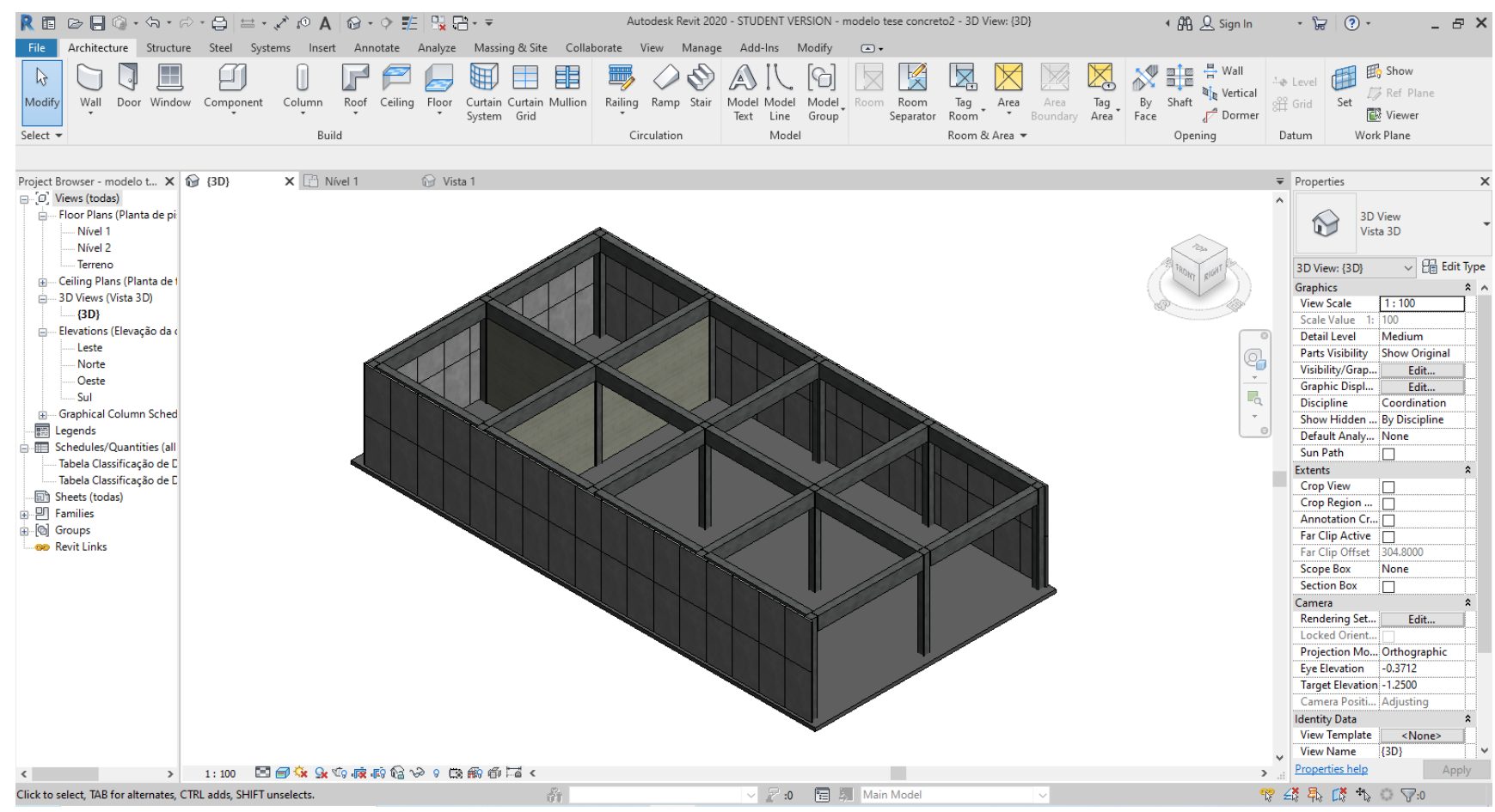

Figura 67 - Modelo conceitual 01



Figura 68 - Tabela de unidades para a Classificação de Desmontagem

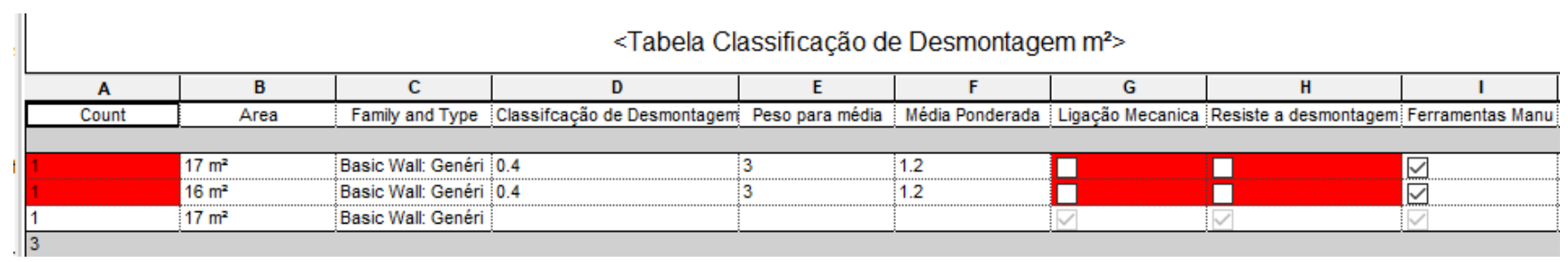

Figura 69 - Tabela com $\mathrm{m}^{2}$ para a Classificação de Desmontagem 




Figura 70 - Modelo conceitual 02

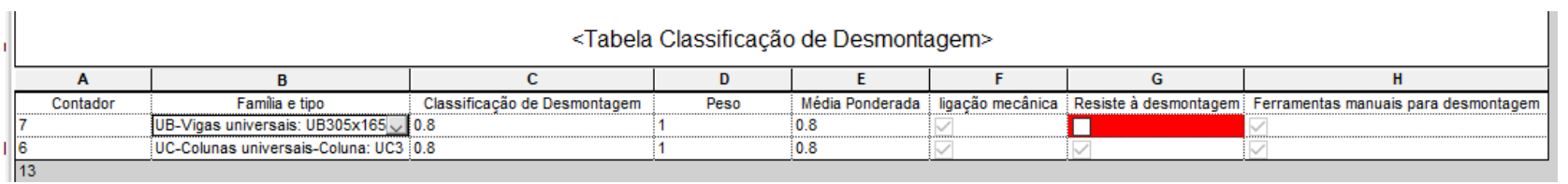

Figura 71 - Tabela de Unidades para a Classificação de Desmontagem

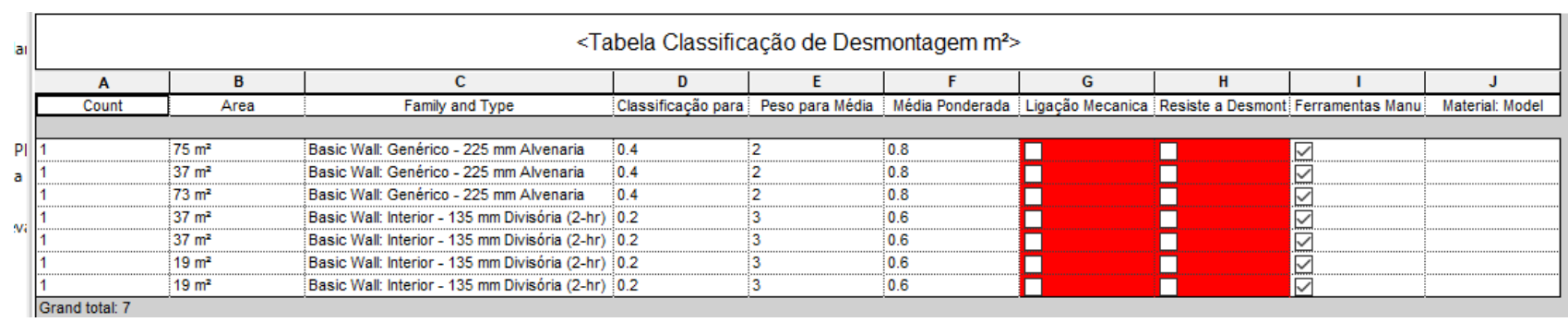

Figura 72 - Tabela com m² para a Classificação de Desmontagem 


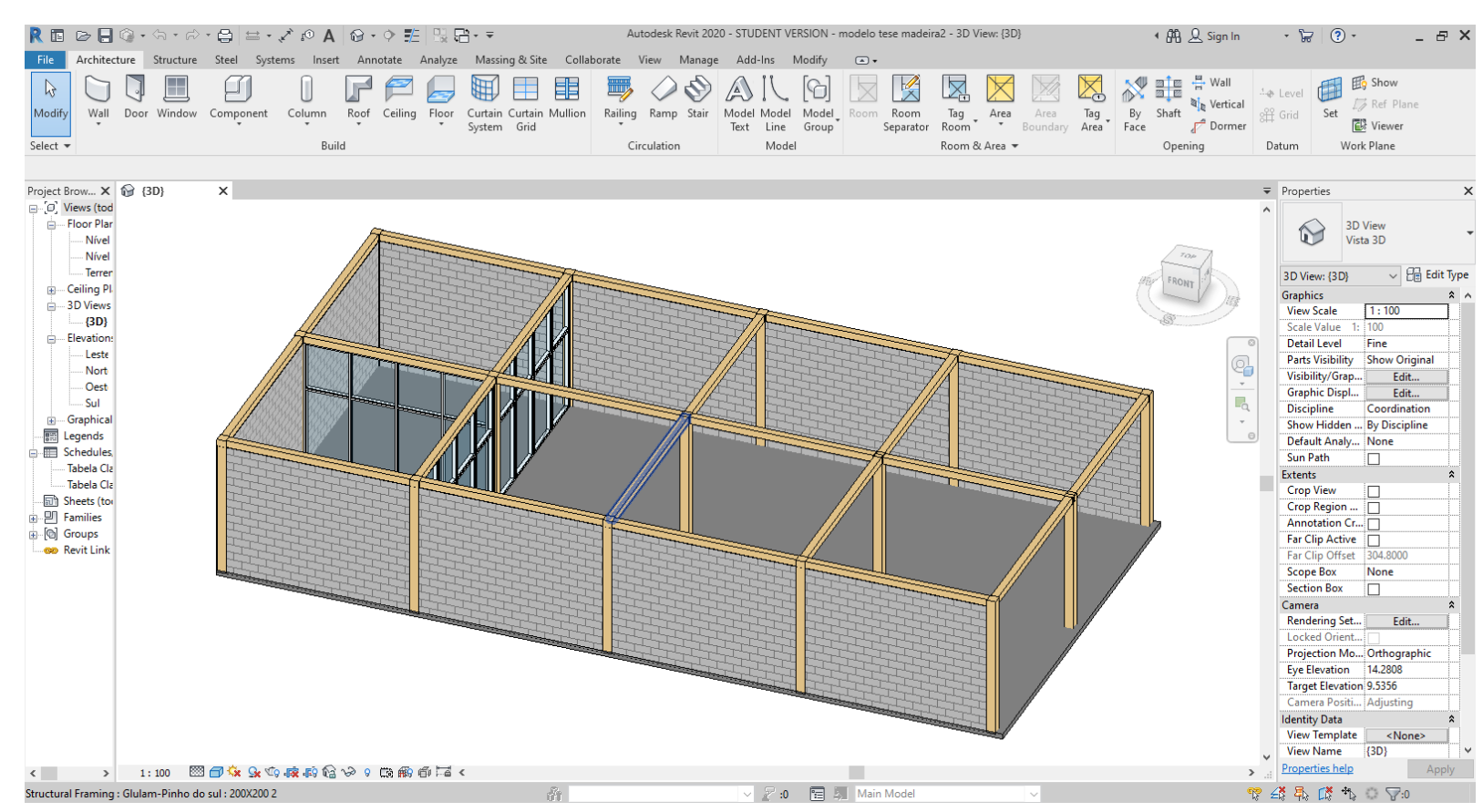

Figura 73 - Modelo conceitual 03



Figura 74 - Tabela de Unidades para a Classificação de Desmontagem

\begin{tabular}{|c|c|c|c|c|c|c|c|c|c|}
\hline A & $B$ & C & $D$ & 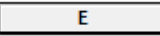 & $\mathrm{F}$ & G & $\mathrm{H}$ & 1 & $\mathrm{~J}$ \\
\hline Count & Area & Family and Type & Classificação de D & Peso para Média & Média Ponderada & Ligaçẫo Mecanica & Resiste a Desmont & Ferramentas Manu & Material: Model \\
\hline 1 & $80 \mathrm{~m}^{2}$ & Basic Wall: Genéri & 0.8 & 2 & 1.6 & 口 & 四 & V & \\
\hline 1 & $41 \mathrm{~m}^{2}$ & Basic Wall: Genéri & 0.8 & 2 & 1.6 & [ & V & v & \\
\hline 1 & $80 \mathrm{~m}^{2}$ & Basic Wall: Genéri & 0.8 & 2 & 1.6 & E & 四 & {[} & \\
\hline
\end{tabular}

Figura 75 - Tabela com m² para a Classificação de Desmontagem

Portanto, quando os projetos são modelados em Revit neste template, é possível inserir a classificação de desmontagem até mesmo em novos elementos e diferentes materiais. Automaticamente já é gerada a tabela, que é atualizada conforme as mudanças do projeto, tornando mais prática e objetiva a avaliação da desmontabilidade do edifício. Além disso, a futura desmontagem deve ser considerada desde o início do projeto e não pode se perder ao longo das decisões que devem ser tomadas. 
Após a modelagem, os parâmetros sobre desmontagem foram inseridos, bem como suas respectivas classificações. Assim, foi possível gerar a tabela para quantificar e gerar o cálculo do edifício como um todo. Foi possível fazer todas as etapas e análises neste software e em um único arquivo, que pode gerar diversos documentos para serem armazenados.

Para exemplificar a utilização da classificação de desmontagem geral para edifícios, foram considerados três tipos de construção. O edifício número 01 é composto por estrutura prémoldada de concreto (C.D. 0,1), a vedação vertical externa é feita por painéis de concreto (C.D. 0,8) e as divisórias internas de tijolos com furos (C.D. 0,4). O edifício número 02 é composto por estrutura metálica parafusada (C.D. 0,8), vedação vertical externa de tijolos com furos (C.D. 0,4) e vedação vertical interna de gesso (C.D. 0,2). O edifício número 3 seria em estrutura de madeira (C.D. 1,0), vedação vertical externa de tijolos maciços (C.D. 0,8) e vedação vertical interna de vidro (C.D. 0,3).

As camadas são multiplicadas pelo peso, devido ao grau de dificuldade e aos danos causados às outras camadas, a estrutura será multiplicada por 1, as vedações por 2 e divisórias internas por 3. Como não há o número de elementos, o C.D. não será dividido. Assim, quanto maior o C.D., mais viável será a desmontagem.

O Gráfico 5 permite comparar o resultado e visualizar o resultado geral, além de verificar qual camada poderia ser considerada para buscar melhores soluções. Por exemplo, o edifício 3, mesmo sendo de estrutura metálica parafusada, o que facilitaria a desmontagem e a reutilização, possui vedação em vidro, que dificilmente é reutilizado, pois quebra na desmontagem, além de precisar de cuidados especiais no armazenamento e transporte. Além disso, as divisórias em gesso também têm poucas chances de serem reutilizadas e têm que cumprir regras especiais para seu descarte. Assim, a classificação de desmontagem total do edifício é comprometida. 


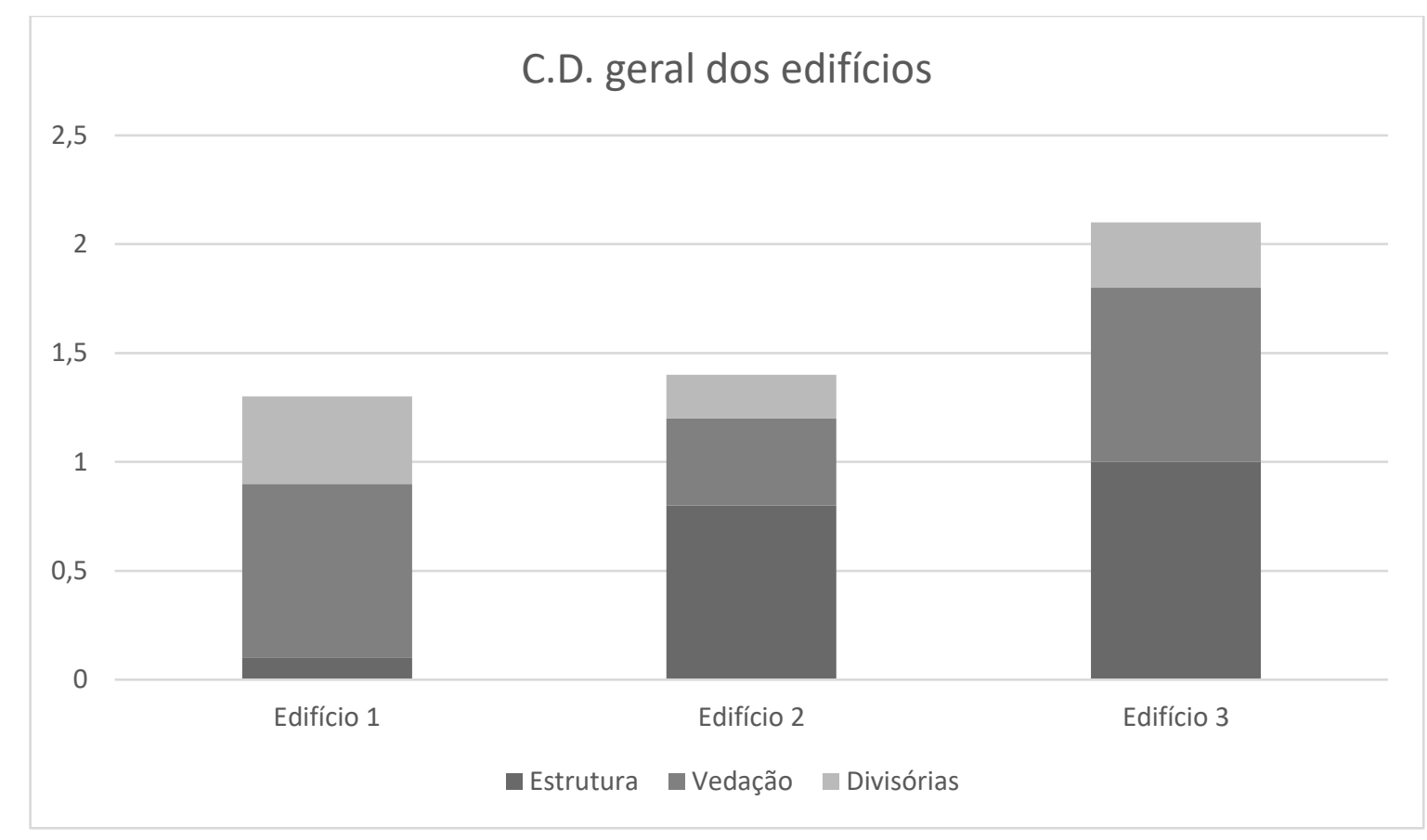

Gráfico 5 - Classificação de Desmontagem geral dos edifícios

Portanto, foi definida a classificação de desmontagem para alguns elementos e materiais de construção para explorar as ferramentas dos softwares BIM e avaliar como podem contribuir para que a desmontagem seja considerada desde o projeto. O objetivo é aumentar a desmontabilidade do edifício, para reduzir o desperdício, otimizar o reaproveitamento e facilitar tomadas de decisões ao longo do projeto.

Assim, o processo de projeto que envolve considerações sobre a desmontagem desde o início para facilitar a análise e escolha dos elementos que mais contribuem para o processo seguiu o fluxo apresentado na figura 76 . Inicialmente, foram escolhidos os materiais e elementos a serem utilizados no projeto e definidos sua classificação de desmontagem; posteriormente, a fórmula foi definida. Assim, foi possível desenvolver o projeto e o modelo 3D, depois inserir a classificação nos parâmetros. Com estas informações foi gerada a tabela, que apresentou o cálculo final. Por fim, foram feitos a conferência geral da classificação e o cálculo. 
Inserir C.D.

dos

Desenvolver o modelo 3D. elementos

nos

parâmetros.
Calcular a

média

ponderada.
Verificar o

resultado.

Figura 76 - Etapas para verificar a Classificação de Desmontagem (C.D.) Fonte: Autora

No entanto, é importante ressaltar que é necessária a cobrança da legislação ou dos consumidores, por exemplo, por meio de selos verdes e normas específicas, que exijam a destinação correta dos resíduos sólidos da construção civil e responsabilizem as empresas pelo descarte adequado ou reutilização. A partir disso, o ideal será que os materiais e elementos já venham com a classificação de desmontagem definidos e a fórmula para o cálculo. Assim, os projetistas apenas confeririam a tabela e o resultado final para escolher os materiais que mais os atendessem e o processo seria mais simples, conforme demonstra a figura 77.

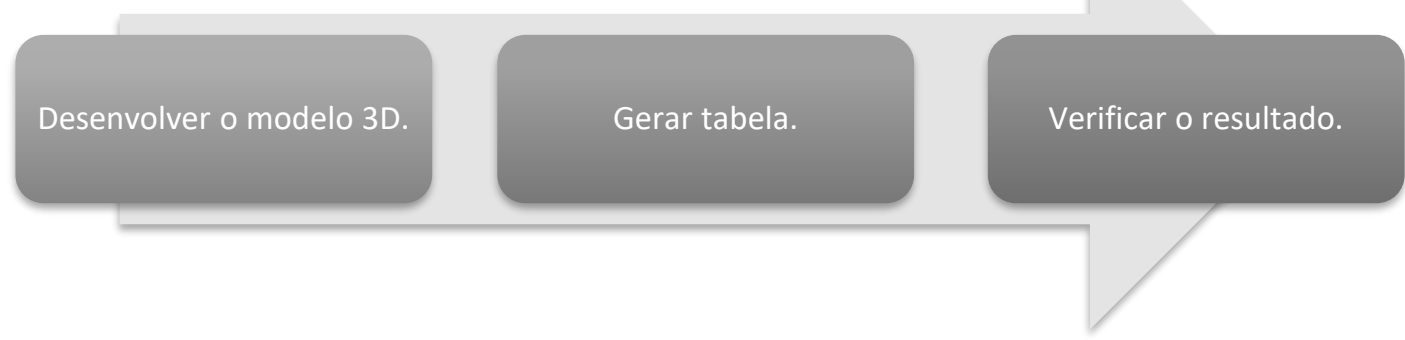

Figura 77 - Etapas para verificar a Classificação de Desmontagem (C.D.) Fonte: Autora

A figura 78 apresenta o processo de projeto que considera a desmontagem, utilizando o BIM e o cálculo da classificação de desmontagem. O ideal é que a intenção de permitir que os materiais sejam reutilizados esteja presente desde o conceito inicial do edifício; assim, já no 
pré-projeto, os profissionais escolhem opções que contribuam para o projeto e seguem recomendações para este propósito. Ao longo do desenvolvimento do projeto, é importante considerar os encaixes, definir os materiais que atendam aos requisitos de desmontagem e reuso. Por meio do modelo 3D é possível visualizar melhor o processo e realizar simulações. Questões presentes do projeto feito em BIM, com compatibilidade entre diversos projetos (arquitetônico, estrutural, hidráulico, elétrico etc.), geração de documentos, memoriais e as built também são importantes na programação da desmontagem.

Após estas definições, segue-se para a etapa de avaliação da Classificação de Desmontagem, conforme apresenta a figura 78, em que estão embutidos conceitos como resistência, análise do ciclo de vida, padronização de materiais e dimensões, escala dos elementos, dados da fabricação e considerações sobre a interferência entre camadas do edifício. Assim, os interessados poderão analisar os resultados de maneira prática e objetiva, para verificar se atendem às expectativas iniciais ou se algum ponto deve ser revisto.

A figura 79 apresenta o diagrama BPMN (Business Process Model and Notation) do Projeto para Desmontagem utilizando o BIM. O ponto de partida é que os conceitos de desmontagem e reutilização sejam considerados, desde o início da concepção do projeto, por todos os agentes envolvidos no empreendimento. A partir disso, é importante avaliar se os parâmetros dos elementos atendem às necessidades de desmontagem e reutilização, como verificar os encaixes e a resistência dos materiais à desmontagem. Feito isso, é necessário estipular a pontuação necessária da Classificação de Desmontagem e também para o checklist. 




Figura 78 - Processo de Projeto que considera o DfD e a utilização da Classificação de Desmontagem Fonte: Autora 


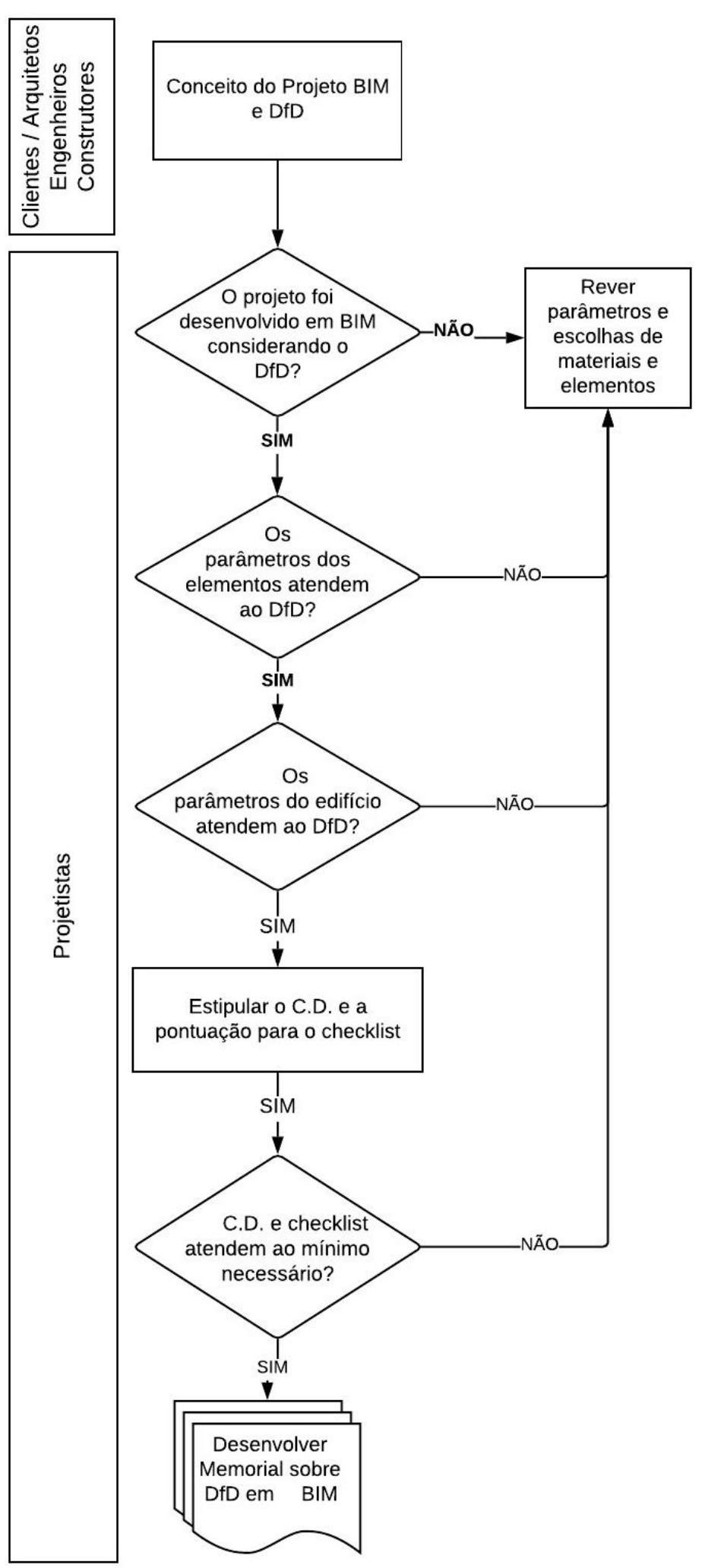

Figura 79 - BPMN de BIM e DfD

Fonte: Autora 
Portanto, estas ferramentas podem auxiliar os profissionais a terem melhores resultados no Projeto para Desmontagem e auxiliar nas decisões. Além disso, futuramente, quando o edifício não atender mais às necessidades dos usuários, será possível fazer as intervenções necessárias ou até a desmontagem, reduzindo o desperdício de materiais e aumentando a possibilidade de reuso.

\subsubsection{Plugin de checklist para avaliar o DfD}

O software Revit permite desenvolver plugins ${ }^{15}$ para as necessidades específicas dos projetistas. Em caráter exploratório desta ferramenta, foi desenvolvido um plugin com um checklist sobre desmontagem. O checklist foi desenvolvido na dissertação de mestrado da autora e foi complementado e adaptado ao plugin ao longo do desenvolvimento desta tese.

Esta ferramenta foi desenvolvida para verificar as possibilidades do software. Inicialmente, a autora, que tem conhecimento sobre Revit suficiente para desenvolver um projeto de arquitetura, propôs-se a fazer um plugin. No entanto, foi necessário conhecimento sobre programação; assim, foi preciso o auxílio de um programador no processo. O programador não tem conhecimento sobre arquitetura, nem Revit, porém, após apenas uma reunião e algumas conversas, foi possível desenvolver o plugin.

O plugin permite que, ao longo do projeto, o edifício seja avaliado como um todo e se suas características atendem ao Projeto para Desmontagem, o que facilita a tomada de decisões dos projetistas e também auxilia na abordagem de questões importantes para a desmontagem.

\footnotetext{
${ }^{15}$ Plugin é um programa de computador que adiciona funções a um programa maior, com alguma funcionalidade específica.
} 


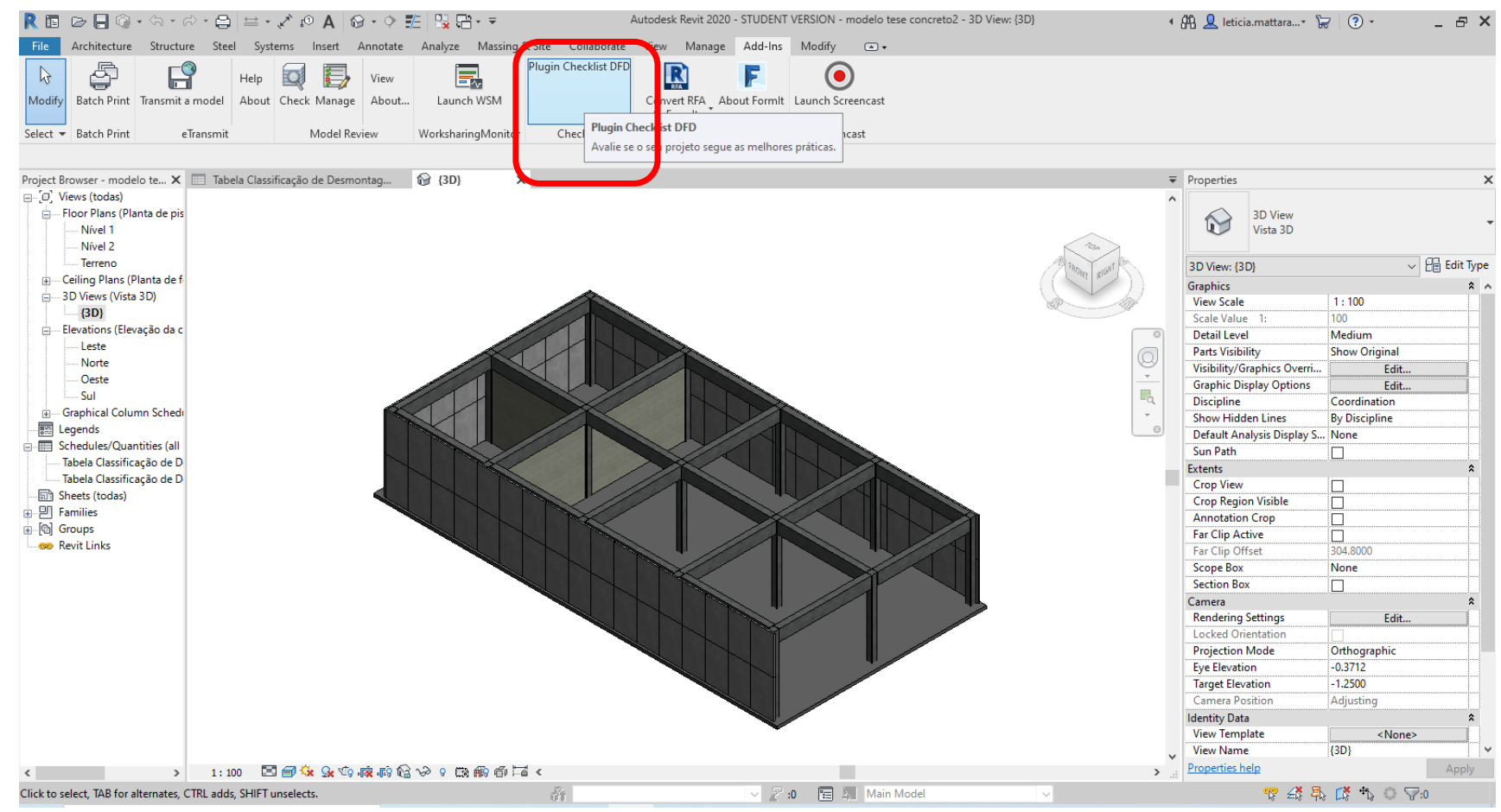

Figura 80 - Nas páginas add-in foi inserido o plugin para o checklist.

Fonte: Autora

A figura 80 apresenta o botão do checklist inserido no programa computacional. As figuras 81, 82 e 83 mostram as questões inseridas no checklist referente a desmontagem. Ao clicar, aparecem as questões com opção de resposta "sim" ou "não". Ao final a respostas são apresentadas com a quantidade de respostas "sim" ou "não". Assim é possível fazer uma avaliação quantitativa do edifício a ser desmontado. 
1. As ligações e conexões entre elementos e materiais facilitam a desmontagem das peças sem danificálas?
$\bigcirc \operatorname{sim}$
Não

2. É possivel separar os elementos com ferramentas manuais?

$\bigcirc \operatorname{sim} \bigcirc$ Não

3. Os elementos são padronizados?

\section{$\bigcirc \operatorname{Sim} \bigcirc$ Não}

4. 0 s elementos são resistentes à desmontagem e remontagem?
Sim
ก กั๊

5. Despois de desmontados é possivel armanezar e transportar os elementos de maneira prática?

\section{Sim $\bigcirc$ Não}

6. Os elementos e materiais estão identificados?
$\bigcirc \operatorname{Sim}$
Não

7. 0s elementos não possuem acabamentos químicos de difícil remoção?
$\bigcirc \operatorname{sim}$
กักัว

8. Os materiais não são tóxicos nem danosos ao meio-ambiente?
Sim
Não

9. 0 sistema construtivo é modular?
$\bigcirc \operatorname{sim}$
Não

10. Os elementos são pré-fabricados?
$\bigcirc \operatorname{Sim}$
Não

11. 0 projeto está atualizado conforme a construção e manutenção?
$\bigcirc \sin$
Não

12. Há diretrizes e medidas para facilitar a manutenção do edifício?
Sim
กัก

13. Há diretrizes e medidas para facilitar a desmontagem do edifício?
$\bigcirc \operatorname{sim}$
Não

14. Os documentos são de fácil acesso e compativeis com diversos softwares?

\section{Figura 81 - Questões inseridas no plugin Fonte: Autora}


Plugin Checklist DFD

$\smile u$ Un! $\quad$ irau

9. 0 sistema construtivo é modular?

$\bigcirc \operatorname{sim} \bigcirc$ Não

10. 0 s elementos são pré-fabricados?

$\bigcirc \operatorname{sim} \bigcirc$ Não

11. 0 projeto está atualizado conforme a construção e manutençã̃o?

$\bigcirc \operatorname{sim} \bigcirc$ Não

12. Há diretrizes e medidas para facilitar a manutenção do edifício?

$\bigcirc \operatorname{sim} \bigcirc$ Não

13. Há diretrizes e medidas para facilitar a desmontagem do edifício?

$\bigcirc \operatorname{sim} \bigcirc$ Não

14. Os documentos são de fácil acesso e compatíveis com diversos softwares?

$\bigcirc \operatorname{sim} \bigcirc$ Não

15. Há análise do ciclo de vida dos materiais utilizados?

$\bigcirc \operatorname{sim} \bigcirc$ Não

16. Algum material ou elemento já é reutilizado nesta obra?
$\bigcirc \operatorname{Sim}$
Não

17. Caso o elemento não possa ser reutilizado diretamente é possível reciclar?
$\bigcirc \mathrm{Sim}$
Não

18. Foi considerado acesso às diferentes camadas do edifício sem danificar as demais?
$\bigcirc \operatorname{sim}$
Não

19. Existem elementos embutidos, mas que são de fácil acesso e manutenção, sem danificar os demais?
Sim
กักัว

20. Foi feita uma previsão de tempo e custo para desmontagem?

$$
\text { Sim } \bigcirc \text { Não }
$$
Responder
Cancelar

Figura 82 - Questões inseridas no plugin

Fonte: Autora 


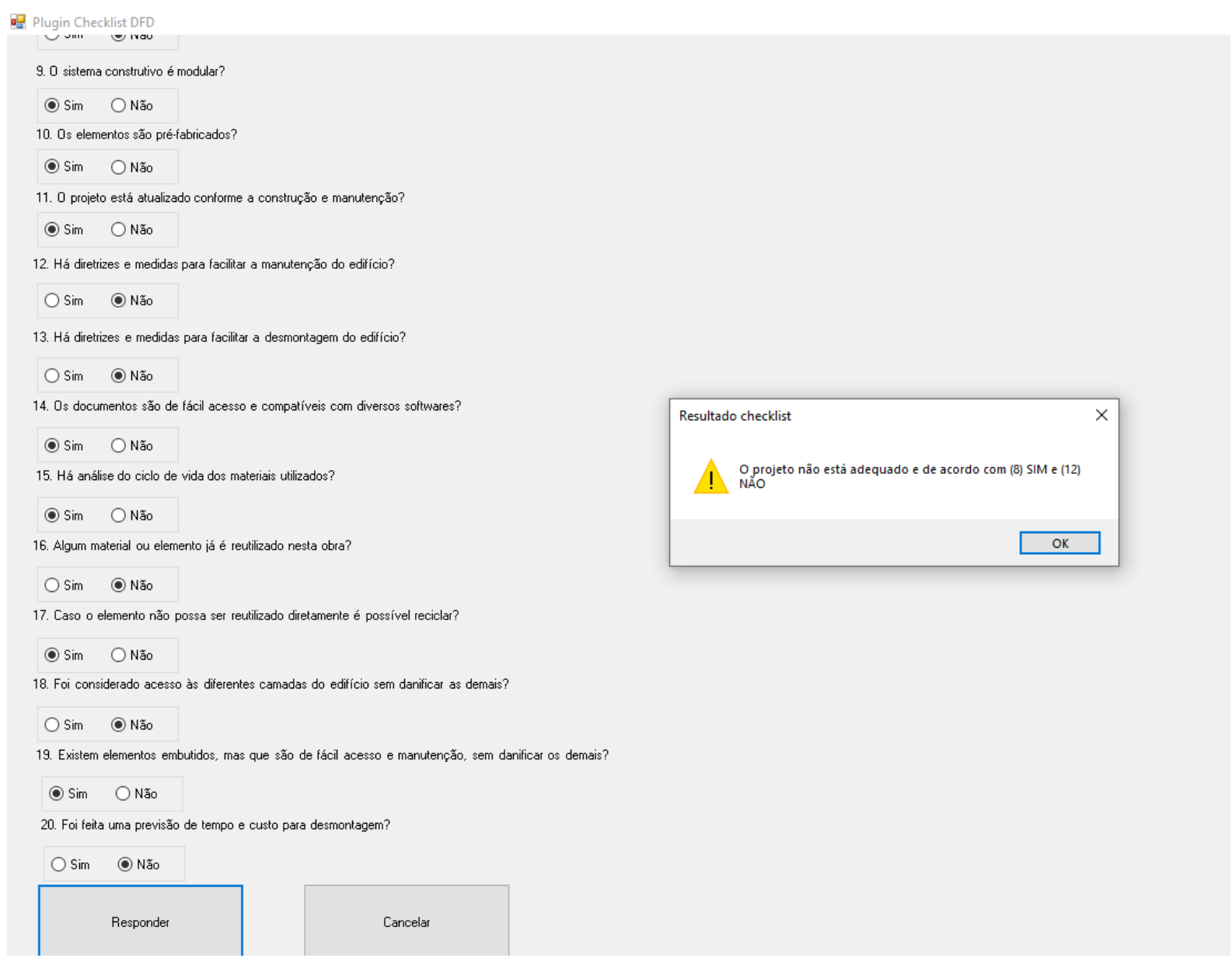

Figura 83 - Resultado das questões no plugin

Fonte: Autora

Ao final, aparece o número de respostas positivas e negativas. Neste caso, das 20 perguntas, 08 foram "sim" e 12 "não".

A escolha por um plugin com checklist sobre desmontagem é para auxiliar o projetista e demais agentes envolvidos, ao longo do projeto, para que eles mesmos verifiquem se está sendo seguido o que foi proposto, pois, para que exista um Projeto para Desmontagem, é importante que isso seja considerado desde o início e não se perca ao longo do desenvolvimento do projeto. As perguntas foram formuladas na dissertação de mestrado da autora e atualizadas.

Além disso, as questões estão diretamente relacionadas às características que contribuem para o potencial de desmontagem apresentadas ao longo deste trabalho. 
1. As ligações e conexões entre elementos e materiais facilitam a desmontagem das peças sem danificá-las?

2.É possível separar os elementos com ferramentas manuais?

3. Os elementos são padronizados?

4. Os elementos são resistentes à desmontagem e remontagem?

5. Depois de desmontados, é possível armazenar e transportar os elementos de maneira prática?

6. Os elementos e materiais estão identificados?

7. Os elementos não possuem acabamentos químicos de difícil remoção?

8. Os materiais não são tóxicos nem danosos ao meio ambiente?

9. O sistema construtivo é modular?

10. Os elementos são pré-fabricados?

11. O projeto está atualizado conforme a construção e manutenção?

12. Há diretrizes e medidas para facilitar a manutenção do edifício?

13. Há diretrizes e medidas para facilitar a desmontagem do edifício?

14. Os documentos são de fácil acesso e compatíveis com diversos softwares?

15. Há análise do ciclo de vida dos materiais utilizados?

16. Algum material ou elemento já está sendo reutilizado nesta obra?

17. Caso o elemento não possa ser reutilizado diretamente, é possível reciclar?

18. Foi considerado o acesso às diferentes camadas do edifício sem danificar as demais?

19. Existem elementos embutidos, mas que são de fácil acesso e manutenção, sem danificar os demais?

20. Foi feita uma previsão de tempo e custo para desmontagem?

Dessa maneira, o checklist serve como verificação para checar as características gerais do edifício e se continuam de acordo com a proposta inicial de projetar para facilitar a desmontagem e o reuso. Além disso, foi possível verificar as ferramentas do software Revit para a criação de plugin.

Para que as informações não se percam, é necessário reuni-las e facilitar o seu acesso após a obra concluída e durante a manutenção do edifício; assim um memorial voltado para o Projeto para Desmontagem pode conter todas as questões abordadas em relação à desmontagem e reutilização dos materiais. 


\subsubsection{Memorial sobre o Projeto para Desmontagem}

O BIM apresenta inúmeras ferramentas que auxiliam no DfD e resultados positivos se resultam desta união, como apresentado na figura 84. Estas ferramentas auxiliam na aplicação do Projeto para Desmontagem e na documentação e facilitam também a criação de um memorial que ajudará a futura desmontagem.

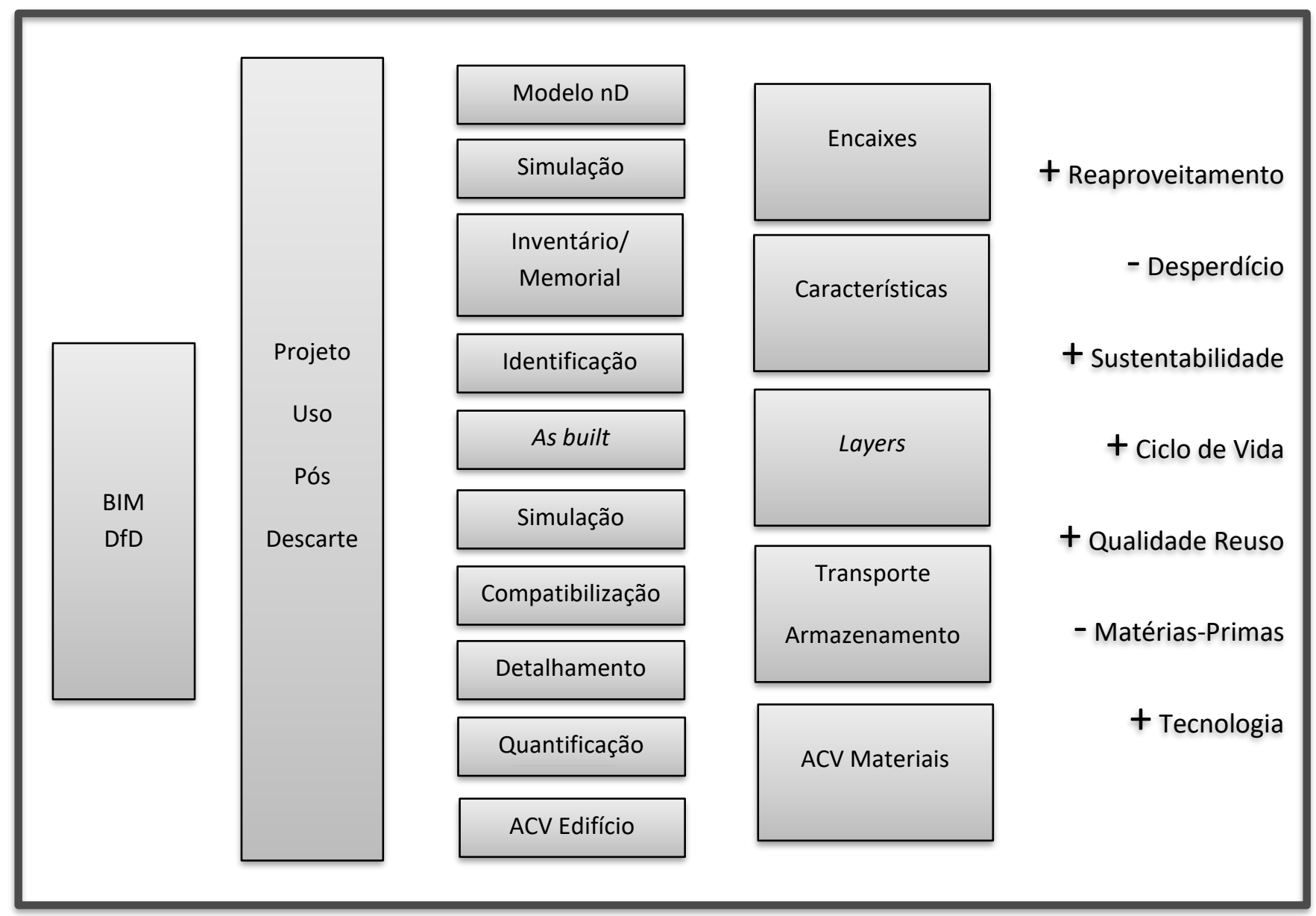

Figura 84 - Considerações do BIM e DfD e resultados Fonte: Autora

Uma das dificuldades em planejar a desmontagem de um edifício é a falta de informações dos materiais e elementos utilizados, que é prejudicial até mesmo para a manutenção. Informações como ciclo de vida, composição dos elementos, expectativa de vida, conexões, entre outras, podem facilitar melhor programação da manutenção e desmontagem. 
A reunião de informações voltadas para o DfD contribui para o planejamento da desmontagem. No Revit, é possível inserir parâmetros, em cada elemento, com conceitos DfD. Por exemplo, quando os elementos utilizam ligações mecânicas, são mais fáceis de serem desmontados, reduzindo os danos causados, facilitando, assim, o desmonte e a reutilização. Portanto, foi inserido o parâmetro "ligação mecânica", em que é possível o projetista do edifício ou do elemento indicar se atende ou não ao requisito (figura 85).

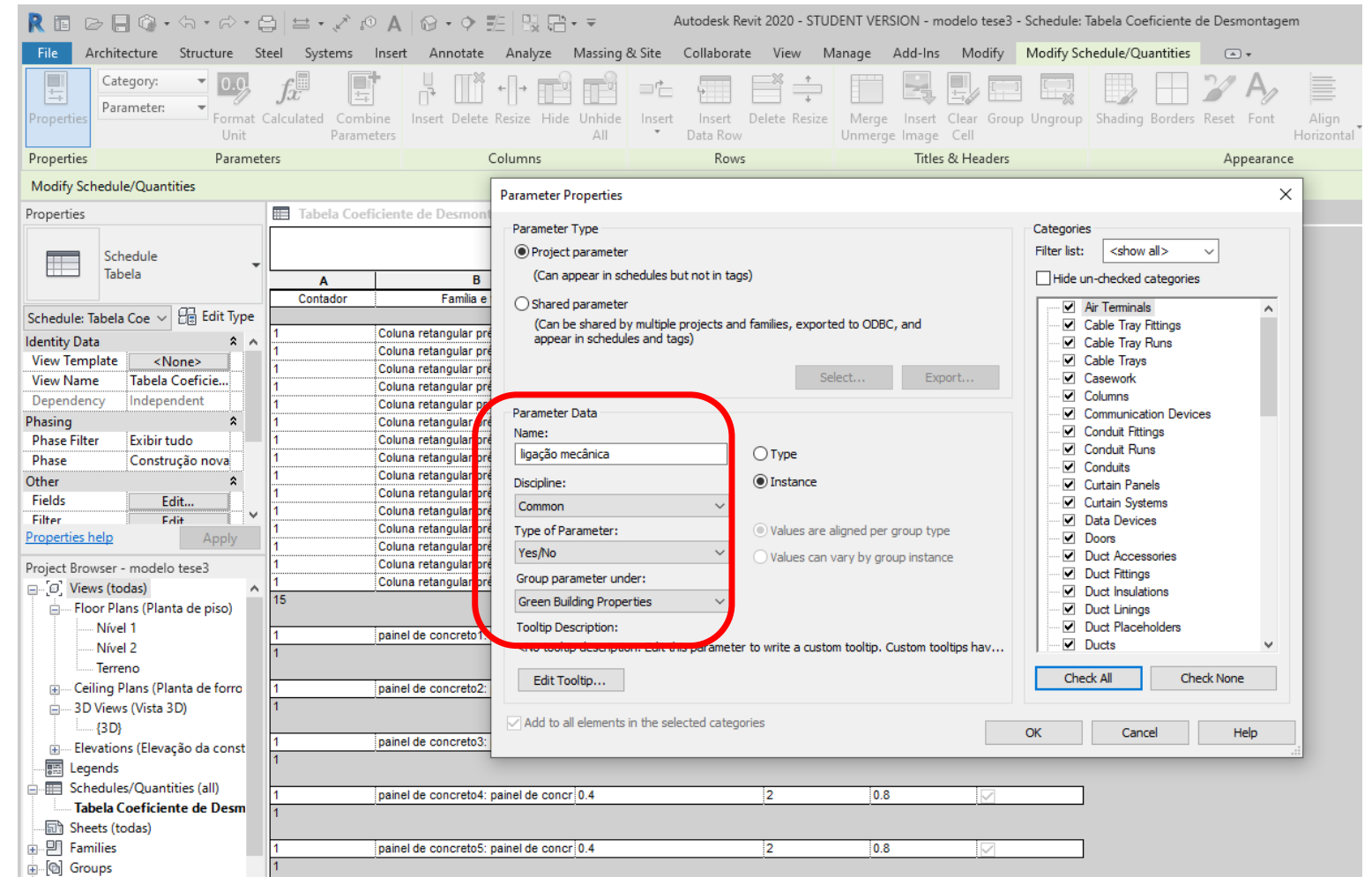

Figura 85 - Novo parâmetro DfD criado no Revit Fonte: Autora

A figura 86 apresenta o parâmetro "ligação mecânica" nas propriedades do elemento. 


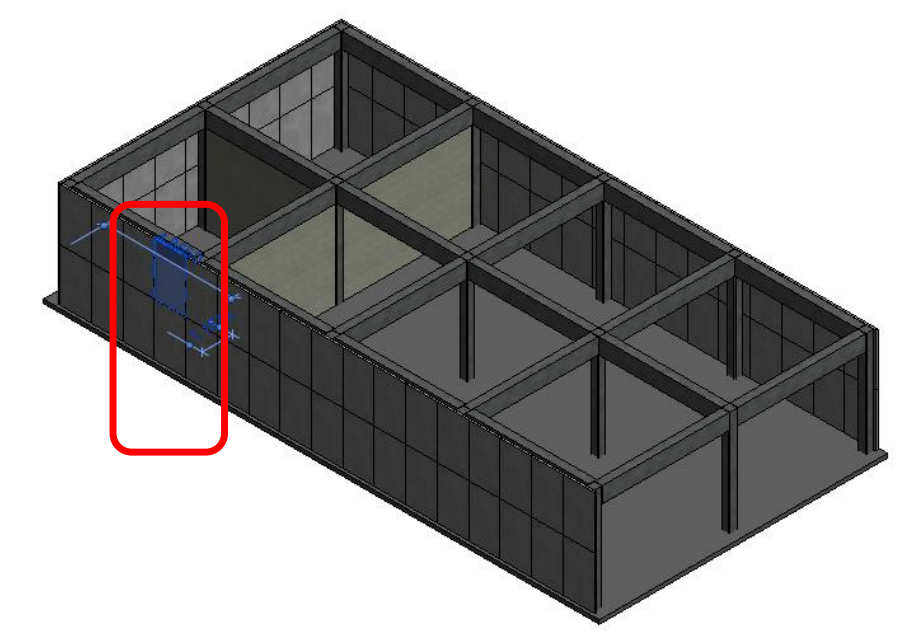

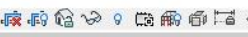



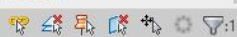

Figura 86 - Parâmetro de construção "verde" criado nas propriedades do elemento Fonte: Autora

Na figura 87 encontra-se o parâmetro "ligação mecânica", na tabela da Classificação de Desmontagem.

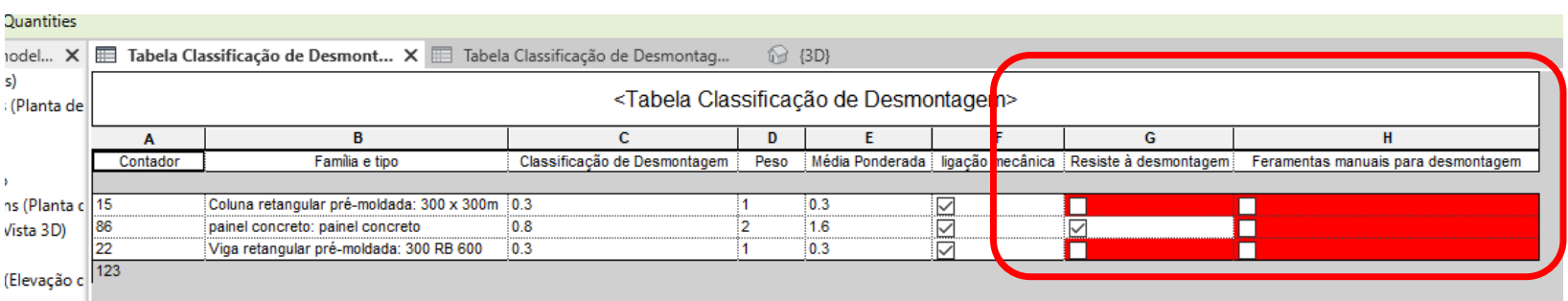

Figura 87 - Parâmetro de construção "verde" criado na tabela Fonte: Autora

Além disso, informações sobre a construção do edifício, como suas camadas, como foi construído, como ter acesso aos elementos, o que é visível e o que está embutido em shafts e alvenarias, quais ferramentas seriam necessárias para desmontar e remover os materiais, contribuem para que a desmontagem seja mais rápida e eficiente. Dessa maneira, o BIM pode reunir informações, que podem ser inseridas ao longo do desenvolvimento do projeto, ao longo da construção e manutenção. 
No entanto, podem ocorrer problemas em relação à compatibilidade, pois nem todos os softwares são totalmente compatíveis e podem aparecer erros que devem ser verificados pelos profissionais responsáveis. Com base na literatura e nas entrevistas, podemos verificar que, para reduzir erros de compatibilização, algumas medidas são tomadas, como transformar os arquivos de projetos em extensão IFC, tornando possível a utilização em diversos softwares, porém isso não elimina totalmente os erros.

Uma alternativa para minimizar os erros de compatibilidade seria criar documentos com extensões que são facilmente visualizadas em outros softwares, como DOC, PDF e JPEG (figura 88). Nestas extensões de arquivos não há muita interação com o projeto, nem é possível modificá-lo, mas as informações contidas podem ser mais bem armazenadas e acessadas. Assim, um memorial que contenha os projetos, documentos e informações sobre DfD, que podem ser acrescentadas ao longo de seu ciclo de vida, pode auxiliar na desmontagem mais precisa. 


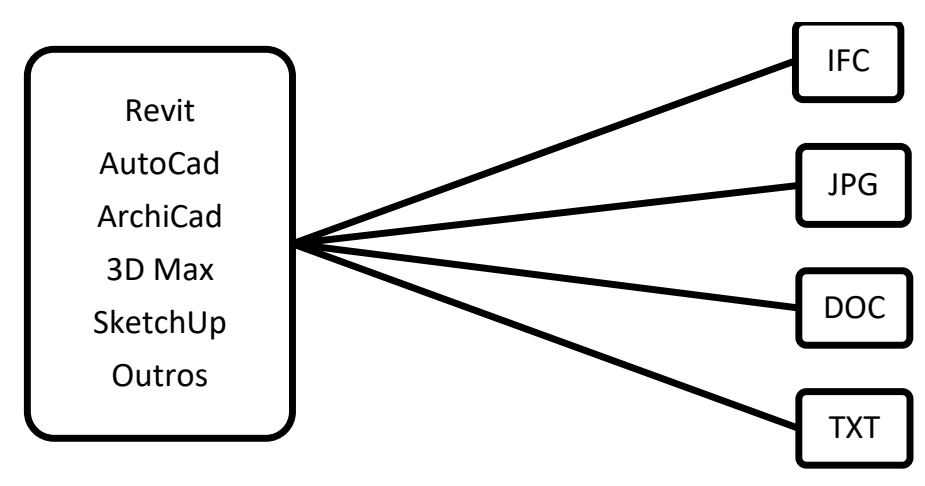

Figura 88 - Extensões de Arquivos utilizados para o Memorial DfD

O Memorial DfD deve conter os projetos (plantas, cortes, elevações, modelo 3D, detalhes construtivos e demais necessários) de arquitetura e complementares, inclusive o projeto compatibilizado e as built. Informações sobre os materiais utilizados (ciclo de vida, conexões, ferramentas utilizadas, dimensões etc.) também devem constar. Além disso, é importante atualizar as informações ao longo do ciclo de vida do edifício, principalmente se houver reformas e ampliações. A figura 89 demonstra os documentos que devem constar no memorial.

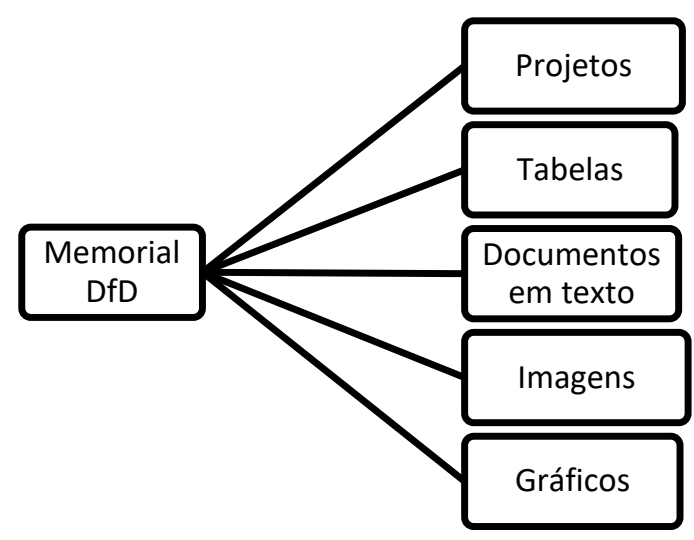

Figura 89 - Documentos que devem constar no Memorial DfD

Os softwares BIM contribuem para o processo de documentação, pois permitem extrair as informações do projeto em diversas extensões de arquivo e de maneira mais prática. Além 
disso, muitas informações são atualizadas automaticamente, como, por exemplo, se se alterar alguma propriedade de um elemento, também as tabelas e os gráficos serão alterados.

Os edifícios são complexos e envolvem variáveis, como condições físicas, econômica e ambientais. Assim, encontrar uma sequência e fórmula ideal para a desmontagem se torna inviável. No entanto, reunir as informações de todos os elementos e processo construtivo é importante para escolher a melhor solução para a desmontagem efetiva.

\subsection{Avaliações da Classificação de Desmontagem e aplicação em BIM}

Foi desenvolvido um questionário para a avaliação da Classificação de Desmontagem, que foi enviado a especialistas de sistemas estruturais com estrutura metálica, de concreto e madeira. Os selecionados são professores da engenheira civil, especialistas em pesquisas de sistemas construtivos. Assim, foi possível avaliar a relevância das características abordadas e a classificação de cada sistema.

A decisão de fazer a avaliação por questionários se dá devido à possibilidade de comparação direta dos resultados, o que permite uma análise objetiva das questões. A escolha dos participantes se deu devido ao vasto conhecimento em estrutura, assim puderam opinar sobre os materiais escolhidos para compor a classificação de desmontagem e os sistemas construtivos. O questionário foi enviado a 10 professores e foram obtidas 04 respostas.

Os participantes da pesquisa não tiveram acesso a todo o conteúdo da tese, apenas às informações apresentadas com o questionário, conforme documento presente nos anexos (item 8.2 desta tese).

O primeiro especialista é professor associado da Universidade Federal de São Carlos UFSCar, tem experiência na área de engenharia civil, com ênfase em estruturas metálicas, e atua nas áreas de estruturas espaciais, treliça espacial, ligações, estruturas mistas de aço e concreto e estabilidade das estruturas. 
Na opinião dele, a classificação de desmontagem pode auxiliar no desenvolvimento do projeto e na escolha de materiais com maior potencial para serem desmontados e reutilizados, pois a logística reversa pode se tornar uma realidade também para o setor da construção civil e a classificação pode ser um ponto de partida. Além disso, ele acredita que a tabela de classificação pode contribuir para a escolha de materiais com maior potencial para serem desmontados, reutilizados e reciclados, porque parece ser eficiente. Ele não indicou falhas na classificação, que está de acordo com a categorização de cada material ou elemento e o peso (para cálculo da média ponderada) atribuído a eles.

De acordo com suas respostas, ele considera que foi adequada a escolha dos materiais e componentes a serem analisados, porque são os principais elementos da construção civil. Ele concorda com a fórmula apresentada e ressalta que alguns materiais não podem ser reaproveitados, mas podem ser reciclados, pois já existem pesquisas sobre concreto com agregados reciclados (blocos cerâmicos e semelhantes) e adição de pó de vidro, por exemplo. Em relação à opinião sobre se um template e um checklist, desenvolvidos em BIM, voltados para a desmontagem, poderiam contribuir para o processo a resposta foi não, porém esta resposta não estava na formatação correta e não foi respondido o porquê. Segundo a opinião do entrevistado, a maior barreira para a utilização do Projeto para Desmontagem em BIM e a utilização da Classificação de Desmontagem seria todas as opções apresentadas no questionário (falta de exigência legal; falta de exigência do cliente; considerar a desmontabilidade na fase de projeto pelos profissionais envolvidos; complexidade em considerar o Projeto para Desmontagem em BIM; tempo e custo que agregaria ao desenvolvimento do projeto), pois são barreiras importantes e interconectadas. Por fim, ele analisa a classificação de desmontagem dos elementos de forma muito interessante, não apresentando críticas, mas sugere um estudo de caso para aferir o processo.

O segundo especialista é docente do Departamento de Engenharia de Estruturas da Universidade de São Paulo. É engenheiro civil, mestre e doutor em Estruturas pela Escola de Engenharia de São Carlos da Universidade de São Paulo. Desenvolve pesquisas no campo 
de estruturas metálicas, estruturas mistas de aço e concreto e análise experimental de estruturas.

Na opinião dele, a classificação de desmontagem pode auxiliar no desenvolvimento do projeto e na escolha de materiais com maior potencial para serem desmontados e reutilizados. Ele acredita que a tabela pode contribuir para a escolha de materiais com maior potencial para serem desmontados, reutilizados ou até mesmo reciclados. O participante não indica falhas na classificação de desmontagem e concorda com a classificação de cada material ou elemento e o peso (cálculo da média ponderada) atribuído a eles. Ele considera que foi adequada a escolha dos materiais e componentes a serem analisados, porém ela pode ser complementada com materiais compósitos nas vedações internas, por exemplo, os compósitos de madeira ou plástico.

De acordo com a opinião dele, a fórmula desenvolvida para medir o potencial de desmontagem do edifício está adequada; além disso, um template e um checklist, desenvolvido em BIM, voltado para a desmontagem, pode contribuir para o processo. Ele afirma que a maior barreira para a utilização do Projeto para Desmontagem em BIM e utilização da Classificação de Desmontagem é a falta de exigência do cliente. Por fim, a proposta para a classificação de desmontagem, de modo geral, está bem elaborada e engloba os pontos centrais que devem nortear o projeto, portanto entende-se que ela tem potencial para evolução.

O terceiro especialista possui graduação em Engenharia Civil pela Universidade Federal de Juiz de Fora, mestrado e doutorado em Engenharia de Estruturas pela Universidade de São Paulo. Colabora com a Associação Brasileira de Normas Técnicas e é professor associado da Universidade de São Paulo. Atua principalmente nos seguintes temas: análise estrutural de edifícios, métodos numéricos e análise experimental.

Para ele, a classificação de desmontagem pode auxiliar no desenvolvimento do projeto e na escolha de materiais com maior potencial para serem desmontados e reutilizados porque 
orienta a sua utilização com um objetivo bem definido. Ele acredita que a tabela pode contribuir para a escolha de materiais com maior potencial para serem desmontados e reutilizados ou até mesmo reciclados pela organização e sistematização que possibilita. Além disso, não indica falhas na Classificação de Desmontagem e concorda com a classificação de cada material ou elemento e o peso (para cálculo da média ponderada) atribuído a eles.

O avaliador considera boa a escolha dos materiais e componentes a serem analisados por serem os mais empregados na construção civil. Ele considera a fórmula adequada, pois trata o assunto de maneira organizada e é flexível na determinação de outros pesos, caso o usuário necessite. Em relação se um template e checklist, desenvolvido em BIM, voltado para a desmontagem, poderia contribuir com o processo, ele afirma não ter como opinar por desconhecer tal ferramenta. Portanto, avaliou a classificação de desmontagem dos elementos como uma ideia muito interessante e com grande potencial de utilização, desde que o BIM esteja mais difundido no setor da construção civil e se torne uma ferramenta usual.

A quarta especialista é professora do Departamento de Engenharia de Estruturas da Escola de Engenharia de São Carlos, da Universidade de São Paulo, possui graduação em engenharia civil, mestrado e doutorado em engenharia de estruturas pela Universidade de São Paulo. Tem experiência na área de engenharia de estruturas, com ênfase em estruturas de concreto armado e mistas, concretos de alto desempenho, aderência aço-concreto, pilares mistos preenchidos e ligações viga-pilar.

Na opinião dela, a classificação de desmontagem pode auxiliar no desenvolvimento do projeto e na escolha de materiais com maior potencial para serem desmontados e reutilizados. No caso de ser uma estrutura temporária, ou com período de utilização limitado, essa classificação poderia direcionar as escolhas feitas na fase de projeto. Ela acredita que a tabela pode servir como um indicativo da solução mais adequada, com materiais com maior potencial para serem desmontados e reutilizados ou reciclados. 
Em relação a falhas na classificação de desmontagem, ela afirma não ter conhecimento suficiente para avaliar a classificação feita, porém questiona alguns pesos, como 1.0 para a madeira, já que as ligações por encaixe, que serviram para justificar o valor, são apenas uma parcela das ligações possíveis; além disso, o custo da desmontagem tem que ser justificado pela durabilidade do material, em que, na opinião dela, nem sempre se sai tão bem. O valor 0,3 para estrutura pré-moldada parece baixo quando confrontado com 1.0 das estruturas em madeira. Ela concorda com a classificação de cada material ou elemento e o peso (para cálculo da média ponderada) atribuído a eles, afirma que a importância do material é inegável, mas o peso também é uma varável a ser considerada, já que, certamente, irá influir no custo do transporte.

A avaliadora está de acordo com a escolha dos materiais e componentes a serem analisados, pois são de uso mais comum. Ela afirma que a fórmula desenvolvida para medir o potencial de desmontagem do edifício é adequada, embora não tenha condições de avaliar melhor os resultados. Um template e checklist, desenvolvido em BIM, voltado para a desmontagem poderia contribuir para o processo, pois tudo o que puder facilitar as escolhas pode ajudar.

Na opinião dela, a maior barreira para utilização do Projeto para Desmontagem em BIM e utilização da Classificação de Desmontagem é a falta de cultura para se fazer o planejamento de longo prazo das edificações, com a inclusão de todos os custos envolvidos. Por fim, afirma que a classificação de desmontagem é um fator a mais para ajudar os projetistas a fazerem escolhas durante a fase de planejamento.

A tabela 14 apresenta as respostas e os comentários de todos os participantes do questionário sobre a Classificação de Desmontagem e o desenvolvimento dos modelos com parâmetros classificatórios.

Tabela 14 - Respostas dos especialistas em estrutura sobre o questionário de Classificação (Continua) de Desmontagem

\begin{tabular}{|l|l|l|c|l|}
\hline Perguntas & SIM & NÃO & $\begin{array}{c}\text { Não } \\
\text { assinalou }\end{array}$ & Por quê \\
\hline
\end{tabular}




\begin{tabular}{|c|c|c|c|c|}
\hline $\begin{array}{l}\text { 1- Na sua opinião, a } \\
\text { classificação de } \\
\text { desmontagem pode auxiliar } \\
\text { no desenvolvimento do } \\
\text { projeto e escolhas de } \\
\text { materiais com maior } \\
\text { potencial para ser } \\
\text { desmontado e reutilizado? }\end{array}$ & 4 & & & $\begin{array}{l}\text { Especialista 01: A logística reversa } \\
\text { pode se tornar uma realidade também } \\
\text { para o setor e isso pode ser um ponto } \\
\text { de partida. } \\
\text { Especialista 03: Porque orienta a sua } \\
\text { utilização com um objetivo bem } \\
\text { definido. } \\
\text { Especialista 04: Caso seja uma } \\
\text { estrutura temporária, ou com período } \\
\text { de utilização limitado, essa } \\
\text { classificação poderia direcionar as } \\
\text { escolhas feitas na fase de projeto. }\end{array}$ \\
\hline $\begin{array}{l}\text { 2- Você acredita que a } \\
\text { tabela pode contribuir para a } \\
\text { escolha de materiais com } \\
\text { maior potencial para serem } \\
\text { desmontados e reutilizados } \\
\text { ou até mesmo reciclados? }\end{array}$ & 4 & & & $\begin{array}{l}\text { Especialista 01: A classificação me } \\
\text { parece bem eficiente. } \\
\text { Especialista 03: Pela organização e } \\
\text { sistematização que possibilita. } \\
\text { Especialista 04: Pode servir como um } \\
\text { indicativo da solução mais adequada. }\end{array}$ \\
\hline $\begin{array}{l}\text { 3- Você indicaria falhas na } \\
\text { Classificação de } \\
\text { Desmontagem? }\end{array}$ & & 3 & 1 & $\begin{array}{l}\text { Especialista 01: não pude perceber } \\
\text { falhas em que possa contribuir. } \\
\text { Especialista 04: não tenho } \\
\text { conhecimento suficiente para avaliar a } \\
\text { classificação feita. } \\
\text { Entretanto, alguns pesos me parecem } \\
\text { questionáveis. Adotar o valor } 1,0 \text { para a } \\
\text { madeira é, no mínimo, estranho, já que } \\
\text { as ligações por encaixe, que serviram } \\
\text { para justificar o valor, são apenas uma } \\
\text { parcela das ligações possíveis. Além } \\
\text { disso, o custo da desmontagem tem } \\
\text { que ser justificado pela durabilidade do } \\
\text { material, quesito no qual a madeira nem } \\
\text { sempre se sai tão bem. Já o valor } 0,3 \\
\text { para estruturas pré-moldadas, mesmo } \\
\text { considerando a estrutura como um } \\
\text { todo, parece muito baixo, } \\
\text { principalmente ao ser confrontado com } \\
\text { o 1,0 das estruturas em madeira. }\end{array}$ \\
\hline $\begin{array}{l}\text { 4- Você concorda com a } \\
\text { classificação de cada } \\
\text { material ou elemento e o } \\
\text { peso (para cálculo da média } \\
\text { ponderada) atribuído a eles? }\end{array}$ & 4 & & & $\begin{array}{l}\text { Especialista 04: Acho que a } \\
\text { importância do material é inegável, mas } \\
\text { o peso também é uma variável a ser } \\
\text { considerada, já que certamente irá } \\
\text { influir no custo do transporte. }\end{array}$ \\
\hline
\end{tabular}


Tabela 14 - Respostas dos especialistas em estrutura sobre o questionário de Classificação (Continua) de Desmontagem

\begin{tabular}{|c|c|c|c|c|}
\hline $\begin{array}{l}\text { 5- Você considera que foi } \\
\text { boa a escolha dos materiais } \\
\text { e componentes a serem } \\
\text { analisados? Acrescentaria } \\
\text { mais algum material? }\end{array}$ & 4 & & & $\begin{array}{l}\text { Especialista 01: Foram cobertos os } \\
\text { principais elementos da construção. } \\
\text { Especialista 02: A tabela pode ser } \\
\text { complementada com materiais } \\
\text { compósitos nas vedações internas, por } \\
\text { exemplo, os compósitos de madeira ou } \\
\text { plásticos. } \\
\text { Especialista 03: Por serem os mais } \\
\text { empregados na construção civil. } \\
\text { Especialista 04: Foram escolhidos os } \\
\text { materiais de uso mais comum. }\end{array}$ \\
\hline $\begin{array}{l}\text { 6- Você considera adequada } \\
\text { a fórmula desenvolvida para } \\
\text { medir o potencial de } \\
\text { desmontagem do edifício? } \\
\frac{(\text { C.D. de cada elemento }}{x \text { Média) }} n^{\circ} \text { elementos (ou } \\
m^{2} \text { ) }\end{array}$ & 4 & & & $\begin{array}{l}\text { Especialista 01: Ocorreu-me que alguns } \\
\text { materiais que não costumam ser } \\
\text { reaproveitados podem ser reciclados. Já } \\
\text { são frequentes pesquisas em concreto } \\
\text { com agregados reciclados (blocos } \\
\text { cerâmicos e } \\
\text { assemelhados) e adição de pó de vidro. } \\
\text { Não sei se esses aspectos poderiam ser } \\
\text { contemplados de alguma forma. } \\
\text { Especialista 03: Trata o assunto de } \\
\text { maneira organizada e é flexível na } \\
\text { determinação de outros pesos, caso o } \\
\text { usuário assim o deseje. } \\
\text { Especialista 04: Parece adequada, } \\
\text { embora não tenha condições de avaliar } \\
\text { melhor os seus resultados. }\end{array}$ \\
\hline $\begin{array}{l}\text { 7- Na sua opinião, um } \\
\text { template e checklist, } \\
\text { desenvolvido em BIM, } \\
\text { voltado para a } \\
\text { desmontagem, } \\
\text { poderia contribuir para o } \\
\text { processo? }\end{array}$ & 2 & 1 & 1 & $\begin{array}{l}\text { Especialista 03: Não tenho como opinar } \\
\text { por desconhecer tal ferramenta. } \\
\text { Especialista 04: Tudo o que puder } \\
\text { facilitar as escolhas pode ajudar. }\end{array}$ \\
\hline
\end{tabular}


Tabela 14 - Respostas dos especialistas em estrutura sobre o questionário de Classificação (Conclusão) de Desmontagem

\begin{tabular}{|c|c|c|c|c|}
\hline $\begin{array}{l}\text { 8- Na sua opinião, qual seria } \\
\text { a maior barreira para } \\
\text { utilização do Projeto para } \\
\text { Desmontagem em } \\
\text { BIM e utilização da } \\
\text { Classificação de } \\
\text { Desmontagem? } \\
\text { a. Falta de exigência Legal. } \\
\text { b. Falta de exigência do } \\
\text { cliente. } \\
\text { c. Considerar a } \\
\text { desmontabilidade na fase de } \\
\text { projeto, pelos profissionais } \\
\text { envolvidos. } \\
\text { d. Complexidade em } \\
\text { considerar o Projeto para } \\
\text { Desmontagem em BIM. } \\
\text { e. Tempo e custo que } \\
\text { agregaria ao } \\
\text { desenvolvimento do projeto. } \\
\text { f. Outro: Qual? }\end{array}$ & & & 1 & $\begin{array}{l}\text { Especialista 01: Todas são barreiras } \\
\text { importantes e interconectadas. } \\
\text { Especialista 02: b. Falta de exigência } \\
\text { do cliente } \\
\text { Especialista 04: f. Outro: Falta de } \\
\text { cultura para se fazer o planejamento de } \\
\text { longo prazo das } \\
\text { edificações, com a inclusão de todos os } \\
\text { custos envolvidos. }\end{array}$ \\
\hline $\begin{array}{l}\text { 9- Por fim, por favor, avaliar } \\
\text { a Classificação de } \\
\text { Desmontagem dos } \\
\text { elementos de forma geral. }\end{array}$ & - &  & & $\begin{array}{l}\text { Especialista 01: Muito interessante, não } \\
\text { tenho críticas. Sugiro uma forma de } \\
\text { aferir o processo em um estudo de caso. } \\
\text { Especialista 02: A proposta para } \\
\text { classificação de desmontagem, de modo } \\
\text { geral, está bem elaborada e engloba os } \\
\text { pontos centrais que devem nortear o } \\
\text { projeto, portanto entendo que tem } \\
\text { potencial para evolução. } \\
\text { Especialista 03: Ideia muito } \\
\text { interessante e com grande potencial de } \\
\text { utilização, desde que o BIM esteja mais } \\
\text { difundido no setor da construção civil e } \\
\text { se torne uma ferramenta usual. } \\
\text { Especialista 04: É um fator a mais para } \\
\text { ajudar os projetistas a fazerem escolhas } \\
\text { durante a fase de planejamento. }\end{array}$ \\
\hline
\end{tabular}

Fonte: Autora

Portanto, por meio das respostas aos questionários, observa-se que os avaliadores concordam com a classificação de desmontagem e não indicam falhas significativas. Porém, há algumas sugestões para acrescentar mais materiais à tabela, como materiais agregados e reciclados, além de madeira e plásticos nas vedações verticais internas. No entanto, evitouse colocar materiais compostos na tabela, pois sua classificação seria mais complexa devido 
à dificuldade de separar os materiais, mas há a possibilidade de os materiais serem inseridos após a avaliação individual, pois é possível complementar a tabela com diversos elementos. A intenção deste trabalho é iniciar a discussão e classificação dos elementos e inserir estes paramentos em BIM para contribuir para o processo de desenvolvimento do projeto.

Além disso, houve um questionamento em relação ao peso gráfico dado aos sistemas construtivos, como a estrutura com madeira encaixada ter o peso 1,0 e a estrutura em concreto pré-fabricado 0,3 . Isso se deu devido às características analisados de cada sistema estrutural (presente na introdução do questionário) e às limitações da tese em definir três tipos de sistemas construtivos para a avaliação da inserção dos parâmetros nos modelos. Certamente uma estrutura de madeira que tivesse um tipo de ligação que danificaria seus elementos da desmontagem, como ligações químicas, reduziria o seu valor para o cálculo. Um dos pontos principais abordados na tese é a questão do encaixe; portanto, para o modelo, foi considerado o sistema estrutural com peças de madeira encaixadas; no entanto, nem todos os sistemas estruturais são conectados da mesma maneira, assim um outro modelo que considerasse outro tipo de conexão (colas, parafusos, entre outros) teria um peso diferente para a média ponderada.

Houve uma sugestão para fazer estudos de caso para aferir o processo, o que realmente é importante e pode ser considerada em uma pesquisa futura. Neste trabalho foram realizados estudos de casos (conforme apresentado no capítulo 4) para reunir informações para o desenvolvimento da classificação de desmontagem e dos modelos. Porém, seria interessante analisar ainda mais questões relacionadas ao tema.

Os avaliadores não tiveram acesso a todo o conteúdo desenvolvido nesta tese, apenas às informações apresentadas no questionário como introdução das questões, assim são compreensíveis alguns questionamentos pertinentes ao desenvolvimento da classificação e definição dos materiais e sistemas estruturais. 
Os avaliadores não propuseram alterações significativas na classificação de desmontagem e nos modelos, mas houve sugestões e questionamentos. Estes se deram devido à limitação da tese. Assim, é importante ressaltar que a tabela pode ser complementada com diversos materiais e também em relação a suas características. Foi necessário estipular algumas limitações para o desenvolvimento da tabela (como apresentado ao longo da tese e enfatizado no item 6.2), porém é importante a participação multidisciplinar de diversos profissionais do setor da construção civil para complementar a classificação para abranger mais características, materiais, elementos e sistemas construtivos.

Desta maneira, é possível concluir que o BIM pode contribuir para o processo do Projeto para Desmontagem de diversas formas. Ferramentas foram analisadas e procedimentos desenvolvidos, como a inserção de parâmetros de desmontagem, a criação de três modelos, além da classificação de desmontagem de materiais e elementos. No geral, a classificação de desmontagem teve uma avaliação positiva, com algumas questões que podem ser aprofundadas e novos materiais abordados. Portanto, neste capítulo, foram apresentados softwares e artefatos para auxiliar o processo de desmontagem ao longo do desenvolvimento do projeto. 


\section{Conclusão}

A geração dos resíduos sólidos é uma preocupação recorrente na literatura e no mercado. No entanto, há uma lacuna a ser preenchida em relação aos materiais provenientes dos edifícios que não atendem mais às necessidades dos usuários. Muitas vezes os materiais, ainda em boa condição de uso, acabam sendo danificados na manutenção ou demolição. A razão disso é a falta de planejamento e a consideração sobre estas etapas do ciclo de vida do edifício ao longo do projeto.

Se houvesse melhor planejamento da desmontagem ao longo do desenvolvimento do projeto, seria possível haver mais soluções para a reutilização dos materiais. O BIM traz inúmeros benefícios para o processo, no entanto é preciso maior conscientização e fiscalização em relação à destinação dos materiais provenientes da demolição e os prejuízos causados ao meio ambiente.

As cidades passam por constantes transformações; atualmente novas tecnologias são desenvolvidas e os edifícios devem atender às necessidades de seus usuários. Além disso, os conceitos também mudam, como a concepção familiar e as adequações referentes aos costumes e às atividades realizadas em uma casa, apartamento, instituição ou ambiente comercial. Portanto, a ideia de que os edifícios devem durar o maior tempo possível, como se fossem monumentos inabaláveis e inflexíveis, cada vez se torna mais obsoleta. Porém, a grande maioria dos profissionais não leva isso em consideração, apesar do agravamento das questões ambientais.

Dessa maneira, este trabalho atendeu ao objetivo de desenvolver ferramentas que contribuem com o processo de desmontagem por decisões tomadas ao longo do desenvolvimento do projeto. Foram desenvolvidos modelos em software BIM, com criações de parâmetros que medem a desmontabilidade do edifico, uma estrutura de Classificação de Desmontagem e um checklist com questões relacionadas as possibilidades de desmontagem 
da edificação. Assim, a documentação destas informações irá contribuir com a futura desmontagem e reaproveitamento dos materiais.

\subsection{Considerações Finais}

Zhong e Wu (2015); Cheng e Ma (2013); Akbarnezhad, Ong e Chandra (2014); Akinade et al. (2017) ressaltam que a questão ambiental está presente no setor da construção civil e os profissionais buscam soluções para reduzir a geração de resíduos. Além disso, órgãos governamentais como a ABRELPE (Associação Brasileira de Empresas de Limpeza Pública e Resíduos Especiais) e o Departamento do Meio Ambiente do Reino Unido alertam sobre a grande quantidade de resíduos gerados e as consequências negativas para o meio ambiente.

Manzini e Vezzoli (2008); Romeiro Filho (2010); Guy e Rocha (2005); Go et al. (2011); Santini et al. (2010); Klohn e Ferreira (2009); Akinade et al. (2016); Couto e Crowther (2005); Guy e Rocha (2005); Akbarnezhad, Ong e Chandra (2014); Akanbi et al. (2019); Eckelman et al. (2018) concordam que o DfD pode contribuir para a reutilização dos materais e aumentar seu ciclo de vida. Como relatado na revisão bibliográfica e nas análises práticas, considerar a desmontagem desde a concepção do projeto realmente é um ponto-chave para possibilitar a reutilização dos materais.

Segundo Campestrini et al. (2015); Eastman et al. (2014); Hilgenberg et al. (2012); Hardin (2009); Volk, Stengel e Schultmann (2014); Cheng e Ma (2013); Akinade, et al. (2017); Penttila, Rajala e Freese (2007), Akanbi et al. (2019), o BIM auxilia nas tomadas de decisões e nas novas exigências do mercado. Os projetos estão cada vez mais complexos e diversos profissionais trabalham no seu desenvolvimento simultaneamente, assim a tecnologia auxilia um processo mais bem-sucedido.

Hardin (2009); Araújo et al. (2017); Zhong e Wu (2015); Rajala e Freese (2007); Akbarnezhad, Ong e Chandra (2014); Geldermans (2016) destacam a necessidade de se considerar o ciclo de vida dos produtos. Quando toda a cadeia produtiva dos elementos é considerada e 
documentada corretamente, é possivel obter as informações sobre o produto e otimizar sua reutilização.

Succar (2009); Brígitte e Ruschel (2016); Mikaldo Jr. (2006); Staub-French; Poirier, et al. (2018); Campestrini et al. (2015); Santos e Ferreira (2008); Leite et al. (2011); Dossick et al. (2010); Eastman et al. (2014); Hilgenberg et al. (2012) abordam o tema da compatibilização de projetos relacionados ao BIM. Como visto nas análises práticas, diversos softwares são utilizados no mercado; assim, além da compatibilização do projeto, também há a questão da compatibilização entre os softwares.

Quando profissionais de diferentes especialidades trabalham no mesmo projeto, a interoperabilidade entre os softwares se torna uma questão a ser discutida. Este tema é abordado por Aram, Eastman (2013); Hilgenberg et al. (2012); Campestrini et al. (2015); Vieira, Calmon e Cavalcante (2017); Andrade e Ruschel (2009); Brígitte e Ruschel (2016); Akcay (2017), que ressaltam algumas dificuldades e desafios neste processo.

Com o BIM, é possível desenvolver modelos 3D que permitem simulações e facilitam a visualização. Brígitte e Ruschel (2016); Campestrini et al. (2015); Vieira, Calmon e Cavalcante (2017); Clarke e Hensen (2015); Staub-French et al. (2018); Akanbi et al. (2019); Kunieda, Codinhoto e Emmitt (2019) ressaltam benefícios desta ferramenta. Como visto ao longo deste trabalho, os modelos 3D podem contribuir significativamente para o DfD, principalmente por facilitar a visualização dos elementos e seus encaixes, além de permitir simulações no processo de desmontagem.

Segundo Yuan, Sun e Wang (2018); Staub-French et al. (2018); Lam, Wong e Chan (2006); Zhong e Wu (2015), o BIM também auxilia na fabricação, montagem e construtibilidade. Assim, consequentemente, contribui para o Projeto para Desmontagem, pois permite reunir informações mais precisas e processos mais racionalizados. 
Reunir documentação correta e atualizada é fundametal. Os autores Hardin (2009); Akcay, Ergan e Arditi (2017); Staub-French et al. (2018) reafirmam a importância de documentar o projeto corretamente.

A utilização de diversos softwares pelas empresas e profissionais dificulta a interoperabilidade e integração do projeto. Mesmo o projeto em IFC, que é considerado uma extensão com maior interoperabilidade, ainda precisa de intervenções para ser utilizado e adaptado às necessidades de outros agentes envolvidos no projeto.

Com base nas entrevistas realizadas, é possível concluir que o tema da desmontagem e da reutilização dos elementos e materiais não é recorrente, apesar da preocupação com a redução da geração de resíduos ao longo da construção. A desmontabilidade do edifício seria considerada caso os clientes requisitassem ou houvesse legislações que cobrassem soluções. Com isso, seria possível propor soluções para a desmontagem com maior sucesso e aumentaria a possibilidade de reutilização.

A questão da enorme quantidade de resíduos sólidos gerado pelo setor é um problema atual que precisa de ações mais rígidas e pontuais. A pré-fabricação contribui para a baixa produção de resíduos ao longo da obra e para a produção dos elementos; no entanto, ainda não apresenta soluções para o fim da vida útil do edifício. Quando o edifício precisa passar por reformas ou mesmo quando não atende mais ao uso de onde está inserido, mesmo que os elementos ainda estejam em boas condições, ainda terão que ser demolidos, causando poluição e desperdício de recursos naturais.

O BIM é utilizado, no entanto cada empresa utiliza um software que atende melhor às suas necessidades, mas que, muitas vezes, não é totalmente compatível com os arquivos recebidos dos outros profissionais envolvidos. A interoperabilidade ainda é uma questão que precisa de melhores soluções. 
Além disso, o BIM auxilia na produção e no desenvolvimento do projeto e na sua compatibilização. No entanto, mais ferramentas presentes nos softwares podem ser mais exploradas para se obterem ainda melhores resultados. Assim, foi verificado que o BIM oferece ferramentas que contribuem para o DfD de forma efetiva e torna o processo mais dinâmico, mas falta considerar a questão da desmontagem ao longo do desenvolvimento do projeto.

A Classificação de Desmontagem desenvolvida neste trabalho pode ser utilizada como parâmetro inicial para elaborar fórmulas e cálculos mais completos, para que seja feita uma análise prática do potencial de desmontagem e reaproveitamento dos materiais. No entanto, não substitui a avaliação dos profissionais envolvidos no projeto, pois cada edifício tem suas especificidades e deve ser analisado como um todo. Assim, um memorial sobre o Projeto para Desmontagem que une informações sobre o edifício, seus elementos e materiais também contribuirá para a futura desmontagem.

O tema da Economia Circular é recorrente na literatura, portanto considerar a desmontagem e o fim da vida útil do edifício ao longo do desenvolvimento do projeto é fundamental para obter melhores resultados e minimizar os prejuízos ambientais. Assim como, em diversos setores industriais, são cobradas medidas sustentáveis para os produtos quando eles chegam ao final da vida útil, o setor da construção civil também terá que oferecer soluções para o final do ciclo de vida do edifício.

Desenvolver um Memorial DfD contribui para a desmontagem mais bem-sucedida, pois, com as informações disponíveis, é mais fácil programar a desmontagem e o reuso dos materiais. O BIM auxilia no armazenamento de informações do projeto e também na geração de documentos. Os arquivos gerados podem ser exportados em diversas extensões como JPG, PDF, TXT, IFC, o que contribui para o armazenamento dos dados e reduz a incompatibilização entre os softwares. No entanto, no caso do IFC, principalmente, alguns 
ajustes ainda precisam ser feitos e os projetistas devem estar atentos a possíveis incompatibilidades.

Ademais, é importante ressaltar que a iniciativa de órgãos públicos, bem como o envolvimento das instituições representativas dos intervenientes na cadeia produtiva do setor, pode contribuir para a inserção do BIM no cenário nacional. Incentivando a integração entre todos os intervenientes em um empreendimento, o BIM é um novo paradigma para a indústria da construção civil brasileira. Melhorias nos processos de projeto e a qualidade de sua execução e uso serão promovidas não apenas com soluções pragmáticas e de curto prazo com o uso da tecnologia, mas também por meio da maturidade organizacional e da evolução dos procedimentos e fluxos de trabalho que unem a plataforma ao longo de todo o processo (VIEIRA; CALMON; CAVALCANTE, 2017).

Portanto, o BIM, aliado Projeto para Desmontagem, oferece ferramentas que contribuem para o reaproveitamento de materiais e para a redução do alto índice de desperdício e consumo de matérias-primas do setor. O avanço da tecnologia e inovações de softwares podem contribuir para o processo, tornando-o mais eficiente e facilitando as tomadas de decisões. Porém, é fundamental que a conscientização da possibilidade de reutilizar e reciclar todos os elementos do edifício esteja presente desde do início da concepção do projeto, por todos agentes envolvidos, além da percepção de que o edifício irá passar por manutenções e transformações ao longo de sua vida útil até, finalmente, ser considerado obsoleto e insuficiente para uso.

\subsection{Contribuição da pesquisa}

A pesquisa contribui com um ponto inicial para o Desenvolvimento de Projetos que considerem a futura desmontagem do edifício, tornando-o mais eficiente quando aliado ao BIM, com a intenção de prolongar a vida útil dos materiais e, assim, reduzir o desperdício e o consumo de matérias-primas. Atualmente, o descarte de resíduos sólidos, principalmente 
oriundos da construção civil, é de grande apreensão de todos que estão conscientes das graves consequências da enorme quantidade de resíduos descartada e dos grandes desafios ambientais que enfrentamos atualmente.

A classificação de desmontagem, assim como o projeto e modelo 3D, pode ser utilizada como referência para um desenvolvimento mais específico focado em algumas das questões abordadas, voltadas para desmontagem e reutilização, além de poder avaliar a eficiência do edifício e questões ligadas ao desenvolvimento sustentável. Ademais, seria importante envolver diversos profissionais, fornecedores de elementos da construção civil para uma possível norma técnica ou até mesmo para responsabilizar as empresas e construtoras a fazer um descarte adequado dos materiais, para aumentar as chances de eles serem reutilizados ou reciclados.

Assim, esta pesquisa contribui para preencher parte da lacuna cientifica relacionada ao desenvolvimento do projeto e fim da vida útil do edifício, utilizando BIM. Foi desenvolvido uma estrutura para classificação de desmontagem que envolve os principais materiais utilizados no setor. Posteriormente, foram apresentados três modelos em software BIM e a criação de parâmetros que medem a desmontabilidade do edifício. Por fim, foi exibido um checklist com questões relacionadas a desmontagem, para verificar se a nova edificação atende aos critérios de desmontagem estabelecidos. Com a reunião destas informações é possível gerar um manual que irá contribuir com a futura desmontagem e consequentemente melhor reaproveitamento dos materiais, assim reduzindo os resíduos gerados pela demolição e economizando matéria-prima para fabricação de novos materiais e elementos, de maneira a poupar o meio ambiente.

\subsection{Limitações da pesquisa}

A pesquisa foi limitada, principalmente, pelo tempo, pois normalmente um edifício leva décadas para ser demolido ou desmontado. A intenção desta pesquisa não é analisar 
estruturas efêmeras, e sim prédios com usos a longo prazo, pois são destes tipos de edifícios que provém a grande quantidade de resíduos. No final da vida útil do edifício, a grande maioria dos materiais é descartada, ou até mesmo ao longo de sua manutenção e construção muito material é perdido. Assim, o ideal seria acompanhar o desenvolvimento de projetos de edifícios a serem desmontados e, depois de passada sua vida útil, analisar o resultado do desmonte.

Outra limitação da pesquisa é a grande variedade de elementos, questões, projetos, profissionais que são envolvidos na construção de um edifício. Sendo assim, algumas definições, como a classificação de desmontagem e o desenvolvimento do projeto de modelo 3D, foram de caráter exploratório, como um protótipo, ao ser tomado como base para classificações e análises mais aprofundadas. Algumas fórmulas, matrizes, algoritmos, principalmente provenientes da indústria automobilística e eletrônica, foram estudados com o intuito de tornar a avaliação mais objetiva, porém o projeto de arquitetura é complexo e com muitas especificidades, assim as fórmulas seriam muito complexas e pouco efetivas. Para Sanchez e Haas (2018), encontrar uma solução ideal de planejamento de desmontagem global para edifícios pode ser demorada e fisicamente impraticável devido ao grande número de soluções possíveis.

Em relação ao artefato apresentado, o modelo foi limitado em avaliar as conexões entre os elementos que compõem a estrutura e a vedação do edifício. Outras características poderão ser analisadas em pesquisas futuras, como a resistência dos materiais, análises do ciclo de vida, entre outras. No entanto, o desenvolvimento do artefato foi importante para verificar ferramentas presentes no software que possam facilitar a avaliação e também contribuir como referência para outros estudos na área de DfD e BIM.

Além disso, o desenvolvimento de projetos em BIM ainda é relativamente novo e ainda não envolve o conceito de desmontagem, uma vez que a grande maioria dos edifícios existentes não foi projetada em BIM. 


\subsection{Recomendações para trabalhos futuros}

O Projeto para Desmontagem no setor da construção civil ainda não é usual e é um conceito que pode ser melhor explorado, principalmente quando relacionado a tecnologias como o BIM. Profissionais de diversos campos, como engenheiros civis, elétricos, hidráulicos e da área de produção, têm muito a contribuir para as possibilidades de desmontagem de materiais e elementos do edifício. Além disso, seria fundamental o envolvimento de especialistas de diversas áreas para desenvolver a classificação de desmontagem e aplicá-las ao projeto. 


\section{Referências}

1192-2:2013, P. Incorporating Corrigendum No.1. Specification for information management for the capital/delivery phase of construction projects using building information modelling. [S.I.]: The British Standards Institution , 2013.

ABRELPE. Panorama dos Resíduos Sólidos no Brasil 2017. São Paulo. 2017.

ABNT. ASSOCIAÇÃO BRASILEIRA DE NORMAS TÉCNICAS. NBR 15575/2013: Edifícios Habitacionais - desempenhos. Rio de Janeiro, 2013.

AJAYI, S. O. et al. Attributes of design for construction waste minimization: a case study of waste-to-energy project. Renewable and Sustainable Energy Reviews, 2017. 1333-1341 p.

AKANBI, L. A. et al. Disassembly and deconstruction analytics system (D-DAS) for construction in a circular economy. Journal of Cleaner Production, v. 223. 2019. 386-396 p.

AKBARNEZHAD, A.; ONG, K. C. C.; CHANDRA, L. R. Economic and environmental assessment of deconstruction strategies using building information modeling. Automation in Construction, v. 37, p. 131-144, 2014.

AKCAY, E. C.; ERGAN, S.; ARDITI, D. Modeling information flow in the supply chain of structural steel components. Journal of Civil Engineerign and Management, 6, n. 753764, 2017.

AKINADE, O. O. et al. Design for Deconstruction (DfD): Critical success factors for diverting end-of-life waste from landfills. Waste Management, 2016.

AKINADE, O. O. et al. BIM-based deconstruction tool: Towards essential funcitonalities. International Journal of Sustainable Built Environment, 2017. 260-271 p.

AKINADE, O. O. et al. Waste minimisation through deconstruction: A BIM based Deconstructability Assessment Score (BIM-DAS). Resources, Conservation and Recycling, 2015. 167-176 p.

ALKASS, S.; JERGEAS, G.; TYLER, A. Constructability evaluation during detailed design phase. E\& FN SPON. In: NICHOLSON, M. P. Architecture Management. 1. ed. Londres: E \& FN Spon, 1992. Cap. 2, 404 p.

ANDRADE, M. L. V. X.; RUSCHEL, R. C. Interoperabilidade de aplicativos BIM usados em arquitetura por meio do formato IFC. Gestão \& Tecnologia de Projetos, v. 4, n. 2, 2009.

ARAM, S.; EASTMAN, C. Integration of PLM solutions and BIM systems for the AEC industry. Proceedings of 30th International Symposium of Automation and Robotics in Construction and Mining. Montréal: [s.n.]. 2013. 1046-1055 p.

ARAÚJO, A. M. et al. Interoperabilidade de ferramentas para BIM e avaliação do ciclo de vida de edificações. 1 Simpósio Brasileiro de Tecnologia da Informação e Comunicação 
na Construção e 10 Simpósio Brasileiro de Gestão e Economia da Construção. Fortaleza: [s.n.], 2017.

AUTODESK. Interface gráfica de programação do Dynamo. Disponível em: <http://www.autodesk.com.br/products/revit-family/features/platform/dynamo-graphicalprogramming-interface $>$. Acesso em: 17 out. 2016.

BARKOKÉBAS JUNIOR, B. et al. Análise das condições dos ambientes de trabalho e das práticas adotadas em um canteiro de obras de demolição. XII Encontro Nacional de Tecnologia do Ambiente Construído. Fortaleza-CE:[s.n.], 2008. p. 10.

BEGUIN, F. As Máquinas Inglesas do Conforto. São Paulo: Espaço \& Debates, v. 34, 1991.

BREWER, G.; MOONEY, J. A best practice policy for recycling and reuse in building. Proceedings of the Institution of Civil Engineers-Engineering Sustainability, v. 161, n. 3, p. 173-180, Setembro 2008.

BRÍGITTE, G. T. N.; RUSCHEL, R. C. Modelo de informação da construção para o projeto baseado em desempenho: caracterização e processo. Ambiente Construído, Porto Alegre, v. 16, p. 9-26, out./dez 2016.

CAMPESTRINI, T. F. et al. Entendendo BIM. 1. ed. Curitiba: Universidade Federal do Paraná, 2015.

CHENG, J. C. P.; MA, L. Y. H. A BIM-based system for demolition and renovation waste estimation and planning. Waste Management, v. 33, p. 1539-1551, 2013.

CLARKE, J. A.; HENSEN, J. L. M. Integrated building performance simulation: Progress, prospects and requirements. Building and Environment, v. 91, p. 294-306, 2015.

CLARKE, J. A.; HENSEN, J. L. M. Integrated building performance simulation: Progress, prospects and requirements, v. 91, p. 294e306, 2015.

CONSIDÉRANT, V. L'architectonique du phalanstère. In: RONCAYOLO, M. Villes \& Civilisation Urbaine. Paris: Larousse, 1992.

CORBUSIER, L. A Carta de Atenas de Le Corbusier. São Paulo: HUCITEC/edusp, 1993.

COUTO, A. B.; COUTO, J. P.; TEIXEIRA, J. C. Desconstrução - Uma Ferramenta para Sustentabilidade na Construção. NUTAU. São Paulo: [s.n.]. 2006.

CROWTHER, P. Design for Disassembly - Themes and Principles. [S.I.]: [s.n.], 2005.

DRESCH, A.; LACERDA, D. P.; ANTUNES JR, J. A. V. Design Science Research: método de pesquisa para avanço da ciência e tecnologia. Porto Alegre: Bookman, 2015.

DOSSICK, C. S.; NEFF, G. Organizational Divisions in BIM-Enabled Commercial Construction. Journal of Construction Engineering and Management, v. 136, n. 4, p. 459-467, Abril 2010. 
EASTMAN, C. et al. Manual de BIM: um guia de modelagem da informação da construção para arquitetos, engenheiros, gerentes, construtores e incorporadores. 1. ed. Porto Alegre: Bookman, 2014.

ECKELMAN, M. J. et al. Life cycle energy and environmental benefits of novel design-fordeconstruction structural systems in steel buildings. Building and Environment, 2018. 421$430 \mathrm{p}$.

FUAD-LUKE, A. Design Activism: Beautiful strangeness for a sustainable world. London: Earthscan, 2009.

GELDERMANS, R. J. Design for change and circularity - accommodating circular material. Energy Procedia 96, 2016. 301-311 p.

GIL, A. C. Como Elaborar Projetos de Pesquisa. 4. ed. São Paulo: Atlas S.A., 2002.

GO, T. F. et al. Disassemblability of end-of-life vehicle: a critical review of evaluation methods. Journal of Cleaner Produtction, v. 19, p. 1536-1546, setembro 2011.

GUY, B.; ROCHA, C. A building lifecycle model based on a design for deconstructions approach. SIMPÓSIO BRASILEIRO DE GESTÃO E ECONOMIA DA CONSTRUÇÃO, IV. Porto Alegre: [s.n.], 2005.

GUY, B.; SHELL, S. Design for Deconstruction and Materials Reuse. CIB Publication. Rotterdam (Netherlands): [s.n.], 2002. p. 20.

HALL, C. Sweet Home. In: PERROT, M. História da Vida Privada. São Paulo: Companhia das Letras, 1991. v. 4.

HARDIN, B. BIM and Construction Management: proven tools, methods and workflows. 1. ed. Indiana, USA: Wiley Publishing, Inc, 2009.

HENRIQSON, J.; ROCHA, C.; SATTLER, M. Análise e Descrição do Processo de Demolição de Edificações. ENTAC. FORTALEZA: [s.n.], 2008. p. 10.

HILGENBERG, F. B. et al. USO DE BIM PELOS PROFISSIONAIS DE ARQUITETURA EM CURITIBA. Gestão e Tecnologia de Projetos, v. 7, n. 1, p. 62-72, Maio 2012.

HOSSAIN, M. A.; YEOH, J. K. W. BIM for Existing Buildings: Potential Opportunities. IOP Conf. Ser: Mater. Sci. 2018.

HOWARD, E. Ciudades-Jardim del Manãna. In: AYMONINO, C. Origenes Y desarrollo de la ciudade moderna. Barcelona: Gustavo Gili, 1972.

KLOHN, S. C.; FERREIRA, N. F. Sustentabilidade e design para desmontagem - estudo de caso. CONGRESSO INTERNACIONAL DE PESQUISA EM DESIGN. Bauru: [s.n.], 2009.

KUNIEDA, Y.; CODINHOTO, R.; EMMITT, S. Increasing the efficiency and efficacy of demolition through computerised 4D simulation. Engineering, Construction and Architectural Management, v.26, p. 2186-2205, 2019. 
LACERDA, D. P. et al. Design Science Research: método de pesquisa para a engenharia de produção. Gest. Prod., São Carlos, v. 20, n. 4, p. 741-761, 2013.

LAM, P. T. I.; WONG, F. W. H.; CHAN, A. P. C. Contributions of designers to improving buidability and constructability. Design Studies, Julho 2006. 457-479 p.

LAWSON, B. Como arquitetos e designers pensam. São Paulo: Oficina do texto, 2011.

LE CORBUSIER. A Carta de Atenas. In: BARBOSA, J. A., et al. Le Corbusier: A carta de Atenas. São Paulo: Edusp, 1993.

LEITE, F. et al. Analysis of modeling effort and impact of different levels of detail in building information model. Automation in Construction, v. 20, p. 601-609, 2011.

LESTER, J. D.; LESTER, J. D. Jr. Writing Research Papers: A Complete Guide. Ed. 15. Pearson. 2015.

LOW, S. P. Quantifying the relationships between buildability, structural quality and productivity in construction. Structural Survey, v. 19, p. 106-112, 2001.

MANZINI, E.; VEZZOLI, C. O Desenvolvimento de Produtos Sustentável. 1. ed. São Paulo: Editora da Universidade de São Paulo, 2008.

MARCH, S.; SMITH, G. Design and Naural Science Research on Information Technology. Decision Support Systems, v. 15, p. 251-266, 1995.

MATTARAIA, L. Arquitetura e Sustentabilidade: Considerações sobre o Desmonte das Edificações. Dissertação de Mestrado, São Carlos, 2013.

MATTARAIA, L.; MARTINS, A.; FABRÍCIO, M. M. Critérios para Avaliação do Potencial de Desmonte e Reciclagem de Materiais de Sistemas Construtivos Inovadores. In: KAZMIERCZAK, C. S.; FABRÍCIO, M. M. Avaliação de Desempenho de Tecnologias Construtivas Inovadoras: materiais e sustentabilidade. [S.I.]: [s.n.], 2016. 315-338 p.

MIKALDO JR., J. Estudo comparativo do processo de compatibilização de projetos em 2D e 3D com uso de T.I. Dissertação (Mestrado) - Programa de pós-graduação da Construção Civil, Universidade Federal do Paraná, Curitiba, p. 150f., 2006.

MORGAN, C.; STEVENSON, F. SEDA e Scottish Ecological Design Association. Design and detailing for deconstruction. Disponível em: http://www.seda.uk.net/dfd/dfd.pdf; 2005 (acesso 10/06/2016).

NATIONAL BUILDING SPECIFICATION. UK BIM survey 2019 findings. National BIM Report 2019: the definitive industry update, Reino Unido, 2019. 9-18.

PAS 1192-2:2013. Incorporating Corrigendum No.1. Specification for information management for the capital/delivery phase of construction projects using building information modelling. The British Standards Institution 2013. Published by BSI Standards Limited 2013. 
PENTTILA, H.; RAJALA, M.; FREESE, S. Building Information Modelling of Modern Historic Building: Case Study of HUT/Architectural Department by Alvar Aalto. eCAADE25, p. 607614, 2007.

ROMEIRO FILHO, E. Projeto do Produto. Rio de Janeiro: [s.n.], 2010.

SANCHEZ, B.; HAAS, C. A novel selective disassembly sequence planning method for adaptive reuse buildings. Journal of cleaner Production, v. 183, p. 998-1010, 2018.

SANTINI, A. et al. Assessment of Ecodesign potential in reaching new recycling targets. Resources, Conservation and Recycling, v. 54, n. 12, p. 1128-1134, Outubro 2010.

SANTOS, E. T.; FERREIRA, R. C. Building Design Coordination: Comparing 2D and 3D Methods. In proceedings of CIB W78 25th International Conference on Information Technology in Construction, Santiago, Chile, p. 166-175, 2008.

SITCHARANGSIE, S.; IJOMAH, W.; WONG, T. C. Decision makings in key remanufacturing activities to optimise remanufacturing outcomes: A review. Journal of Cleaner Production, 2019. 1465-1481.

STAUB-FRENCH, S. et al. Building Informaton Modeling (BIM) and Design for Manufacturing and Assembly (DfMA) for Mass Timber Construction. Canadá. 2018.

SUCCAR, B. Building Information modeling framework: A research and delivery foundation for industry stakeholders. Automation in Construction, v. 18, p. 357-375, 2009.

TOTH, G.; SZIGETI, C. The historical ecological footprint: From over-population to overconsumption. Ecological Indicators, v. 60, p. 283-291, 2016.

UK DEPARTMENT FOR ENVIRONMENT FOOD \& RURAL AFFAIRS , 2015. Disponivel em:

$<$ https://www.gov.uk/government/uploads/system/uploads/attachment_data/file/487916/UK_ Statistics_on_Waste_statistical_notice_15_12_2015_update_f2.pdf $>$. Acesso em: 11 abril 2016.

UK DEPARTMENT FOR ENVIRONMENT FOOD \& RURAL AFFAIRS. UK Statistics on Waste. Inglaterra. 2019.

USTINOVIčIUS, L. et al. Innovative research projects in the field of Building Lifecycle Management. Procedia Engineering, v. 122, p. 166 - 171, 2015.

V, D. Building Information Modeling (BIM) in Brazil's Architecture, Engineering and Construction (AEC) Industry: a Review and a Bibliometric Study.

VANEGAS, P. et al. Ease of disassembly of products to support circular economy strategies. Resources, Conservation \& Recycling, v. 135, p. 323-334, 2018.

VIEIRA, D.; CALMON, J. L.; CAVALCANTE, M. C. Building Information Modeling (BIM) in Brazil's Architecture, Engineering and Construction (AEC) Industry: a Review and a Bibliometric Study. Journal of Modern Projetct Management, 2017. 
VOLK, R. . S. J. . S. F. Building Information Modeling (BIM) for existing buildings - Literature review and future needs. Automation in Construction, v. 38 , p. 109-127, 2014.

VOLK, R.; STENGEL, J.; SCHULTMANN, F. Building Information Modeling (BIM) for existing buildings - Literature review and future needs. Automation in Construction, v. 38, p. 109127, 2014.

WEBSTER, M. D.; COSTELLO, D. T. Designing structural systems for deconstruction: How to extend a new building's useful life and prevent it from going to waste when the end finally comes. Greenbuild Conference. Atlanta: [s.n.]. 2005.

WINTER, R. Design science research in Europe. European Journal of Information Systems, v. 17, n. 5, p. 470-475, 2008.

YUAN, Z.; SUN, C.; WANG, Y. Design for Manufacture and Assembly-oriented parametric desigfn of prefabricated buildings. Automation in Construction, 2018. 13-22.

YUBA, A. N. Análise da pluridimensionalidade da sustentabilidade da cadeia produtiva de componentes construtivos de madeira de plantios florestais. $213 f$. Tese (Doutorado em Ciências da Engenharia Ambiental) - Escola de Engenharia de São Carlos, Universidade de São Paulo, São Carlos, 2005.

ZHONG, Y.; WU, P. Economic sustainability, environmental sustainability and constructability indicators to concrete- and steel-projects. Journal of Cleaner Production, p. 748-756, 2015. 


\section{Anexos}

\subsection{Questionários para entrevistas com profissionais do Reino Unido}

\subsubsection{Indústria automobilística}

\section{Section 1: General Questions}

Senior Body Structures Architecture Manager

1. Please, could you provide information about the sector (i.e. nuclear, healthcare, automotive, etc.) that you represent, including:
a. Name of the company:
b. Type of service it offers:
c. How long you have been operating:
d. Number of employees:

2. Are you or have you been involved in the development, redevelopment or disassemble of an automobile? Could explain what experience that you have in this area?

\section{Section 2: Design Guidance}

3. Are they related or linked to any specific specify design guidance or standard disassemble and reassembly of an automobile?

4. In your view, could you list at least three things that facilitates, and three things that hinders the disassembly and maintenance of an automobile?

5. How materials and connexions influences the process of disassembly?

6. In the context of car manufacturing, which components would you consider to be the most easy or difficult to disassembly or maintenance? Why?

7. In the context of car manufacturing, is assembly and disassembly discussed as part of the initial stages of design? If yes, to which discipline or disciplines this topic is more relevant?

8. In the context of car manufacturing, is it possible (as a whole or in part) to reuse or recycle the automobile components? If yes, could you give examples of material destinations? 
9. In the context of car manufacturing, does any environmental laws and regulations influence the process of disassembly?

10. In the context of car manufacturing, is the reuse and recycling a client requirement?

11. In the context of car manufacturing, is the life expectancy of the asset and LCA of the materials considered within the design stage? If yes, are decisions or guidance put in place for the disassembly process?

12. How is done the identification of the materials?

13. Could you elaborate on the disassembly process?

14. How to deal with hazardous materials

\section{Section 3: Technology and Softwares}

15. Do you think softwares could contribute to improve understanding of the process and implications of design for disassembly? How?

16. In your opinion, how softwares could be used for the evaluation of "disassembly assessment"?

\subsubsection{Construtora}

Gestor de Resíduos

\section{Section 1: General Questions}

1.Please, could you provide information about the sector (i.e. nuclear, healthcare, automotive, demolition, etc.) that you represent, including:

a. Name of the company:

b. Type of service it offers:

c. How long you have been operating:

d. Number of employees:

2. Are you or have you been involved in the development, redevelopment or decommissioning of a building? Could explain what experience that you have in this area?

\section{Section 2: Design}

3. Is there or are you aware of guidance for the decommissioning a building? Are they related or linked to any specific specify design guidance or standard?

4. In your view, could you list at least three things that facilitates, and three things that hinders the decommissioning or refurbishment of nuclear building? 
5. Which building components (e.g. structure, services/M\&E, superstructure, fit-outs, cladding, etc.) would you consider to be the most easy or difficult to decommission or refurnish? Why?

6. Which building's materials (e.g. concrete, wood, steel, bricks, stones, etc.) would you consider to be the most easy or difficult to decommission? Why?

7. In your opinion, how design contribute could contribute for decommissioning?

8. Which elements and materials are possible (as a whole or in part) to reuse or recycle the material waste of the demolition or refurbishment? Could you give examples of material destinations?

9. In the context of nuclear building, does any building or environmental laws and regulations influence the process of decommissioning?

10. Does time and cost of decommission is considered?

11. Is the decommissioning for reuse and recycling a client requirement?

12. Are you aware of any building(s) that has reached (or is about to reach) the end of its useful life? If yes, could you elaborate on the decommissioning process?

13. Is it a common issue to gather updated information about the building to program the demolition? What are the most difficulties information to collect?

\section{Section 3: BIM}

14. Do you think BIM (Building Information Modelling) could contribute to improve understanding of the process and implications of decommissioning a building? How?

15. In your opinion, how could BIM be used for the evaluation of "disassembly assessment" and/or deconstructability?

16. In your opinion, a 3D model simulation could help to improve the decommissioning, disassembly our demolition process? Have you ever used it?

\subsubsection{Gestor hospitalar}

\section{Section 1: General Questions}


1.Please, could you provide information about the sector (i.e. nuclear, healthcare, automotive, etc.) that you represent, including:
a. Name of the company:
b. Type of service it offers
c. How long you have been operating:
d. Number of employees:

2. Are you or have you been involved in the development, redevelopment or decommissioning of a healthcare building? Could explain what experience that you have in this area?

\section{Section 2: Design Guidance}

3. What would you say are the areas within the healthcare buildings that are specific for this sector (e.g. office and admin spaces, or operating theatres in hospitals) that are common to most buildings of this type?

4. Is there or are you aware of guidance for the design or re-development of healthcare buildings?

5. Is there or are you aware of guidance for the decommissioning of healthcare buildings? Are they related or linked to any specific design guidance or standard?

6. In your view, could you list at least three things that facilitates, and three things that hinders the decommissioning or refurbishment of healthcare buildings?

7. In the context of healthcare buildings, which building components (e.g. structure, services/M\&E, superstructure, fit-outs, cladding, etc.) would you consider to be the most easy or difficult to decommission or refurnish? Why?

8. In the context of healthcare buildings, is building assembly and decommissioning discussed as part of the initial stages of design? If yes, to which discipline or disciplines this topic is more relevant?

9. In the context of healthcare buildings, is it possible (as a whole or in part) to reuse or recycle the material waste of the demolition or refurbishment? If yes, could you give examples of material destinations?

10. In the context of healthcare buildings, does any building or environmental laws and regulations influence the process of decommissioning?

11. In the context of healthcare buildings, is the decommissioning for reuse and recycling a client requirement? 
12. In the context of healthcare buildings, is the life expectancy of the asset considered within the design stage? If yes, are decisions or guidance put in place for the decommissioning process?

13. Are you aware of any building(s) that has reached (or is about to reach) the end of its useful life? If yes, could you elaborate on the decommissioning process?

\section{Section 3: BIM}

14. Do you think BIM (Building Information Modelling) could contribute to improve understanding of the process and implications of decommissioning a building? How?

15. In your opinion, how could BIM is used for the evaluation of "disassembly assessment" and/or deconstructability?

\subsubsection{Edifícios nucleares}

\section{Section 1: General Questions}

1.Please, could you provide information about the sector (i.e. nuclear, healthcare, automotive, etc.) that you represent, including:

a. Name of the company:

b. Type of service it offers:

c. How long you have been operating:

d. Number of employees:

2. Are you or have you been involved in the development, redevelopment or decommissioning of a nuclear building? Could explain what experience that you have in this area?

\section{Section 2: Design Guidance}

3. What would you say are the areas within the nuclear building that are specific for this sector (e.g. office and admin spaces, or operating theatres in hospitals) that are common to most buildings of this type?

4. Is there or are you aware of guidance for the design or re-development of nuclear building?

5. Is there or are you aware of guidance for the decommissioning of nuclear building? Are they related or linked to any specific specify design guidance or standard?

6. In your view, could you list at least three things that facilitates, and three things that hinders the decommissioning or refurbishment of nuclear building? 
7. In the context of nuclear building, which building components (e.g. structure, services/M\&E, superstructure, fit-outs, cladding, etc.) would you consider to be the most easy or difficult to decommission or refurnish? Why?

8. In the context of nuclear building, is building assembly and decommissioning discussed as part of the initial stages of design? If yes, to which discipline or disciplines this topic is more relevant?

9. In the context of nuclear building, is it possible (as a whole or in part) to reuse or recycle the material waste of the demolition or refurbishment? If yes, could you give examples of material destinations?

10. In the context of nuclear building, does any building or environmental laws and regulations influence the process of decommissioning?

11. In the context of nuclear building, is the decommissioning for reuse and recycling a client requirement?

12. In the context of nuclear building, is the life expectancy of the asset considered within the design stage? If yes, are decisions or guidance put in place for the decommissioning process?

13. Are you aware of any building(s) that has reached (or is about to reach) the end of its useful life? If yes, could you elaborate on the decommissioning process?

\section{Section 3: BIM}

14. Do you think BIM (Building Information Modelling) could contribute to improve understanding of the process and implications of decommissioning a building? How?

15. In your opinion, how could BIM be used for the evaluation of "disassembly assessment" and/or deconstructability?

\subsubsection{Arenas esportivas}

\section{Section 1: General Questions}


Name:

17. Please, could you provide information about the sector (i.e. nuclear, healthcare, automotive, etc.) that you represent, including:
a. Name of the company:
b. Type of service it offers:
c. How long you have been operating:
d. Number of employees:

18. Are you or have you been involved in the development, redevelopment or decommissioning of a building? Could explain what experience that you have in this area?

\section{Section 2: Design Guidance}

19. What would you say are the areas of a building that are specific for this sector (e.g. office and admin spaces, or operating theatres in hospitals) that are common to most buildings of this type?

20. Is there or are you aware of guidance for the design or re-development of a building?

21. Is there or are you aware of guidance for the decommissioning of buildings? Are they related or linked to any specific specify design guidance or standard?

22. In your view, could you list at least three things that facilitates, and three things that hinders the decommissioning or refurbishment of nuclear building?

23. Which building components (e.g. structure, services/M\&E, superstructure, fit-outs, cladding, etc.) would you consider to be the most easy or difficult to decommission or refurnish? Why?

24. Is building assembly and decommissioning discussed as part of the initial stages of design? If yes, to which discipline or disciplines this topic is more relevant?

25. Is it possible (as a whole or in part) to reuse or recycle the material waste of the demolition or refurbishment? If yes, could you give examples of material destinations?

26. Does any building or environmental laws and regulations influence the process of decommissioning?

27. Is the decommissioning for reuse and recycling a client requirement?

28. Is the life expectancy of the asset considered within the design stage? If yes, are decisions or guidance put in place for the decommissioning process?

29. Are you aware of any building(s) that has reached (or is about to reach) the end of its useful life? If yes, could you elaborate on the decommissioning process? 


\section{Section 3: BIM}

30. Do you think BIM (Building Information Modelling) could contribute to improve understanding of the process and implications of decommissioning a building? How?

31. In your opinion, how could BIM be used for the evaluation of "disassembly assessment" and/or deconstructability?

\subsubsection{Visita à fábrica de pré-moldados de concreto}

\section{Questões iniciais}

\section{Seção 01: Questões gerais}

1. Por favor preencha as informações sobre sua empresa ou escritório.

Nome:

Tipo de Serviço:

Tempo no Mercado:

Número de Empregados:

\section{Seção 02: Questões projetuais}

Montagem/Processo construtivo

2. A montagem ou processo construtivo é considerado no desenvolvimento do projeto?

3. Quais os principais pontos a serem considerados? Por exemplo: encaixes, materiais, camadas do edifício, transporte, dimensionamento, ferramentas necessárias, etc.

4. Por que foi feita a escolha de determinados materiais, ligações e elementos? Por exemplo: estrutura metálica, pré-fabricado de concreto, utilização de parafusos ou soldagem, etc.

5. Você poderia listar três características que podem contribuir com a desmontagem?

6. Quais elementos ou materiais você considera mais práticos para serem desmontados? Por quê?

7. Quais foram os maiores desafios ao longo do projeto e construção?

8. Você já participou da desconstrução, desmontagem de um edifício ou parte dele? Por favor, descreva como foi o processo.

9. É comum considerar a desmontagem no desenvolvimento do projeto inicial? Na sua opinião isto facilitaria o processo de desmontagem?

10. Tem alguma norma, orientação ou legislação que deve ser considerada na desmontagem? Há algo específico para o seu setor?

11. Por que foi tomada a decisão para desmontar o edifício ou parte dele? 
12. Você poderia listar três características que podem contribuir para a desmontagem?

13. Quais elementos ou materiais você considera mais práticos para serem desmontados? Por quê?

14. Quais foram os maiores desafios ao longo do projeto e construção, caso tenha sido considerada a desmontagem?

15. É possível reutilizar ou reciclar os materiais casos sejam desmontados?

16. O processo e fases de construção ou montagem seria parecido com o inverso da desmontagem?

17. O que não poderia ser reutilizado? Por quê?

18. É considerado o ciclo de vida dos materiais e elementos do edifício? Qual é a expectativa de vida do edifício?

19. As decisões de projeto relacionadas à desmontagem eram baseadas em quais requisitos? Por exemplo, resistência dos materiais, facilidade de encaixe e desencaixe, tempo, custo, etc.

\section{Seção 3: BIM}

20. Você conhece o conceito Building Information Modeling - BIM (Modelagem da Construção)?

21. Foi utilizado no desenvolvimento do projeto?

22. Algum software que envolve este processo (Revit, Archicad ou outro) foi utilizado para o desenvolvimento do projeto?

23. Quantos profissionais e áreas (calculistas, projetistas, etc) estão envolvidos no projeto?

24. Foi feito modelo 3D para simulação a montagem? E uma possível desmontagem? Se sim, como isto facilitou o processo? Se não, você considera que teria ajudado no processo?

25. O projeto visou a atingir algum selo verde?

\section{Seção 01: Questões gerais}

1. Por favor preencha as informações sobre sua empresa ou escritório.

Nome:

Tipo de Serviço: estruturas metálicas

Tempo no Mercado: o engenheiro entrevistado está a 05 meses na empresa

Número de Empregados: 90 


\section{Seção 02: Questões projetuais}

Montagem/Processo construtivo

2. A montagem ou processo construtivo é considerado no desenvolvimento do projeto? Sim, a montagem

3. Quais os principais pontos a serem considerados? Por exemplo: encaixes, materiais, camadas do edifício, transporte, dimensionamento, ferramentas necessárias, etc. encaixes, materiais, transporte, no entanto há adaptações na obra

4. Por que foi feita a escolha de determinados materiais, ligações e elementos? Por exemplo: estrutura metálica, pré-fabricado de concreto, utilização de parafusos ou soldagem, etc.

5. Você poderia listar três características que podem contribuir com a desmontagem? Parafusos melhor que solda

6. Quais elementos ou materiais você considera mais práticos para serem desmontados? Por quê? parafusados

7. Quais foram os maiores desafios ao longo do projeto e construção? Compatibilização Desmontagem / Demolição

8. Você já participou da desconstrução, desmontagem de um edifício ou parte dele? Por favor, descreva como foi o processo. Partes quando precisa ampliar ou alterar o projeto

9. É comum considerar a desmontagem no desenvolvimento do projeto inicial? Na sua opinião isto facilitaria o processo de desmontagem? Não é comum, mas facilitaria

10. Tem alguma norma, orientação ou legislação que deve ser considerada na desmontagem? Há algo específico para o seu setor?

11. Por que foi tomada a decisão para desmontar o edifício ou parte dele? Ampliar ou reformar

12. Você poderia listar três características que podem contribuir com a desmontagem? Encaixes, dimensões, resistência

13. É possível reutilizar ou reciclar os materiais casos sejam desmontados? Sim

14. O processo e fases de construção ou montagem seria parecido com o inverso da desmontagem? Sim

15. O que não poderia ser reutilizado? Por quê?

16. É considerado o ciclo de vida dos materiais e elementos do edifício? Qual é a expectativa de vida do edifício? 
17. As decisões de projeto relacionadas à desmontagem eram baseadas em quais requisitos? Por exemplo, resistência dos materiais, facilidade de encaixe e desencaixe, tempo, custo, etc. baseada na necessidade de reforma ou ampliação

\section{Seção 3: BIM}

18. Você conhece o conceito Building Information Modeling - BIM (Modelagem da Construção)? Sim

19. Foi utilizado no desenvolvimento do projeto? Não

20. Algum software que envolve este processo (Revit, Archicad ou outro) foi utilizado para o desenvolvimento do projeto? Archicad

21. Quantos profissionais e áreas (calculistas, projetistas, etc) estão envolvidos no projeto? 2 engenheiros, 1 arquiteto

22. Foi feito modelo 3D para simulação a montagem? E uma possível desmontagem? Se sim como isto facilitou o processo? Se não, você considera que teria ajudado no processo? Sim, facilitou

23. O projeto visou a atingir algum selo verde? Não 


\subsection{Questionário sobre a Classificação de Desmontagem}

Atualmente a grande quantidade de resíduos provenientes da Indústria da Construção Civil compromete o desenvolvimento sustentável do setor, principalmente quando o edifício não atende ao uso proposto inicialmente. A solução mais utilizada é a demolição, o que gera grande quantidade de resíduos, desperdício e poluição. Portanto, a tese de Doutorado intitulada "BIM aliado ao Projeto para Desmontagem: ferramentas projetuais para aperfeiçoar a reutilização dos materiais e reduzir o desperdício", no Instituto de Arquitetura e Urbanismo da Universidade de São Paulo (IAU-USP), sob orientação do Prof. Dr. Márcio Minto Fabrício e co-orientação do Prof. Dr. Ricardo Codinhoto, tem como objetivo pesquisar e propor soluções para ampliar as possibilidades de reutilização dos materiais no setor. Considerar a desmontagem do edifício desde a concepção do projeto seria fundamental para evitar a demolição e o desperdício de materiais. Ao longo da pesquisa foi desenvolvida uma classificação para o potencial de desmontagem de materiais e elementos que compõem um edifício.

Para a classificação, foram consideradas questões como conexões (químicas ou mecânicas), durabilidade dos materiais em relação a desmontagem, expectativa de vida, facilidade ou dificuldade no transporte e armazenamento, ferramentas necessárias para a separação dos elementos, as camadas dos edifícios (para evitar que outros elementos se quebrem quando um for desmontado), possibilidades de reuso e reutilização, entre outras características.

O processo de desmontagem está diretamente ligado ao processo de montagem e elementos pré-fabricados, assim diversas outras questões consideradas na montagem também facilitarão a desmontagem. Como a desmontagem ainda não é usual, foram selecionados profissionais da área acadêmica ligados ao processo de fabricação e conhecimentos específicos de diversos sistemas estruturais. A sua participação será fundamental, pois irá contribuir para a pesquisa. A participação é voluntária, sua identidade será preservada e os resultados serão utilizados apenas para pesquisas acadêmicas. 


\section{Classificação de Desmontagem}

Os materiais escolhidos para a classificação de desmontagem são bastante usuais na construção civil no Brasil. Outros materiais podem ser adequados à tabela, conforme a necessidade da análise de desmontagem, e seguir os parâmetros de desmontagem. Os materiais foram classificados devido às suas características, que estão relacionadas ao potencial de desmonte e de reuso. Com base na revisão bibliográfica científica realizada ao longo do doutorado, entrevistas e visitas a profissionais do mercado, foram identificadas as seguintes características:

11. CONEXÕES: conforme a escolha de ligação entre as peças, o processo de desmontagem pode ser prejudicado; por exemplo, quando são peças encaixadas, é possível desmontá-las sem danificá-las, enquanto peças com ligações químicas dificilmente podem ser separadas sem danos.

12. RESISTÊNCIA À DESMONTAGEM E REMONTAGEM: é importante que o material resista à desmontagem sem se quebrar, para que possa ser mais bem aproveitado e ser reutilizado; diversos materiais não resistem e precisam ser reciclados ou descartados.

13. PADRONIZAÇÃO: se os elementos e materiais são padronizados, a desmontagem é mais eficiente, pois são necessárias as mesmas ferramentas, o mesmo número de pessoas, além de ser mais prático projetar a reutilização.

14. ARMAZENAGEM e TRANSPORTE: assim como na montagem, o armazenamento e o transporte são fundamentais para que o material possa ser reaproveitado. Por exemplo, peças muito grandes que dificultam o transporte e o armazenamento dificilmente serão reutilizadas, o que é o objetivo da desmontagem projetada.

15. ESCALA: a escala dos elementos é fundamental para programar sua retirada e reutilização, pois quanto menos ferramentas, pessoas e tempo levar para a desmontagem mais chances terá de ser reutilizada.

16. FABRICAÇÃO: manter as informações sobre a fabricação dos elementos é importante para saber a melhor maneira de proceder com a desmontagem e remontagem, além disso, assim como o BIM contribui com a racionalização da fabricação, também contribui com a desmontagem e remontagem.

17. CAMADAS: o edifício é construído em camadas, como estrutura, vedações, sistemas hidráulicos, elétricos, entre outros. Assim quanto melhor o acesso a cada um desses elementos, mais chances de serem desmontados sem danificar outros, até mesmo na manutenção do edifício.

18. RECICLAGEM: alguns materiais não são reciclados quando removidos dos edifícios por serem tóxicos, por exemplo, ou se quebrarem facilmente, muitas vezes o valor e tempo para desmontar e reciclar não são suficientemente rentáveis ao mercado, como por exemplo vidro e gesso. No entanto, alguns materiais podem ser demolidos, separados e reciclados, como o concreto

19. REUTILIZAÇÃO: alguns materiais resistem à desmontagem e pode ser reutilizado da mesma maneira, como as estruturas metálicas parafusadas, por exemplo, que podem ser reaproveitadas se precisar de elementos exatamente com a mesma medida em uma nova obra.

20. ADAPTAÇÃO: poucos materiais resistem a desmontagem e ainda podem ser adaptados a novos usos, os elementos em madeira, por exemplo, podem ser reutilizados de diversas maneiras. 
A tabela 01 apresenta os materiais e a classificação de desmontagem, além do "peso" para a média ponderada. A tabela é um exemplo, um ponto de partida para classificar os materiais conforme sua possibilidade de desmontagem. A classificação de desmontagem varia entre 0 a 1; sendo que quanto menor o número, menor a possibilidade de desmontagem e o valor 1 seria o ideal com possibilidade de $100 \%$ de reaproveitamento. A tabela está dividida em três partes: estrutura, vedação vertical externa e vedação vertical interna. Assim aborda o edifício com elementos básicos da sua composição.

Tabela 1 - Classificação de Materiais

(Continua)

\begin{tabular}{|c|c|c|c|}
\hline $\begin{array}{l}\text { Materiais e } \\
\text { Elementos }\end{array}$ & $\begin{array}{c}\text { Classificação } \\
\text { Desmontage } \\
\text { m (0 a 1) }\end{array}$ & $\begin{array}{l}\text { Peso para } \\
\text { media } \\
\text { ponderada }\end{array}$ & Características \\
\hline \multicolumn{4}{|l|}{$\begin{array}{c}\text { ESTRUTUR } \\
\text { A } \\
\text { PRINCIPAL }\end{array}$} \\
\hline $\begin{array}{l}\text { Concreto } \\
\text { armado } \\
\text { moldada no } \\
\text { local }\end{array}$ & 0,1 & 1 & $\begin{array}{l}\text { - Ligações químicas } \\
\text { - Necessita de equipamentos pesados } \\
\text { - Difícil Manuseio, transporte e armazenamento } \\
\text { - Alto custo, trabalho e tempo para remoção } \\
\text { - Geralmente é demolido } \\
\text { - Pode ser reciclado, mas para outros usos } \\
\text { - Não pode ser reutilizado com a função original }\end{array}$ \\
\hline $\begin{array}{l}\text { Elementos } \\
\text { pré- } \\
\text { fabricados de } \\
\text { concreto } \\
\text { protendido }\end{array}$ & 0,3 & 1 & $\begin{array}{l}\text { - Algumas ligações podem ser desfeitas } \\
\text { - Peças são produzidas considerando transporte a } \\
\text { armazenamento } \\
\text { - Pode se quebrar na desmontagem } \\
\text { - Equipamentos utilizados na montagem podem ser usados } \\
\text { na desmontagem } \\
\text { - Maioria das ligações são químicas } \\
\text { - Pode ser reciclado, mas para outros usos } \\
\text { - Dificilmente é reutilizado }\end{array}$ \\
\hline $\begin{array}{l}\text { Metálica } \\
\text { soldada }\end{array}$ & 0,6 & 1 & $\begin{array}{l}\text { - Elementos pré-fabricados facilitam o transporte e } \\
\text { armazenamento } \\
\text { - Equipamentos utilizados na montagem podem ser usados } \\
\text { na desmontagem } \\
\text { - Resiste a desmontagem } \\
\text { - Ligação por solda dificulta a separação das peças e pode } \\
\text { causar danos } \\
\text { - Pode ser reciclado } \\
\text { - Pode ser reutilizado, mas não é usual }\end{array}$ \\
\hline $\begin{array}{c}\text { Metálica } \\
\text { parafusada }\end{array}$ & 0,8 & 1 & $\begin{array}{l}\text { - Elementos pré-fabricados facilitam o transporte e } \\
\text { armazenamento } \\
\text { - Equipamentos utilizados na montagem podem ser usados } \\
\text { na desmontagem } \\
\text { - Resiste a desmontagem } \\
\text { - Ligação por parafusos facilita a separação das peças e } \\
\text { reduz os danos } \\
\text { - Pode ser reciclado } \\
\text { - Pode ser reutilizado }\end{array}$ \\
\hline Madeira & 1,0 & 1 & $\begin{array}{l}\text { - Elementos pré-fabricados facilitam o transporte e } \\
\text { armazenamento } \\
\text { - Equipamentos utilizados na montagem podem ser usados } \\
\text { na desmontagem } \\
\text { - Resiste a desmontagem } \\
\text { - Ligações mecânicas através de peças ou encaixes facilita } \\
\text { a separação dos elementos reduz os danos } \\
\text { - Pode ser reciclado } \\
\text { - Pode ser reutilizado } \\
\text { - É um material sustentável desde que certificado e sem } \\
\text { aditivos químicos danosos ao meio ambiente }\end{array}$ \\
\hline & & & \\
\hline
\end{tabular}




\begin{tabular}{|c|c|c|c|}
\hline $\begin{array}{l}\text { Materiais e } \\
\text { Elementos }\end{array}$ & $\begin{array}{l}\text { Classificação } \\
\text { Desmontage } \\
\text { m (0 a 1) }\end{array}$ & $\begin{array}{l}\text { Peso para } \\
\text { media } \\
\text { ponderada }\end{array}$ & Características \\
\hline \multicolumn{4}{|l|}{$\begin{array}{l}\text { VEDAÇÃO } \\
\text { VERTICAL } \\
\text { EXTERNA }\end{array}$} \\
\hline Vidro & 0,3 & 2 & $\begin{array}{l}\text { - Requer muito cuidado na desmontagem e se quebra com } \\
\text { facilidade } \\
\text { - Para armazenamento e transporte necessita de muito } \\
\text { cuidado para não quebrar } \\
\text { - Geralmente são descartados quando há demolições e } \\
\text { reformas } \\
\text { - Não costumam ser reaproveitados }\end{array}$ \\
\hline $\begin{array}{l}\text { Alvenaria de } \\
\text { tijolos com } \\
\text { furos }\end{array}$ & 0,4 & 2 & $\begin{array}{l}\text { - Não resistem a desmontagem } \\
\text { - Geralmente são quebrados, removidos e descartados. } \\
\text { - Podem ser reciclados, mas não reutilizados. }\end{array}$ \\
\hline $\begin{array}{l}\text { Alvenaria de } \\
\text { tijolos } \\
\text { maciços }\end{array}$ & 0,8 & 2 & $\begin{array}{l}\text { - Depende do modelo e argamassa que foram utilizados que } \\
\text { podem facilitar ou dificultar o processo } \\
\text { - É um material pequeno que pode ser removido com } \\
\text { poucas ferramentas e manualmente } \\
\text { - Fácil de transportar e armazenar } \\
\text { - Podem ser reutilizados da mesma maneira que o uso } \\
\text { original }\end{array}$ \\
\hline $\begin{array}{l}\text { Elementos } \\
\text { pré- } \\
\text { fabricados de } \\
\text { concreto }\end{array}$ & 0,8 & 2 & $\begin{array}{l}\text { - Elementos resistente e encaixados } \\
\text { - Resistem a desmontagem } \\
\text { - Podem ser reutilizados da mesma maneira que } \\
\text { originalmente } \\
\text { - Podem ser reciclados também }\end{array}$ \\
\hline \multicolumn{4}{|l|}{$\begin{array}{l}\text { VEDAÇÃO } \\
\text { VERTICAL } \\
\text { INTERNAS }\end{array}$} \\
\hline Gesso & 0,2 & 3 & $\begin{array}{l}\text { - Ligações químicas } \\
\text { - Não resistem a desmontagem } \\
\text { - Não são reutilizados nem reciclados }\end{array}$ \\
\hline Vidro & 0,3 & 3 & $\begin{array}{l}\text { - Requer muito cuidado na desmontagem e se quebra com } \\
\text { facilidade } \\
\text { - Também no armazenamento e transporte também } \\
\text { necessitas de cuidados para não quebrar } \\
\text { - Geralmente são descartados quando há demolições e } \\
\text { reformas } \\
\text { - Não costumam ser reaproveitados }\end{array}$ \\
\hline $\begin{array}{l}\text { Alvenaria } \\
\text { com tijolos } \\
\text { com furos }\end{array}$ & 0,4 & 3 & $\begin{array}{l}\text { - Não resistem a desmontagem } \\
\text { - Geralmente são quebrados, removidos e descartados. } \\
\text { - Podem ser reciclados, mas não reutilizados }\end{array}$ \\
\hline $\begin{array}{l}\text { Alvenaria } \\
\text { com tijolos } \\
\text { maciços }\end{array}$ & 0,8 & 3 & $\begin{array}{l}\text { - Depende do modelo e argamassa que foram utilizados que } \\
\text { podem facilitar ou dificultar o processo } \\
\text { - É um material pequeno que pode ser removido com } \\
\text { poucas ferramentas e manualmente } \\
\text { - Fácil de transportar e armazenar } \\
\text { - Podem ser reutilizados da mesma maneira que o uso } \\
\text { original }\end{array}$ \\
\hline
\end{tabular}

Fonte: Autora

A estrutura de concreto moldada no local tem baixo potencial de desmontagem, por possuir ligações químicas e precisar de equipamentos pesados, de difícil manuseio para desmontar, além de ser difícil de transportar quando desmontada. Muitas vezes a única opção é a demolição, devido a altos custos, quantidade de trabalho e tempo para uma efetiva desmontagem. Assim sua classificação de desmontagem é $\mathbf{0 , 1}$. 
A estrutura de concreto pré-fabricada é mais fácil de ser desmontada quando comparada a de concreto moldado no local, por permitir pontos de encaixes e ligações que podem ser desfeitas. Além disso, as peças são produzidas já considerando o transporte e armazenamento na montagem, o que contribuirá com a desmontagem. No entanto, podem se quebrar na desmontagem e possuem ligações químicas. Como por exemplo as lajes de concreto da empresa que foi visitada são fabricadas e apenas montadas no local, mas depois precisa ser grauteada, assim impossibilita a futura separação e desmontagem sem danos nas peças. No entanto, outros elementos como terças pode ser desmontada sem maiores prejuízos. Como estamos analisando a estrutura pré-fabricada de concreto como um todo, neste trabalho, a sua classificação de desmontagem será prejudicada por alguns elementos e beneficiados por outros, portanto será $\mathbf{0 , 3}$.

A estrutura metálica também tem algumas vantagens e desvantagens. As considerações sobre montagem, assim como os elementos pré-fabricados de concreto, também contribuem com a desmontagem. Considerar o transporte, armazenamento, equipamentos para montagem, trazem benefícios para a desmontagem. A possibilidade de reciclagem e durabilidade do material também são vantagens, no entanto há riscos de corrosão. Além disso, quando os elementos são soldados se tornam mais difíceis de serem removidos sem danos, porém se forem parafusados permitem maior flexibilidade de desmontagem e remontagem. Assim, neste método construtivo, alguns elementos contribuem e outros beneficiam o processo de desmontagem para facilitar uma futura reciclagem e até reutilização. Portanto sua classificação de desmontagem é $\mathbf{0 , 6}$ para as estruturas soldadas e 0,8 para as parafusadas.

As estruturas de madeira também são consideradas por serem muito utilizadas em algumas regiões do Brasil, serem flexíveis, ser um material renovável, portanto, se certificado, é considerado sustentável. Além disso, são utilizados parafusos ou pequenas peças para ligar os elementos e, em alguns casos, são apenas encaixadas. Por utilizar peças que também são consideradas na montagem, facilitam o transporte, também contribuem com a desmontagem. A madeira é um material considerado sustentável, com ligações mecânicas ou encaixes, permite reutilização e é muito flexível e também duradouro. Portanto, tem uma alta classificação de desmontagem, será considerado 1,0.

\section{Vedações Verticais Externas:}

O vidro é um material frágil, pois requer muito cuidado na desmontagem. No entanto por ser considerada sua montagem, armazenamento e transporte, pode contribuir com a desmontagem. No entanto não foi encontrado nenhum caso de reutilização de vidro sem que estivesse quebrado. Geralmente são quebrados e descartados, quando são reutilizados é para fazer algum detalhe, mas não como foi utilizado originalmente. Portanto sua classificação de desmontagem é 0,3.

As vedações de alvenaria, neste caso serão consideradas de tijolos maciços e com furos, de barro, é uma opção que é bastante utilizada no Brasil. Esta opção tem diversas variáveis, como o tipo de tijolo utilizado, como foi feita sua ligação, se ficaram aparentes ou foram rebocados, podem ter sidos envernizados ou pintados. Por ser um material resistente e pequeno, permite ser desmontado, armazenado e transportado. No entanto, demanda cuidado e tempo para que seja desmontado corretamente e seja possível reutilizar e muitas vezes o custo do processo não compensa o esforço. Assim, sua classificação é $\mathbf{0 , 8}$. No entanto os tijolos de barro com furos não são tão resistentes e quebram na desmontagem, assim sua classificação é $\mathbf{0 , 4}$.

As vedações feitas por elementos pré-fabricados de concreto, como visto nas visitas a empresas especializadas neste processo, permitem desmontagem e remontagem. Além disso, é possível armazenar e transportar sem maiores danos. Por serem apenas encaixadas facilita o desencaixe sem danificar as peças. Em alguns casos se utiliza um silicone para maior vedação, no entanto é possível remover com apenas algumas horas de trabalho. Assim, sua classificação é $\mathbf{0 , 8}$. 


\section{Vedação Vertical Interna:}

As divisórias de gesso geralmente são demolidas quando precisa alterar a disposição interna dos ambientes. Não é um material resistente a desmontagem e pode ser prejudicial ao meio ambiente se não tiver a destinação correta. Assim, sua classificação é 0,2.

As divisórias de vidro também costumam ser destruídas e não permitem se adaptar a novas medidas. No entanto não é um material tóxico, mas requer bastante cuidado no seu manuseio. Portanto sua classificação é $\mathbf{0 , 3}$.

As paredes de alvenaria de tijolo com furos são muito utilizadas, principalmente em edifícios residenciais de até 02 pavimentos. No entanto, quando passam por reformas, geralmente são demolidas. Assim sua classificação de desmontagem é $\mathbf{0 , 4}$.

As paredes de alvenaria de tijolos maciços são mais resistentes quando comparadas à opção anterior. No entanto, o responsável pela reforma pode optar por demolir ou remover os tijolos, dependendo de sua necessidade e disponibilidade. Portanto sua classificação de desmontagem é $\mathbf{0 , 8}$.

\section{Peso para média ponderada:}

Para se obter uma estimativa da classificação de desmontagem geral do edifício é possível fazer uma média dos diversos materiais e elementos utilizados. No entanto, algumas partes da edificação são mais viáveis de serem desmontadas que outras, pois o edifício é composto por camadas que normalmente seguem a sequência oposta da montagem ou construção. Por exemplo, as vedações verticais podem ser menos complicadas que as estruturas. Assim, torna-se necessário fazer uma média ponderada. Neste estudo as vedações horizontais internas terão peso 03, as externas pesos 02 e as estruturas peso 01 .

Por fim, o cálculo será realizado da seguinte maneira: o número da classificação de desmontagem de cada elemento, vezes o valor para média ponderada e o resultado dividido pelo número de elementos (ou $\mathrm{m}^{2}$ ). Uma fórmula simples foi desenvolvida para colocar a classificação de desmontagem em prática e analisar as possibilidades do software, no entanto conforme a tabela se torna mais complexa a fórmula também pode ser mais específica, desde que siga os mesmos princípios. Assim, a fórmula para esta pesquisa será:

\section{C.D. de cada elemento x Média Ponderada} $n^{\circ}$ elementos (ou $\mathrm{m}^{2}$ )

\section{Aplicação da Classificação de Desmontagem em BIM}

Para a aplicação da classificação ser utilizada de maneira mais prática e objetiva sem aumentar consideravelmente o tempo do desenvolvimento do projeto e consequentemente o custo, utilizar um software BIM como o Revit facilitaria o processo. A autora desenvolveu três modelos conceituais para implementar a classificação. São três galpões com a mesma área construída, sendo o primeiro em estrutura pré-fabricada de concreto, vedação vertical externa de painéis de concreto e vedação vertical interna de tijolos com furos (figuras 01,02 e 03). O segundo galpão é de estrutura metálica, vedação vertical externa de tijolos com furos e interna de gesso (figuras 04,05 e 06). Por fim, o terceiro composto por estrutura de madeira, vedação vertical externa de tijolos maciços e internas de vidro (figuras 07,08 e 09). 
Os modelos foram criados em um template, também desenvolvido pela autora, no Revit, com a intenção de gerar tabelas com informações sobre quantidade de elementos utilizados, materiais, classificação de desmontagem e tags sobre pontos importantes a serem considerados no Projeto para Desmontagem. Outras questões também são fundamentais para a desmontagem, como peso, expectativa de vida, entre outras, no entanto este estudo focou na quantidade dos materiais utilizados e como seriam as conexões entre eles e possibilidade de desmontagem. As linhas destacadas em vermelho representam que não atendem a alguma exigência específica, como não ser possível ligações mecânicas e serão utilizadas ligações químicas, como argamassa, por exemplo.

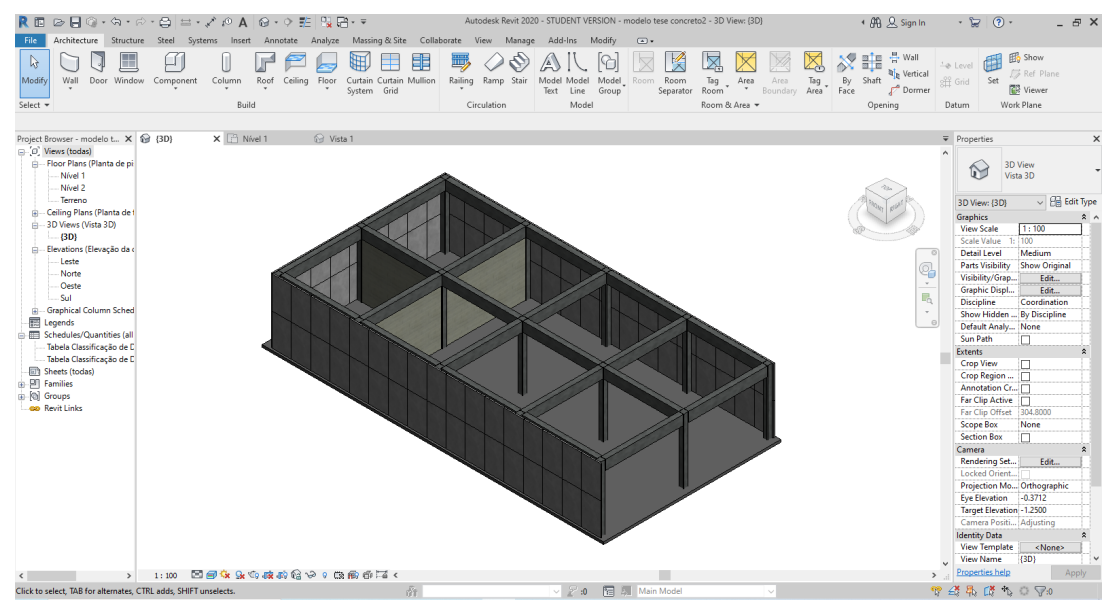

Figura 1 - Modelo Conceitual 01

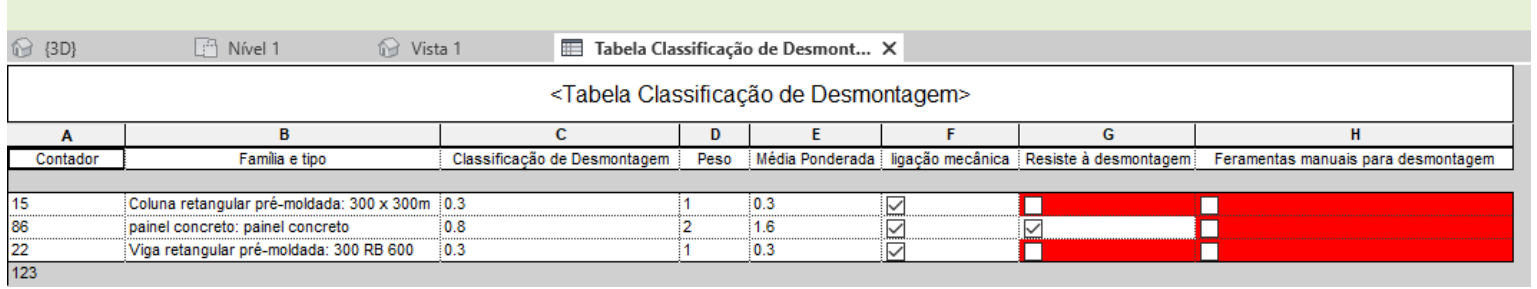

Figura 2 - Tabela de Unidades para Classificação de Desmontagem

\begin{tabular}{|c|c|c|c|c|c|c|c|c|}
\hline & \multicolumn{8}{|c|}{$<$ Tabela Classificação de Desmontagem m²> } \\
\hline A & B & c & D & $E$ & $\mathrm{~F}$ & G & $\mathrm{H}$ & 1 \\
\hline Count & Area & Family and Type & Classifcação de Desmontagem & Peso para média & Média Ponderada & Ligação Mecanica & Resiste a desmontagem & Ferramentas Manu \\
\hline & $17 \mathrm{~m}^{2}$ & Basic Wall: Genéri & 0.4 & 3 & 1.2 & 口 & $\square$ & V \\
\hline & $16 \mathrm{~m}^{2}$ & Basic Wall: Genéri & 0.4 & 3 & 1.2 & 口 & $\overrightarrow{\mathbf{a}}$ & 更 \\
\hline 1 & $17 \mathrm{~m}^{2}$ & Basic Wall: Genéri & & & & 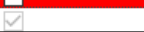 & $\bar{\Omega}$ & 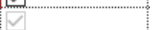 \\
\hline
\end{tabular}

Figura 3 - Tabela com m² para Classificação de Desmontagem



Figura 4 - Modelo Conceitual 02 


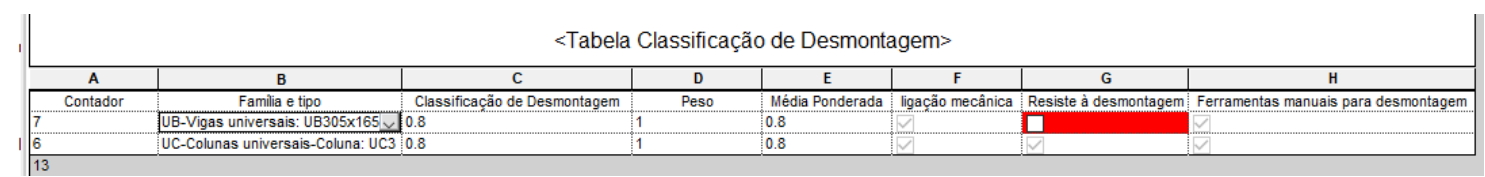

Figura 5 - Tabela de Unidades para Classificação para Desmontagem



Figura 6 - Tabela com $\mathbf{m}^{2}$ para Classificação de Desmontagem

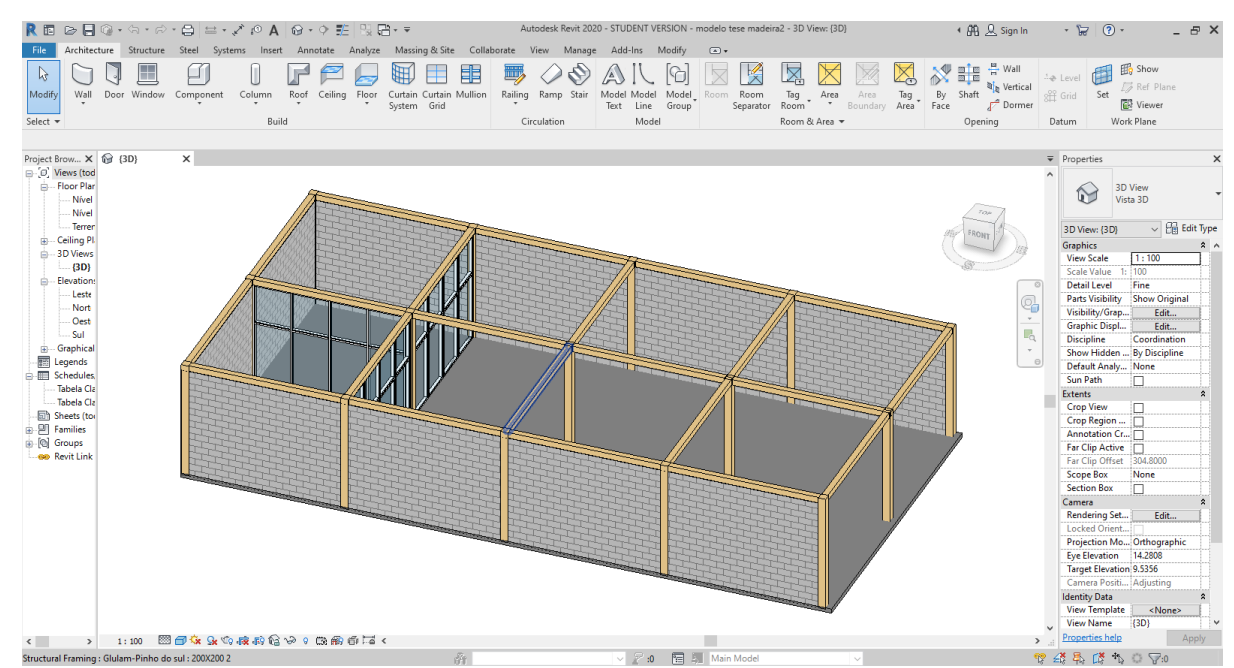

Figura 7 - Modelo Conceitual 03

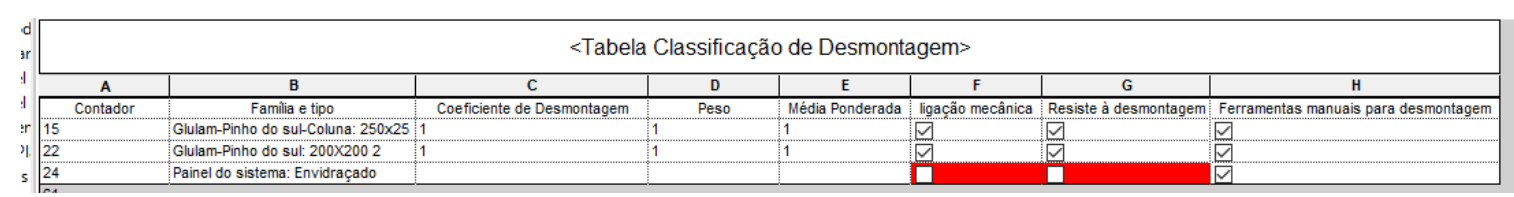

Figura 8 - Tabela de Unidades para Classificação para Desmontagem

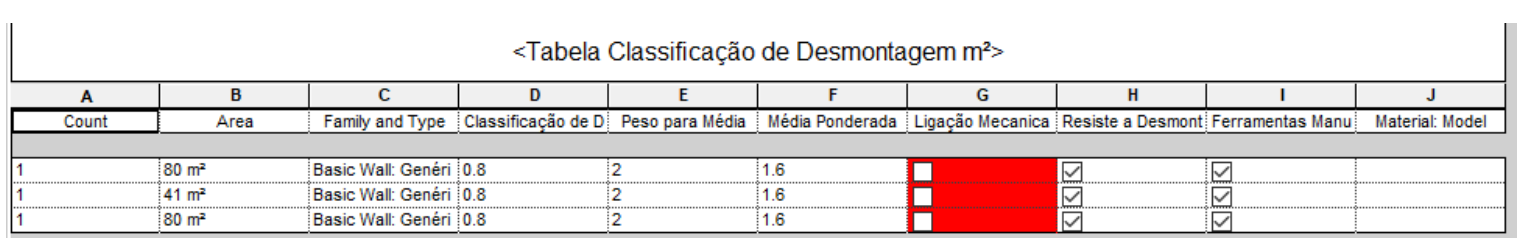

Figura 9 - Tabela com $\mathrm{m}^{2}$ para Classificação de Desmontagem

Portanto, quando os projetos são modelados em Revit neste template, é possível inserir a classificação de desmontagem até mesmo em novos elementos e diferentes materiais. Automaticamente é gerada 
a tabela, que é atualizada conforme as mudanças do projeto, tornando mais prática e objetiva a avaliação da desmontabilidade do edifico. Além disso, a futura desmontagem deve ser considerada desde o início do projeto e não pode se perder ao longo das diversas decisões que devem ser tomadas.

\section{Questionário}

1) Na sua opinião, a classificação de desmontagem pode auxiliar no desenvolvimento do projeto e escolhas de materiais com maior potencial para ser desmontado e reutilizado?

( ) SIM ( ) NÃO

Por quê?

2) Você acredita que a tabela pode contribuir com a escolha de materiais com maior potencial para ser desmontados e reutilizados ou até mesmo reciclados?

( ) SIM ( ) NÃO

Por quê?

3) Você indicaria falhas na Classificação de Desmontagem?

( ) SIM ( ) NÃO

Quais?

4) Você concorda com a classificação de cada material ou elemento e o peso (para cálculo da média ponderada) atribuído a eles?

( ) SIM ( ) NÃO

Por quê?

5) Você considera que foi boa a escolha dos materiais e componentes a serem analisados? Acrescentaria mais algum material?

( ) SIM ( ) NÃO

Por quê? 
6) Você considera adequada a fórmula desenvolvida para medir o potencial de desmontagem do edifício?

\section{C.D. de cada elemento $x$ Média \\ $n^{\circ}$ elementos (ou $\mathrm{m}^{2}$ )}

( ) SIM ( ) NÃO

Por quê?

7) $\mathrm{Na}$ sua opinião, um template e checklist, desenvolvido em BIM, voltado para a desmontagem, poderia contribuir com o processo?

( ) SIM ( ) NÃO

Por quê?

8) Na sua opinião, qual seria a maior barreira para utilização do Projeto para Desmontagem em BIM e utilização da Classificação de Desmontagem.
a. Falta de exigência Legal.
b. Falta de exigência do cliente.
c. Considerar a desmontabilidade na fase de projeto, pelos profissionais envolvidos.
d. Complexidade em considerar o Projeto para Desmontagem em BIM.
e. Tempo e Custo que agregaria ao desenvolvimento do projeto.
f. Outro: Qual?

9) Por fim, por favor, avaliar a classificação de desmontagem dos elementos de forma geral.

Muito obrigada pela contribuição!

\subsubsection{Respostas do Questionário sobre a Classificação de Desmontagem}

\section{Especialista 01}

1) Na sua opinião, a classificação de desmontagem pode auxiliar no desenvolvimento do projeto e escolhas de materiais com maior potencial para ser desmontado e reutilizado? (X) SIM ( ) NÃO 
Por quê? A logística reversa pode se tornar uma realidade também para o setor e isso pode ser um ponto de partida

2) Você acredita que a tabela pode contribuir com a escolha de materiais com maior potencial para ser desmontados e reutilizados ou até mesmo reciclados?

( X ) SIM ( ) NÃO

Por quê? A classificação me parece bem eficiente

3) Você indicaria falhas na Classificação de Desmontagem?

( ) $\operatorname{SIM}(X) N A \tilde{O}$

Quais? não pude perceber falhas em que possa contribuir

4) Você concorda com a classificação de cada material ou elemento e o peso (para cálculo da média ponderada) atribuído a eles?

( X ) SIM ( ) NÃO

Por quê?

5) Você considera que foi boa a escolha dos materiais e componentes a serem analisados? Acrescentaria mais algum material?

( X) SIM ( ) NÃO

Por quê? Foram cobertos os principais elementos da construção

6) Você considera adequada a fórmula desenvolvida para medir o potencial de desmontagem do edifício?

C.D. de cada elemento x Média

$n^{\circ}$ elementos (ou $\left.\mathrm{m}^{2}\right)$

( X) $\operatorname{SIM}($ ) NÂO

Por quê? Me ocorreu que alguns materiais que não costumam ser reaproveitados podem ser reciclados. Já é frequente pesquisas em concreto com agregados reciclados (blocos cerâmicos e assemelhados) e adição de pó de vidro. Não sei se esses aspectos poderiam ser contemplados de alguma forma

7) Na sua opinião, um template e checklist, desenvolvido em BIM, voltado para a desmontagem, poderia contribuir com o processo?

$\operatorname{SIM}(X) \mathrm{NÃO}($ )

Por quê?

8) Na sua opinião, qual seria a maior barreira para utilização do Projeto para Desmontagem em BIM e utilização da Classificação de Desmontagem.

a. Falta de exigência Legal.

b. Falta de exigência do cliente.

c. Considerar a desmontabilidade na fase de projeto, pelos profissionais envolvidos.

d. Complexidade em considerar o Projeto para Desmontagem em BIM.

e. Tempo e Custo que agregaria ao desenvolvimento do projeto.

f. Outro: Qual? Todas são barreiras importantes e interconectadas 
9) Por fim, por favor, avaliar a classificação de desmontagem dos elementos de forma geral. Muito interessante, não tenho críticas. Sugiro uma forma de aferir o processo em um estudo de caso.

\section{Especialista 02}

\section{Questionário}

1. Na sua opinião, a classificação de desmontagem pode auxiliar no desenvolvimento do projeto e escolhas de materiais com maior potencial para ser desmontado e reutilizado? ( X) SIM ( ) NÃO

Por quê?

2. Você acredita que a tabela pode contribuir com a escolha de materiais com maior potencial para ser desmontados e reutilizados ou até mesmo reciclados?

(X) SIM ( ) NÃO

Por quê?

3. Você indicaria falhas na classificação da desmontagem?

( ) SIM (X) NÃO

Quais?

4. Você concorda com a classificação de cada material ou elemento e o peso (para cálculo da média ponderada) atribuído a eles?

(X) SIM ( ) NÃO

Por quê?

5. Você considera que foi boa a escolha dos materiais e componentes a serem analisados? Acrescentaria mais algum material?

(X) SIM ( ) NÃO

Por quê?

A tabela pode ser complementada com materiais compósitos nas vedações internas, por exemplo os compósitos de madeira ou plásticos.

6. Você considera adequada a fórmula desenvolvida para medir o potencial de desmontagem do edifício?

(X) SIM ( ) NÃO

CD de cada elemento x Média

Por quê? 
7. Na sua opinião, um template e checklist, desenvolvido em BIM, voltado para a desmontagem, poderia contribuir com o processo?

(X) SIM ( ) NÃO

Por quê?

8. Na sua opinião, qual seria a maior barreira para utilização do Projeto para a Desmontagem em BIM e utilização da Classificação da Desmontagem.

a. Falta de exigência Legal.

b. Falta de exigência do cliente.

c. Considerar a desmontabilidade na fase de projeto, pelos profissionais envolvidos.

d. $\quad$ Complexidade em considerar o Projeto para Desmontagem em BIM.

e. $\quad$ Tempo e Custo que agregaria ao desenvolvimento do projeto.

f. Outro: Qual?

9. Por fim, por favor, avaliar a classificação de desmontagem dos elementos de forma geral.

A proposta para classificação de demontagem, de modo geral, está bem elaborada e engloba os pontos centrais que devem nortear o projeto, portanto entendo que tem potencial para evolução.

\section{Especialista 03}

1) Na sua opinião, a classificação de desmontagem pode auxiliar no desenvolvimento do projeto e escolhas de materiais com maior potencial para ser desmontado e reutilizado?

(x) $\operatorname{SIM}($ ) NÃO

Por quê?

Porque orienta a sua utilização com um objetivo bem

definido

2) Você acredita que a tabela pode contribuir com a escolha de materiais com maior potencial para ser desmontados e reutilizados ou até mesmo reciclados?

(x) $\operatorname{SIM}($ ) NÃO

Por quê?

Pela organização e sistematização que possibilita

3) Você indicaria falhas na classificação da desmontagem?

( ) $\operatorname{SIM}(x)$ NÃO

Quais?

4) Você concorda com a classificação de cada material ou elemento e o peso (para cálculo da média ponderada) atribuído a eles?

( $x$ ) $\operatorname{SIM}($ ) NÃO

Por quê?

5) Você considera que foi boa a escolha dos materiais e componentes a serem analisados? Acrescentaria mais algum material?

( $x$ ) $\operatorname{SIM}($ ) NÃO 
Por quê?

Por serem os mais empregados na construção civil

6) Você considera adequada a fórmula desenvolvida para medir o potencial de desmontagem do edifício?

\section{$\underline{C D}$ de cada elemento $\times$ Média \\ $n^{\circ}$ elmentos (ou $\mathrm{m}^{2}$ )}

$\operatorname{SIM}(x)$ NÃO

Por quê?

Trata o assunto de maneira organizada e é flexível na determinação de outros pesos, caso

o usuário assim o deseje.

7) Na sua opinião, um template e checklist, desenvolvido em BIM, voltado para a desmontagem,

poderia contribuir com o processo?

( ) SIM ( ) NÃO

Por quê?

Não tenho como opinar por desconhecer tal ferramenta

8) Na sua opinião, qual seria a maior barreira para utilização do Projeto para a Desmontagem em BIM e utilização da Classificação da Desmontagem.

a. Falta de exigência Legal.

b. Falta de exigência do cliente.

c. Considerar a desmontabilidade na fase de projeto, pelos profissionais envolvidos.

d. Complexidade em considerar o Projeto para Desmontagem em BIM.

e. Tempo e Custo que agregaria ao desenvolvimento do projeto.

f. Outro: Qual?

9) Por fim, por favor, avaliar a classificação de desmontagem dos elementos de forma geral. Ideia muito interessante e com grande potencial de utilização desde que o BIM esteja mais difundido no setor da construção civil e se torne uma ferramenta usual.

Muito obrigada pela contribuição!

\section{Especialista 04}

\section{Questionário}

10) Na sua opinião, a classificação de desmontagem pode auxiliar no desenvolvimento do projeto e escolhas de materiais com maior potencial para ser desmontado e reutilizado?

(x) SIM ( ) NÃO

Por quê?_Caso seja uma estrutura temporária, ou com período de utilização limitado, essa classificação poderia direcionar as escolhas feitas na fase de projeto. 
11) Você acredita que a tabela pode contribuir com a escolha de materiais com maior potencial para ser desmontados e reutilizados ou até mesmo reciclados?

(x ) SIM ( ) NÃO

Por quê? Pode servir como um indicativo da solução mais adequada.

12) Você indicaria falhas na classificação da desmontagem?

( ) SIM ( ) NÃO

Quais? Primeiramente, não tenho conhecimento suficiente para avaliar a classificação feita. Entretanto, alguns pesos me parecem questionáveis. Adotar o valor 1,0 para a madeira é no mínimo estranho, já que as ligações por encaixe, que serviram para justificar o valor, são apenas uma parcela das ligações possíveis. Além disso, o custo da desmontagem tem que ser justificado pela durabilidade do material, quesito no qual a madeira nem sempre se sai tão bem. Já o valor 0,3 para estruturas pré-moldadas, mesmo considerando a estrutura como um todo, parece muito baixo, principalmente ao ser confrontado com o 1,0 das estruturas em madeira.

13) Você concorda com a classificação de cada material ou elemento e o peso (para cálculo da média ponderada) atribuído a eles?

(x ) SIM ( ) NÃO

Por quê? Acho que a importância do material é inegável, mas o peso também é uma variável a ser considerada, já que certamente irá influir no custo do transporte.

14) Você considera que foi boa a escolha dos materiais e componentes a serem analisados? Acrescentaria mais algum material?

(x ) SIM ( ) NÃO

Por quê? Foram escolhidos os materiais de uso mais comum.

15) Você considera adequada a fórmula desenvolvida para medir o potencial de desmontagem do edifício?

\section{CD de cada elemento $x$ Média}

$n^{\circ}$ elmentos (ou $\mathrm{m}^{2}$ )

\section{( x ) SIM ( ) NÃO}

Por quê? Parece adequada, embora não tenha condições de avaliar melhor os seus resultados.

16) Na sua opinião, um template e checklist, desenvolvido em BIM, voltado para a desmontagem, poderia contribuir com o processo?

( $\mathrm{x}) \operatorname{SIM~(~)~NÃO~}$

Por quê? Tudo o que puder facilitar as escolhas pode ajudar.

17) Na sua opinião, qual seria a maior barreira para utilização do Projeto para a Desmontagem em BIM e utilização da Classificação da Desmontagem.

g. Falta de exigência Legal. 
h. Falta de exigência do cliente.

i. Considerar a desmontabilidade na fase de projeto, pelos profissionais envolvidos.

j. Complexidade em considerar o Projeto para Desmontagem em BIM.

k. Tempo e Custo que agregaria ao desenvolvimento do projeto.

I. Outro: Qual? Falta de cultura para se fazer o planejamento de longo prazo das edificações, com a inclusão de todos os custos envolvidos.

18) Por fim, por favor, avaliar a classificação de desmontagem dos elementos de forma geral. É um fator a mais para ajudar os projetistas a fazerem escolhas durante a fase de planejamento.

Muito obrigada pela contribuição! 